\title{
4. KONFLIKTVERMEIDUNG: APRIL-OKTOBER 1938
}

\subsection{Neue Entscheidungsträger: Daladier, Bonnet und Mandel}

Die Regierungsbildung änderte die Struktur der Entscheidungsfindung in der französischen Fernostpolitik mit der Dominanz des Außenministeriums und der mächtigen Position Légers nicht. Allerdings sollte der neue Kolonialminister Georges Mandel Weisungen des Quai d'Orsay weitgehend ignorieren.

Der neue Regierungschef Édouard Daladier, 56 Jahre alt, Geschichts- und Geographielehrer, war seit 1919 Abgeordneter, 1924 wurde er Kolonialminister. 1925 übernahm er erstmals das Kriegsministerium, das er bis 1934 in vier Kabinetten 16 Monate lang führte. Vor der Wahl im Mai 1936 galt Daladier, seit Januar 1936 Parteivorsitzender der Radikalsozialisten, als designierter Regierungschef. Als überraschend die Sozialisten die Wahl gewannen, wurde Daladier im Juni 1936 Vize-Premier, Armee- und Verteidigungsminister. Die Verantwortung im Kabinett für das Militär behielt er bis zum 18. Mai 1940 ${ }^{1}$.

Zwei Charakterzüge vereinte Daladier: Er war ehrlich und unentschlossen. Seine Integrität lobten die britischen Diplomaten Sir Eric Phipps, Sir Ronald Campbell und Oliver Harvey. Er gewann durch Aufrichtigkeit und Unbestechlichkeit Vertrauen, so Jean-Louis Crémieux-Brilhac. Seit Poincaré war nach François Bédaridas Urteil kein Regierungschef so populär ${ }^{2}$. Doch weil er für die Niederlage von 1940 verantwortlich gemacht wurde, galt Daladier rasch, auch bei Hans-Peter Schwarz, als "völlig gescheiterte[r] Realpolitiker ${ }^{3}$.

Rückblickend wurde vor allem Daladiers zweite markante Eigenschaft, der Wankelmut, herausgestellt. Senatspräsident Jeanneney, Senator Bardoux, die Minister Cot und de Monzie, der Journalist Pertinax und Orme Sargent im Foreign Office kritisierten seine Zögerlichkeit, Entscheidungsschwäche und Launenhaftigkeit. Mittelmäßig und apathisch nannte ihn Oberst de Villelume. Der Diplomat Crouy-Chanel schrieb, Daladier habe bisweilen einen Astrolo-

\footnotetext{
${ }^{1}$ Elisabeth DU RÉAU, Édouard Daladier, in: Dictionnaire des ministres, S. 420-425; Serge BERSTEIN, Édouard Daladier, in: Biographical Dictionary, S. 101-103; DERS., Édouard Herriot, S. 228f.

${ }^{2}$ Phipps an Halifax, 30.3.1938 (FO 800/311); Phipps, Personalities Report, 13.7.1939 (FO 371/22939, C 9935/9935/17); CrÉmIEUX-BrilhaC, Les Francais, Bd. 1, S. 136; S. 146; Campbell an Halifax, 23.3.1940, zit. nach François BÉDARIDA, La stratégie secrète de la drôle de guerre. Le Conseil suprême interallié, septembre 1939-avril 1940, Paris 1979, S. 52; HARVEY, Diplomatic Diaries, S. 435; BÉDARIDA, La stratégie secrète, S. 53.

${ }^{3}$ Bullitt an Hull, 5.6.1940 (SD 740.0011 European War 1939/3545 1/2); Hans-Peter SCHWARZ, Das Gesicht des Jahrhunderts. Monster, Retter, Mediokritäten, Berlin 1998, S. 346.
} 
gen befragt, wann er handeln solle. Botschafter Corbin nannte Daladier einen schwachen Mann. Phipps warf ihm vor, er rede stets größer, als er handle. Einen "Stier mit den Hörnern einer Schnecke« nannten ihn deshalb seine Gegner. Mandel klagte über Daladiers Unentschlossenheit und Schwäche ${ }^{4}$. Grund für diese Züge waren womöglich gesundheitliche Probleme ${ }^{5}$.

Die Literatur fällt ähnliche Urteile: Als unsicheren Politiker ohne Entschlußkraft, der den starken Mann spielte, schildern ihn François Bédarida, JeanLouis Crémieux-Brilhac, Robert J. Young und Michael Jabara Carley. Donald C. Watt zufolge wälzte Daladier Verantwortung auf Bonnet ab. Serge Berstein urteilt, Bonnet sei der wahre Führer (»véritable inspirateur«) der Regierung gewesen, der eher eine kohärente Linie zu verfolgen schien als Daladier ${ }^{6}$.

Wenn Daladier auf die Asienpolitik Einfluß nahm, unterstützte er China. Er billigte den Waffentransit durch Indochina und die Entsendung einer französischen Militärmission nach China. Drei Motive prägten sein Handeln: Als langjähriger Kriegsminister besaß er enge Kontakte zu Waffenherstellern und -händlem, die ihrem Hauptkunden China nahe standen. Daladier mochte China: Einträge in seinem während des Krieges geführten Tagebuch zeigen, daß er Respekt vor Chinas Größe und Widerstandskraft hatte und ihn die Frage des Nachschubs für die Chinesen bewegte ${ }^{7}$. Vor allem aber sollte französisches Engagement für China in Washington für Sympathien sorgen.

\footnotetext{
${ }^{4}$ Jules JEANNENEY, Journal politique, septembre 1939-juillet 1942, hg. von Jean-Noël JEANNENEY, Paris 1972, S. 7, S. 20, S. 23, S. 35f.; Bardoux, Journal, S. 113; Pierre Cot, Le Procès de la République, 2 Bde., New York 1944, Bd. 2, S. 166f; De Monzle, Ci-devant, S. 100; PertinaX, Les fossoyeurs, Bd. 1, S. 101f;; Sergent, Memorandum, 18.11.1938 (FO 371/21592, C 14138/13/17); VILleLUME, Journal, S. 250; CROUY-CHANEL, Alexis Leger, S. 148f.; Note Strang, 17.11.1938 (FO 371/21592, C 14068/13/17); Phipps an Halifax, 14.9.1938 (FO 800/311, H/HIV), zit. nach HERMAN, The Paris Embassy, S. 105; CrÉMIEUX-BrilHaC, Les Français, Bd. 1, S. 143; SAl.AN, Mémoires, S. 62; Suritz an Litwinow, 24.9.1938, zit. nach: Michael Jabara CARLEY, 1939. The Alliance that never was and the Coming of the World War II, Chicago 1999, S. 64.

${ }^{5}$ Daladier trank viel Alkohol, wie CADOGAN (Diaries, S. 126) und HARVEX nach dem Gipfeltreffen am 24.11.1938 (Diplomatic Diaries, S. 223) sowie später der Labourabgeordnete Harold NICOLSON (Journal des années tragiques, 1936-1942, Paris 1971, S. 194) bemerkten. In London hieß es, der Regierungschef rieche oft nach Wermut (NeVILLE, Why France Fell, S. 20). Nach einer Kammersitzung im März 1940 warf ihm sein Minister Anatole de Monzie vor, er habe getrunken. Daladiers Mitarbeiter Maurice Pelletier bezeichnete ihn als Alkoholiker (JEANNENEY, Journal, S. 34; Journal de Madame Decori, 15.3.1940, zit. nach: John C. CAIRNS, Reflections on France, Britain and the Winter War Prodrome, 1939-40, in: Historical Reflections 22.1 [1996], S. 21 1-234 [S. 213]).

${ }^{6}$ François BÉDARIDA, Huit mois d'attente et d'illusion: la »drôle de guerre«, in: Jean-Pierre AZÉMA, DERS. (Hg.), La France des années noires, Bd. 1: De la défaite à Vichy, Paris 1993, S. $37-67$ (S. 61); DERS., La stratégie secrète, S. 53f.; CrémIEUX-BrILHAC, Les Français, Bd. 1, S. 143f.; YouNG, In Command, S. 205; Carley, 1939, S. 47; WaTt, How War Came, S. 72, S. 617; Serge Berstein, Le parti radical-socialiste, arbitre du jeu politique français, in: René RÉMOND, Janine BOURDIN (Hg.), La France et les Français en 1938-1939, Paris 1978, S. 277-306 (S. 292f.).

${ }^{7}$ DALADIER, Journal, S. 246f. (Einträge 17.11., 18.11.1943), S. 115f. (16.12.1941).
} 
US-Botschafter William C. Bullitt war für Daladier ein wichtiger Berater. Der Diplomat, der 1936 als Antikommunist aus Moskau an die Seine gekommen war, stand Roosevelt persönlich nah ${ }^{8}$. In Paris blieb dies nicht verborgen. Blum, Delbos, Léger und Daladier hofierten den Botschafter. Weil sich Roosevelt oft in die Asienpolitik einschaltete, band Paris Bullitt bei fernöstlichen Fragen gern ein ${ }^{9}$. Besonders intensiv bemühte sich Daladier ab Anfang 1939 um enge Kontakte zu Bullitt. Jean-Baptiste Duroselle und Elisabeth du Réau schreiben von einer tiefen Freundschaft zwischen Bullitt und Daladier ${ }^{10}$.

Der Regierungschef suchte jedoch erst nach der Münchener Konferenz Bullitts Nähe: Ausgerechnet drei Tage nach dem deutschen Einmarsch in Prag bat Daladier Bullitt »als enger persönlicher Freund, nicht als Premierminister«, im Falle seines Todes für seine, Daladiers, Kinder zu sorgen, da er schon bald mit Krieg rechne. Verbunden damit war die Bitte um Aufhebung der US-Neutralitätsgesetze. Daladier band Bullitt eng in seine Politik ein. Nach Kriegsausbruch wurde Bullitt als der Mann, der Frankreich noch retten könnte, umworben. Er nahm nicht an Kabinettssitzungen teil, wie Gerüchte behaupteten, doch er war als einziger Ausländer bei wichtigen Militärkonferenzen anwesend und saß bei der Messe in Notre Dame, die am 19. Mai 1940 in größter Not gelesen wurde, neben den Ministern in der ersten Reihe ${ }^{11}$.

Außenminister Georges Bonnet, 48 Jahre alt, hatte bis April 1938 als Minister 14 Kabinetten angehört, beginnend 1925 als Budgetminister, zuletzt bis Januar 1936 als Handelsminister. In der Volksfrontregierung besaß er als Führer des konservativen Flügels der Radikalsozialisten großes Gewicht. Um Bonnet auszuschalten, ernannte ihn Blum im Juni 1936 zum Botschafter in Washington. Der Jurist, der kein Englisch sprach, nahm die Berufung an, behielt aber das Kammermandat. Nach Blums Sturz wurde er im Juni 1937 unter Chautemps Finanzminister. Als im Januar 1938 die Koalition zerbrach, wollte Bonnet eine Regierung bilden, bekam aber in der eigenen Fraktion keine Mehrheit. Bonnet besaß, anders als später Parteichef Daladier, nicht die

\footnotetext{
${ }^{8}$ William W. KaUfMANN, Two American Ambassadors: Bullitt and Kennedy, in: CraIG, GILBERT (Hg.), The Diplomats, S. 649-681; JUNKER, Der unteilbare Weltmarkt, S. 201, S. 255; William C[hristian] BuLlitT, The Great Globe itself, New York 1946. Zu Bullitts Zeit in Paris: Gordon Wright, Ambassador Bullitt and the Fall of France, in: World Politics 10.1 (1957), S. 63-90. Hull hegte keine großen Sympathien für Bullitt und warf ihm vor, er trinke übermäßig (Ralph F. DE BEDTS, Ambassador Joseph Kennedy 1938-1940. An Anatomy of Appeasement [American University Studies. Series 9, History, 12], New York, Bern, Frankfurt a. M. 1985, S. 196).

${ }^{9}$ Bullitt, For the President, S. 181, S. 196, S. 350, S. 318; TABouIS, Cassandre, S. 302; WATT, How War Came, S. 125f; KaufmanN, Two Ambassadors, S. 657; CHauvel, Commentaire, S. 52.

${ }^{10}$ Bonnet, Dans la tourmente, S. 32; Hull, The Memoirs, Bd. 1, S. 789; Duroselle, L'Abîme, S. 35; DU RÉAU, Daladier, S. 223.

"Wright, Ambassador Bullitt, S. 66, S. 72, S. 81; Bullitt an Hull, 18.3.1939, 18.5.1940 (SD 740.00/632, 740.0011 European War 1939/3131); BARDouX, Journal, S. 313. DALADIER nennt Bullitt aber auch im Tagebuch einen Freund und französischen Patrioten (Joumal, S. 69, S. 344).
} 
Autorität, um in der Partei den Wechsel der Koalitionspartner durchzusetzen. Chautemps' neue Regierung scheiterte im März 1938 nach sieben Wochen, Blums zweites Kabinett im April nach drei Wochen Amtszeit. Damit war der Weg für Daladier als Ministerpräsident und Bonnet als Außenminister frei ${ }^{12}$.

Als Bonnet als Verkörperung des apaisement im Januar 1939 immer unbeliebter wurde und Senatspräsident Jeanneney und der frühere Minister Pierre Cot im März 1939 auf Bonnets Ablösung drängten, kündigte Daladier mehrfach Bonnets Entlassung an: Er verdächtige den Außenminister des Verrates. Schon in der Kabinettssitzung am 27. September 1938 während der Sudetenkrise hatte Daladier Bonnet mit der Entlassung gedroht. Doch Daladier hatte gute Gründe, an Bonnet festzuhalten, wie Serge Berstein zeigt: Bonnet band den rechten Flügel der Radikalsozialisten und die Pazifisten an die Regierung, zudem war er für unpopuläre Entscheidungen, wie die Anerkennung des frankistischen Spanien, der geeignete Sündenbock ${ }^{13}$.

Unter seinen Zeitgenossen fand Bonnet kaum Freunde: Minister Jean Zay und der Journalist Alexander Werth beschrieben ihn als übertrieben ehrgeizig, Senatspräsident Jeanneney nannte ihn »überaus perfide«, für den sowjetischen Außenminister Litwinow war er »der geborene Kapitulant«, für Churchill der »Inbegriff des Defätismus«, die Diplomaten Harvey und Sargent nannten ihn intrigant, unaufrichtig und betrügerisch. Berichte, Bonnet habe in der Sudetenkrise mit Spekulationen viel an der Börse verdient, überraschten das Foreign Office nicht. Geneviève Tabouis hingegen nannte ihn charmant und sehr intelligent. Pertinax beschrieb Bonnet als fleißigen, hart arbeitenden Politiker, der aber auch betrüge. Die französische Diplomaten René Massigli und Étienne de Crouy-Chanel warfen ihm vor, er habe Botschaftern geheime Anweisungen gegeben, Nachrichten unterdrückt und Geheimemissäre entsandt ${ }^{14}$.

Auch die Literatur fällt negative Urteile: Als machtdurstig, prinzipien- und charakterlos beschreibt ihn Robert J. Young. J.F. McMillan stellt Bonnets

\footnotetext{
${ }^{12}$ Du RÉau, Georges Bonnet, S. 378f.; Phipps, Personalities Reports, 6.1.1938, 13.7.1939 (FO 371 /21604, C 102/102/37; FO 371/22939, C 9935/9935/17); BERSTEIN, Histoire du parti radical, Bd. 2, S. 466f., S. 505f., S. 522f.; DerS., Le parti radical-socialiste, S. 278f., S. 303f.; THOMAS, Britain, France and Appeasement, S. 125. Bonnet fand noch keinen Biographen.

${ }_{13}$ Jean ZAY, Les carnets secrets de Jean Zay. De Munich à la guerre, publiés et commentés par Philippe HENRIOT, Paris 1942, S. 21, S. 54; Bullitt an Hull, 30.1., 18.3., 23.3.1939 (SD 740.00/561, 632, 668); BERSTEIN, Histoire du parti radical, Bd. 2, S. 569.

${ }_{14}$ Jean ZAY, Souvenir et Solitude, Paris 1946, Nachdruck Le Roulx 1987, S. 67; WERTH, The Twilight, S. 164; JeAnNeney, Journal, S. 5; Churchill, Gathering Storm, S. 301; BarTeL, Frankreich und die Sowjetunion, S. 102; HARVEY, Diplomatic Diaries, S. 223, S. 226, S. 233, S. 313, S. 319, S. 341; Memorandum Sargent, 18.11 .1939 (FO 371/21592, C 14138/13/17); FO Minute, 12.11.1938 mit Note Strang (FO 371/21600, C 14023/55/17); TABOUIs, Cassandre, S. 332, S. 330; Pertinax, The Gravediggers, Bd. 2, S. 392f.; Massigli, La Turquie devant la guerre, S. 24; CrouYCHANEL, Alexis Leger, S. 146f.
} 
Ehrgeiz, Intelligenz und große Unredlichkeit heraus ${ }^{15}$. Die Außenpolitik in Europa, so Yvon Lacaze, habe Bonnet fest gelenkt. Doch in Fernostfragen war er ohne Erfahrung. Wellington Koo und Bullitt gewannen den Eindruck, daß sich Bonnet kaum mit Asien befasse. Chauvel zufolge gab der Minister nur unklare, zweideutige Anweisungen. Bonnet hatte sich aber doch soweit ein Urteil gebildet, daß Léger ihn für japanophil hielt. Mit zwei Männern, die eine wichtige Rolle in Frankreichs Außenpolitik spielten, stand Bonnet auf Kriegsfuß: Der US-Botschafter mißtraute Bonnet, seit sie sich bei einer Konferenz 1933 gestritten hatten. Bullitt drängte Daladier mehrfach auf Bonnets Ablösung. Das Verhältnis zwischen Bonnet und Mandel war vor ihrem Amtsantritt bereits zerrüttet. Bei der Kabinettsbildung im April 1938 versuchte Mandel, Bonnets Eintritt in die Regierung zu verhindern ${ }^{16}$.

Grund dafür waren Bonnets und Mandels gegensätzliche Auffassungen von Frankreichs Position in Europa. Bonnet glaubte, daß Paris wegen seiner militärischen Schwäche Konflikte vermeiden müsse. Mandel nahm hingegen an, daß sich Frankreichs relative Position verschlechtere. Paris müsse sich deshalb gegenüber Berlin behaupten, selbst wenn dies Krieg bedeute. Mandel sagte Bonnet, der Krieg solle besser früher als später ausbrechen. Bei ausländischen Vertretern schwärzten die Minister einander an. Bonnet warnte Bullitt und Phipps, Mandel sei ein Kriegstreiber, der, so Bonnet zu Phipps, unter sowjetischem Einfluß stehe. Mandel sagte zu Churchills Schwiegersohn Duncan Sandys, Bonnet sei niederträchtig. Der Kolonialminister stieß im Quai d'Orsay und bei den meisten Botschaftern auf Ablehnung: Crouy-Chanel zufolge gehörte Mandel zwar zu Légers Freunden. Gemeinsam traten Léger und Mandel seit Anfang 1939 für Festigkeit in Europa ein; gelegentlich erhielt Mandel aus dem Quai d'Orsay Unterlagen, ohne daß Bonnet davon erfuhr. Doch in der Asienpolitik konnten der um Japans apaisement bemühte Léger und der risikofreudige Mandel kaum zusammenkommen ${ }^{17}$.

Daladier und Bonnet suchten die Nähe zu London und Washington, die Paris jedoch wenig schätzten: In London galt die französische Regierung als

\footnotetext{
${ }^{15}$ Robert J. Young, In Command, S. 204; DERs., France and the Origins of the Second World War, New York 1996, S. 30; J.F. MCMILlAN, Georges Bonnet, in: Biographical Dictionnary, S. 41-42.

${ }^{16}$ Wilson an Hull, 16.11., Bullitt an Hull, 25.11., 16.9.1938 (FRUS 1938, III, S. 609, SD 741.51/312, SD 760f.62/858); CHAUVEL, Commentaire, S. 48; Yvon LACAZE, La France, S. 437; DERS., Daladier, Bonnet and the Decision-making Process during the Munich Crisis, in: Robert BoYCE (Hg.), French Foreign and Defence Policy, 1918-1940. The Decline and Fall of a Great Power, London, New York 1998, S. 215-233 (S. 224); BullitT, For the President, S. 324; BonNET, Dans la tourmente, S. 13-14. ${ }^{17}$ Bullitt an Hull, 16.5.1938 (SD 740.00/387); Phipps an Halifax, 14.9.1938 (FO 800/311 (H/HIV), zit. nach Herman, The Paris Embassy, S. 105; Phipps an Halifax, 22.6.1939 (DBFP, $3^{\text {rd }}$ series, VI, S. 150f.); William MANCHESTER, Winston Churchill, 2 Bde., London 1983-1988, Bd. 2, S. 468; CROUYChANel, Alexis Leger, S. 152; Georges WORMSER, Georges Mandel, l'homme politique, Paris 1967 , S. 230; ZAY, Les camets secrets, S. 46; MAY, Strange Victory, S. 160.
} 
unzuverlässig, die französische Armee und das Land als schwach. London wollte sich deshalb nicht an Paris binden. Der französisch-sowjetische Beistandspakt und Léon Blums Volksfront verbesserten Frankreichs Bild in Großbritannien, vor allem bei den regierenden Konservativen, nicht. Die Premierminister Macdonald, Baldwin und Chamberlain waren nach Duroselles Urteil ebenso gallophob wie die Außenminister Simon, Hoare und Halifax. Stanley Baldwin freute sich bei seinem Rückzug im Mai 1937, nun müsse er keine französischen Politiker mehr treffen. Im Juni 1938 nannte die Konservative Partei Frankreich, Spanien und die Sowjetunion als Beispiele dafür, wie schlecht der Sozialismus funktioniere; Lloyd George bezeichnete Frankreich im Oktober 1938 als »second-rate power«. Halifax' Privatsekretär schrieb im März 1938, Halifax und Chamberlain verhandelten lieber mit Diktatoren als mit den französischen Demokraten. Allein der Abgeordnete Winston Churchill setzte sich öffentlich für die enge Verbindung mit Frankreich ein.

Auch Diplomaten und Militärs in London sahen Paris ablehnend: "The French have a remarkable capacity for changing rapidly their opinions on important aspects of policy«, klagten Beamte des Central Department. Sir Orme Sargent, Unterstaatssekretär im Foreign Office, schrieb im Mai 1939, man könne dem Quai d'Orsay und französischen Politikern nicht trauen, für Phipps war französische Politik grundsätzlich unaufrichtig. »[P]usillanimous and parochial [...] in almost everything « nannte Ronald aus der Fernostabteilung die Franzosen, Sir John Pratt aus dem gleichen Department bezeichnete sie als - nach den Japanern - »the most egocentric race on earth $/$. Mit dem Urteil, $"$ French mentality, owing no doubt to a secular belief in the superiority of French civilisation, is apt to be narrow and self-centered«, begann die Royal Navy eine Analyse Frankreichs. Daß die Briten chiffrierte Telegramme der französischen Diplomatie mitlasen, war kein Zeichen großen Vertrauens ${ }^{18}$.

Den französischen Regierungen, die kurzlebig waren und die über ein vermeintlich schwaches Land regierten, fühlte sich Whitehall überlegen. Vor

${ }^{18}$ CAdogan, Diaries, S. 126 (Eintrag 21.11.1938); COOPER, Old Men Forget, S. 228; [Edward WOOD] Earl of Halifax, Fullness of Days, London 1957, S. 197; Sir Hughe KNATCHBULL-HUGESSEN, Diplomat in Peace and War, London 1949, S. 93; Martin GiLBERT, The Roots of Appeasement, London 1966, S. 180; Herman, The Paris Embassy, S. 28f.; Duroselle, Décadence, S. 201; NEVILLE, Why France Fell, S. 20; ADAMTHWAITE, France and the Coming of the Second World War, S. 49; HarveY, Diplomatic Diaries, S. 153, S. 124; Robert A.C. PARKER, Churchill and Appeasement, London, Basingstoke, Oxford 2000, S. 28f., S. 77f., S. 108f., S. 206f;; Maisky (London) an Litvinov, 2.10.1938 (SPE I, 10); Phipps an Halifax, 12.1. mit Notes Nichols, Ingram 13.1.1938 (FO 371/22418, R 343/43/22); John C. CAIRNS, A Nation of Shopkeepers in Search of a Suitable France: 1919-40, in: American Historical Review 79 (1974), S. 710-743 (S. 740f.); Ronald, Minute, 28.2.1939 (FO 371/23560, F 3478/456/23); Pratt, Memorandum, 1.12.1933, zitiert nach LouIs, British Strategy, S. 234; McGrath (Admirality), Intelligence Report on France, Dezember 1937 (FO 371/20688, C 8615/18/17); BEST, Britain, Japan and Pearl Harbor, S. 59, S. 201. 
keinem seinem Versuche, mit Mussolini und Hitler Übereinkünfte zu finden, konsultierte Chamberlain Paris. Dafür mischte sich die britische Diplomatie unverfroren selbst in personelle Entscheidungen der französischen Regierung ein: Ab Ende März 1938 drängte die britischen Botschaft auf den Sturz von Außenminister Paul-Boncour und machte Daladier und Reynaud klar, daß die Wiederernennung des Ministers, der für die Erfüllung des Bündnisses mit Prag stand, unerwünscht sei ${ }^{19}$. Die britische Regierung duldete, daß ihr Botschafter enge Kontakte $z u$ den Anhängern des apaisement hielt und daß er nach dem Münchener Abkommen bei Bonnet intervenierte, um die Versetzung von Diplomaten wie Léger, Massigli und Comert zu erreichen, die für Härte eintraten. Phipps intrigierte ebenfalls gegen Daladier und bei der Regierungsbildung im September 1939 gegen Bonnet. Der langjährige Staatssekretär Vansittart unterhielt enge Verbindung zur französischen Parteipolitik. Dies war in Paris, ebenso wie Phipps' Intervention gegen Paul-Boncour vom April 1938, durchaus bekannt. Die britischen Interventionen in Frankreichs Innenpolitik waren vor allem deshalb möglich, weil die französischen Politiker versuchten, sich ihrerseits der Briten zu bedienen. Léger setzte etwa im September 1938, so Harvey, auf das Foreign Office, um Bonnet zu umgehen; Bonnet bat Phipps im April und im Juli 1939, Daladier unter Druck zu setzen. Richard Davis' Urteil, London habe gewußt, daß beide Demokratien zusammenarbeiten mußten, verdient deshalb die Korrektur, daß London versuchte, so lange wie möglich auf Distanz zu Paris zu bleiben ${ }^{20}$.

Seinerseits stieß England in Frankreichs Marine, dem Heer und Teilen der Gesellschaft auf Abneigung. Dies beeinflußte die Diplomatie aber kaum. Die Gewinnung britischer Unterstützung in Europa war für den Quai d'Orsay das zentrale Ziel. Wirtschaftlich, politisch und militärisch war die Weltmacht England der einzige Partner, mit dem Paris den Frieden bewahren konnte. Léger und Daladier ordneten der Erhaltung der britischen Solidarität deshalb bisweilen französische Interessen unter. Nur ein einziger Wutausbruch Daladiers gegen London ist überliefert: Als er Anfang 1939 annahm, Chamberlain habe Rom Konzessionen auf Kosten der Franzosen angeboten, sagte er Bullitt:

\footnotetext{
${ }^{19}$ TABOUIS, Cassandre, S. 326f.; WERTH, The Twilight, S. 162; DU RÉAU, Édouard Daladier, S. 219; LACAZE, La France, S. 121; CARLEY, 1939. The Alliance, S. 15, S. 42; Michael Dockrill, British Establishment Perspectives on France, 1936-40, Houndmills u.a. 1999, S. 80f.

${ }^{20}$ Philipp M. H. BeLL, France and Britain 1900-1940: Entente and Estrangement, London 1996, S. 211; BARBIER, Henti Hoppenot, S. 101; WaTT, How War Came, S. 73, S. 423; GIRAUlT, La décision gouvernementale, S. 225; HARveY, Diplomatic Diaries, S. 182, S. 227f., S. 234, S. 286, S. 295, S. 319; Raffaele Guariglia (Paris) an Ciano, 13.9.1939 (DDI Serie 9, 1, 189); Phipps an Halifax, 15.9.1939 (FO 371/22910, C 13909/25/17); CAIRNS, A Nation of Shopkeepers, S. 737; Richard DAVIS, Anglo-French Relations before the Second World War. Appeasement and Crisis, Basingstoke, New York 2001, S. 188, S. 199.
} 
Daladier said that he fully expected to be betrayed by the British. He [...] considered Chamberlain a desiccated stick, the King a moron; and the Queen an excessively ambitious woman who would be ready to sacrifice every other country in the world in order that she might remain Queen [...]. He added that he considered Eden a young idiot and did not know [...] one single Englishman for whose intellectual equipment and character he had respect. [...] The British would give away every possession of their friends rather than stand up to Germany and Italy ${ }^{21}$.

In Washington hatte Roosevelt die Beziehungen zu Paris zur "Chefsache« erklärt. Die französischen Minister glaubten, der französisch sprechende Präsident liebe ihr Land und komme ihm eines Tages zu Hilfe. Frisch im Amt, hatte Roosevelt 1933 versichert, er wolle eng mit Paris kooperieren. 1936 feierte Frankreich seine Wiederwahl. Er schien als Freund, der Krieg in Europa verhindern könne ${ }^{22}$. Selbst wenn er nicht gegen die Neutralitätsgesetze vorging, wurde der Präsident heimlich aktiv: Er half 1938, daß Paris in den USA 655 Kampfflugzeuge kaufen konnte ${ }^{23}$. Doch Roosevelt mißtraute den Franzosen mehr, als diese ahnten: Dem sowjetischen Botschafter sagte er, er traue der französischen Regierung, vor allem Bonnet, nicht. Ihn ärgerte, daß Frankreich wie eine Großmacht behandelt werden wollte, aber nicht einmal seine innere Schwäche überwand. Roosevelts Freund Morgenthau klagte, die Franzosen seien eine viertklassige Macht: Sie wollten gut leben, ohne hart zu arbeiten ${ }^{24}$.

Roosevelts Haltung zum französischen Regime in Indochina war kritisch. Von 1942 bis Anfang 1945 äußerte er mehrfach, er lehne die Wiederherstellung der französischen Kolonie ab, denn, so seine oft gebrauchte Formel, nach hundert Jahren französischer Herrschaft gehe es den Menschen in Indochina

${ }^{21}$ Samuel M. OsGOOD, Le mythe de la "perfide Albion« en France 1919-1940, in: Cahiers d'histoire 201 (1975), S. 5-20; TRINQUIER, Le temps perdu, S. 105; Arnold WolfERS, Britain and France between Two Wars: Conflicting Strategies of Peace from Versailles to World War II, New York 1966, S. 76; Jean DOISE, Maurice VAlsSE, Diplomatie et outil militaire, 1871-1991, Paris ${ }^{2} 1992$, S. 297; CrouY-CHANEL, Alexis Leger, S. 103f., S. 266; DU RÉAU, Édouard Daladier, S. 236, S. 342; Albert Carl GaY, The Daladier Administration, University of. North Carolina, Diss., Chapel Hill 1970 [Mikrofilm], S. 393f.; Bullitt an Hull, 6.2.1939 (SD 740.00/568).

${ }_{22}$ RosSI, Roosevelt, S. XI, S. XX, S. 33; Jean-Baptiste DUROSELLE, La France et les États-Unis, des origines à nos jours, Paris 1976, S. 152f;; BLuMENTHAL, Illusion and Reality, S. 179, S. 227f.

${ }_{23}$ André KASPI, Franco-American Relations, 1918-1941, in: Amerikastudien 39 (1994), S. 67-72 (S. 71); John McVickar HAIGHT, France's Search for American Military Aircraft: Before the Munich Crisis, in: Aerospace Historian 25 (1978), S. 141-152; DeRS., American Aid to France, 1938-1940, New York 1970. Bis September 1939 wurden 200 Jagdflugzeuge geliefert. Von November 1939 bis März 1940 orderte Daladier weitere 3700 Flugzeuge, von denen bis Mai 1940166 Maschinen in Frankreich ankamen (HAIGHT, American Aid to France, S. 130f., S. 217f.). Die Entscheidung vom Mai 1939, für 1,27 Milliarden Francs in den USA eine, in Kanada zwei Flugzeugfabriken für Frankreich zu errichten (DUROSELlE, L'Abîme, S. 122), wurde nicht mehr umgesetzt. Zu den Hilfen zuletzt Gérard BossouARD, Les aides américaines économiques et militaires à la France, 1938-1960. Une nouvelle image des rapports de puissance, Paris 2001.

${ }^{24}$ Botschaft Washington an Molotov, 2.7.1939 (SPE II, 359); MARKS, Wind over Sand, S. 124f;; BLUMENTHAL, Illusion and Reality, S. 200. 
schlechter als zuvor ${ }^{25}$. Es gibt zwar keinen Hinweis, daß der Präsident bis 1940 ebenso dachte, aber er traute der französischen Verwaltung nicht. Im Februar 1938 ließ er seine Diplomaten Informationen über den Nachschub sammeln, den China über die Nachbarländer erhielt. Während Roosevelt die Zahlen aus London akzeptierte, gingen US-Diplomaten in Indochina konspirativ vor. Das State Department kooperierte indirekt mit Japans Geheimdienst: Zwei Griechen, die in Port Said Waffentransporte nach China ausspionierten, arbeiteten zugleich für Japan und Amerika ${ }^{26}$. Doch auch Frankreichs Führung hatte Vorbehalte gegenüber einer Zusammenarbeit mit den USA in Asien: Die Angelsachsen hätten das Ziel, Asien zu dominieren, schrieb Daladier später. Vize-Admiral Decoux äußerte den Verdacht, Amerika freue sich über Englands und Frankreichs Probleme in China und wolle heimlich ihr Erbe antreten. Es gibt aber zeitgenössisch keine Belege, daß sich Paris über eine den Kolonialismus in Indochina ablehnende Haltung Washingtons sorgte. Jean Chauvel klagt erst in seinen Memoiren darüber ${ }^{27}$.

Kolonialminister Georges Mandel nimmt unter den Politikern, die am Ende der Dritten Republik politische Verantwortung trugen, eine besondere Rolle ein: Er allein plädierte bei der Rheinlandbesetzung im März 1936 und vor dem Münchener Abkommen im September 1938 für Härte gegenüber Hitler und forderte im Juni 1940 die Fortsetzung der Kämpfe. Wäre er danach nach London geflohen, hätte wahrscheinlich er den Widerstand geführt, nicht de Gaulle $^{28}$. Mandel wurde stattdessen inhaftiert und am 7. Juli 1944 im Wald von Fontainebleau von der Vichy-nahen Miliz erschossen. Posthum wurde er mit Ehren überhäuft: Politiker wie Édouard Herriot und Jacques Chirac erklärten Georges Mandel zum Märtyrer. Als Ausdruck des öffentlichen Respekts ließ die Stadt Paris am 7. Juli 1945 eine Avenue Georges Mandel

${ }^{25}$ Gary R. HESS, Franklin D. Roosevelt and Indochina, in: Joumal of American History 59 (1972), S. 353-368; Walter LAFEBER, Roosevelt, Churchill, and Indochina: 1942-1945, in: Amerian Historical Review 80 (1975), S. 1277-1295; John J. SBREGA, The Anticolonial Policies of Franklin D. Roosevelt: A Reappraisal, in: Political Science Quarterly 101.1 (1986), S. 65-84.

${ }^{26}$ Hull an Kriegsminister Harry H. Woodring, 2.3., Woodring an Hull, 4.3., Hull an Roosevelt, 4.3., Hamilton, Note, 13.12.1938, Hull an Reed, 4.11.1939 (SD 893.24/360A, 363 1/2, 512, 636); Horace Remillard (Port Said) an Hull, 13.5., 14.5., 20.5., 27.5.1938 (SD 893.24/410, 411, 414, 418); Note, Augé, 26.9.1938 (MAEN Pékin A 55 bis); J.W.M. CHAPMAN, Japan, Germany and International Political Economy of Intelligence, in: KREINER, MATHIAS (Hg.), Deutschland - Japan, S. 27-60 (S. 40).

27 Daladier, Journal, S. 337; FNEO, compte rendu, 5.7.1939 (SHM IBB4 74); ChaUVEL, Commentaire, S. 228.

${ }^{28}$ SCHWARZ, Das Gesicht des Jahrhunderts, S. 207; David Robin WaTSON, Georges Mandel, in: Biographical Dictionary, S. 261f. (S. 261). Geneviève TABOUIS zufolge sahen noch 1941 viele Franzosen Mandel als den Mann, unter dem die Vierte Republik erbaut werde (Cassandre, S. 211). 
einweihen. Vier Mitarbeiter Mandels äußerten sich posthum über ihren Chef, in gleich fünf Biographien würdigte die Historiographie sein Leben ${ }^{29}$.

Vorbildlich war jedoch nicht die Art, wie er Politik betrieb. Mandel war ein Meister der Intrige. Als klugen, charakterlosen Mann beschrieb ihn Bullitt, für Phipps war er »der Mephistokles der Abgeordnetenkammer«, Daladier nannte Mandel einen skrupellosen Gauner mit großen Fähigkeiten im Lügen; er sei der einzige Minister, der es an Skrupellosigkeit mit Moskau aufnehmen könne. Beide Aspekte, Größe und Niedertracht, gehörten bei Mandel zusammen, mahnt Bertrand Favreau. Jacques Chirac nennt Mandels Methoden den notwendigen Gegenpol einer verzehrenden Leidenschaft für das Gemeinwoh $1^{30}$.

Mandel, im April 193852 Jahre alt, kam als Mitarbeiter Clemenceaus in die Politik, als dieser 1906 erst Innenminister und dann Regierungschef wurde. Im November 1917, als Clemenceau erneut die Regierung führte, wurde Mandel dessen mächtiger directeur de cabinet. Im November 1919 errang er ein Abgeordnetenmandat, das er mit einer Unterbrechung bis 1940 verteidigte. Mandel galt als politischer Erbe des »Vaters des Sieges«. Den Titel »Ancien chef de cabinet de M. Georges Clemenceau « gab er bis 1940 im Abgeordnetenhandbuch an. Im November 1934 wurde er unter Flandin Postminister und behielt das Ressort in drei Kabinetten. Er galt als Modernisierer von Luftpost, Radio und Fernsehen sowie als durchsetzungsstarker, autoritärer Chef, auch im Konflikt mit den Gewerkschaften. Diese veröffentlichten, daß er Telegramme an Politiker mitlas und Telefongespräche abhören ließ. Abgeordnete fürchteten seine Dossiers. Pertinax kommentierte dies, halb bewundernd: „Qui veut la fin veut les moyens! « Unbekannt blieb bis 1967, daß Mandel im Dezember 1935 versucht hatte, Ministerpräsident Laval über den LavalHoare-Plan zur Teilung Abessiniens zu stürzen ${ }^{31}$.

\footnotetext{
${ }^{29}$ Édouard HERRIot, Episodes 1940-1944, Paris 1950, S. 61; Jacques ChIRAC, Georges Mandel, in: Revue des deux mondes (Juli 1985), S. 118-123 (S. 118); BÜHRER, Aux heures tragiques; Paul CoblentZ, Georges Mandel, Paris 1946; Francisque VarenNe, Mon patron Georges Mandel, Paris 1947; WORMSER, Georges Mandel; Bertrand FAVREAU, Georges Mandel, un clemenciste en Gironde, Paris 1969; John M. SHERwood, Georges Mandel and the Third Republic, Stanford 1970; Jean-Noël JeANNEnEY, Georges Mandel. L'homme qu'on attendait, Paris 1991; Nicholas Sarkozy, Georges Mandel, le moine de la République, Paris 1994; Bertrand FAVreau, Georges Mandel ou la passion de la République, Paris 1996.

${ }^{30}$ BulLITT, For the President, S. 174; Phipps, Personalities Report, 6.1.1938 (FO 371/21604, C 102/102/37); Bullitt an Hull, 18.3.1939 (SD 740.00/632); FAVREAU, Clemenciste, S. 7, S. 18; CHIRAC, Georges Mandel, S. 119.

${ }^{31}$ Jean-Baptiste DuRoselle, Clemenceau, Paris 1988, S. 445, S. 500, S. 575f.; S. 633f.; Dictionnaire des parlementaires français, Bd. 7, S. 2354-2357; RÉMOND, Frankreich im 20. Jahrhundert, S. 68; Cédric DE Fougerolles, Georges Mandel, in: Dictionnaire des ministres, S. 532; Henry Coston, Georges Mandel, in: Dictionnaire de la politique française, Bd. I, S. 660-661; Jean VAVASSEURDESPERRIERS, Georges Mandel, in: Dictionnaire historique de la vie politique française au $\mathrm{XX}^{\mathrm{e}}$ siècle, S. 615-618; PertinaX, Les fossoyeurs, Bd. 1, S. 286f.; WORMSER, Georges Mandel, S. 192f;; JEANNENEY, Mandel, S. $116 \mathrm{f}$.
} 
Im Juni 1936 von der Volksfront aus dem Amt gedrängt, wurde Mandel von Daladier im April 1938 in die Regierung berufen, um die Öffnung der Mehrheit nach rechts zu verkörpern und um ihn als Exponent einer harten Haltung gegen Berlin einzubinden. Daladier bot Mandel zunächst das Luftfahrtministerium an. Doch einige Generäle lehnten es ab, daß Mandel in den obersten Verteidigungsrat einrückte. Vermutlich wollte auch Daladier den intriganten Mandel nicht mit einem Militärressort betrauen. Als Kompromiß nahm Mandel das Kolonialministerium an, das einen Generalstab bekam. Dessen Chef rückte in den Conseil supérieur de la défense nationale ein. Dies war Moutet noch verweigert worden. Zur Asienpolitik hatte sich Mandel bis dahin nie geäußert. Nach einem Monat Amtszeit hatten der Quai d'Orsay und Chinas Botschaft jedoch bereits den Eindruck gewonnen, der Minister sei China wohlgesonnen ${ }^{32}$.

Mandels Zeitgenossen waren beeindruckt von seinem Willen, Pläne durchzusetzen. Er arbeitete lang und hart. Von seinen Mitarbeitern erwartete er $\mathrm{Ge}-$ horsam. Vieles erledigte er selbst. Fast die gesamte Korrespondenz mit anderen Ministerien redigierte er persönlich. Aus den Papierbergen voller Dossiers blickte nur eine kleine Statue von Clemenceau hervor ${ }^{33}$. Mandel, der unter mangelnder Rednergabe litt, wollte als Mann des Handelns überzeugen, der mit Autorität, Disziplin und Hingabe Vorhaben realisierte ${ }^{34}$.

Gleich nach Übernahme des Amts zeigte er sich als energischer Ressortchef: Innerhalb einer Woche begann der lange geplante Ausbau des Hafens von Dakar für die Flotte. Bis Ende Mai versetzte er 432 Bedienstete in die Kolonien, hohe Beamte mußten fünf Jahre dort bleiben. Mitarbeiter, die drei Jahre lang nicht in Übersee gewesen waren, wurden entlassen. Bewerber für die Kolonialverwaltung mußten sich einem concours unterziehen, Schüler der École coloniale mußten eine bestimmte Zeit in Übersee verbringen; Beamte, die die Sprache der Einheimischen lernten, erhielten Prämien. Schüler, Studenten und Beamte aus den Kolonien wurden nach Frankreich eingeladen. Im Januar 1939 bekam die einheimische Bevölkerung Zugang zu allen lokalen Verwaltungs-

${ }^{32}$ WORMSER, Georges Mandel, S. 210; Bürer, Aux heures tragiques, S. 57; FAVREAU, Clemenciste, S. 203f.; SARKOZY, Georges Mandel, S. 221; Comité permanent de la défense nationale, procèsverbal de la séance du 15.2.1937 (SHAT 2 N 22); VARENNE, Mon Patron, S. 149; Wilson an Hull, 14.5., Maynard B. Barnes (Paris) an Hull, 9.6.1938 (SD 793.94/13078, 13285).

${ }^{33}$ Favreau, Clemenciste, S. 22; Queuille, Joumal, S. 332; CrouY-ChaNEL, Alexis Leger, S. 152; Max BRUSSET, Georges Mandel, in: Revue des deux mondes (Juli 1985), S. 124-129 (S. 124); André DAviD, Anatole de Monzie et Georges Mandel, in: Revue des deux mondes (Okt. 1976), S. 98-101 (S. 101); BüHRER, Aux heures tragiques, S. 114; MARTIN DU GARD, Les Mémorables, Bd. III, S. 245f.; JEANNENEY, Georges Mandel, S. 63f;; lediglich WORMSER schreibt, Mandel habe die Mitarbeiter kollegial behandelt (Georges Mandel, S. 212); SALAN, Mémoires, S. 57; Duff CoOPER, Old Men Forget. The Autobiography of Duff Cooper (Viscount Norwich), London 1953, S. 275.

${ }^{34}$ Berl, 10 juillet 1940, S. 62; VARENNE, Mon Patron, S. 95f., S. 146; WorMSER, Mandel, S. 226; Marcel LuCAIN, Mandel, in: Dictionnaire national, S. 54; MARTIN DU GARD, Les Mémorables, S. 245. 
ämtern, im August 1939 erhielten die Vietnamesen mehr Mitsprache im Grand Conseil des intérêts économiques et financiers de l'Indochine ${ }^{35}$.

Mandel entsandte am Außenministerium vorbei Emissäre nach Asien. Im Juli 1938 schickte er gegen den Widerstand des Quai d'Orsay den Literaten Marc Chadourne nach Shanghai. Dieser sollte einen Nachrichtendienst aufbauen, obwohl der Kolonialminister bereits Zugriff auf fünf Geheimdienste in Shanghai hatte: seinen eigenen Service de renseignement intercolonial, den Service politique der Polizei sowie die Netze des Service de transit de Shanghai, der Militärattachés und des Corps d'occupation. Chadourne reiste Ende 1938 nach Chungking, wo er als Korrespondent des »Paris-Soir« Chiang Kaishek, T.V. Soong und Wang Ching-wei traf. Ende 1939 zog Mandels Agent nach Bangkok, dann nach Manila ${ }^{36}$. Welche Aufträge Chadourne erledigte, ist ebenso unklar wie bei den Geographen André Guibaut und Louis Liotard. 1936/37 hatten sie Yunnan, Birma und vor allem die Birmastraße erkundet. Im November 1939 reisten sie - angeblich für den Bildungsminister - nach Chungking, wo sie im März 1940 ankamen. Guibaut stellte die Reisen später als rein wissenschaftlich dar. Mandel und Bührer hätten die zweite Expedition als Zeichen der Freundschaft gegenüber China begrüßt. Raoul Salan, Chef des Kolonialgeheimdienstes, betont aber in seinen Memoiren, auf Bührers Wunsch habe er Guibaut und Liotard den Auftrag für die erste Reise gegeben. Nach ihrer Rückkehr hätten sie ihm eine reiche Dokumentation übergeben. Pascal Krop hält Salans Darstellung für korrekt. Im März 1940 erklärten die Geographen dem französischen Militärattaché, sie seien vom Kolonialministerium mit einem nachrichtendienstlichen Auftrag nach China geschickt worden. Mandel selbst teilte dem Quai d'Orsay mit, er habe die Mission entsandt, um russischem Einfluß entgegenzuwirken ${ }^{37}$.

\footnotetext{
35 VARenNe, Mon Patron, S. 150f; COBLEnTZ, Georges Mandel, S. 195; Tableau synoptique des principales initiatives prises du 15 avril 1938 au 15 janvier 1939 (CAOM Indo NF 263); Le Journal, 20.1., "Le Petit Parisien«, 17.8.1939 (CAOM Fonds Mandel 17/PA/1). Wie wenig ohne Mandels Durchgriff voranging, zeigte sich beim im Juni 1938 beschlossenen Bau einer militärisch wichtigen Nord-Süd-Verbindung durch Vietnam. Die Ausführung wurde zwischen zivilen und militärischen Behörden so lange hin und her geschoben, bis im April 1939 die Regenzeit begann und die Bauarbeiten bis Oktober liegen blieben (rapport par M. Ruffel, 16.4.1939, CAOM CM 1067).

${ }^{36}$ Naggiar an Bonnet, T 929-30, 5.7., note de la sous-direction pour M. Léger, 30.7., Hoppenot an Naggiar, L 110, 4.8.1938; Knobel an Bonnet, L 79, 2.3., Willoquet (Manila) an Bonnet, T 70, 3.10.1939 (MAE Indfr 52); FNEO an EMG.2, T 7122-33, 19.12.1938 (SHM 1 BB9 42); Brévié an Mandel, T 2, 3.1., T 380, 7.3.1939 (CAOM FM Tel 80); DecouX, À la barre de l'Indochine, S. 131; CATROUX, Deux actes, S. 39; Léger an Lépissier, T 91, 8.5., Lépissier an Reynaud, T 80-81, 10.5.1940 (MAE Siam 85); Sayre (Manila) an Hull, 8.7.1940 (SD 851g.01/31); MILLER, Shanghai, S. 251.

${ }^{37}$ André Guibaut, Tibetan Venture. In the Country of the Ngolo-Setas. Second Guibaut-Liotard Expedition, London 1947, S. 3; Yvon an EMG.2, L 134, 15.4.1939 (SHAT 7 N 3292); SaLAN, Mémoires, S. 59; Pascal KroP, Les secrets de l'espionnage français de 1870 à nos jours, Paris ${ }^{2} 1995$, S. 453; Charvériat an Cosme, L, 31.12.1939; Cosme an Daladier, T 206, 12.3., Diplomatie an Colonies, L 267, 14.3., Colonies an Diplomatie, L, 18.3., Chauvel an Chungking, T 108, 18.3.1940 (MAE Ac 83).
} 
Zwei Techniker sandte Mandel nach China: Der Ingenieur Steck arbeitete im Juli 1938 drei Monate in Yunnan, wo er wohl den Aufbau von Rüstungsfirmen besprach. Die Existenz solcher Gespräche, die aber in Paris stattgefunden haben sollen, bestätigt Bührer. Der Chemiker Nicoletis war im Sommer 1938 in Hankou, um für China eine Granatenproduktion aufzubauen, so der ArmeeGeheimdienst in Hanoi. Mandel habe Nicoletis' Einsatz gebilligt ${ }^{38}$.

\subsection{Aufrüstungsbemühungen in Indochina}

Wenige Stunden nach der Amtsübernahme verkündete Mandel, er wolle eine Kolonialarmee aufbauen. Frankreich brauche jetzt die Hilfe der Kolonien. Er begann mit Indochinas Aufrüstung, um die französische Position in Europa zu stärken, nicht etwa, um die Kolonie vor Japan zu schützen. Wormser und Catroux schreiben, Mandel habe eine Armee zum Transport nach Frankreich aufbauen wollen. Eine geplante, wenn auch nur Ostafrika betreffende, internationale Regelung, indigene Soldaten nur in deren Heimat einzusetzen, stieß deshalb am 19. April 1938 bei Mandel auf scharfe Ablehnung ${ }^{39}$.

Am Tag darauf befahl Mandel dem Generalgouverneur in Hanoi, 40000 Soldaten zu rekrutieren. Bis dahin verfügten die Streitkräfte in Indochina über 18000 einheimische Armeeangehörige und 10800 Soldaten aus Frankreich $^{40}$. Brévié solle rasch und unter strenger Geheimhaltung handeln. Telegramme mußte er persönlich dechiffrieren. Falls die Rekrutierung nicht bis 1. August erfolge, drohte Mandel, übernehme ein Offizier die Aufgabe. Brévié protestierte: Er finde 40000 Freiwillige für den Dienst in Indochina, aber nur die Hälfte für einen Einsatz in Frankreich. Den Rest müsse man einberufen, was

\footnotetext{
${ }^{38}$ Mandel an Brévié, T 385, 19.5., T 419, 4.6., T 433, 11.6.1938 (CAOM FM 672); Brévié an Mandel, T 687, 15.6., T 762, 1.7.1938 (CAOM FM 678); BÜHRER, Aux heures tragiques, S. 62; SEH, renseignement $\mathrm{n}^{\circ}$ 534, 2.7.1938 (CAOM CM 82).

${ }^{39}$ BŨHRER, Aux heures tragiques, S. 34; S. 48f.; Claude HESSE D'Alzon, L'évolution des conceptions stratégiques du commandement français en Indochine entre 1940 et 1945, in: Revue d'histoire de la Deuxième Guerre mondiale 138 (1985), S. 5-20 (S. 6); BENABI, Les Français, les Japonais et le mouvement national, S. 20f.; RoQUES, DONNADIEU, L'Empire, S. 146; WORMSER, Mandel, S. 214; CATRoux, Deux actes, S. 7; Mandel an Bonnet, D 402, 19.4.1938 (DDF IX, 203). Nach 1945 wurde der Dritten Republik vorgeworfen, sie habe die Verteidigung Indochinas vernachlässigt. Wohl deshalb betonen Mitarbeiter Mandels, der Minister habe die Stärkung der Kolonien und die Hilfe für die Metropole gleichrangig verfolgt (VARENNE, Mon Patron, S. 155f.) oder die Kolonien in das Zentrum der Anstrengungen gestellt (BÜHRER, Aux heures tragiques, S. 14).

${ }^{40} \mathrm{LÉVY}$, La politique française, S. 112; 1937 lebten 42300 Franzosen in Indochina. Die Soldaten und die 3800 Beamten stellten 72 Prozent der in der Kolonie berufstätigen Franzosen dar (Pierre-Richard FERAY, Le Viêtnam au XX $X^{e}$ siècle, Paris 1979, S. 65).
} 
auf Widerstand stoßen werde. In Indochina koste der Einsatz von 20000 Mann bis Ende 193850 Millionen, in Frankreich 150 Millionen Francs. Mandel ließ die Frage des Einsatzortes offen: Die neuen Verbände sollten zum Einsatz außerhalb Indochinas fähig sein. Mit den Kosten konfrontiert, reduzierte er im Mai die Zahl der Einberufungen auf 20000 und ordnete die Stationierung der Truppe in Indochina an. Bei Kleidung und Ausrüstung sollte gespart werden. Die Gebäude, für die Brévié 20 Millionen Francs verlangte, sollten die zehn neuen Bataillone selbst bauen. Die Forderung nach Ärzten und Offizieren aus Frankreich lehnte Mandel ab. Um Proteste in Indochina zu verhindern, erklärte Mandel, die neuen Kontingente erfüllten den Wunsch der Bevölkerung nach größerer Beteiligung bei der Verteidigung. Die Aushebung verfehlte knapp ihr Ziel 14900 Soldaten wurden für drei Jahre eingezogen, 3500 freiwillige Gebirgsjäger verpflichteten sich für zwei Jahre ${ }^{41}$.

In Afrika wurden 24500 Mann ausgehoben. Am 6. Mai - Mandel war kaum einen Monat im Amt - sprachen die Generäle Gamelin, Georges und Colson mit dem Chef der Kolonialtruppen General Bührer über die Eingliederung der neuen Verbände in die Metropole. Die Generäle einigten sich, daß 27000 afrikanische und indochinesische Soldaten, teils in geschlossenen Verbänden, teils aufgeteilt auf »weiße « Heereseinheiten, sukzessive nach Frankreich kommen sollten. Die Luftstreitkräfte sollten 10000 Mann aus den Kolonien aufnehmen. Ein Erlaß vom 17. Juni 1938 regelte, daß Kolonialtruppen regulär in Europa eingesetzt werden konnten ${ }^{42}$. In Europa tatsächlich eingeplant wurden die Überseeverbände bis 1940 aber nicht. Noch unter Moutet hatte der Conseil supérieur de la France d'outre mer den Wehrdienst für Einheimische abgelehnt, da er Unruhen auslösen könne und Verpflichteten desertieren würden. Weitere Aushebungen erfolgten 1938 und 1939 nicht. Im Sommer 1939 wurden lediglich 2000 Soldaten des Bergstammes der Mö̈s eingezogen, die als gute Soldaten galten. Dafür wurden 2000 andere Soldaten entlassen ${ }^{43}$.

Der Chef der Kolonialtruppen General Jules-Antoine Bührer arbeitete eng mit Mandel zusammen. Im Dezember 1937 war der Elsässer Generalinspekteur der Kolonialtruppen geworden. Zuvor hatte er zwei Jahre lang das Heer in Indochina befehligt und stets vor der Gefährdung der Kolonie im Fall eines

\footnotetext{
${ }^{41}$ Mandel an Brévié, T 318, 20.4., T 325, 22.4., T 344, 3.5., T 359, 9.5., T 364, 11.5., T 373, 14.5., T 380, 18.5., T 392, 20.5., T 394, 21.5., T 403, 27.5.; Brévié an Mandel, T 460, 21.4., T 478, 23.4., T 553, 8.5., T 568, 13.5., T 579, 17.5., T 593-95, 20.5.1938 (CAOM FM 672, 677).

42 Tableau des principales initiatives prises du 15 avril 1938 au 15 janvier 1939 (CAOM FM-Indochine NF 263); leicht abweichende Zahlen bei BÜHRER, Aux heures tragiques, S. 54; Note, 6.5.1938 (SHAT 2 N 225); Lieutenant-colonel P. SARRAT, Les troupes coloniales et l'organisation défensive de l'empire français, in: Revue des troupes coloniales 253 (August 1938), S. 759-764 (S. 763).

${ }^{43} \mathrm{Mandel}$ an Brévié, T 442, 9.5.1939; Note de service, troupes de l'Indochine, état-major, $\mathrm{n}^{\circ} 210$, 4.7.1939; General Martin an Brévié, L 183, 24.5., L 298, 3.9., Catroux an Mandel, L 99-CMA 11.9.1939 (CAOM CM 397); Graffeuil an Catroux, L 925, 15.4.1940 (CAOM CM 395).
} 
Kriegs in Europa gewarnt. Anders als Mandel sah Bührer das Ziel der Aufrüstung darin, Indochinas Fähigkeit zur Selbstverteidigung zu stärken. Im Januar 1938 hatte Bührer in einem Aufsatz und bei einem Vortrag in Hanoi seine Ideen skizziert: Bei Indochinas Verteidigung habe Frankreich den Vorteil, daß ein Gegner - Bührer ging von Japan aus, ohne es zu nennen - fern der Heimat operiere und Frankreich gegenüber einer Macht, die die Hegemonie im Pazifik wolle, nicht allein bleiben werde. Da Indochina in einem Weltkrieg aber keine Hilfe aus Europa erhalte, müsse es eine eigene Kriegsindustrie aufbauen und einheimische Reservisten heranziehen. Man müsse Einheimischen Zugang zu hohen Positionen in Militär und Verwaltung gewähren und dürfe die Arbeiter in Indochina nicht im Elend lassen und die gebildete Mittelschicht durch die Verweigerung von Führungspositionen weiter verbittern. Wen man als Soldaten brauche, den dürfe man sich nicht zum Feind machen.

Am 20. Mai 1938 wandte sich Bührer an den Conseil supérieur de la guerre, das oberste Gremium des Heeres, mit der Bitte, die Einheimischen im Militär aufzuwerten und sie auch als höhere Offiziere einzusetzen. In der Armeeführung stieß Bührer auf Ablehnung: Für General Georges war es unannehmbar, daß Vietnamesen in Indochina größere Einheiten kommandierten. Militär und Verwaltung müßten von Franzosen geführt werden. Alles andere zerstöre das Prinzip der französischen Herrschaft und säe »den Keim des Todes« in die Kolonien. Als Kompromiß schlug Georges vor, einheimische Offiziere besser zu bezahlen und einige Offiziersstellen für sie zu schaffen. General Gaston Billotte, der 1930 bis 1933 Oberkommandeur in Indochina war, warnte vor der revolutionären Energie vietnamesischer Truppen, die 1930 in Yen Bay fast Frankreichs Herrschaft beendet habe. Bührer antwortete, es gehe nur darum, ob die Metropole alle Lasten tragen wolle, um Indochina zu halten, oder ob man der Kolonie eine gewisse Autonomie bei der Verteidigung gebe. Am 22. September 1938, während der Sudetenkrise, beschloß die Armee, Indochinesen, aber keine Afrikaner, zu Militärakademien zuzulassen ${ }^{44}$.

Bührer versuchte im Oktober 1938, seine Ideen - Einsatz einheimischer Soldaten und Offiziere, Bemühen um die Loyalität der Einheimischen, Aufbau eigener Rüstungsbetriebe und Militärverbände in Indochina - General Gamelin als Konsequenz der Münchener Konferenz nahezubringen. Im November 1938 und im Februar 1939 ging er mit seinem Konzept erneut an die Öffentlichkeit. Nun stellte Bührer die Ideen unter das Motiv der imperialen Verteidigung:

\footnotetext{
44 Général BüHRER, Regards sur la défense de l'Indochine, in: Revue des troupes coloniales 246 (1938), S. 29-33; Coultas an Eden, 5.2 .1938 (FO 371/21589, C 1582/8/17); Mandel an Brévié, T 689, 27.9.1938 (CAOM FM 672); BÜHRER, Aux heures tragiques, S. 20, S. 28f., S. 102f.; ROQUES, DonNadieU, L'Empire, S. 149; État-major du général Georges, note sur les cadres indigènes, 20.5.1938 (SHAT $1 \mathrm{~N}$ 47); Procès-verbal du Conseil supérieur de la guerre, 22.9.1938 (SHAT $1 \mathrm{~N}$ 38); Oberstleutnant Bertraux, note sur la défense de I'Indochine, 8.8.1939, S. 7f. (CAOM CM 938).
} 
Dem Großdeutschland müsse sich ein Großfrankreich einschließlich der Kolonien entgegenstellen. Es ist unklar, ob die Debatte über die imperiale Verteidigung für ihn nur ein Mittel war, um seine alte Idee vorzubringen, oder ob er wirklich, wie er sagte, mit den Kolonialtruppen Frankreichs Position in Europa stärken wollte. Seine Argumente, das Schicksal der Kolonien entscheide sich nicht am Rhein, die Franzosen müßten lernen, daß man das gesamte Empire verteidigen müsse und daß Indochina die am meisten bedrohte Kolonie sei, deuten aber darauf hin, daß die Sicherheit Indochinas im Zentrum seiner Überlegungen blieb. Allerdings lehnten es Gamelin und Darlan weiter ab, Verstärkungen aus den Kolonien zu Frankreichs Verteidigung einzuplanen ${ }^{45}$.

Um Indochinas Aufrüstung zu finanzieren, nahm Brévié im Juni 1938 eine Anleihe über 440 Millionen Francs auf. Zinsen und Abtrag trug die Kolonie, denn, so erklärte Mandel öffentlich, die Kolonien müßten die Mittel für ihre Verteidigung selbst aufbringen. Brévié sagte im Radio, die Kolonie müsse für ihre eigene Sicherheit sorgen ${ }^{46}$. Dabei hielt sich Mandel den Einsatz der Verbände in Europa offen. Die Anleihe ließ sich aber leichter begründen, wenn man von der Kolonie einen Beitrag zur Selbstverteidigung forderte. Mitte August 1939 erklärte Mandel schließlich auch in Indochina, er wolle 100000 Soldaten aus der Kolonie in die Metropole schicken können. Mandels Äußerung im Herbst 1939, notfalls solle man Indochina aufgeben, zeigt, daß die Verteidigung der Kolonie für ihn keine absolute Priorität hatte.

Von den 440 Millionen Francs der Anleihe verplante Mandel im Juli 1938 für die Ausrüstung der 20000 Mann 82 Millionen Francs. Am 1. September 1938 entnahm Mandel 40 Millionen, um Flugzeuge zu kaufen. Am 15. Mai 1939 erhöhte der Grand Conseil des intérêts économiques et financiers de l'Indochine die Steuern um 100 Millionen Francs im Jahr. Weitere 80 Millionen wurden der Reservekasse für Kautschuk entnommen ${ }^{47}$. Mit diesem Geld wollte Mandel in Indochina eine Rüstungsindustrie aufbauen, die Produkte von der Gasmaske bis hin zu kompletten Flugzeugen herstellen konnte.

${ }^{45}$ Bührer an Gamelin, D 74/S, 19.10., Gamelin an Daladier, D 936/DN 3, 26.10., Darlan, Note, 17.10.1938 (DDF XII, 174, 225, 147); *** [i.e. Jules BÜHRER], La défense de l'Indochine, in: Revue des deux mondes 108 (1938) 48, S. 438-450; General BÜHRER, Quelques pensées sur l'empire français, in: Revue des troupes coloniales 259 (1939), S. 115-132.

${ }^{46}$ Mandel an Brévié, T 422-23, 7.6., T 427, 9.6.1938 (CAOM FM 672); Bullitt an Hull, 31.5 .1938 (SD 851.014/89); Cochrane an Hull, 6.7., Palmer an Hull, 29.7.1938 (SD 851g.51/42, 44); Walsh an Halifax, 28.11.1938 (FO 371/22921, C 249/249/17); Les décrets interéssants les colonies, in: L'Industrielle, 29.5.1938 (SHAT 2 N 247).

${ }^{47}$ Mandel an Brévié, T 517, 9.7., T 520, 11.7.1938 (CAOM FM 672); Sharman an Halifax, 4.8.1938 (FO 371/21590, C 9113/8/17); Mandel an Brévié, T 623, 1.9., T 655, 15.9., T 758, 19.10; Brévié an Mandel, T 977, 2.9.1938 (CAOM FM 672, 678); Walsh an Halifax, 18.3., 20.5., 12.7., 11.8.1939 (FO 371/22921, C 4684, 7743, 10342, 11770/249/17); Neumann an Ribbentrop, 18.5.1939 (AA Pol VIII 60 2); Brévié an Mandel, T 853, 17.5., T 860, T 863-64, 18.5., T 900, 24.5.1939 (CAOM FM Tel 81); Flood an Hull, 17.6., Phipps an Halifax, 7.9 .1939 (SD 851G.512/5, FO 371/22913, C 13206/90/17). 
Initiativen zur industriellen Entwicklung Indochinas hatte Paris bis dahin noch nie ergriffen. Industriell gefördert oder hergestellt wurden in Indochina nur Kohle (mit einer Rekordproduktion von 2,3 Millionen Tonnen 1937) und Zement. Selbst Stahl wurde importiert. Eine Textilindustrie war nur rudimentär vorhanden. Der Ökonom Louis Mérat, ein Berater Moutets, plädierte 1936 dafür, die gesamte Industrie zu entwickeln, um die wachsende Bevölkenung zu ernähren und die Nachfrage in Indochina zu steigern, wovon auch Frankreichs Wirtschaft profitiere. Dies sei zudem zur Verteidigung Indochinas notwendig. Moutet lehnte aber, wie seine Vorgänger, die Industrialisierungspläne ab: Die neue Konkurrenz führe zu Arbeitslosigkeit in der Metropole und in Indochina zur Entstehung eines gefährlichen Proletariats. Indochinas Zukunft liege auf dem Land. Bauern seien zudem zuverlässigere Soldaten als Arbeiter.

Frankreichs Wirtschaft strebte an, die Zustände zu erhalten: 1936 ging die Hälfte des Exportes in die Kolonien. Vor allem die Textilproduktion und die Metallverarbeitung waren stark auf die Kolonien angewiesen. In der Wirtschaftskrise wollten Frankreichs Wirtschaft und Politik den wichtigen Markt der Kolonien nicht durch eine Industrialisierung gefährden. Der Ökonom Paul Bernard nannte schon 1934, als er die Industrialisierungsdebatte anstieß, als Ziel, Indochina solle wirtschaftlich unabhängig werden. Genau das lehnte die Politik bis $1938 \mathrm{ab}$. Sie wollte nicht die Kolonie autark entwickeln, sondern sie eng an die schwächelnde französische Wirtschaft binden ${ }^{48}$.

Auf Drängen Bührers befaßten sich die Oberkommandierenden der Teilstreitkräfte und der Kolonialtruppen im Comité consultatif de défense des colonies am 29. Juli 1937 mit der Waffenproduktion in Indochina. Seit 1902 werde diese Frage diskutiert, stellte General Marin fest, aber alle Vorschläge seien verworfen worden. Bührer verwies auf Studien, wonach in Indochina Munition, leichte Artillerie und Gasmasken hergestellt und vorgefertigte Flugzeugteile montiert werden könnten. Ebenso wie der Aufbau lokaler Streitkräfte verlange aber auch die Schaffung einer Militärindustrie eine neue Kolonialpolitik. Das Comité urteilte, die Voraussetzungen für den Aufbau einer Waffenindustrie fehlten. Es entsandte dennoch zwei Ingenieure aus dem Kriegsministerium, die Experten für die Sprengstoff- und Waffenherstellung

\footnotetext{
${ }^{48}$ Catherine COQUERY-VIDROviTCH, Vichy et l'industrialisation aux colonies, in: Revue d'histoire de la Deuxième Guerre mondiale 114, Bd. 29 (1979), S. 69-94 (S. 69f); Irene NøRLUND, The French Empire, the Colonial State in Vietnam and Economic Policy, 1885-1940, in: Australian Economic History Review 31.1 (März 1991), S. 72-89; Jacques MARSEILLE, Empire colonial, S. 240f., S. 334f.; DERS., L'industrialisation des colonies: Affaiblissement ou renforcement de la puissance française?, in: Revue française d'histoire d'outre-mer 254, Bd. 59 (1982), S. 23-35; BouchE, Histoire de la colonisation française, Bd. 2, S. 310f.; vON ALBERTINI, Europäische Kolonialherrschaft, S. 176; Paul BERNARD, Le problème économique indochinois, Paris 1934. Seine Thesen griff BERNARD auf in: Nouveaux aspects du problème économique indochinois, Paris 1937.
} 
Nicoletis und Steck, nach Indochina. Anfang Dezember 1937 reisten die Experten $\mathrm{ab}$. Vor Ort untersuchten sie, ob in der Kolonie Bomben, Granaten und Zünder, Patronen, Sprengstoff und Gasmasken hergestellt werden könnten. 85 Millionen Francs koste der Aufbau der Fabriken, berechnete Nicoletis im April 1938, 30 Millionen davon sofort. Anfang Juni 1938 ordnete Mandel die Herstellung von Acht-Millimeter-Patronen an $^{49}$.

Indochina legte währenddessen eine Eisenreserve an: Moutet hatte kurz nach Österreichs »Anschluß« am 22. März 1938 ein Exportverbot für Eisenspäne und -schrott, Gußeisen und Stahl verhängt. Am 25. Mai wurde in Indochina der Export von Maschinen zur Metallverarbeitung verboten. Während der Sudetenkrise, am 24. September 1938, verhängte Mandel zudem ein (vorübergehendes) Exportverbot für Eisen- und Manganerz.

Angesichts der technischen und wirtschaftlichen Entwicklung Indochinas sei die Produktion von Waffen unmöglich, warnte Brévié. Das Kriegsministerium hielt nur die Herstellung von Bomben, Infanteriewaffen und -munition für denkbar. Mandel ließ sich aber nicht bremsen. Im Dezember 1938 schuf er den Service de l'industrie et des fabrications d'armement unter der Leitung von Ingenieur Steck und die Position eines Generalinspekteurs, der das wirtschaftliche Kriegspotential der Kolonie erhöhen sollte. Ob die Position jemals besetzt wurde, ist unklar ${ }^{50}$. Mitte Januar 1939 verbreitete Mandel in der Presse sowie im März 1939 im Senat und im Kolonialausschuß der Kammer, in Indochina habe die Produktion von Gasmasken und Flugzeugen begonnen. Diese fand aber nur auf dem Papier statt. Der Marineoffizier Charbonneau nannte die Berichte Selbstbetrug und Bluff. Zwar wurden ab Frühjahr 1939 in Indochina Bomben und Granaten produziert, ab Oktober 1939 auch Gasmasken - aber ohne Filter, weil die Aktivkohle fehlte. Die Herstellung von Munition kam bis zum Zusammenbruch der Dritten Republik nicht zustande. Für den Aufbau der Pulverfabrik fehlten Maschinen und Fachpersonal ${ }^{51}$.

\footnotetext{
${ }^{49}$ BÜHRER, Aux heures tragiques, S. 31f., S. 61; Note de la sous-direction d'Asie-Océanie, 25.5.1939 (MAE Indfr 42); Comité consultatif de défense des colonies, note, séance du 29.7., procès-verbal, Comité consultatif de défense des colonies, 29.7.1937 (SHAT 7 N 4194); Moutet an Daladier, L 2214, 4.11.1937 (SHAT 2 N 247); Brévié an Moutet, T 304, 21.3., T 321, 24.3.1938 (CAOM FM 677); Note secrète, Nicoletis (avril 1938) (CAOM Fonds Moutet 28/PA/5, 5).

${ }^{50}$ Bertraux, note sur la défense de l'Indochine, 8.8.1939, S. 40f. (CAOM CM 938); Conseil supérieur de la défense nationale, note sur l'organisation de la défense autonome de l'Union indochinoise, 27.10.1938 (SHAT 2 N 247); Walsh an Halifax, 13.2.1939 (FO 371/22921, C 2644/249/17).

${ }^{51}$ Tableau synoptique, 15.1.1939 (CAOM FM-Indo-NF 263); Walsh an Halifax, 1.2., 18.3.1939 (FO 371/22921, C 1721, C 4684/249/17); Phipps an Halifax, 30.3 .1939 (FO 371/22916, C 4447/130/17); Direction des fabrications d'armement, rapport sur la mobilisation industrielle, 1.1.1939; Commission chargée de l'étude de l'utilisation des ressources des territoires d'outre-mer, rapport général, 3.4.1940 (SHAT 2 N 57); BauCHAR, Rafales sur l'Indochine, S. 28; Bertraux, note sur la défense de l'Indochine, 8.8.1939, S. 46f. (CAOM CM 938); Conseil supérieur de la défense nationale, mobilisation économique des colonies, extrait de L 570 SPDN, 8.4.1940 (SHAT $2 \mathrm{~N} 63$ ).
} 
Prestigereichstes Objekt der Aufrüstung war der Bau einer Flugzeugfabrik in Tong, 45 Kilometer von Hanoi entfernt. Bereits 1935 hatten die Chinesen französische Diplomaten und den Waffenhändler Audinet um den Bau einer Flugzeugfabrik in China gebeten. Die Bitte blieb unbeantwortet. Im Oktober 1937 bat Chinas Regierung das Luftfahrtministerium in Paris um Hilfe bei der Errichtung einer Flugzeugfabrik in Indochina. Am 15. November 1937 teilte das Luftfahrtministerium dem Quai d'Orsay mit, man unterstütze den chinesischen Vorschlag; ein Abkommen zwischen den Regierungen stehe kurz vor dem Abschluß. Gustave Moutet, Sohn des Kolonialministers, sollte vor Ort die Verträge unterzeichnen. Im März 1938 gründeten Gustave Moutet und Chiang Kai-sheks Vertrauter Li Yu Ying in Saigon eine Gesellschaft mit 500000 Francs Kapital zum Bau und zur Montage von Flugzeugen. Die Firma sollte vorgefertigte Flugzeugteile montieren und Reparaturen durchführen. Der Bau ganzer Flugzeuge sollte später folgen. Warum das Projekt eingestellt wurde, ist unklar. Eventuell lag es daran, daß Marius Moutet im April 1938 aus dem Amt schied, denkbar sind auch Finanzprobleme: Im Dezember 1937 waren die Banque de l'Indochine und die Banque franco-chinoise bereit, in die Firma zu investieren, doch im Februar 1938 äußerten sie sich skeptisch ${ }^{52}$. In jedem Fall scheiterte das Projekt zunächst. Mit dem Plan, in Indochina Flugzeuge bauen zu lassen, mußte Georges Mandel bei null anfangen.

Am 15. November 1938 wies Mandel Brévié an, binnen eines Jahres für 100 Millionen Francs eine Flugzeugproduktion aufzubauen, die 150 Flugzeuge und 400 Motoren jährlich herstellte. Brévié widersprach nicht, warnte aber, ohne einheimische Spezialisten werde das Projekt langwierig, riskant und sehr teuer. Brévié hatte Recht. Im Februar 1939 schätzte das Verteidigungsministerium, der Bau der Fabrik werde vier Jahre dauern. Kurz darauf beugte sich Mandel den Problemen. Er erklärte, die Fabrik solle »zunächst« Flugzeugteile aus Europa zusammensetzen. Dem Flugzeugkonstrukteur Breguet, der die technische Leitung besaß, erschienen die Risiken so groß, daß er betonte, er habe nur als technischer Berater mit der Fabrik zu tun. Immerhin informierte sich Anfang April 1939 François Breguet, Sohn des Konstrukteurs und Schwiegersohn des Politikers Pierre-Étienne Flandin, vor Ort in Tong ${ }^{53}$.

\footnotetext{
52 BonNAY-BARBIER, Henri Hoppenot, S. 135; Audinet an Wilden, 14.1.1935 (MAEN Pékin A 54); Sous-direction des affaires administratives, note, 16.10.1937 (MAE Ac 134); Note pour le secrétaire général, 15.11.1937 (MAE Ac 135); Projet de télégramme au Dr. H. H. Kung, 29.11.1937 (MAE Chine 559); Gründungsvertrag Société auxiliaire de constructions mécaniques et métalliques, März 1938; Note, 22.3., Brévié an Steeg, L, 18.2.1938 (CAOM Fonds Moutet 28/PA/5, 5).

${ }^{53}$ Mandel an Brévié, T 845, 15.11., T 1345, 21.11.; Brévié an Mandel, T 1345, 21.11.1938 (CAOM FM 672, 678); Conseil supérieur de la défense nationale, mobilisation économique des colonies, 28.2.1939 (SHAT 2 N 63); Walsh an Halifax, 18.3., 20.5.1939 (FO 371/22921, C 4684, 7743/ 249/17); Neumann an Ribbentrop, 18.5 .1939 (AA Pol VIII 60 2); ELPHICK, Far Eastern File, S. $202 f$.
} 
Indochinas Luftstreitkräfte verfügten 1937 nur über 48 wertlose Potez 25Doppeldecker und acht unbrauchbare Wasserflugzeuge. "Herzzerreißend" nannte der Chef von Bréviés Militärkabinett die Lage. Wegen ihres Zustands dürften die Geschwader keine Auslandsbesuche unternehmen. Die gesamte Luftabwehr bestand 1937 aus nur 14 Geschützen. Bis zum Sommer 1939 kamen 32 Geschütze hinzu - davon die Hälfte aus dem Jahr 1913.

In Paris war die Lage bekannt. Der Luftfahrt- und der Kolonialminister entsandten im September 1937 drei Flugzeuge, um zu klären, ob Kräfte der Metropole Indochina unterstützen könnten. Der Generalstab der Luftwaffe urteilte danach, man müsse die Kräfte in den Kolonien nicht verstärken, da man rasch Verstärkungen heranführen könne. General Bührer kam zum gegenteiligen Ergebnis. Die Geschwader in Indochina wurden im Herbst 1937 schließlich nur durch zwei Farman 221 verstärkt, darunter eine fluguntaugliche. 1939 kamen nur vier Potez- und zwei Farman-Maschinen sowie zwölf Loire-Wasserflugzeuge hinzu. Insgesamt besaßen die Luftstreitkräfte in Indochina im Juni 1940 knapp 100 meist veraltete Flugzeuge. Nur 17 Flugzeuge vom Typ Morane 406, die für China bestimmt, aber in Haiphong trotz unvollständiger Bewaffnung beschlagnahmt worden waren, waren moderne Jäger. Die japanischen Piloten, die im Sommer 1940 die französischen Maschinen inspizierten, konnten ihr Gelächter nicht verbergen ${ }^{54}$.

Mandel erreichte, daß der Conseil supérieur de l'air, die Konferenz der zehn höchsten Offiziere der Luftwaffe und ihres Ministers, am 26. Juli 1938 erstmals seit 1929 mit der Spitze des Kolonialministeriums die Verteidigung der Kolonien besprach. Die Generäle beschlossen, jede Kolonie solle bis Ende 1939 die zur Verteidigung notwendigen Flugzeuge erhalten. Mandel sagte, wegen Indochinas und Französisch-Westafrikas kritischer Lage sei er bereit, die Flugzeuge aus dem Kolonialetat zu finanzieren. Auf Vorschlag von Luftfahrtminister Guy La Chambre beschloß der Rat, den Kauf von Flugzeugen im Ausland zu prüfen. Mandel bot für 1938 und 1939 je 200 Millionen Francs an. Zur Verteidigung Indochinas plante der Conseil zwölf Geschwader ein. Doch tatsächlich wurden nicht einmal die zwei Jagdflugzeuggruppen, mit denen Mandel fest gerechnet hatte, in Indochina aufgestellt ${ }^{55}$.

\footnotetext{
${ }^{54}$ Roy, note $\mathrm{n}^{\circ}$ 301, 11.3.1937; Bertraux, défense de l'Indochine, 8.8.1939, S. 2, S. 20f.; EMAA an Commandant Air en Indochine, T 830, 11.12., Moutet an Brévié, T 583, 16.9., T 630, 2.10., T 643, 8.10., T 784, 28.11., T 791, 2.12.1937 (CAOM CM 891, 938, FM 661); Cot an Daladier, L 1051, 8.12.1937; Procès-verbal, Conseil supérieur de l'air, 26.7.1938 (SHAT 2 247, SHAA 1 B 5); Rapport semestriel ( $2^{\mathrm{e}}$ semestre 1937) du commandant de l'air en Indochine (CAOM CM 898); Georges GAUTIER, Une mission civilisatrice, in: HÉDUY, Histoire de l'Indochine, Bd. 2, S. I-III (S. II).

${ }_{5 s}$ Procès-verbal, Conseil supérieur de l'air, 26.7.1938 (SHAA 1 B 5); Mandel an Brévié, T 414, 3.6., T 665, 17.9.1938; (CAOM FM 672); Brévié an Mandel, T 650, 6.6., T 1034, 15.9. 1938 (CAOM FM 678); Brévié an Mandel, T 557, 6.4.1939 (CAOM FM Tel 80).
} 
Die Minister Mandel und La Chambre vereinbarten, 100 niederländische Kolhoven-Flugzeuge zu kaufen. Der Kolonialminister überwies zwar den Kaufpreis für 46 Maschinen, vermutlich 96 Millionen Francs, aber keine einzige davon wurde nach Asien geliefert. Als Mandel entschied, eine Flugzeugwerft in Indochina aufzubauen, begehrte die Armée de l'air erneut auf und kündigte an, sie stelle keine Piloten dafür ab. Da Mandel mit der Fabrik, "vielleicht mit übertriebener Hast«, wie Bührer einräumt, an die Presse gegangen war, das Projekt aber nur schwer anlief, machte er Brévié dafür verantwortlich und löste ihn später auch deswegen als Generalgouverneur ab. Im August 1939 wurde die Zufahrt zur Fabrik gebaut, im Januar 1940 begann die Errichtung der beiden Hallen, in der die Flügel und der Rumpf hergestellt werden sollten. Die Motoren würden importiert werden, so die Pläne. Beginn der Produktion sollte der Januar 1941 sein. Ende Mai 1940 stand in Hanoi eine Flugschule vor der Eröffnung. Angesichts der Widerstände im Luftfahrtministerium hatte Georges Mandel selbst drei Piloten als Ausbilder gewonnen. Ausgerüstet war die Schule mit britischen De Havilland Flugzeugen ${ }^{56}$.

Der Grand Conseil des intérêts économiques et financiers de l'Indochine beklagte Ende 1939 die hohen Kosten des Projekts, die Sabattier, Decoux und Catroux übereinstimmend mit der exorbitanten Summe von 600 Millionen Francs angeben. Der Rat empfahl, Flugzeuge zu kaufen und nur eine einfache Montagehalle in Tong zu errichten. Selbst Bührer zweifelte an der Richtigkeit des Projekts. Das gigantische Vorhaben trug zur bitteren Kritik hoher französischer Offiziere bei, Mandel sei ein Politiker mit vielen, oft unnützen Ideen. Die Generalgouverneure Catroux und Decoux nehmen in ihren Memoiren beide für sich Anspruch, das Vorhaben gestoppt zu haben. Mehrere hundert Millionen Francs Verlust waren aber bereits entstanden, wie Decoux beklagt. Militärattaché Sabattier schloß sich Decoux' Urteil, man hätte das Geld besser ausgeben können, an. Als teure, unnütze Rüstungspolitik kritisiert Jacques Valette das Projekt, da weder die Flugzeugmontage noch die Waffenschmieden jemals funktioniert hätten. Buttinger hingegen lobt Mandels beachtliche Leistungen: Ihm sei es gegen große Widerstände gelungen, in vielen Feldern Veränderungen auf den Weg zu bringen. Allerdings habe Mandel nicht in zwei Jahren die Sünden von 80 Jahren wiedergutmachen können ${ }^{57}$.

\footnotetext{
${ }^{56}$ Claude D'ABZAC-EPEZY, Le prix de la survie: l'armée de l'air d'Indochine de septembre 1940 à mars 1945, in: Revue historique des armées, 1/1994, S. 77-89 (S. 78); Mandel im Kolonialausschuß der Kammer, 28.11.1939, bulletin de commissions, Bd. IV, $2^{\mathrm{e}}$ partie, Paris 1946; BūHRER, Aux heures tragiques, S. 64f.; Reed, 21.2., Flood an Hull, 3.6.1940 (SD 851g.248/4, 796/19).

${ }^{57}$ BENABl, Les Français, les Japonais et le mouvement national, S. 28; Hesse D'ALzon, L'armée française d'Indochine, S. 83; Notes on a liaison visit to French Indochina, 5.-20.12.1939 by Major General L.V. Bond (WO 106/5455); CATRouX, Deux actes, S. 43; DECOUX, À la barre de I'Indochine, S. 78; SABATTIER, Le destin, S. 29; VAlETTE, Indochine, S. 30; ButTINGER, Vietnam, Bd. 1, S. 230f.
} 
Mandels Plan zum Aufbau einer Rüstungsindustrie paßte nicht in das Indochina des Jahres 1939. Technisch aufwendiges Kriegsgerät in einem industriell unterentwickelten Land herstellen zu lassen, war unklug ${ }^{58}$. Der teure Aufbau der Flugzeugfabrik war ein spektakuläres Projekt, das vor allem entstand, um in Paris politischen Eindruck zu machen. Daß sich Mandel bereits im November 1938 für die Gründung der Fabrik feiern ließ, zeigt, wie wichtig es ihm war, die Öffentlichkeit zu beeindrucken. Bei allen Rüstungsprojekten in Kolonien legte er Wert darauf, daß man die treibende Kraft nicht übersah. Während Zeitungen Mandels unvergleichliche Tatkraft lobten, hatte sein Ministerium naheliegende Fragen, wie die der Versorgung der Kolonien und der Metropole im Krieg, bis August 1939 nicht untersucht $t^{59}$.

Auch der strategisch wichtige Flottenstützpunkt in Camranh, der 1904 für die russische Flotte und 1941/42 für Japan vor dem Angriff auf Singapur und Java eine wichtige Rolle spielte, wurde kaum verstärkt. Der Ausbau der Basis für U-Boote und die Verstärkung der Küstenverteidigung wurden oft geplant, aber immer wieder verschoben, weil Mandel andere Projekte für wichtiger hielt, wie die Aufrüstung der Häfen Dakar (Westafrika) und Fort de France (Antillen) oder den Kauf von Schleppern und den Ausbau der Docks in Saigon. Im September 1939 wurde Camranh mit vier Artilleriebatterien verteidigt, von denen eine von 1910 und eine von 1887 stammte $^{60}$.

Einfacher als der Aufbau einer Rüstungsindustrie aus dem Nichts hätte es für Mandel sein müssen, die Unterstützung der Marine für die Verstärkung der Flotte im Fernen Osten zu gewinnen. Die Marine war im 19. Jahrhundert eine der Triebkräfte der Expansion in Asien gewesen, und sie bediente sich auch jetzt intern und öffentlich ständig der Kolonialpropaganda: Frankreich sei nur dank seines Empire Weltmacht und nur dank der Kolonien, zu deren Verteidigung eine starke Marine benötigt werde, wohlhabend und unabhängig, betonte Generalstabschef François Darlan unermüdlich. Bei der Sicherheit der Kolonien gehe es um Frankreichs Weltgeltung und Prestige ${ }^{61}$.

\footnotetext{
${ }^{58}$ Wohl deshalb wurden die Pläne des Werkes vernichtet. Weder das Musée de l'air et de l'espace in Le Bourget, noch das Centre des archives d'outre-mer in Aix-en-Provence, noch das Archiv der Firma Dassault Aviation in Vaucresson, in der Breguet aufging, besitzen entsprechende Akten.

${ }^{59}$ Et voilà l'Empire, in: Le Voltaire, 26.11.1938; L'œuvre de M. Mandel, in: Le Journal, 17.1.1939 (CAOM Fonds Mandel 17/PA/1); Phipps an Halifax, 22.10.1939 (FO 371/22932, C 17126/797/17); EMG-Colonies, instruction $\mathrm{n}^{\circ} 1083,7.8 .1939$ (SHAT $2 \mathrm{~N} 63$ ).

${ }^{60}$ Campinchi an Mandel, L 123, 1.9.1938 (SHM 1BB2 171); Conférence des services d'action du 8 juin 1939 , procès-verbal sommaire, $\mathrm{n}^{\circ} 94$; Note pour le directeur du cabinet militaire, $\mathrm{n}^{\circ} \mathbf{9 6}$, 9.6.1939 (SHM 1BB2 172); Bertraux, défense de l'Indochine, 8.8.1939, S. 35 (CAOM CM 938).

${ }^{61}$ Admiral Darlan, Le rôle impériale de notre flotte, pour une publication dans le Miroir du Monde, $\mathrm{n}^{\circ} 7$, 1.4., Darlan, rapport au ministre, $\mathrm{n}^{\circ} 138$ très secret, 8.11.1937 (SHM 1BB2 170); Section d'études, rapport au ministre, $\mathrm{n}^{\circ} 5$, très secret, 10.1., transmise à la présidence du Conseil par $26 \mathrm{Cab} 0$ du 13/1/38; Note, EMG-SE, 17.6., note pour Cab.O, EMG-SE, 25.6.1938 (SHM 1BB2 171).
} 
Die praktische Haltung der Marine in Paris zur Verteidigung Indochinas war jedoch eine andere: Schon vor Ausbruch des Fernostkonfliktes lehnte es die Marine ab, Indochina zu verstärken. Flottenverbände in Indochina könnten nie stark genug sein, um es bei einem Angriff der stärksten Flotte der Region, der Marine Japans, zu verteidigen. Konteradmiral Petit, der Chef der Marine Indochinas, warnte jedoch, daß die Verbände vor Ort nicht einmal reichten, um sich gegen die Seestreitkräfte Siams zu behaupten. Vergeblich verlangte Petit im Juni 1937 sieben kleinere Schiffe und vier U-Boote zur Verstärkung.

Bei Ausbruch des japanisch-chinesischen Krieges umfaßten die Forces navales d'Extrême-Orient in China den Kreuzer Lamotte-Picquet, die vier Hochsee-Patrouillenboote (Avisos) Dumont d'Urville, Savorgnan de Brazza, Amiral Charner und Tahure, sowie die fünf Kanonenboote Doudart de Lagrée, Francis Garnier, La Grenadière, Balny im Jangtse und Argus im Si-Kiang vor Kanton. In Indochina stationiert waren die Aviso Marne und auf den Flüssen fünf Kanonenboote, die Polizeifunktionen ausübten ${ }^{62}$. Nach Beginn des Kriegs im Juli 1937 erwog Paris, die Schlagkraft der Einheiten zu erhöhen. Bereits am 23. Juli 1937 bat Moutet die Marineführung in Paris um die Verstärkung der Marine in Indochina. Im August 1937 intensivierte er das Drängen. Der Generalstab der Marine lehnte zunächst jede Verlegung $a b^{63}$.

Anfang Oktober 1937 entschied die Regierung, die U-Boote Acheron und Fresnel, den Kreuzer Primauguet und das Schulschiff Jeanne d'Arc Anfang Dezember sowie die vierte Kreuzerdivision mit den Kreuzern Georges Leygues, Montcalm und Gloire Anfang Januar 1938 nach Indochina zu verlegen. Die Entscheidung fiel gegen den Widerstand des Generalstabs der Marine, der vor einer Schwächung der Kräfte im Mittelmeer warnte. Die sieben Schiffe hatten militärisch keinen großen Wert, aber die Regierung in Paris demonstrierte damit die Bedeutung, die sie der französischen Position im Fernen Osten beimaß. Daß es Paris vor allem um ein symbolisches Handeln ging, zeigte sich, als der Aufenthalt der Kreuzerdivision und der Jeanne d'Arc vor Indochina auf drei Wochen beschränkt wurde. Die U-Boote konnten wegen des feucht-heißen Klimas nur sechs Monate in Südostasien bleiben.

Die Marine könne die Verstärkung nur kurz aufrechterhalten, teilte Marineminister Campinchi Anfang Dezember 1937 mit. Um Ansprüche des Kolonialministers auf eine dauerhafte Verstärkung abzuwehren, betonte die Marine, die entsandten Schiffe sollten nicht die Verteidigung Indochinas stärken,

\footnotetext{
${ }^{62}$ Petit an Gasnier-Duprac, L 45 EM.3, 19.6., Petit an Brévié, L 42 EM.3, 19.6.1937 (SHM IBB3 220); Section d'études générales, note 104, budget de l'exercise 1938, 23.8.1937; Note sur les possibilités de renforcement des FNEO, EMG.3 [Herbst 1937] (SHM 1BB2 170, 113).

${ }^{63}$ FNEO an Marine Saigon, T 6042, 15.8., T 6045, 17.8., Saigon an FNEO, T 893, 15.8., EMG.3 an Marine Saigon, T 7267, 17.8.1937 (SHM 1 BB9 270); Brévié an Moutet, T 608, 15.8.1937 (CAOM FM 666); Moutet an Marine, Défense maritime de l'Indochine, 17.8.1937 (MAE Indfr 42).
} 
sondern sie unternähmen nur eine Ausdauerfahrt. Für längere Zeit könne man äußerstenfalls den Kreuzer Primauguet entsenden, dessen Verlegung ohnehin für 1940 vorgesehen war. Am 16. Dezember 1937 wurde die Primauguet für zwei Jahre in den Fernen Osten entsandt - die erste deutliche Verstärkung der Marine im Fernen Osten seit 1919. Zu Reparaturen sollten die Kreuzer Lamotte-Picquet und Primauguet in die Metropole kommen. Die Erfüllung weiterer Bitten, wie die Moutets vom 4. November 1937 nach vier Torpedobooten, drei Torpedoabwehr-Schiffen und vier U-Booten, war illusorisch ${ }^{64}$.

Während die Fernostflottille mit Sitz in Shanghai vor allem französische Interessen in China für bedroht hielt, setzte die Marineführung in Paris die Verstärkungen zu gleichen Teilen in Shanghai und an Indochinas Küsten ein. Der Kreuzer Primauguet fuhr bis Shanghai, die übrigen Schiffe kreuzten vor Indochina. Als sich im Dezember 1937 die Lage in Shanghai beruhigte, befahl Campinchi, die Präsenz um Indochina zu erhöhen. Ein Bericht der britischen Nachrichtenagentur Reuter und eine Nachfrage von Admiral Hasegawa in Shanghai zeigte Paris, daß seine Aktivitäten registriert worden waren ${ }^{65}$.

Anfang 1938 kehrten die entsandten Schiffe wie geplant nach Frankreich zurück. Lediglich zwei Unterseeboote, regelmäßig abgelöst, blieben als Verstärkung vor Indochinas Küsten. Ausgerechnet eines dieser U-Boote legte offen, mit welchem Material Frankreich operierte, als am 15. Juni 1939 die Phénix verloren ging. Alle 71 Besatzungsmitglieder an Bord kamen nach der Explosion der überalterten Batterien ums Leben. Der Marine war der Untergang so peinlich, daß sie ihn erst geheimhielt ${ }^{66}$.

Die Abordnung der U-Boote zeigte, daß Asien für die Marineführung an Bedeutung gewann. Obwohl Admiral Darlan Ende April 1939 fürchtete, in Europa könne sofort Krieg ausbrechen, duldete er, daß im Mai ein dritter Kreuzer, die Suffren, nach Indochina entsandt wurde. Die Suffren löste die

\footnotetext{
${ }^{64}$ Marine an Moutet, T 8896, 2.10., FNEO an EMG.2, T 1893, 10.10 .1937 (SHM 1 BB9 270, 35); Moutet an Brévié, T 632, 5.10., T 674, 23.10.; T 900, 30.12.1937 (CAOM FM 661, 666); Billotte an Gamelin, L 286/IGS, 12.10., Moutet an Marine, T 2089, 16.10.1937 (SHAT 7 N 4196, 10 H 75); Hoppenot an Consul Singapur, T 7, 25.10.1937 (MAE Ac 78); Moutet an Campinchi, Daladier L 2213, L 2214, 4.11.1937, Conseil supérieur de la défense nationale, secrétaire général, note sur le renforcement des moyens maritimes et aériens en Indochine et en AOF, janvier 1938 (SHAT 2 N 247, 25); Note sur les possibilités de renforcement des FNEO, EMG.3, ohne Datum [Herbst 1937], note sur des conditions de la guerre, EMG-SE, 12.11.1937 (SHM 1BB2 113, 170).

${ }^{65}$ Naggiar an Brévié, T 671, 7.11., Campinchi an Daladier, L, 8.12., Campinchi an Petit, L, 16.12., FNEO an EMG.2, T 6161, 4.12.1937 (SHM 1BB2 108, 170, 110, 1BB9 36); Naggiar an Delbos, T 679-80, 10.11., T 829, 8.12.1937, L 134, 13.2.1938 (MAE Indfr 33, Chine 575, CAOM IndoNF 105).

${ }^{66}$ FNEO an EMG.2, T 7690-91, 15.6.1939 (SHM 1 BB9 47); Brévié an Mandel, T 1017-18, 17.6.1939 (CAOM FM Tel 81); Marine Saigon an EMG.2, T 1639, 18.6.; T 1711-12, 22.7.1939 (SHM 1 BB9 47, 48); Walsh an Halifax, 19.6 .1939 (FO 371/22938, C 10406/8607/17); LE MASSON, The French Navy, Bd. 1, S. 29; MORDAL, Marine Indochine, S. 11; Berichte über Verschwinden der Phénix enthält das Dossier SHM 1 BB4 74.
} 
Primauguet ab, so daß einschließlich der Lamotte-Picquet am 23. Juli 1939 drei französische Kreuzer in Saigon zusammentrafen. Weitere Verstärkungen gab es nicht. Die Forderung des Vizepräsidenten des Marineausschusses in der Kammer, mehr Schiffe nach Indochina abzuordnen, blieb unerfüllt. Während der Generalstab der Marine trotz der Herausforderungen in Europa in Asien Flagge als Weltmacht zeigen wollte, sahen die Soldaten den Fernen Osten mit Defätismus. Fernostflottillen-Chef Vize-Admiral Decoux schrieb im Sommer 1939, französische Seeleute bis hin zu höchsten Offizieren meldeten sich vor Verlegungen nach Asien massenhaft krank oder quittierten den Dienst. In den unteren Rängen sei so die Hälfte, in oberen Chargen mehr als zwei Drittel der Mannschaft neu auf den Schiffen ${ }^{67}$. Die französische Seestreitmacht bewies jedoch später, daß sie ihrer Mission gewachsen war: In der einzigen Seeschlacht mit französischer Beteiligung in beiden Weltkriegen schlugen der Kreuzer Lamotte-Picquet sowie die Avisos Dumont d'Urville, Amiral Charner, Tahure und Marne im Januar 1941 bei Koh Chang Thailands Marine vernichtend ${ }^{68}$.

Der Zustand des Heeres in Indochina war noch schlechter als der der Marine. Bewaffnung, Ausrüstung und Verteilung der Truppen hatten sich bis dahin nach dem Auftrag gerichtet, Sicherheit nach innen und an den Grenzen zu Siam und China zu gewährleisten. Dafür waren sie nach Auffassung des britischen Militärs 1938 gut gerüstet. Auf eine Konfrontation mit Japan war das Heer aber nicht vorbereitet. Ein einziges Mal war in den dreißiger Jahren ein Aufrüstungsplan für Indochina entwickelt worden: Im Februar 1935 hatte Kolonialminister Louis Rollin vorgeschlagen, die Verteidigung Indochinas zu verbessern - um in einem Weltkrieg Reserven nach Europa entsenden zu können. 260 Millionen Francs solle Paris dafür bis 1945 investieren. Wegen des Widerstandes der Armee scheiterte das Projekt ${ }^{69}$.

Nach der Aushebung neuer Kontingente 1938 verfügte das Militär in Indochina über 32000 Mann sowie über 17000 Mann in paramilitärischen Verbänden. Nach der Mobilisierung im September 1939 standen 90000 Soldaten, darunter 14500 Europäer, unter Waffen. Die Rüstung war rudimentär: Die Infanteriewaffen und die 20 Renault F.T. Panzer stammten aus dem Ersten Weltkrieg. Hesse d'Alzon beurteilt allein das Artilleriematerial als quantitativ und qualitativ genügend. Die Munition reichte für nur drei bis sechs Monate, die Entfernung von 15000 Kilometern zur Metropole gefährdete die Versorgung mit Ersatzteilen und Munition. Die Truppe war kaum motorisiert, die

\footnotetext{
${ }^{67}$ Procès-verbal, conférence des services, 29.4.; Circulaire, 17.5.; FNEO an EMG.2, T 7557-58, 7.5.; EMG.3 an FNEO, T 5398, 13.5 .1939 (SHM 1 BB 2 172, 104, 1 BB9 45, 185); FNEO, compte rendu, 1.8., Decoux an EMG.3, L 386, 24.8.1939 (SHM 1 BB4 74); Note sur l'organisation actuelle de la marine, EMG-SE, 24.5.; Rapport Bousquet, 20.1.1939 (SHAT 5 N 583, 2 N 247).

${ }^{68}$ LE MASSON, The French Navy, Bd. 1, S. 48; MARTIN DU GARD, La carte impériale, S. 438.

${ }^{69}$ Rollin an Flandin, L, 22.2., EMA an Flandin, défense des colonies, 11.3.1935 (SHAT 2 N 246).
} 
Transporte ruhten auf Last- und Zugtieren. Die paramilitärischen Verbände, die im Inneren eingesetzte garde indigène sowie die Grenztruppe partisans, wuchsen bei der Mobilisierung auf 30000 Mann an. Schwach und unvorbereitet nannte Hesse d'Alzon die Armee in Indochina, für Sun und Brocheux blieb das Militär eine Kolonialarmee, die weder strategisch noch materiell fähig gewesen sei, sich gegen einen äußeren Feind zu behaupten ${ }^{70}$.

Nicht einmal in Krisen konnte das Militär Stärke zeigen. Als Brévié in der Sudetenkrise im September 1938 forderte, seine Truppe aufzurüsten, weil bei einem Krieg in Europa ein Angriff Japans möglich sei, ließ Mandel ihm 256 Maschinengewehre von 1915 zukommen. Nach der Besetzung Hainans durch Japan im Februar 1939 versetzten die Franzosen 2000 Soldaten, die bis dahin im Straßenbau eingesetzt waren, an die Nordgrenze. Im Sommer 1939 wurden zusätzlich vier Kompanien an die Grenze zu Siam abgeordnet.

Bréviés höchster Militärberater Oberst Bertraux schrieb im August 1939, an mangelndem Geld habe die klägliche Rüstung nicht gelegen, sondern daran, daß die Streitkräfte in Frankreich kein Material abgegeben hätten. Als Mandel im März 1939 mit der Forderung scheiterte, daß französische Waffenhersteller Bestellungen der Kolonialtruppen und der Streitkräfte der Metropole gleich behandelten, kaufte er für 20 Millionen Francs Maschinengewehre in der Schweiz und 1500 Gewehre in Belgien. Im April 1939 erhielt das Kolonialministerium 26000 Gewehre, die geflüchtete spanische Soldaten abgegeben hatten. Selbst danach fehlten 65000 Handfeuerwaffen, wenn man alle Reservisten in den Kolonien mit einem Gewehr ausstatten wollte. $\mathrm{Zu}$ allem Überfluß wurde der Rüstungsstand in Indochina in der französischen Presse diskutiert.

Mandels Aussage vor dem Kolonialausschuß der Kammer im März 1939, die Verteidigungsanstrengungen in den Kolonien seien soweit fortgeschritten, daß diese vor Überraschungen sicher seien, und ein Artikel in "L'Asie

\footnotetext{
${ }^{70}$ Pierre BrocheUX, Le déclin et la fin de l'empire français en Extrême-Orient, in: DERS., HÉMERY (Hg.), Indochine: La colonisation amibiguë, S. 325-365 (S. 326); ToINET, Une guerre de trente-cinq ans, S. 24, S. 27; HeSSE D'ALzon, L'armée française d'Indochine, S. 77f.; FRANCHINI, Les guerres d'Indochine, Bd. 1, S. 153; HAAS, Französisch-Indochina, S. 49f.; SUN, La France et le conflit, S. 351. Einige Autoren nennen etwas abweichende Zahlen für die Stärke des französischen Militärs. VALETTE errechnet 50000 Mann, davon 14000 Europäer (Indochine, S. 30). MONTAGNON kommt auf 60000 Militärangehörige (La France coloniale, Bd. 2, S. 114); Jean COGNIET und Jules BÜHRER gehen von 70000 Soldaten, davon 18000 Europäer, aus (Histoire et épopée des troupes coloniales, Paris 1956, Neuauflage als: Les troupes de marine, 1622-1984, Paris, Limoges 1986, S. 254), MCALISTER kommt auf 74000 Mann in regulären und $24700 \mathrm{Mann}$ in den paramilitärischen Verbänden, darunter 19700 Europäer (Viet Nam, S. 110), auch BUTTINGER errechnet 100000 Mann, davon 20000 Europäer (Vietnam, Bd. 1, S. 233). Martin THOMAS verweist auf eine Studie des Generalstabes vom Februar 1941, wonach bis Juni 1940116000 Wehrpflichtige in Indochina eingezogen worden seien (The French Empire at War, 1940-1945, Manchester, New York 1998, S. 12). In keiner anderen Kolonie waren soviele Europäer eingesetzt. Grund waren die Zweifel an der Loyalität der einheimischen Soldaten in Indochina (BÜHRER, Aux heures tragiques, S. 43).
} 
française« vom Juni 1939, der in der Aussage gipfelte, »l'Indochine se présente en Extrême-Orient comme un bastion solide de la puissance française«, hatten allein das Ziel, die Öffentlichkeit zu beruhigen ${ }^{71}$.

Briten und Amerikaner wußten von den Schwächen: Der britische Major Vinden urteilte im Frühjahr 1938 nach einem Besuch in Indochina, wegen der unzuverlässigen vietnamesischen Soldaten sei es unwahrscheinlich, daß die Franzosen einen ernsthaften Angriff Japans abwehren könnten. Wenn Frankreich der Kolonie nicht mehr Aufmerksamkeit widme, drohe in einem Krieg im Pazifik Indochinas Verlust. Nach einer Truppenparade im November 1938 schrieb der britische Generalkonsul, der körperliche Zustand der Soldaten sei schlecht, die Panzer stammten von 1918. Der US-Vizekonsul bezeichnete im August 1938 die französische Luftwaffe als im Krieg fast wertlos ${ }^{72}$.

Mit aufwendig inszenierten Manövern vor internationalen Beobachtern versuchte die Militärführung, den Ruf der Truppe aufzupolieren. Ein britischer Beobachter kam im Januar 1940 zu dem Schluß, die am Manöver teilnehmenden 12000 Soldaten seien in bester Verfassung, das Material sei stark und modern. Mit dem Zusatz, das Manöver habe einen exzellenten Eindruck bei den Einheimischen hinterlassen, relativierte er sein Urteil über die Kampfkraft der französischen Truppen. Decoux schildert diese Übung noch dramatischer: Das Manöver habe ohne bewaffnete Fahrzeuge und ohne Panzer, dafür aber mit prähistorischen, von Ochsen gezogenen Karren stattgefunden. Die 15 verfügbaren Panzer hätten nur in einem Gefecht eingesetzt werden dürfen, weil die Motoren nur wenige Stunden hielten. Deshalb habe man die Panzer schließlich auf Lastwagen gesetzt. In jedem Fall habe dies den ausländischen Beobachtern die französische Schwäche demonstriert ${ }^{73}$.

Mandels Bemühungen, das jahrzehntelang militärisch vernachlässigte Indochina aufzurüsten, waren im Ergebnis ein Fehlschlag. Dies lag am Widerstand der Streitkräfte in der Metropole, an der fehlenden industriellen Basis in der Kolonie und daran, daß er den größten Teil der verfügbaren finanziellen Mittel für ein überdimensioniertes Prestigeprojekt, eine Flugzeugfabrik, ausgab.

\footnotetext{
${ }^{71}$ Colonel Bertraux, défense de l'Indochine, 8.8.1939, S. 1f., S. 37f., S. 75 (CAOM CM 938); Mandel an Brévié, T 660, 16.9.1938 (CAOM FM 672); Mandel an Daladier, L 426, 31.3.1939 (SHAT $5 \mathrm{~N}$ 583); Mandel an Daladier, L 700, 3.3., L 2087, 18.4., L 2399, 8.5.1939 (SHAT 2 N 247); Naggiar an Bonnet, T 846, 28.6.1938 (MAE Indfr 42); Phipps an Halifax, 30.3.1939 (FO 371/22916, C 4447/130/17); BŨHRER, Aux heures tragiques, S. 59f;; DE LA BROSSE, L'Indochine, S. 201.

${ }^{72}$ Report on a visit to Indochina by Major H. Vinden, 26.3.1938 (WO 106/5455); Walsh an Halifax, 10.12.1938 (FO 371/22921, C 250/249/17); Palmer (Saigon) an Hull, 20.8.1938 (SD 851G.20/10).

${ }^{73}$ Neumann an AA, 8.2.1938, 6.3.1939 (AA Pol VIII 59/1, 60/2); Note, 11.8.1938 (SD 851g.21/2); Pullan an Halifax, 30.1.1940 (FO 371/24655, C 2423/166/17); DECOUX, À la barre de l'Indochine, S. $79 f$.
} 


\subsection{Die Strategie zur Verteidigung Indochinas}

Worauf bauten die Verantwortlichen trotz Frankreichs militärischer Schwäche in Asien und der wiederholten, kaum widerlegbaren Analysen von Admiral Castex, Indochina sei nicht zu verteidigen ${ }^{74}$, ihr Vertrauen in die Sicherheit der Kolonie? Oder nahmen Politiker, Diplomaten und Militärs das Risiko eines Verlustes Indochinas in Kauf? Die Verlegung von Truppen aus der Metropole nach Indochina schloß die Armee seit 1925 aus. In den 1930er Jahren durfte Indochina erst recht nicht auf Hilfe aus Europa bauen: Im Januar 1937 legte das Kolonialministerium im überarbeiteten Verteidigungsplan für Indochina fest, die Kolonie müsse für ihre Sicherheit allein sorgen, weil Italien eventuell die Wege von der Metropole nach Asien kontrolliere. Moutet verlangte, die Kolonie müsse fähig sein, einen Überraschungsangriff allein zu überstehen ${ }^{75}$.

Der Quai d'Orsay hatte im September 1936 nach einer drohenden Landung der Japaner auf Hainan erstmals in der Zwischenkriegszeit den Fall eines Kriegs mit Tokio erwogen. Militärattaché Sabattier schrieb im Januar 1937 nach dem Antikominternpakt vom November 1936 -, in einem Weltkrieg müsse Paris hoffen, daß Japan Indochina verschone. Mit den Einheimischen könne Frankreich aber mehr Truppen einsetzen als Japan, für das die Eroberung Indochinas mit zu großen Opfern verbunden sei. Die Kolonie könne man vor allem dann verteidigen, wenn Japan gleichzeitig gegen China und Rußland Krieg führe, zumal der japanische Soldat das Klima in Indochina nicht vertrage. Frankreichs Position in Indochina sei stark: Die Kolonie könne in einem Weltkrieg so viele japanische Kräfte binden, daß sich Tokios Druck auf Moskau vermindere. Militärattaché Mast schrieb im Februar 1937, der Antikominternpakt mache einen Angriff Japans auf Indochina viel wahrscheinlicher. Selbst bei einem Krieg gegen die Sowjetunion könne Japan mit drei bis vier modernen Divisionen in Indochina landen. Der Angriff werde von nationalistischen Aufständen und der Subversion einheimischer Einheiten begleitet werden. Tokio werde Prinz Cuong-Dê als neuen Herrscher ausrufen ${ }^{76}$.

\footnotetext{
${ }^{74}$ In Band 3 der Théories stratégiques hatte Castex 1931 geurteilt, wegen der Dispersion französischer Kräfte sei Indochina nicht zu verteidigen. Im März 1939 griff er die These auf: Indochinas Lage sei prekär geblieben, bedrohlich sei nun vor allem Japans Marsch auf Südchina. Japan habe alle Möglichkeiten, um sich Indochinas zu bemächtigen, was Frankreich militärisch nicht verhindern könne. Bestes Mittel, um Indochina zu schützen, seien gute Beziehungen zu Japan (Amiral Raoul CASTEX, Le problème stratégique colonial 1939, in: Marins et océans 1 [1991], S. 207-228 [S. 209, S. 225]).

${ }^{75}$ Guerre an Conseil supérieur de la défense nationale, L 9688, 14.11 .1925 (2 N 224); Rapport de M. Édouard Bousquet, vice-président de la commission sur sa mission, 20.1.1939 (SHAT 2 N 247).

${ }_{76}$ Note de la sous-direction d'Asie-Océanie pour le secrétaire général, 28.9.1936 (DDF III, 295); Sabattier an Daladier, Note, 25.1.; Mast an Bührer, L 181/D, 25.2., Mast an EMA.2, L 236/S, 26.2.1937 (MAE Chine 689, SHAT 7 N 3330).
} 
Die Urteile der Attachés waren vom Schock über den Antikominternpakt geprägt. Später klangen ihre Analysen beruhigter. Im April 1937 schrieb Sabattier, daß kein Vorgehen Japans gegen Indochina zu befürchten sei, außer bei einem Krieg in Europa. Ende Juni wurde Sabattier noch zuversichtlicher: Japan könne zwar Frankreichs Verbindung mit Indochina abschneiden, sei aber nicht in der Lage, militärisch gegen die Kolonie vorzugehen, weil Indochina zu weit entfernt liege. Japan müsse zunächst Hainan besetzen und sich dort gegen China behaupten. Mast meinte im Juni 1937, für Frankreich sei die japanische Expansionspolitik in Südostasien lästig, gefährlich sei sie nur für die Niederlande ${ }^{77}$. Zwar hielt das Militär in Indochina die Möglichkeit einer japanischen Landung für so realistisch, daß sie im Mai 1937 in einer Stabsübung und im Dezember 1937 bei einem Manöver die Landung einer asiatischen Macht an der Küste Annams durchspielte. Doch letztlich erschien der Konflikt mit Japan so unwahrscheinlich, daß das Militär in Indochina noch im Oktober 1937 in seinen Alben Silhouetten nicht eines einzigen japanischen Flugzeugs besaß, obwohl die Daten der japanischen Flugzeuge beim Generalstab der Armée de l'air in Paris bekannt waren ${ }^{78}$.

Das Deuxième Bureau des Generalstabs in Paris urteilte nach dem Antikominternpakt, Japan sei eine größenwahnsinnige Nation, die militärisch und wirtschaftlich expandieren wolle. Japan werde sich aber nicht mit den »weißen Nationen « anlegen, da es diese respektiere und wirtschaftlich benötige. Konsequenterweise spielte das Marineministerium im April 1937 in der Anweisung für den Kriegsfall an die Fernostflottille nur die Möglichkeit eines Krieges mit Deutschland und Italien durch, erörterte die Hypothese eines Konfliktes mit Japan aber nicht. Noch im Juni 1939 besaß der Chef der Forces navales d'Extrême-Orient Anweisungen für den Krieg gegen Deutschland und Italien, während der Krieg gegen Japan nicht vorgesehen war $^{79}$.

Der Krieg band starke japanische Kräfte in China und an der Grenze zur Sowjetunion. Selbst als im Spätherbst 1937 japanische Offiziere und Diplomaten drohten, wegen des dortigen Waffentransits gegen Indochina vorzugehen, sorgte sich keiner der französischen Experten um die Sicherheit der Kolonie.

\footnotetext{
77 Sabattier, note $n^{\circ} 235 / \mathrm{S}, 21.4$., EMA.2, bulletin de renseignement, $\mathrm{n}^{\circ}$ 164, 27.6.1937 (MAEN Tschongking 9, SHAT 7 N 2514); Sabattier an Daladier, D 289, 30.6., Mast an Daladier, D 252, 10.6.1937 (DDF VI, 161, 81).

${ }^{78}$ Mast an EMA.2, D 236/S, 26.2.1937 (SHAT $7 \mathrm{~N} \mathrm{3330);} \mathrm{Coultas} \mathrm{an} \mathrm{Eden,} \mathrm{17.1.1938} \mathrm{(FO}$ 371/21589, C 1204/8/17); Brévié an Moutet, T 875, 25.10.1937 (CAOM FM 666); Dossier de fiches d'avions en service dans les pays étrangers, très secret, $n^{\circ}$ CM150EMAA, 25.1.1938 (SHAA 2B 59).

${ }^{79}$ EMA.2, Bulletins de renseignement, novembre/décembre 1936, janvier/février 1937: Le budget japonais 1936-1937, Transformation de l'armée japonaise, janvier/février 1937 (SHAT 7 N 2506); EMA.2, note, 27.11.1936 (SHAT 7 N 3334); EMA.2, bulletin de renseignement $n^{\circ} 151,14.3 .1937$; EMG.3: instruction pour le temps de guerre. Instruction pour $M$. le vice-amiral commandant en chef les FNEO, n 333, 9.4.1937 (SHM 1BB2 110); PrJTCHARD, Far Eastem Influences, S. 195.
} 
Selbst Sabattier, der schrieb, es sei klar, daß Japan Asien erobern wolle, nannte als nächste Ziele Japans die Sowjetunion, Hongkong, die Philippinen und dann erst »vielleicht Indochina«. Die Ministerien in Paris waren sich einig, daß Japan eventuell Hainan besetze oder die Yunnanbahn bombardiere. Ein Angriff auf Indochina galt als undenkbar. Der Kolonial-Geheimdienst schrieb im November 1937, Japans Ziele seien die Philippinen, Niederländisch-Indien, Siam, Australien und Neuseeland. Indochina nannte er nicht. Der Marine-Generalstab analysierte, Japans Hegemoniestreben richte sich vor allem gegen England. Indochina sei wegen des von den Japanern ungeliebten Klimas kaum bedroht, vor allem dann nicht, wenn es nicht zu Chinas Nachschubweg werde. Auch das Grün-Buch der Marine vom Januar 1938 stellte Tokios Gegnerschaft zu Moskau und London dar, beschrieb die Ängste in Niederländisch-Indien und den Philippinen vor Japan, ging aber mit keinem Wort auf eine Bedrohung Indochinas ein. Der Generalstab des Heeres spielte ebenfalls allein die Möglichkeit japanischer Angriffe auf England und Rußland durch. Das französische Militär in Hanoi hoffte, so der deutsche Konsul, daß Japan kein Interesse an zusätzlichen Gegnern habe ${ }^{80}$.

Für die in Paris herrschende Meinung war ein Konflikt zwischen Japan und Frankreich unvorstellbar. Alfred Silbert, früherer Attaché im Cabinet des Generalgouverneurs in Indochina, der Kommunist Chassagne und der Publizist Leurquin schrieben alle, Japans denkbare Gegner seien die Sowjetunion, England und Amerika. Indochina und Frankreich nannten Silbert und Leurquin nicht einmal in einem Nebensatz, Chassagne beschränkte sich auf den Hinweis, Japan hege Ambitionen auf Indochina ${ }^{81}$. Es entsprach dem Konsens, als der Conseil supérieur de la défense nationale im Februar 1938 über Frankreichs militärische Lage in Asien folgerte:

Le Japon, profitant des dissensions européennes, poursuivrait, sans doute, sa politique d'expansion en Chine: [...] absorbé par cette tâche considérable et la surveillance de la Russie, il ne paraît pas en mesure d'effectuer, pour le moment, un effort terrestre de quelque envergure.

Im Sommer 1938 waren sich Bonnet, Mandel und Militärattaché Thiébaut einig, daß Japan noch lange unfähig bleibe, weitere Nachbarn zu behelligen, weil es so tief in Kämpfe in China verwickelt sei, daß es keine Feindseligkei-

${ }^{80}$ Sabattier, note $\mathrm{n}^{\circ} 317,1.12$, Colonies, bulletin de renseignement, 15.11.1937 (SHAT 7 N 3289, 11 H 76); EMG-SE, note sur la situation, $\mathrm{n}^{\circ} 136,3.11 .1937$; Marine, livre vert 1938, S. 259f. (SHM 1BB2 170, 98); EMA.2 an Diplomatie, L 120, 10.1.1938 (DDF VII, 456); Neumann an von Neurath, 25.11.1937 (AA Pol VIII 59, 1). Auch das State Departement hielt nur einen Angriff Japans auf niederländische, britische und US-Besitzungen für denkbar (BORG, Far Eastern Crisis, S. 403).

${ }^{81}$ Alfred SilberT, Japon d'hier et de demain?, in: Sciences politiques 6 (1938), S. 2-24; ChASSAGNE, Le Japon contre le monde, S. 266f.; LEURQUIN, Stratégie, S. 266f. 
ten mit einer westlichen Macht riskieren wolle ${ }^{82}$. Frankreichs Militär sah auch dann keinen Anlaß, die beruhigenden Analysen zu ändern, als sich ab Herbst 1938 Tokios Ton gegenüber Paris deutlich verschärfte. Hinweise, daß Japans Militär oder gar die Regierung einen Angriff auf Indochina planten, der über die Bombardierung der Yunnanbahn hinausging, gab es nicht. Japans Generalkonsul in Hanoi sagte seinem deutschen Kollegen wiederholt, daß Japan keine Angriffsabsichten gegen Indochina hege. Der deutsche Konsul schrieb, selbst in einem Krieg in Europa werde Japan abwarten, um sich dann auf die Seite der Sieger zu schlagen. Jean Delmas urteilt, daß der französische Generalstab Japan nicht als potentiellen Gegner nannte, sei ein implizites Eingeständnis der Einsicht in Paris, daß man Indochina nicht gegen Japan verteidigen konnte. Naheliegender ist, daß Militärs und Diplomaten Indochina einfach für nicht ernsthaft bedroht hielten, so Hesse d'Alzon: "Der Kampf erschien weit entfernt $[. .$.$] und die Bedrohung irreal und undeutlich { }^{83}$.

Für wie stabil der Generalstab in Paris die Lage in Indochina hielt, zeigte sich auch daran, daß Paris regelmäßig auf die Fernostflottille zugriff, um am Indischen Ozean Ordnung zu schaffen. Im Oktober 1937 und im April 1938 sandte Paris wegen innerer Unruhen Heerestruppen und Schiffe von Indochina nach Pondichéry in Indien. Von Ende Januar bis Ende April 1939 wurden mit der Primauguet der einzige verfügbare Kreuzer aus Ostasien sowie eines von $z w e i$ U-Booten von Indochina in das von Italien bedrohte Djibouti verlegt ${ }^{84}$.

Für Beunruhigung in Indochina sorgte nur die wachsende Aktivität des japanischen Geheimdienstes. Seit Juli 1937 wurden Besucher aus Japan in Indochina enger überwacht, womöglich sogar alle 225 in Indochina lebenden Japaner. Ende April 1938 schuf Georges Mandel zur Spionageabwehr in Indochina einen Service d'informations spéciales. Die Geheimhaltung militärischer Informationen wurde verschärft. Ab Herbst 1938 errichtete das Militär um Kasernen, Lager, Flughäfen, Bahnlinien und Häfen Sperrzonen für Ausländer. Nach zwei Jahren der Entspannung gingen die Behörden in Indochina

\footnotetext{
${ }^{82}$ Note du secrétariat général du Conseil supérieur de la défense nationale, 8.2., Bonnet an Daladier, D 1842, 22.6.1938 (DDF VIII, 127; X, 74); Thiébaut an EMA.2, L 41, 12.7 .1938 (SHAT 7 N 3331); Bullitt an Hull, 5.8., 8.8.1938 (SD 760f.62/544; FRUS 1938, III, S. 544f.); CATROUX, Deux actes, S. 10.

${ }^{83}$ Neumann an Ribbentrop, 27.7.1939 (AA Pol VIII 60, 2); Général Jean DELMAS, La perception de la puissance militaire française, in: René GIRAULT, Robert FranK (Hg.), La puissance en Europe 19381940, Paris 1984, S. 127-140 (S. 129f.); Hesse D'AlzoN, L'armée française, S. 76.

${ }^{84}$ Moutet an Brévié, T 679, 25.10.1937, Mandel an Brévié, T 323, 21.4.1938 (CAOM FM 661, FM 672); EMG.3 an FNEO, T 3095, 24.4., Marine an Colonies, T 3237, 17.5.1938 (SHM 1 BB9 181); Marine, note pour le ministre, 16.6.1938 (SHM 1BB2 113); Marine an Diplomatie, T 418, 4.1., T 4419, 17.1.; Diplomatie an Marine, T 24, 26.1.; Marine an Diplomatie, T 3455, 22.4.1939 (SHM 1 BB9 184, 43, 185); Pondichéry war Hauptort von fünf in Indien verstreuten, 510 Quadratkilometer großen Gebiete der Inde française, die seit dem 17. Jahrhundert zu Frankreich gehörte und 350000 Einwohner besaß (Arthur ANNASSE, Les comptoirs français de l'Inde. Trois siècles de présence française, 1664-1954, Paris 1975, S. 108f.; MARTIN, L'Empire triomphant, Bd. 2, S. 332f.).
} 
wieder schärfer gegen Nationalisten vor, weil sie meinten, daß diese mit Japans Geheimdienst gegen Frankreich kooperierten. Prinz Cuong Dê, der in Japan lebte, schien beide Gegner der französischen Herrschaft zu verbinden ${ }^{85}$.

Im März 1938 wurde ein Japaner wegen Spionageverdachts ausgewiesen, im Juli 1938 nahm die Sûreté einen Japaner fest, der das Verladen von Waffen in Haiphong beobachtet hatte und Kontakte zum japanischen Generalkonsulat in Hanoi unterhielt. Dieses Konsulat war erneut verwickelt, als im Oktober 1938 drei Taiwanesen wegen Spionage verhaftet wurden. Pech hatte Shiomi Saisaku, Kanzleichef dieses Konsulats, als er im Dezember 1938 im indochinesisch-chinesischen Grenzgebiet Waffentransporte beobachten wollte und ihn Chinesen festnahmen ${ }^{86}$. Der Generalkonsul in Saigon Minoda Yoshio und sein Mitarbeiter Kawamura Sadao wurden 1938, die Händler Yamada und Matusita 1939 wegen Spionage ausgewiesen. Wegen Agententätigkeit für Japan wurden im März 1939 ein französischer Journalist und ein Vietnamese zu 15 Jahren Haft verurteilt. Drei japanische Bahnexperten wurden im Januar 1939 mit vielen Geheimdokumenten in Singapur festgenommen. Auch China spionierte in Indochina und Frankreich, aber unauffäliger als Japan ${ }^{87}$.

Die Kolonialverwaltung in Hanoi nahm an, daß Japan nicht nur Indochinas Militäranlagen auskundschaftete, sondern auch einen Aufstand der Einheimischen plante. Japaner gaben Zeitungen in Vietnam Geld und schienen sich mit Revolutionären in Birma zu verbünden. Mandel sowie die Vize-Admiräle Le Bigot und Decoux waren überzeugt, daß Japan die französischen TelegrammCodes kenne ${ }^{88}$. Sicher ist, daß Tokio Briefe französischer Diplomaten mitlas. Ein Schreiben Cosmes vom Mai 1939 kam in intaktem Umschlag mit intaktem

${ }^{85}$ MORLAT, La répression coloniale, S. 245f.; ROUSSET, Communisme et nationalisme vietnamien, S. 179; Troupes en Indochine, EM.2, instruction sur l'organisation et le fonctionnement du Service d'informations spéciales en Indochine, [mai 1938](CAOM CabMil 1222); MURAKAMI, Japan's Thrust, S. 41. Die Maßnahmen der Spionageabwehr dokumentiert CAOM CabMil 762 und 763.

${ }^{86}$ Brévié an Moutet, T 1041, 30.11.1937; Mandel an Brévié, T 544, 22.7.; Brévié an Mandel, T 681, 12.6., T 718, 23.6., T 779, 2.7., T 1172-73, 15.10 .1938 (CAOM FM 666, 672, 678); Brévié an Mandel, L 199, 7.7.1938; T 7, 5.1., T 31, 9.1., T 85-86, 21.1.1939 (CAOM lndo-NF 107; FM Tel 80); Pichon an General Martin, L, 2.3.1938 (MAE Indfr 29); Jarvis an Hull, 13.1.1939 (SD 793.94/14722); Neumann an Ribbentrop, 14.1.1939 (AA Pol VIII 60, 2).

${ }^{87}$ BUtTINGER, Vietnam, Bd. 1, S. 252; Walsh an Halifax, 18.3., 12.7.1939 (FO 371/22921, C 4684, 10342/249/17); JACQUIN, La guerre secrète, S. 83, S. 26; ROBERTSON, The Japanese File, S. 143; Jarvis an Hull, 13.1.1939 (SD 793.94/14722); MILLER, Shanghai, S. 111.

${ }^{88}$ Yvon an EMG.2, L 47, 25.5., compte rendu de liaison, 22.2.1939 (DDF XVI, 284; XIV, 176); Neumann an Ribbentrop, 2.5.1938 (AA Pol VIII 59, 1); STS-bulletin, 1.3., Lacoste an Cosme, L 132, 30.3., Brévié an Mandel, T 280, 17.2., T 872, 20.5.1939 (MAE Chine 534, 772, CAOM FM Tel 80); Mandel an Brévié, T 365, 11.5.1938 (CAOM FM 672); FNEO an EMG.2, T 6891, 26.9.1938, FNEO, compte rendu, 1.8.1939 (SHM 1 BB 4 41, 74). Michael A. BARNHART zufolge kannte Japan viele amerikanische und britische Codes; französische Codes nennt er nicht (Japanese Intelligence Before the Second World War: »Best Case Analyses, in: Ernest R. MAY [Hg.], Knowing One's Enemies: Intelligence Assessments before the Two World Wars, Princeton 1984, S. 424-455 [S. 426]). 
Siegel in Paris an - doch im Kuvert befanden sich auch drei Blätter mit der japanischen Übersetzung. Dabei hatten die Franzosen ihre Briefe schon nicht mehr japanischen Postschiffen anvertraut ${ }^{89}$. Japans Geheimdienst wurde aber auch überschätzt, wie die "Gnôme-Rhône-Affaire« im Mai 1939 bewies. Ein japanischer Offizier war in Paris mit Plänen eines Flugzeugsmotors der Firma Gnôme-Rhône festgenommen worden. Als sich die Aufregung legte, zeigte sich, daß der Motor keiner Geheimhaltung mehr unterlag ${ }^{90}$.

Frankreichs Lage in Europa war so ernst, daß eine Abzweigung von Kräften für die Verteidigung der Kolonien die Sicherheit des Mutterlands gefährdete. Den Leitgedanken der französischen Politik zur Verteidigung Indochinas formulierte Paul Reynaud in der Debatte der Kammer am 25. Februar 1938. Reynaud bezog sich auf Clemenceau, der erklärt hatte, Kolonien verteidige oder verliere man am Rhein, und sagte: "Mais si l'empire français a un pied en Indochine et un pied à Madagascar, son artère carotide est sur le Rhin«. Das Schicksal Frankreichs und seiner Kolonien werde auf Europas Schlachtfeldern entschieden, war die Annahme, die nicht einmal profilierte Kolonialpolitiker wie Gaston Monnerville und Anhänger eines starken Empire wie Ex-Premierminister André Tardieu anzweifelten. Auch Bildungsminister Jean Zay, Militärattaché Sabattier, der Generalstab der Marine und Generalsekretär Léger waren überzeugt, daß ein in Europa siegreiches Frankreich sein Kolonialreich behaupten werde, während Paris nach einer Niederlage am Rhein seine Kolonien verliere. In einem Weltkrieg - und nur in diesem Fall schien ein Angriff Japans denkbar - konnte ein zeitweiliger Verlust Indochinas riskiert werden, weil Frankreich nach dem Sieg in Europa die Kolonie zurückerhalten würde. Der Diplomat René Cassin und Étienne Dennery, Generalsekretär im Centre d'étude de politique étrangère, teilten die Analyse ${ }^{91}$. Die Streitkräfte im

\footnotetext{
${ }^{89}$ Chauvel an Cosme, L, 8.6.1939, FNEO an EMG, T, 22.9.1938 (MAE Chine 514, SHM 1 BB9 41).

${ }^{90}$ Palllole, Services Spéciaux, S. 83; Phipps an Cadogan, 4.5., Air Attaché Colyer, Memorandum für Phipps, 5.5.1939 (FO 371/22916, C 6552, 6858/130/17); Service des fabrications de l'aéronautique an Fa. Gnôme et Rhône, Paris, L, 22.2., 21.6.1937 (AN Fonds Daladier 496/AP/33).

${ }^{91}$ REYNAUD, Envers et contre tous, S. 187; Yves Gras, L'intrusion japonaise en Indochine (juin 1940-mars 1945), in: Revue historique des armées 4 (1983), S. 86-102 (S. 87); MONNERVILLE, Témoignage, S. 228; TARDIEU, La mort de l'Europe centrale, in: Gringoire, 23.2.1939, zit. nach Damon MAYAFFre, Exalter l'empire pour déserter l'Europe: le répli impérial dans le discours munichois, in: Revue française d'Histoire d'outre-mer, April 2000, S. 273-286 (S. 281); ZAY, Souvenir et Solitude, S. 86; Sabattier, note, 25.1.1937 (MAE Chine 689); Note, EMG-SE, 2.2.1939 (SHM 1BB2 172); Bullitt an Hull, 10.4.1939 (SD 740.00/758); René Cassin, note, 13.7.1939 (DDF XVII, 197); Étienne DenNERY, La France et le conflit d'Extrême-Orient, in: Questions du Pacifique, hg. vom Centre européen de la dotation Carnegie, Paris 1939, S. 145-184 (S. 183f.); DERS., Les puissances, S. 261f. Diese Annahme wurde aber auch (selten) angezweifelt. Der Abgeordnete Bousquet warnte im Januar 1939, die bisherige Annahme, das Schicksal jeder Kolonie entscheide sich auf Europas Schlachtfelder, gelte nicht mehr. Weil die Grenzen in Europa kaum zu überwinden seien, könnten sich Feinde zuerst der Kolonien bemächtigten (Rapport, 20.1.1939, SHAT 2 N 247).
} 
Fernen Osten mußten lediglich so stark sein, um Indochina gegen Siam oder China zu behaupten, denn solche Verluste waren kaum in Europa rückgängig zu machen. Frankreich hatte nur begrenzte militärische Kapazitäten, und die Prioritäten lagen nicht in Asien.

Das allgemeine Urteil, ein japanischer Angriff auf Indochina sei undenkbar, hatte Folgen für die Rüstung in Indochina: Kolonialminister Moutet äußerte im Februar 1937 im Comité consultatif de défense des colonies die Hypothese, in einem Weltkrieg könnten Japan und Siam gegen Indochina vorgehen. Als Konsequenz regte er aber nur Generalstabsgespräche mit den Niederlanden und Truppenverschiebungen innerhalb Indochinas an. Das Comité blieb bei seinem Urteil vom Dezember 1936: Die Kräfte in den Kolonien reichten, um Überraschungen zu verhindern. Neue Infanteriewaffen sollte Indochina ausdrücklich als letzte Kolonie erhalten. Wegen seiner Entfernung wurden für Indochina lediglich mehr Munitionsvorräte eingeplant. Indochina galt als so ungefährdet, daß 1936 sogar Reduzierungen der Truppenstärke für die Jahre 1938 bis 1940 geplant wurden. Anfang 1937 wurde erwogen, den Wehrdienst für Einheimische von drei auf zwei Jahre zu reduzieren. Im März 1937 billigte General Bührer, daß Truppen, die für Indochina eingeplant waren, nach Westafrika geschickt wurden. Als Reaktion auf den Fernostkonflikt wurden im Juli 1937 die Reduzierungen revidiert. Noch Mitte Juli 1939 einigten sich General Colson und der Chef der Kolonialtruppen General Bührer, ein für Indochina vorgesehenes Bataillon der Fremdenlegion ins östliche Mittelmeer zu entsen$\operatorname{den}^{92}$. Die Vorwürfe des Generalinspekteurs der Kolonialtruppen General Billotte im Dezember 1936, »les chars de combat sont à bout de souffle. Ceux de Saigon ne sortent que le 14 juillet [...]. Les chars de Tonkin ne sont plus réparable. Ce n'est plus que de la ferraille«, und die Tatsache, daß Aufklärung, Motorisierung und Panzerabwehr, Pionier- und Sanitätswesen in Indochina fast nicht existierten, blieben deshalb ebenso ohne Folgen wie schon 1931 der Hilferuf des Chefs der Fernostflottille Vize-Admiral Herr, jede Macht, die es wolle, könne Saigon besetzen ${ }^{93}$.

Falls es doch zum Konflikt mit Japan käme, baute das Militär darauf, daß Briten und Amerikaner Japans Hegemonie im Pazifik nicht dulden und Frankreich unterstützen würden. Der Chef der Marine in Indochina, Konteradmiral Petit, erklärte im Juni 1937, zu verteidigen sei Indochina nur, wenn die Mächte intervenierten, die ein Interesse am Gleichgewicht im Pazifik hätten.

${ }^{92}$ Colonel Bertraux, défense de l'Indochine, 8.8.1939, S. 1 (CAOM CM 938); Max TACEL, La France et le monde au XX' siècle, Paris u.a. 1989, S. 130; THomas, The French Empire, S. 28; Procès-verbal de la réunion des chefs d'EMG du 17.7.1939 (SHAT 5 N 579).

${ }_{93}$ Comité permanent de la défense nationale, procès-verbal, 15.2.1937, Comité consultatif de défense des colonies, procès-verbal, 23.12.1936 (SHAT 2 N 22, 7 N 4194); HESSE D'ALzON, La présence militaire, S. 10 . 
Englands und Amerikas Eingreifen sei wahrscheinlich. Im November 1938 schrieb der Generalstabschef der Luftstreitkräfte General Vuillemin, nur mit Großbritannien sei die Verteidigung Indochinas vorstellbar. Der Abgeordnete und Flottenpolitiker Bousquet äußerte im Januar 1939, die Flotte in Hongkong sowie die Unverzichtbarkeit Indochinas bei der Verteidigung Singapurs schützten die Kolonie. Dem deutschen Konsul in Hanoi wurde im Mai 1938 erklärt, die Verteidigung Indochinas baue auf

die Bereitschaft der [...] Bundesgenossen Frankreichs, die Verteidigung der Kolonien zu übernehmen. Alle Vorbereitungen sind hierzu getroffen. Wie mir offen von unterrichteter französischer Seite zugegeben wird, ist für den Fall kriegerischer Verwicklungen [...] eine englisch-französisch-amerikanische Kooperation in Aussicht genommen.

Admiral François Darlan sagte in einem Treffen der Generalstabschefs, man könne den Fernen Osten als zweitrangig betrachten und sich auf Europa konzentrieren, da jeder Krieg in Ostasien eine Intervention der USA auslösen werde. Über Washingtons Absichten besaß der Marinechef aber keine Erkenntnisse. Er hoffte schlicht, die USA würden im Ernstfall schon eingreifen. Außenminister Paul Baudouin klagte 1943, Frankreich habe im Pazifik unter dem Schutz des Union Jack gelebt oder zumindest an den britischen Schutz geglaubt. Jacques Valette und Paul-Marie de la Gorce stimmten ihm zu. Der Oberste Verteidigungsrat beschloß im Februar 1938, außerhalb Europas eine Zusammenarbeit mit den Briten und eventuell den USA zu suchen, doch dies entbinde Frankreich keinesfalls davon, sein Empire an allen Grenzen zu verteidigen $^{94}$. Doch dies geschah: Das Vertrauen auf London und Washington wurde zur bequemen Ausrede für eigene Untätigkeit.

Auf britischen Schutz im Fernen Osten zu bauen, war aber um so widersinniger, als Paris mit Macht darauf drängte, daß Großbritannien sich in Ostasien so gering wie möglich militärisch engagierte. Spätestens seit 1936 wußte die französische Marine, daß die Royal Navy in einer Konfrontation mit Japan starke Verbände aus dem Mittelmeer abziehen wollte. Die Überlegenheit der Flotten Frankreichs und Großbritanniens dort sah die Marineführung in Paris als so gering an, daß bei der Verlegung britischer Mittelmeer-Verbände nach Ostasien die Seeherrschaft an Italien gefallen wäre. Als sich im Dezember

${ }^{94}$ Decoux, À la barre de l'Indochine, S. 74; Petit an Brévié, L 42, 19.6.1937 (SHM IBB3 220); Vuillemin an Gamelin, L 1489, 8.11.1938 (SHM 1BB2 182); Rapport Bousquet, 20.1.1939 (SHAT 2 N 247); Neumann an Ribbentrop, 2.5.1938 (AA Pol VIII 59 1); Réunion des chefs d'état-major généraux, procès-verbal, 21.4.1939 (DDF XV, 466); Allied Expeditionary Force an State Department, 8.11.1944 (SD 851 g.00/11-844); VALETTE, Indochine, S. 30, S. 501; DE LA GORCE, L'Empire écartelé, S. 277; Note du secrétariat général du Conseil supérieur de la défense nationale, 8.2.1938 (DDF VIII, 127). Der von THOMAS genannte Bericht des Oberkommandos vom Dezember 1937, der vom Eingreifen der Angelsachsen in Asien zugunsten Frankreichs ausgehe (Britain, France and Appeasement, S. 163), existiert nicht. Die zitierte Quelle befaßt sich mit Truppenentsendungen zur Bewachung von Chinesen in Shanghai (Diplomatie an Naggiar, T 377, 18.12.1937, MAE PAAP Naggiar 4). 
1937 eine japanisch-britische Konfrontation anbahnte, setzte Paris deshalb alles in Bewegung, damit London keine Schiffe nach Asien entsandte.

Im April 1939 warnten Daladier und Bonnet Botschafter Phipps, es sei ein schwerer Fehler, auch nur einige britische Schiffe in den Pazifik zu entsenden. Ein Verlust des Mittelmeers sei »katastrophal« und werde zum Verlust des Krieges in Europa führen. Eine Niederlage in Asien könne man wettmachen. Als sich im Sommer 1939 die Tientsin-Krise verschärfte, warnte die französische Regierung die Briten erneut so heftig vor einer Kräfteverlagerung nach Asien, daß Donald C. Watt von »Panik« in Paris spricht. Zudem waren die Briten in Asien auch nicht so stark, daß Paris darauf die Sicherheit Indochinas hätte gründen können. Das Foreign Office stellte im November 1938 intern fest, man verfüge in Asien über keine militärischen Kapazitäten, mit denen man die Franzosen unterstützen könnte. General Bührer klagte Ende Juli 1939, die Briten hätten ihre Rüstung in Asien kaum vorangetrieben ${ }^{95}$.

Daß Paris den Schutz Indochinas gegen Japan auf britische militärische Unterstützung gründete, war aber nicht nur eine widersinnige Hypothese - auf deren Widersinn schon 1938 und 1939 ein französischer Politikwissenschaftler hinwies $^{96}$-, weil sie Frankreichs gesamter europäischer Strategie widersprach, sondern sie war auch nur eine Annahme, um deren Fundierung sich Paris bis zum Sommer 1939 nicht einmal bemühte. Der Grund war, daß das Szenario eines französisch-japanischen Krieges in Frankreich als irreal galt.

Japans Hegemoniestreben richtete sich per se zunächst gegen die Positionen der stärkeren Mächte, Großbritannien, die USA und die Sowjetunion, nicht gegen Frankreich, dessen Potential beim Austarieren der Machtverhältnisse vernachlässigbar war. In ihrer machtpolitischen Nische geschützt, erschienen den Franzosen Stabsgespräche mit den Briten über Ostasien deshalb bis 1939 verzichtbar. Hinzu kam ein Mißbehagen bei dem anglophoben Admiral $\operatorname{Darlan}^{97}$ und bei General Gamelin, französische Truppen einem gemeinsamen, britisch geführten Oberkommando zu unterstellen.

Hinter den Briten und Amerikanern verschanzten sich die französischen Militärs und Diplomaten auch in der grundsätzlichen Frage der Erhaltung eines Kräftegleichgewichts im Fernen Osten. Während das Foreign Office und

\footnotetext{
${ }^{95}$ Procès-verbal de la séance du Comité permanent de la défense nationale du 8.12.1937 (DDF VII, 325); PereTt, French Naval Policy, S. 329; Phipps an Halifax, 9.4., 10.4.1939 (DBFP $3^{\text {td }}$ series, V, 106, 115); WATT, How War Came, S. 356; Anglo-French relations in the Far East, Memoranda, 16.11.1938 (FO 371/22176, F 12923/4727/61); Bührer an Gamelin, D 184, 26.7.1939 (DDF XVII, 318).

${ }^{96}$ DENNERY, La France et le conflit, S. 178; DERS., Les puissances occidentales, S. 259.

${ }^{97}$ DALADIER, Journal, S. 191f.; Biddle an Hull, 19.6.1940 (SD 740.0011 European War 1939/3973); WELLES, Seven Decisions, S. 37, S. 50; Jean-François MURACCIOLE, François Darlan, in: Dictionnaire Historique de la vie politique, S. 254-256 (S. 254). HooD zufolge war Darlans Abneigung gegen die Briten in Frankreichs Marine weit verbreitet (Royal Republicans, S. 98, S. 120, S. 156).
} 
das State Department, wie vom Quai d'Orsay zutreffend angenommen, die Erhaltung der Machtbalance in Ostasien, insbesondere zwischen Japan und China, ins Zentrum ihrer Politik stellten, weil dies die Basis des Erhalts ihrer Stellung als asiatische Großmacht darstellte, war das Gleichgewicht nicht einmal ein französisches $\mathrm{Ziel}^{98}$. Paris sorgte sich kaum um die Bewahrung einer Balance, weil es wußte, daß Washington und London dieses Ziel verfolgten, aber auch, weil man glaubte, sich in einer japanische Hegemonie in China gut einrichten zu können: Mit Japans wirtschaftlicher Dominanz hatten sich die Franzosen, die kaum Handelsinteressen in China hatten, längst arrangiert. Daß Japan einmal willens und fähig sein würde, die Ordnung im Pazifik umzustürzen, war für die Verantwortlichen in Paris nicht denkbar. Als schlimmste Folge einer japanischen Hegemonie in China erschien den Franzosen, daß diese britische und sowjetische Kräfte band.

In der geopolitischen Nische in Indochina, wie sie sich bis 1940 darstellte, konnte Paris das Ringen in China ruhiger betrachten als die Angelsachsen: Großbritannien sah sich als führende Wirtschaftsmacht durch Japans Streben nach Herrschaft über China ebenso herausgefordert wie die USA durch das Ziel der japanischen Marine, den Westpazifik zu beherrschen. In der Frage des Gleichgewichts zeigte sich Frankreich, trotz des Weltmachtanspruchs, als europäische Regionalmacht. Da es den Franzosen möglich schien, sich auch ohne Kräftegleichgewicht in Asien zu behaupten, duldeten sie Japans Vormarsch. Weltpolitisch war die Zeit der concordances franco-japonaises der ersten Hälfte der dreißiger Jahre vorbei, da sich Japan gegen Frankreichs tatsächliche oder potentielle Partner Sowjetunion, Großbritannien und die USA stellte. In Asien aber standen französische und japanische Interessen nicht im unauflöslichen Widerspruch. Weil Paris nicht die Absicht und nicht die Mittel hatte, sich der Verschiebung des Gleichgewichts in Asien zu widersetzen, war Frankreich für Japan keine unausweichliche Hürde. Tokio tolerierte deshalb auch in den Konzessionen manche französische Eitelkeit.

Pfeiler des französischen Glaubens an die eigene Sicherheit war die Überzeugung, daß Frankreich in Asien nicht herausgefordert werde, solange es den Nimbus einer Großmacht habe. Auf das Prestige setzten vor allem die Botschafter Naggiar und Henry. Die Privilegien in China gegen Japan zu verteidigen, stärke Frankreichs Position in ganz Asien, riet Naggiar im Juni 1938:

\footnotetext{
${ }^{98}$ Anders als DREIFORT annimmt, war es Paris daher gleichgültig, ob zu große Vorsicht in Asien das Gleichgewicht dort gefährdete (Myopic Grandeur, S. 131). Einer der seltenen Momente, in denen der Quai d'Orsay äußerte, Paris habe gemeinsam mit London ein Interesse, »de maintenir dans cette partie du monde un équilibre nécessaire à la préservation des intérêts vitaux «, ist bemerkenswerterweise vor einem französisch-britischen Spitzentreffen. Vermutlich sympathisierte Hoppenot lediglich mit diesem britischen Wunsch (note de la sous-direction d'Asie-Océanie, 26.4.1938, MAE Chine 722).
} 
Nos questions de prestige et d'ascedant moral sont ici comme ailleurs essentielles. [...] Comme il convient à une grande puissance, il importe de ne se laisser ni émouvoir ni entraîner.

Henry schrieb, es sei Frankreichs traditionelle Politik, Japans Freundschaft zu suchen und sich Respekt zu verschaffen. Da Paris aber so von seinem Prestige, von »la mise en œuvre d'un patrimoine accumulé d'ascendant moral« lebte, wie Naggiar es mehrfach nannte, dürfe man dieses Kapital nicht leichtfertig aufs Spiel setzen, indem man etwa mit dem Verhängen von Sanktionen gegen Japan den Verlust der Konzessionen riskiere. Eine solche Erniedrigung hätte Folgen in Indochina, wo Frankreichs Herrschaft ebenfalls auf seinem Prestige beruhe. Auch für Geschäftsträger Frédéric Knobel in Shanghai war das Renommee Frankreichs wichtigstes Kapital:

Par notre énergie nous avons conservé ici un prestige certain grâce auquel les Japonais n'ont avancé que très lentement dans leurs préten-tions et se sont toujours montré intimidés devant notre calme et froide résolution. Je ne suis convaincu que vis-à-vis des Asiatiques et des Japonais en particulier ce ne soit pas l'attitude la plus saitisfaisante.

$\mathrm{Daß}$ die französische Diplomatie Prestige als Machtfaktor sah, war nicht auf Asien begrenzt: Daladier und Bonnet glaubten, daß Frankreich in Europa auch sein Ansehen, seine puissance morale, in die Waagschale werfen könne ${ }^{99}$.

Militär und Diplomatie in Paris waren davon überzeugt, daß Frankreich, Großbritannien und die USA bei Stabilität in Europa über genügend Prestige, wirtschaftliche und finanzielle Macht in Asien verfügten, um Japan von einem Überfall abzuhalten. Es war deshalb Konsens in Paris, Europa unbedingte Priorität einzuräumen und in Indochina die Kräfte gerade so zu stärken, daß es nicht als leichte Beute angesehen werden konnte.

Diese Haltung wurde nach 1945 scharf angegriffen: Admiral Jean Decoux kritisiert in seinen Memoiren das blinde Vertrauen in Paris, daß sich in einem Krieg Indochinas Schicksal am Rhein regeln werde. Diese Bewertung sei für die Regierung eine bequeme Ausrede gewesen, um über die Bedrohung durch Japan hinwegzusehen. Wenn die Ressourcen aber nicht zur Verteidigung ausgereicht hätten, hätte man Japan nicht durch den Waffentransit durch Tonkin provozieren dürfen. Indochinas fehlende Rüstung und das Vertrauen, das Schicksal der Kolonien werde auf Europas Schlachtfeldern entschieden, tadelt auch General Georges Catroux in seinen Erinnerungen. Angesichts der Expansion Japans hätten die Regierungen Indochina besser bewaffnen müssen. Claude Hesse d'Alzon zufolge führten die unklare Bedrohungslage, der

${ }^{99}$ Naggiar an Bonnet, T 41-49, 20.6., 27.5., T 1427-32, 30.9., T 1355-57, 22.9.1938 (DDF X, 61; IX, 461, XI, 486; MAE Chine 662); Henry an Bonnet, L, 26.8.; Knobel an Delbos, T 359-67, 8.3.1938 (MAE Chine 726, 761); René GIRAULT, Les décideurs français et la puissance française en 19381939, in: Girault, Frank (Hg.), La puissance, S. 24-43 (S. 30f.). Auch Englands Einfluß ruhte mehr auf dem Charisma der Großmacht als auf faktischer Macht (CLAYTON, The British Empire, S. 11f.). 
Eindruck, Japans Vorgehen richte sich nur gegen China, und das Vertrauen auf die »Solidarität der Weißen« zu zwei Irrtümern: Die Kolonien hätten ihre Sicherheit allein gewährleisten und sich an der Verteidigung des Mutterlandes beteiligen sollen. Paris habe sich zu sehr auf den Rhein fixiert und sich leichtfertig auf sein unvorbereitetes Empire verlassen ${ }^{100}$.

Der Glaube an das eigene Prestige war ebenso von eurozentrischer, von Rassismus nicht freier Überheblichkeit geprägt wie die Annahme, nach einem Weltkrieg werde man an den Verhandlungstischen Europas Verluste in Asien korrigieren können. Doch angesichts der korrekten Analyse der Bedrohungen in Asien und in Europa und Frankreichs begrenzter Ressourcen war die Prioritätensetzung völlig richtig: Es gab in Tokio bis zu Frankreichs Zusammenbruch im Sommer 1940 keine Pläne für einen Angriff auf Indochina. Erst die Niederlage in Europa ruinierte Indochinas Sicherheit.

Verstärkt wurde die beruhigende Einschätzung der Sicherheit Indochinas durch das Urteil der französischen Beobachter, die Kampfkraft der Japaner sei gering. Militärattaché Mast schrieb im Oktober 1937, in Japans Heer sei die Zusammenarbeit der Waffengattungen mangelhaft, die Führung ungenügend. Nördlich von Hongkong sei das Heer zwar jeder europäischen Armee überlegen. Doch für Indochina bestehe wegen der Distanz zu Japan keine Gefahr. Selbst in Kwangtung und auf Hainan könne Frankreichs Militär ein japanisches Expeditionskorps besiegen. Der Generalstab der Armee in Paris dämpfte Japans Erfolgsmeldungen meist mit dem Hinweis, Japan habe die Siege gegen eine fast wertlose chinesische Armee errungen. Daß Tokio im Januar 1938 einräumte, es werde einen langen Krieg gegen China führen müssen, bestätigte den Eindruck einer zweitklassigen Armee. Gegenüber Militärattaché Thiébaut gab Divisionsgeneral Sakai im Mai 1938 Defizite seiner Armee zu. Der Stab der Armée de l'air analysierte im Juni 1938, technisch seien die japanischen Flugzeuge westlichem Material weiter unterlegen, auch die Pilotenausbildung besitze kein hohes Niveau. Botschafter Henry urteilte im August 1938, Japans Oberkommando habe keine Strategie, die Offiziere seien ungehorsam. Japan erringe seine Siege in China gegen die schlechtesten Soldaten der Welt ${ }^{101}$.

Im Juni 1938 bestätigte in Shanghai Militärattaché Rousselle Masts Urteil: Japan sei weiter nicht in der Lage, militärisch gegen die Nachbarregionen Indochinas in Südchina vorzugehen. In Tokio vermied Militärattaché Thiébaut abfällige Urteile über Japans Heer. Sein Stellvertreter Hauptmann Aiby, der

\footnotetext{
${ }^{100}$ DeCouX, À la barte, S. 74f.; CATroux, Deux actes, S. 100f.; HeSSE D'Alzon, La présence, S. $10 \mathrm{f}$.

${ }^{101}$ Mast an EMA.2, L 304, 21.10., EMA.2, notes, Dezember 1937, 27.12.; EMA.2, extrait d'un compte rendu du colonel Jacomy, 18.1.1938 (SHAT 7 N 3300, 3133); Tientsin an Guerre, T 491-93, 25.1., Colonies, bulletin de renseignement, 15.1., Thiébaut an EMA.2, L 31, 17.5.1938 (SHAT 11 H $60,7 \mathrm{~N} 2507,7 \mathrm{~N} 3331$ ); EM Air, Notice sur les forces aériennes au Japon, juin 1938 (SHAA 2 B 58); Henry an Bonnet, L 164, 26.8.1938 (MAE Chine 726).
} 
von Juli bis September 1938 ein japanisches Infanterieregiment begleitete, schrieb, Japaner seien zäh, mutig und opferbereit, besäßen aber nur langsame Intelligenz. Sie seien schlecht ausgebildet und unfähig, auf Unvorhergesehenes zu reagieren. Man dürfe Japans Armee nicht unterschätzen, aber gegen moderne Verbände, vor allem aus Europäern, habe sie kaum Chancen. Oberst Jacomy, Chef der französischen Truppen in China, äußerte sich ähnlich. Der Generalstab der Armee urteilte im Dezember 1938, daß Japan siege, liege allein am schwachen China. Gegen andere Gegner renne Japan in ein sicheres Desaster. Noch abfälliger über Japan äußerte sich der Publizist Leurquin im Juni 1938 nach der Rückkehr aus China:

L'armée ne peut être comparée à une armée européene. Elle se compose de guerriers et non des militaires, [...] les officiers et les soldats japonais recherchent le combat avec une frénesie de primitifs ${ }^{102}$.

Japans Niederlage gegen die Sowjets bei den Grenzgefechten von Nomonhan im Herbst 1939 verstärkte bei den Militärattachés Thiébaut in Japan und Yvon in China den Eindruck, Japan verfüge über eine schlecht ausgebildete, miserabel geführte und ärmlich ausgestattete Truppe. Admiral Decoux räumte nach Kriegsende ein, man habe ein falsches Bild vom japanischen Soldaten gehabt, nämlich das eines demoralisierten, kränklichen und zum Nachtkampf unfähigen Kämpfers. Auch Oberst Trinquier gab zu, an die Überlegenheit der französischen Soldaten geglaubt zu haben. General Nolde schrieb noch 1946, Japaner seien schlechtere Soldaten als Franzosen und Deutsche, weil sie keine Intelligenz und Spontaneität für moderne Operationen hätten. Nur wegen der Schwächen der Chinesen seien sie einer Katastrophe entgangen ${ }^{103}$. Doch der US-Beobachter Hauptmann Carlson und das britische Militär bezeichneten Japans Armee ebenfalls als drittklassig; der deutsche General Falkenhausen äußerte im Februar 1938, es sei ein leichtes, »nur mit zwei bis drei deutschen Divisionen die Japaner in kurzer Zeit aus China herauszuwerfen ${ }^{104}$.

Auch wenn die Militärs in Paris zu keinem Zeitpunkt von der realistischen Möglichkeit eines japanischen Angriffs auf Indochina ausgingen, so hatten sie

${ }^{102}$ Rousselle, note $\mathrm{n}^{\circ}$ 72, 20.6.; Thiébaut an EMA.2, L 41, 12.7., L 56, 20.9., L 64, 15.11.1938 (SHAT 7 N 3290, 3331); Daladier an Casseville, L 112, 25.1., EMA.2, compte rendu du colonel Jacomy, arrivé à Paris 18.1., EMA.2, note ${ }^{\circ}$ 3378, 27.12.1938 (SHAT 11 H 63, $7 \mathrm{~N} 3133,3300$ ); SEH, renseignements, 9.11., 10.11.1939 (CAOM CM 87); LEURQUN, Stratégie, S. 271.

${ }^{103}$ Thiébaut an EMA.2, L 51, 21.9., L 134, 10.10., L 54, 2.11.1939 (SHAT 7 N 3332); DeCoux, À la barre de l'Indochine, S. 82; TRINQUIER, Le temps perdu, S. 59f.; NOLDE, La Chine, S. $42 \mathrm{f}$.

${ }^{104}$ WILSON, When Tigers Fight, S. 48; Martin an EMA.2, L 237, 25.3.1938 (SHAT 10 H 75); ONG, Operation Matador; John FERRIS, "Worthy of Some Better Enemy?« The British Estimate of the Imperiale Japanese Army, 1919-41, and the Fall of Singapore, in: Canadian Journal of History 28 (1993), S. 223-256 (S. 236f); LIANG His-huey, Alexander von Falkenhausen (1934-1938), in: Bernd MARTIN (Hg.), Die deutsche Beraterschaft in China 1927-1938. Militär, Wirtschaft, Außenpolitik, Düsseldorf 1981, S. 135-146 (S. 143). 
doch für alle Eventualitäten zu planen. Am 29. Juli 1937 urteilte das Comité consultatif de défense des colonies, angesichts der militärischen Entwicklung Chinas, der Drohungen Siams und vor allem der japanischen Absichten gegen Südchina sowie der schwachen Kräfte der Kolonie solle man bestimmte Flieger- und Marineeinheiten der Verteidigung Indochinas fest zuordnen und mehr Rekruten in Indochina einberufen. Zwei U-Boote und acht Flugzeuge müßten nach Indochina verlegt, die Luftabwehr und die Küstenartillerie verstärkt werden. Der Regierung rieten die Militärs, alles zu unterlassen, was Frankreich in den Konflikt hineinziehen könne, selbst wenn sich der Krieg auf die Sowjetunion ausdehne. Danach beruhigte sich aus Sicht des Komitees die Lage soweit, daß in den Sitzungen im November und Dezember 1937 sowie im Februar 1938 über afrikanische Fragen gesprochen werden konnte ${ }^{105}$.

Im Februar 1938 begann der Chef der Kolonialtruppen, General Billotte, einen Gesamtplan für die Verteidigung der Kolonien zu entwerfen. Indochina müsse sich angesichts der großen Entfernung zur Metropole selbst verteidigen können. Dies gelinge nur bei starken Kräften, gut ausgebildeten Reserven, der maximalen Nutzung einheimischer Soldaten und einer industriellen Mobilisation. Bei der Entwicklung des Plans warf das Comité consultatif de défense des colonies am 24. April 1938 die früheren Hypothesen um: Bisher hielt das Militär einen Angriff durch China, gefolgt von einem Überfall durch Siam und einer gemeinsamen Aggression durch Siam und China für die wahrscheinlichsten Szenarien. Erst an vierter und letzter Stelle folgte der Angriff durch eine maritime Macht. Japans Aktivitäten sowie die Haltung Siams ließen das Comité consultatif die jahrzehntealten Prioritäten ändern: Japan wurde jetzt zum potentiell gefährlichsten Gegner erklärt. Die ungünstigste Annahme war ein kombinierter Angriff durch Japan und Siam. Als Strategie in diesem Falle wurde festgelegt, zunächst den Hauptgegner an der Küste auszuschalten. Dazu müßten Luftwaffen-, Marine-, Infanterie- und Artillerieeinheiten aufgestockt werden ${ }^{106}$. Konkrete Folgen hatte die neue Ordnung der Kriegsszenarien nicht.

Die Planungen wurden durch Kompetenzstreite erheblich beeinträchtigt: Das Kolonial- und das Kriegsministerium verlangten das Kommando über alle Truppen in den Kolonien. Das Marine- und Luftfahrtministerium lehnten dies ab. Daladier behielt sich schließlich die Entscheidung über die Zuordnung von Marine- und Luftstreitkräften selbst vor ${ }^{107}$. Im Juli 1938 forderte Bührer im Comité consultatif, die Kolonien nach ihrem strategischen, wirtschaftlichen

\footnotetext{
${ }^{105}$ Note sur les mesures à prendre en Indochine, 29.7., Comité consultatif de défense des colonies, procès-verbal, 29.7., 23.11,, 23.12.1937, 11.2.1938 (SHAT 7 N 4194).

${ }^{106}$ Billotte, plan d'ensemble de défense des colonies, février 1938, Comité consultatif, plan de défense de l'Indochine, 24.4.1938 (SHAT 2 N 246, 7 N 4194); HESSE D'ALzON zufolge (L'armée française d'Indochine, S. 77, La présence militaire, S. 23) wurden die Prioritäten im Oktober 1938 geändert.

${ }^{107}$ Dokumente zu dem Kompetenzstreit finden sich in SHM 1BB2 182 und SHAT 2 N 246.
} 
und demographischen Wert für die Metropole zu ordnen. Die wichtigste Kolonie solle man mit dem größten Aufwand verteidigen. Die Diskussion verlief anders, als Bührer erhofft hatte. Alle drei Teilstreitkräfte gaben Schwarzafrika höchste Priorität. Marine und Luftwaffe urteilten, Indochina spiele keine vitale Rolle, denn es könne die Metropole wegen der unsicheren Seewege kaum mit Rohstoffen und Soldaten versorgen. Bührer wollte Indochina dennoch auf Rang eins setzen: Die Kolonie benötige wegen der Entfernung zu Europa und der Nähe zu einer imperialistischen Macht ein starkes Militär. Gleichzeitig sei seine Wirtschaft für Frankreich sehr wichtig: Indochina könne im ersten Kriegsjahr 67000 Soldaten, 60000 Arbeiter, 1,9 Millionen Tonnen Lebensmittel und 1,5 Millionen Tonnen Steinkohle liefern. Bührer schlug allein für Indochina Verstärkungen vor. Offensichtlich hatte Bührer die gesamte Prioritätensetzung betrieben, um Indochinas Aufrüstung in der Regierung durchzusetzen. Am 25. November 1938 erhoben die Chefs der Generalstäbe die Verteidigung Schwarzafrikas zur obersten Priorität ${ }^{108}$. Der aufwendige bürokratische Streit zwischen dem Kolonialministerium und den Streitkräften blieb folgenlos und brachte Indochinas Verteidigung nicht voran.

Die Militärs in Paris hatten mit der Debatte bewiesen, daß sie der Verteidigung Indochinas kein großes Gewicht beimaßen. Ihr Vertrauen in die Sicherheit der Kolonie beruhte auf einer Mischung aus (zutreffender) Einschätzung der Lage, Vertrauen auf die Unterstützung durch Amerikaner und Briten, dem Glauben an die eigene Autorität als Weltmacht, dem Bemühen um gute Beziehungen zu Japan sowie dem Unterschätzen der japanischen Möglichkeiten. Ein Angriff Japans war nur im Fall eines Weltkrieges realistisch. Auch deshalb mußte die Aufrüstung in Europa Priorität haben.

${ }^{108}$ Bourragué an Billotte, L 19, 4.2., Vuillemin an Gamelin, L 121, 24.9., L 1489, 8.11., Gamelin an Darlan, L 806, 1.10.1938, L 70, 18.1.1939 (SHM 1BB2 182); Procès-verbal de la réunion des chefs d'état-major généraux, 28.9.1938 (SHAT 2 N 225); Darlan an Gamelin, L 124, 24.8., L 145, 14.10., L 165, 22.11 .1938 (SHM 1BB2 171); Note secrète, la défense des colonies, November 1938 (SHM 1BB2 210); Bührer an Gamelin, L 72, 12.10 .1938 (SHAT 2 N 246); EMA, note, 10.11., Gamelin, note, 18.11.1938 (SHAT 7 N 4169); Procès-verbal de la réunion des chefs d'état-major généraux, 25.11.1938 (DDF XII, 404); DE LA GORCE, L'Empire écartelé, S. 44f. Marc MICHEL glaubt, Bührer habe mit der Debatte ein Gesamtkonzept zur Verteidigung der Kolonien angestrebt (La puissance par l'empire. Note sur la perception du facteur impérial dans l'élaboration de la défense nationale [19361938], in: Revue française d'histoire d'outre-mer 254, Bd. 69 [1982], S. $35-46$ [S. 42f.]). Daß Bührer aber sofort alle Überlegungen einstellte, als Indochina nicht zur ersten Priorität erklärt wurde, zeigt, $\mathrm{da}$ es ihm bei der Debatte ausschließlich um die Aufwertung Indochinas ging. 


\subsection{Erstes Spiel mit der chinesischen Karte}

Daladiers Regierung erwog zu Beginn ihrer Amtszeit, Legers Linie zu verlassen und sich für China zu engagieren. Die Bestimmungen des Waffentransits durch Indochina wurden gelockert, Regierungsmitglieder führten offiziöse Gespräche über die Entsendung französischer Offiziere nach Chungking.

Chinas Regierung hatte bereits Amerikaner und Briten nach Militärberatern gefragt. Im Herbst 1936 lehnten die USA die Anfrage ab, im Juli 1937 und erneut im Januar und Mai 1938 wies London die Bitten zurück ${ }^{109}$. Anfang März 1938 baten chinesische Emissäre Paris um eine Militärkooperation. Die Chinesen fühtten diese Gespräche zunächst nur über inoffizielle Regierungsvertreter. Botschafter Koo beteiligte sich erst 1939 daran. Im März 1938 besuchte der ehemalige Verkehrsminister Wang Pai-shien in Bangkok den britischen und den französischen Gesandten, Sir Josiah Crosby und Paul Lépissier. Wang stellte sich als geheimer Emissär Chiang Kai-sheks vor und schlug eine Allianz zwischen China, Frankreich und Großbritannien vor, um die Grenzen Chinas, Indochinas und Burmas zu schützen und GeheimdienstInformationen auszutauschen. Außenminister Paul-Boncour lehnte die Initiative nicht rundweg ab. Das Foreign Office verwarf Chinas Ansinnen aber. Solche Vorschläge habe es in den vergangenen zehn Jahren ständig gegeben. Auch Naggiar mahnte zur Vorsicht, da man sich weder des Mandats, noch der Diskretion dieser Vertreter sicher sein könne. Die Grenzen seien derzeit ohnehin nicht bedroht. Damit sei das Bündnis wenig opportun ${ }^{10}$.

Anfang April wurden die Avancen seriöser: Bereits im Herbst 1937 hatte Chinas Regierung entschieden, den Völkerbund-Direktor Ludwik Rajchman nach Paris zu entsenden, um Frankreich für eine Zusammenarbeit zu gewinnen und die Frage des Waffentransits durch Indochina zu lösen. In der Transitfrage übten die Chinesen parallel Druck aus: Mitte April 1938 drohten sie in Shanghai und in Hanoi, unter dem Personal der Yunnanbahn einen Streik anzuzetteln. Französische Diplomaten protestierten bei der Provinzregierung und im chinesischen Außenministerium und betonten die wirtschaftlichen Schäden eines Streiks für China. Damit war die Streikdrohung vom Tisch ${ }^{11 !}$.

\footnotetext{
${ }^{109}$ TUCHMAN, Sand gegen den Wind, S. 158; SHAl, Origins of the War, S. 156.

${ }^{110} \mathrm{CS}$ Guerre, EM du vice-président, compte rendu du lieutenant-colonel Petibon de l'EM du général Gamelin au sujet d'une demande d'audience du général Yang, 25.6.1938 (SHAT 5 N 579); Crosby an Halifax, 12.3.1938 (FO 371/22168, F 4226/318/61); Lépissier an Delbos, T 24-25, 8.3.; L 52, 11.3., Corbin an Bonnet, L 277, 24.4., Naggiar an Delbos, T 338-39, 9.3.1938 (MAE Chine 676, Indfr 33).

${ }^{11}$ Knobel an Paul-Boncour, T 482, 7.4., T 518-19 an Bonnet, 18.4., Crépin an Naggiar, L 33, 27.4., L 40, 3.5.; Brévié an Moutet, T 448, 16.4., T 457, 21.4.1938 (MAE Chine 949, CAOM FM 677); Crépin an Naggiar, L 34, 28.4.1938 (MAEN Pékin A291 bis); BALINSKA, Une vie pour l'humanitaire, S. 203.
} 
In der Frage der Militärmission unternahmen die Chinesen Anfang April 1938 in Paris bei General Henri Dentz, dem sous-chef des Generalstabs, dem der Geheimdienst unterstand, weitere Sondierungen. Der chinesische Militärattaché erklärte, China wolle sich von der deutschen Militärmission trennen, und fragte, ob stattdessen eine französische Mission kommen könne. Das von Dentz informierte Außenministerium teilte mit, aktive Offiziere zu entsenden sei unmöglich, die Abordnung von Reserveoffizieren gefährlich ${ }^{12}$. Ebenfalls im April schlugen chinesische Militärs in Fort Bayard, Hauptstadt des Pachtgebiets Kwangchowan, dem französischen Hauptmann Graille einen gemeinsamen Verteidigungsplan für Hainan vor.

Nachdem Léger die Abstellung von Offizieren verhindert hatte, umgingen ihn die Chinesen. Rajchman nahm in Genf Kontakt zu Mitarbeitern Bonnets und Daladiers auf, um Li Yu Ying, dem Präsidenten der Union francochinoise de Pékin et de Shanghai, den Zutritt zur Ministeretage des Kriegsministeriums zu ermöglichen ${ }^{113}$. Auf Bitten von Delbos' früherem Kabinettschef Dr. Laugier sprach General Alphonse Georges vom Conseil supérieur de guerre mit Rajchman. Dieser schlug Georges vor, daß China die indochinesische Grenze garantieren und Truppen zur Verteidigung Indochinas stellen könne; im Falle eines Weltkrieges entsende es Arbeiter und Soldaten nach Frankreich. Paris seinerseits solle den Waffentransit durch Indochina erlauben, Ingenieure für die chinesische Rüstungsindustrie abstellen und vor allem eine Militärmission entsenden. Weitere Gespräche, so Rajchman, wolle Li Yu Ying mit Georges führen. Für Li war es nicht die erste Bemühung um französische Berater: Bereits im Oktober 1932 hatte er den damaligen Ministerpräsidenten Édouard Herriot um die Entsendung einer Militärmission gebeten ${ }^{114}$. Auch damals wurde der - letztlich ergebnislose - Kontakt in Genf geknüpft.

General Georges informierte Daladier über das Gespräch mit Rajchman, dann traf Li Yu Ying mit dem Regierungschef zusammen. Li stellte sich als Freund Chiang Kai-sheks vor. Chinas suche eine diskrete Kooperation mit Paris. Man denke vor allem an den Bau chinesischer Flugzeuge in Indochina, die Entwicklung der Luftverbindungen zwischen Indochina und China sowie die Munitionproduktion in Indochina, die das französische Bankenkonsortium

\footnotetext{
${ }^{112}$ Note de la sous-direction d'Asie-Océanie und Rückseite, 8.4.1938 (MAE Chine 538).

${ }^{113}$ Brévié an Konsul Hoihao, L 225, 4.8.1938 (MAEN Pékin A 344); Hoppenot an Naggiar, L, 13.7.1938 (MAE PAAP, Fonds Hoppenot 6). Li Yu Ying war Delegierter Chinas bei den internationalen Organisationen der intellektuellen Zusammenarbeit, Präsident der chinesischen Nationalakademie und Chef der chinesischen Delegation im Komitee des Kulturfonds CEuvres franco-chinoises in Peking. Er verfuigte Cosme zufolge in Chinas Regierung über Einfluß, den er stets für Frankreich eingesetzt habe (Beauvais, note pour le cabinet du ministre, 14.8.1937, MAE Chine 676).

${ }^{114}$ Note du général Georges, Conseil supérieur de la guerre, 5.5.1938 (MAE Chine 676); Wilden an Herriot, T 245-46, 10.10.1932 (DDF $1^{\mathrm{re}}$ série, I, 234, Fußnote 1).
} 
Groupe uni finanzieren wolle. Zudem bitte man um die Entsendung einer Militärmission. Luftfahrtminister Paul Painlevé habe 1931 diese Mission bereits versprochen. Weil er nach China zurückreise, so Li Yu Ying, solle Rajman die Gespräche weiterführen. Erst jetzt, als General Georges ein Protokoll seines Gespräches mit Rajchman vom 5. Mai übermittelte, erfuhren Léger und die Asienabteilung des Außenministeriums von den Sonderierungen ${ }^{115}$.

Motiv für die Initiative Bonnets und Daladiers, die am 10. April 1938 erst in ihre Ämter gekommen waren, dürfte der Versuch gewesen sein, die wchinesische Karte « zu spielen: Als Hitler am 20. Februar 1938 vor dem Reichstag ankündigte, den japanischen Marionettenstaat Mandschukuo anzuerkennen, und am 22. Februar erste Berichte in Paris auftauchten, Berlin ziehe die Militärberater aus China ab, wurde klar, daß Berlin seine Schaukelpolitik zugunsten Japans beenden würde, auch wenn sich die Abreise der Berater bis Juli 1938 verzögerte ${ }^{116}$. In dieser Lage erschien es dem Ministerpräsidenten und dem Außenminister offenbar klug, die Option für eine Zusammenarbeit mit China auszuloten. Daß London und Washington eine chinafreundliche Politik verfolgten, mochte Daladier und Bonnet bestärkt haben.

Erleichtert wurden ihre Überlegungen, sich deutlicher auf Chinas Seite zu schlagen, durch die Stabilisierung der militärischen Lage zugunsten Chinas: Französische Militärs schätzten das chinesische Militär zunehmend kampfkräftiger ein. Im Sommer 1937 und nach Beginn der Kämpfe waren die Urteile französischer Experten über Chinas Armee noch verheerend. Im Spätherbst 1937 erachtete das französische Militär, Chinas Widerstand sei zwar stärker als angenommen, doch Japans Überlegenheit sei überdeutlich ${ }^{117}$.

Im Frühjahr 1938 änderten sich die Urteile grundlegend: Ab Februar kamen Meldungen auf, Japans Armee sei müde, sie könne die eroberten Gebiete nicht besetzen, sondern nur Städte und Verkehrsverbindungen kontrollieren. Im März 1938 äußerten der Generalstab in Paris und der Marine-Geheimdienst in Shanghai Zweifel, ob Japan seine Offensive fortsetzen könne. Anfang April beurteilte Sabattier Chinas Kampfkraft besser als je zuvor. Chinas Sieg in der

\footnotetext{
${ }^{115}$ Lawrence Higgins (Paris) an Hull, 20.6.1938 (SD 895.51/6637); Bonnet an Naggiar, T 255-59, 3.6., Note du général Georges, Conseil supérieur de la guerre, 10.5.1938 (DDF IX, 510, 434); Hoppenot an Naggiar, L, 13.7.1938 (MAE PAAP, Fonds nominatif Henri Hoppenot 6).

${ }_{116}$ BLoss, Die Zweigleisigkeit, S. 80; François-Ponçet an Delbos, T 966, 22.2.1938 (MAE Chine 538); Colonies, bulletin de renseignement, 15.3.1938 (CAOM FM, AP 1416); Naggiar an Bonnet, $T$ 622-27, 10.5.1938 (MAE Chine 679); WuU, Die deutsche Beraterschaft, S. 229f.

${ }^{117}$ EMA.2, bulletin de renseignement, 27.6., 24.10.; EMA.2, notes, 15.10.1937 (SHAT 7 N 2514, 3133); Lacoste an Delbos, T 204-6, 31.7 .1937 (MAE SDN 354); Mast an EMA.2, 11.8., EMA.2, note, 11.9.1937 (SHAT $7 \mathrm{~N}$ 3329, 3334); Mast an EMA.2, 23.9., 6.10., EMA.2, note, 11.10., 8.11.1937, 10.1.1938 (SHAT 7 N 3300); Lépissier an Delbos, L 42, 8.11.1937 (CAOM INF 1016); Guillermaz an EMA.2, 11.8., 23.9., 20.10., Sabattier, note, 12.11.1937 (SHAT 7 N 3289); Naggiar an Delbos, T 845-46, 8.12.1937, Hoppenot an Colonies T 634, 7.5.1938 (MAE Chine 714, 538).
} 
Schlacht von Taierchwang in Süd-Shantung vom 24. März bis 7. April zeigte seine wachsende Kraft. Der deutsche General Falkenhausen sagte, Japan habe China zwei Jahre zu spät angegriffen, China werde die Schlachten verlieren, aber den Krieg gewinnen. Offenbar wurde es für Paris ungefährlicher, für China Partei zu ergreifen ${ }^{118}$. Im Sommer 1938 kam Japan beim Vormarsch auf Hankou nur langsam voran. Als die Chinesen im Juni 1938 die Deiche des Gelben Flusses durchbrachen, hielt dies die Japaner monatelang auf. Japans Armee geriet buchstäblich immer tiefer in den chinesischen Sumpf ${ }^{19}$.

In dieser Situation plädierten auch der Politische Direktor René Massigli und Militärattaché Sabattier dafür, die Haltung gegenüber China zu überdenken. Mit Léger war der Kurswechsel aber nicht zu machen. Um die von Bonnet und Daladier initiierten Gespräche zu beenden, sprach er mit $\mathrm{Li} \mathrm{Yu}$ Ying. Li unterbreitete Léger das Projekt eines französisch-chinesischen Nichtangriffspaktes, bot chinesische Truppen zur Verteidigung Indochinas an und bat um eine Militärmission. Léger wies die Pläne als unvereinbar mit der französischen Neutralität strikt zurück. Zu Zusammenarbeit im Bereich der Finanzen oder des Eisenbahnbaus sei man jedoch gern bereit ${ }^{120}$.

Rajchman setzte jedoch die Gespräche im französischen Außenministerium fort. Georges Bonnet traf sich gleich zweimal mit Rajchman, am 14. und am 21. Mai, und versicherte, Daladier und er hätten Interesse an einer vertieften französisch-chinesischen Zusammenarbeit. Auf Bonnets Bitte sprach General Georges am 25. Mai mit Rajchman. Vier Bereiche möglicher Kooperation legten Alphonse Georges und Ludwik Rajchman fest: Das Abstellen chinesischer Truppen im Fall eines Angriffs auf Indochina oder eines Weltkriegs, die Entsendung einer französischen Militärmission und die Erleichterung des

118 Corbin an Delbos, T 79-82, 13.1.1938 (MAE SDN 363); Sabattier, notes, 3.2., 12.4., 26.4.; 6.4.1938 (SHAT 7 N 3290; DDF IX, 120); Thiébaut, notes, 1.2., 19.5.1938 (SHAT 7 N 3331); Jacomy an Steeg, T 512-15, 6.2.1938 (SHAT 11 H 60); EMG.2, bulletin de renseignement 18.3., 16.4., 24.5.1938 (SHM 1BB2 92); STS-bulletin 1.4., 1.5., 1.6.1938 (MAE Chine 533); EMA.2, notes, 31.3., 11.4., 25.4.1938 (SHAT 7 N 2519, 3300); EMA.2, rapport du ministre, 4.4., 1.5.1938 (SHAT 7 N 2515); US-Hauptmann Carlsson, Bericht über die Schlacht von Taierchwang, 11.4.1938 (SHAT 7 N 3291); Colonies, bulletin de renseignement, 15.4.1938 (SHAT 7 N 2507); Henry an Bonnet, T 26769, 7.6., Troupes de l'Indochine, EM.2, compte rendu, 8.6.1938 (MAE Chine 723, 565).

${ }^{119}$ Diplomatie an Colonies, L, 7.5., Henry an Bonnet, D 65, 12.5.1938 (MAE Chine 782, DDF IX, 326); EMA.2, rapport du ministre, 13.6., 11.7.1938 (SHAT $7 \mathrm{~N}$ 2515); Colonies, bulletin de renseignement 15.6., 15.7., 15.8.1938 (CAOM FM, AP 1416); EMG.2, bulletin de renseignement, 24.6., 10.8.1938 (SHM 1BB2 92); STS-bulletin 1.7., 1.8., 1.9.1938 (MAE Chine 533); EMA.2, note, 11.7., Jacomy an EMG.2, T 648, 15.7.1938 (SHAT 7 N 3300, 3319); EMA.2, note, 5.9.1938 (SHAT 7 N 3133); Colonies, bulletin de renseignement 15.9., 15.10.; Service de renseignement de Hankéou, rapport, 24.9.1938 (SHAT 11 H 76, 77); Thiébaut an EMA.2, 6.10.1938 (SHAT 7 N 3331).

${ }_{120}$ Note de la sous-direction d'Asie-Océanie pour le ministre, 25.4.1938 (MAE Ac 136); Compte rendu, 11.5., Bonnet an Naggiar, T 255-59, 3.6.1938 (DDF IX, 316, 510); Sabattier, note, 25.5.1938 (SHAT 7 N 3290); Léger an Coulondre, T 371-72, 30.6.1938 (MAE Chine 782); Hoppenot an Naggiar, L, 13.7.1938 (MAE PAAP, Fonds nominatif Henri Hoppenot 6). 
Waffentransits durch Indochina. Zum Bereich wirtschaftlicher Kooperation gehörten das Abstellen französischer Experten für Rüstungsbetriebe, der Flugverkehr zwischen China und Indochina sowie die Produktion von Munition in Indochina. Georges bat den Regierungschef, Grundsatzentscheidungen zu treffen und eine interministerielle Gruppe unter Leitung des Außenministeriums einzusetzen. Daladier zögerte. Er teilte Bonnet mit, technisch sei die $\mathrm{Zu}$ sammenarbeit möglich. Doch da diese Frage Folgen für Frankreichs gesamte Weltpolitik habe, wolle er die Ansicht des Außenministeriums hören ${ }^{121}$.

$\mathrm{Li} \mathrm{Yu}$ Ying hatte unterdessen in Shanghai Kontakt zu Naggiar gesucht, der die von einigen Zeitungen Chinas verbreiteten Gerüchte über die Ablösung der deutschen durch eine französische Militärmission dementiert hatte. Zwei Indizien deuten darauf hin, daß in Paris im Juni 1938 sehr ernsthaft über die Entsendung einer Militärmission nachgedacht wurde: Tokio protestierte gegen die Verpflichtung zweier pensionierter Generäle als Berater in China, und in Meldungen aus Genf war von 40 französischen Beratern die Rede. Bei der 1939 entsandten Militärmission nahmen tatsächlich zwei Generäle im Ruhestand teil, und erneut ging es um 40 Offiziere $^{122}$.

Naggiar warnte sein Außenministerium deshalb offenbar mit Grund vor einer Parteinahme. Dilatorische Antworten aus Paris gewohnt, schloß Naggiar, wenn er nichts Gegenteiliges höre, werde er Li eine Absage erteilen. In einem Brief an Léger nannte Naggiar die Geheimgespräche in Paris einen Sumpf, der ihn anwidere. Nach dem Gespräch mit Li wiederholte Naggiar seine Mahnung an Paris: Frankreich müsse seine Interessen in Asien ausbalancieren. Man dürfe in dem Konflikt nicht Partei ergreifen, weil dies Frankreich gegenüber Japan kompromittiere. In Paris gelang es dem Generalsekretär mit Mühe, den Außenminister umzustimmen. Spätestens am 3. Juni schwenkte Bonnet auf die Linie Naggiars und Légers ein, nachdem Massigli noch zwei Tage zuvor erklärt hatte, nur Naggiar lehne die Militärmission $a^{123}$.

Bonnet wies Naggiar an, er solle $\mathrm{Li}$ Yu Ying die europäischen und asiatischen Hindernisse für die Hilfe aufzeigen und erklären, daß die französische Hilfe um so effizienter sei, je diskreter sie bleibe. Paris sei bemüht, nicht durch Unbedachtsamkeiten seine moralische Autorität und seine politische Position im Fernen Osten zu gefährden. Von der festen, ausgewogenen Haltung Frankreichs habe China in Shanghai und in Genf profitiert. Léger

\footnotetext{
${ }^{121}$ Georges an Daladier, 28.5.1938 (DDF IX, 475); Daladier an Bonnet, 11.6.1938 (MAE Chine 676).

${ }^{122}$ Naggiar an Bonnet, T 670, 21.5.1938 (MAE Chine 676); STS-bulletin, 1.6.1938 (MAE Chine 533); Memorandum, 24.6.1938 (SD 793.94/13645); Bucknell an Hull, 17.6.1938 (SD 893.51/6629).

${ }^{123}$ Naggiar an Bonnet, T 700-2, 27.5., T 733-38, 3.6., T 41-49, 20.6.1938 (DDF IX, 461, MAE Chine 676, DDF X, 61); Naggiar an Léger, L, 6.6.1938 (MAE PAAP Naggiar 4); Hoppenot an Naggiar, L, 13.7.1938 (MAE PAAP, Fonds nominatif Henri Hoppenot 6); Compte rendu de la réunion interministerielle hebdomadaire, 1.6.1938 (DDF IX, 500).
} 
erklärte Naggiar, die traditionelle Freundschaft zu China und die Sympathien für seine Sache könnten Frankreich nicht dazu bringen, eigene Interessen zu gefährden. Paul-Émile Naggiar reiste sofort nach Hongkong, um Li Yu Ying und vielleicht auch T.V. Soong die französische Position zu erklären ${ }^{124}$.

In Paris begründete Bonnet seine Ablehnung damit, die Chinesen hätten die Vorschläge nicht offiziell vorgebracht, da sie angesichts der internationalen Lage keine positive Antwort erwartet hätten. Gegenüber dem Kriegsministerium unterstrich der Quai d'Orsay, das Eingehen auf Chinas Vorschläge hätte eine Intervention Frankreichs in den Konflikt bedeutet. Mit internationalen Garantien und im Rahmen einer kollektiven Aktion hätte Frankreich China unterstützt, doch ohne diese Einbettung müsse Frankreich sich auf die Verteidigung eigener Interessen konzentrieren. Diese verlangten eine Politik des Gleichgewichts zwischen den Parteien. Alles andere bedeute das sofortige Risiko von Repressalien Japans. Alexandre Varenne kam mit seiner Idee, einer französischen Militärmission einen internationalen Anstrich zu geben, indem man britische, türkische oder belgische Offiziere aufnehme, zu spät $t^{125}$.

Unmittelbar nachdem das Kriegsministerium in Paris Bonnets ablehnende Stellungnahme erhalten hatte, baten die Chinesen, die Gespräche fortzusetzen. Sie regten an, unter Umgehung der diplomatischen Kanäle direkt mit Generalstabschef Gamelin zu verhandeln. Major Chang Kin bat, man möge über den Gesprächswunsch des chinesischen Generalstabschefs General Yang weder den Botschafter noch den Militärattaché, sondern nur Huang Tien Mai, Chinas Generalkonsul in Paris, informieren. Diesmal erhielten die Chinesen von Daladiers Büro eine klare Absage. Als Anfang Juli die letzte Kontaktaufnahme von General Yang und Generalkonsul Huang im Verteidigungsministerium scheiterte, äußerte sich die chinesische Regierung in Hankou tief enttäuscht. Dafür konnte Botschafter Henry Außenminister Ugaki Kazushige, der sich nach Gerüchten erkundigte, Frankreich wolle die deutsche Militärmission ersetzen, wahrheitsgemäß erklären, jede chinesische Anfrage sei chancenlos ${ }^{126}$.

Die Militärmission beschäftigte Daladier weiter: Im September sagte er Bullitt, Militärbestimmungen verböten die Entsendung pensionierter französischer Generäle nach China. Vom chinesischen Regierungssitz in Chungking berichtete der französische Geheimdienst im November 1938, die Regierung erwäge, eine französische Militärmission einzuladen und ihr weitreichende Befugnisse einzuräumen ${ }^{127}$. Auf die Tagesordnung der Pariser Ministerien

\footnotetext{
${ }^{124}$ Bonnet an Naggiar, T 255-59, 3.6.1938 (DDF IX, 510); Léger an Naggiar, T 265-68, 4.6., Naggiar an Delbos, T 754, 5.6.1938 (MAE Chine 676, 723).

${ }^{125}$ Bonnet an Daladier, L 1842, 22.6., Varenne, note pour M. Bonnet, 26.7.1938 (DDF X, 74, 272).

${ }^{126}$ Compte rendu de M. Petibon, 25.6., note du général Decamp, 1.7.1938 (SHAT 5 N 579); Georges Picot an Naggiar, T 792-94, 19.7., Henry an Bonnet, T 377-79, 12.7.1938 (MAE Chine 725, 747).

${ }^{127}$ Bullitt an Hull, 16.9.1938 (SD 760f.62/858); SEH, renseignement 1619, 3.11.1938 (CAOM CM 82).
} 
gelangte das Thema der staatlichen französisch-chinesischen militärischen Zusammenarbeit erst wieder im Januar 1939.

Französische Piloten hatten unterdessen auf privater Basis Chinas Luftwaffe unter die Arme gegriffen. Schon kurz nach Konfliktausbruch reisten die ersten Piloten nach China. Noch ehe sie Frankreich verlassen hatten, kamen Berichte über ihren Einsatz auf. Ende August 1937 schrieb Japans Presse, elf französische Piloten seien aus Marseille nach China abgereist, was Botschaftsrat Uchiyama gegenüber Cosme sofort mit Drohungen beantwortete. Im September wurde in Japan vermutet, 25 Franzosen hätten bei der chinesischen Luftwaffe angeheuert. Der »Strait Times« in Singapur vom Januar 1938 zufolge waren sogar 124 Franzosen in Chinas Luftstreitkräfte eingetreten. Im Mai 1938 erfuhr Japans Geheimdienst aus Port Said, auf zwei französischen Schiffen reisten je 65 französische Piloten nach Ostasien ${ }^{128}$.

Tatsächlich war die Zahl gering: Fünf Piloten hatten sich in China gemeldet. Im September 1937 kam Omer Poivre nach China. Er starb im Dezember bei einem Luftkampf. Mitte Oktober 1937 meldeten sich die Piloten André Boulingre, Marcel Florein und William Labussière, die auf republikanischer Seite im Spanischen Bürgerkrieg gekämpft hatten, und Martial Laroche in Shanghai. Japanische und französische Behörden ignorierten die Präsenz der Piloten in den Konzessionen in Shanghai und Hankou. Nach ersten Einsätzen reisten Florein und Laroche im Februar 1938 wieder $a b^{129}$. Im Januar 1938 trat mit Drouillet ein weiterer Franzose in Chinas Luftwaffe ein. Er nutzte einen Übungsflug in Indochina, um sich mit seinem Flugzeug nach China abzusetzen. In Hankou trafen sie die verbliebenen beiden Piloten Labussière und Boulingre. Drouillet erklärte, er wolle mit 32 französischen Piloten ein französisch-chinesisches Geschwader aufbauen. Mit drei deutschen Piloten

\footnotetext{
${ }^{128}$ Henry an Delbos, T 287, 26.8.1937 (MAE Ac 133); Note de la sous-direction d'Asie-Océanie, 31.8.1937 (MAE Chine 704); Attaché de l'Air Commandant Max Bruière (Tokio) an Cot, L 67, 8.9.1937 (SHAT 7 N 3329); Troupe de l'Indochine, EM.2, compte rendu de renseignement, $n^{\circ} 3$, 1.2.1939 (SHAT 10 H 75); Remillard (Port Said) an Hull, 20.5., 27.5.1938 (SD 893.24/414, 418).

${ }^{129}$ Marine Saigon an EMG.2, T 913-14, 15.10 .1937 (SHM 1 BB9 35); Brévié an Moutet, T 840, 16.10., Moutet an Brévié, T 682, 25.10.1937 (CAOM FM 666, 661); Léger an Naggiar, T 251, 17.10., Naggiar an Delbos, T, 17.10.; T 563, 16.10., L 23, 28.10.1937 (MAE Chine 753, 709, Ac 135); Hentschel an Moutet, T 401, 28.10.1937 (SHAT 11 H 60); Naggiar an Delbos, T 878, 16.12., T 897, 18.12., Léger an Naggiar, T 380, 21.12.; Dormoy an Delbos, L 11.996, 28.10.1937 (MAE Chine 715, 710); Patrick Laureau, Des Français en Chine, in: Avions 3 (1993), S. 11-16 (S. 14f.), 4 (1993), S. 32-38 (S. 36f.). Die Identität der im Oktober angereisten Piloten steht nicht zweifelsfrei fest. Die vier aufgefühten Namen nennen Naggiar am 18.12.1937 sowie Laureau in dem Aufsatz. Laroche und Florein tauchen in allen Quellen auf, Boulingre und Labussière fehlen oft. Dafür nennen die Marine Saigon, Brévié, Moutet, Hentschel und das Innenministerium in Paris Alfred Pillain als fünften Piloten. Auch der Konsul in Hankou zählte nach der Ankunft Drouillets sechs französische Piloten (Diplomatie an Air, L 114, 21.2.1938, MAE Chine 720). Später nannte auch Sabattier die Namen Labussière und Boulingre (Sabattier an Air, L, 12.4.1938, SHAT 7 N 3290).
} 
bildeten die drei Franzosen eine deutsch-französische Staffel, die nach Informationen aus Shanghai im Februar 1938 Taiwan angriff ${ }^{30}$.

Im Frühjahr 1938 rekrutierten der Waffenhändler Audinet und der General der Armée de l'air Paul Berger 20 französische Flieger, die die an China verkauften Dewoitine-Maschinen fliegen sollten. Ende Mai 1938 kamen sieben Piloten und acht Mechaniker unter der Leitung des Spanienveteranen Major Jean Labitte in Yunnanfu an. Die Piloten reisten aber nicht mehr nach Zentralchina. Dort waren bis Juni nur 13 Flugzeuge angekommen. Als sich die Front Hankou näherte, flogen auch die Piloten Labussière, Boulingre und Drouillet von dort nach Yunnanfu. Die Franzosen sollten chinesische Piloten ausbilden und die Maschinen selbst im Kriegseinsatz fliegen ${ }^{131}$.

Japans Presse protestierte, daß Franzosen für China kämpften. Bonnet erklärte Tokio, die wenigen Piloten seien ohne Beteiligung ihrer Regierung nach China gelangt. Immerhin war aber ein General der Armée de l'air an ihrer Verpflichtung beteiligt, und die Flieger waren - neben einem Major und zwei Hauptmännern - Leutnante der französischen Streitkräfte ${ }^{132}$. Zu französischjapanischen Luftkämpfen kam es nicht. Die Piloten und Chinas Regierung stritten nämlich monatelang über die Bezahlung der Löhne, des Benzins und der Versicherung. Als neun japanische Bomber am 29. September 1938 den Flugplatz in Yunnanfu angriffen, stiegen die Franzosen zwar mit fünf oder sechs Maschinen auf, griffen aber nicht an. Die Chinesen entließen daraufhin die Franzosen. Die Piloten Boulingre und Labussière, die bereits in Hankou für China geflogen waren und einen Vertrag für den gesamten Krieg besaßen, wurden im Februar 1939 durch russische Flieger ersetzt ${ }^{133}$.

Für das französische Militär und die französische Rüstungsindustrie endete die Episode ruhmlos. Chinas Versuche, eine Militärkooperation mit Paris zu einzuleiten, waren 1938 gescheitert. Léger betrachtete dies aber als Wohltat für seinen vorsichtigen Kurs auf dem verminten Gelände der Fernostpolitik.

${ }^{130}$ Brévié an Steeg, T 122, 5.2., T 135, 9.2.; Steeg an Brévié, T 119, 15.2.1938 (CAOM FM 677, 672); Naggiar an Delbos, T 204-6, 10.2., T 224, 14.2., Hoppenot an Naggiar, T 90, 12.2.; Steeg an Delbos, L 172, 16.2., Knobel an Bonnet, T 528, 20.4.1938 (MAE Chine 719, 720, 721); Diplomatie an Guerre, L 1166, 27.4.1938 (SHAT 7 N 3294); Service de police, rapport, 6.5.1938 (CAOM CM 901).

${ }^{131}$ Note de la sous-direction d'Asie-Océanie, 6.4., Yvon an EMA.2, L 1, 10.4.1939 (MAEN Pékin A 344); SEH, renseignement, 9.5.1938 (CAOM CM 98); Hankou an Tientsin, T 143, 18.5., T 148, 23.5.1938 (SHAT 11 H 60); Naggiar an Bonnet, T 721, 31.5., T 761, 6.6.1938 (MAE Japon 126, Chine 723); Meyer an Hull, 31.5., 15.6.; Southard an Hull, 8.6.; G-2 Digest of Information, June 4-10, Memorandum, 24.6., Wilson an Hull, 14.5.1938 (SD 893.24/415, 433; 893.113/1700, 793.94/13220, 13645, 13078); Patrick LaUreau, Des Français en Chine, in: Avions 5 (1993), S. 38-44 (S. 38).

${ }^{132}$ Bonnet an Henry, T 158-60, 1.6., T 230-33, 13.7.1938 (DDF IX, 496, DDF X, 201); eine undatierte Liste mit den Namen und Dienstgraden der französischen Offiziere findet sich in MAE Chine 560.

${ }^{133}$ Meyer an Hull, 29.6., 11.7., 26.7., 9.8., 9.11., 11.11.1938 (SD 893.24/434, 437, 448, 461, 507, 893.20/693); SEH, renseignement $n^{\circ} 293,24.2 .1939$ (CAOM CM 98); Fourth Marines, R-2 report, 25.2.1939 (SD 793.94/14844); Brévié an Mandel, T 321-22, 27.2.1939 (CAOM FM Tel 80). 


\subsection{Stabilität zwischen Paris und Tokio im Sommer 1938}

Geprägt wurde das französisch-japanische Klima im Frühsommer 1938 von der Frage möglicher Waffenlieferungen über Indochina nach China. Japan versuchte, mit Drohungen die Transporte zu unterbinden.

Am 31. März und 6. April 1938 meldete die Morning Post in Hongkong, Indochina schickaniere Japaner, via Haiphong kämen große Mengen Waffen nach China. Mit weiteren frei erfundenen Berichten eröffnete Domei am 20. April eine Kampagne gegen Paris: Die Agentur schrieb, Naggiar habe in Kanton einen französisch-chinesischen Geheimpakt unterzeichnet, der China die Nutzung von Flughäfen in Indochina erlaube. Ein Sprecher des Gaimusho sagte, China erhalte über die Kolonie Waffen. Japanische Zeitungen schrieben, nur die Besetzung Hainans könne Waffentransporte verhindern. Henry forderte Paris auf, das Verbot des Waffentransits strikt durchzusetzen ${ }^{134}$.

Bei der Völkerbundtagung Mitte Mai bemühte sich Paris gegenüber Tokio um äußerste Zurückhaltung. Vor dem Treffen in Genf warnte die Sousdirection de la Société des nations im Quai d'Orsay, Wellington Koo werde die Mächte drängen, China zu helfen. Paris müsse eine Resolution anstreben, die lediglich diejenige des 5. Oktober 1937 bestätige. Ungehalten schrieb die Asienabteilung, China wolle den Völkerbund zwingen, erneut seine Ohnmacht zu zeigen. Doch kein Land - Frankreich schon gar nicht - wolle Risiken eingehen. Im Rat sagte Wellington Koo am 10. Mai, ihn enttäusche die Gleichgültigkeit der Mächte. Die Staaten hätten bisherige Resolutionen nicht angewandt. Er verlangte Maßnahmen gegen Japans Aggression ${ }^{135}$.

Koo ließ sich von der Forderung eines Wirtschaftsboykotts gegen Japan durch Franzosen und Briten abbringen. Im Gegenzug versprachen diese China öffentlich moralische Unterstützung für "seinen heroischen Kampf bei der Verteidigung seiner Unabhängigkeit und territorialen Integrität« und drückten Mitgefühl für die Leiden des chinesischen Volkes aus. Gemeinsam verhinderten Franzosen und Briten die Empfehlung, die Mitglieder sollten China die gleichen Konditionen beim Kauf, Transport und Transit von Waffen gewähren wie vor dem Konflikt. Beschlossen wurde die Aufforderung des Rates an die Mitglieder, alles ihnen Mögliche zu tun, um die früheren Entschließungen anzuwenden. Die Beschlußlage blieb damit unverändert. Als Zugeständnis an

\footnotetext{
${ }^{134}$ Botschaft Japan, Noten, 7.6., 9.6; Brévié an Mandel, T 473, 22.4.1938 (MAE Japon 126, CAOM FM 677); STS-bulletin, 1.5., Henry an Bonnet, T 228-31, 12.5.1938 (MAE Chine 533, SDN 364).

${ }^{135}$ Note de la sous-direction de la SDN, 22.4., note de la sous-direction d'Asie-Océanie pour le ministre, 23.4.1938 (MAE SDN 367; DDF IX, 224); SDN, $101^{\mathrm{e}}$ session du conseil, compte rendu de la deuxième séance, 10 mai 1938 (MAE Chine 661, JO-SDN 1938, S. 304f.).
} 
China verurteilte der Rat allgemein den Einsatz von Giftgas und forderte die Mächte auf, Informationen über den Gaseinsatz in China zu sammeln. Öffentlich sprach Bonnet dem Heroismus und der Opferbereitschaft des chinesischen Volkes Bewunderung aus. Frankreich habe Chinas Anstrengungen mit der Jacquinot-Schutzzone in Shanghai und die Beteiligung an der assistance sanitaire des Völkerbundes unterstützt. Hoppenot war mit der Ratstagung zufrieden, denn Paris hatte sich kaum exponiert. René Massigli war deprimiert. Durch die faktische Anerkennung der italienischen Herrschaft in Abessinien habe sich der Völkerbund mit dieser Sitzung aus der Geschichte verabschiedet. Paris und London zogen sich im Sommer 1938 politisch weiter aus dem Völkerbund zurück, wie auch Generalsekretär Avenol beklagte ${ }^{136}$.

Die Untersuchung, ob Japan Giftgas einsetzte, erbrachte nicht das von China erhoffte Ergebnis. Schon im Oktober 1937 hatten die Chinesen zwei Giftgaseinsätze durch Japan und die Vergiftung von 45 Soldaten beklagt. Britische und amerikanische Experten fanden jedoch keine Anzeichen für den Gebrauch von Gas. Im April 1938 meldete China, Japan setze biologische und chemische Kampfstoffe in der Provinz Shensi ein. Anfang Mai erklärte China, zwei Spezialeinheiten zur chemischen Kriegführung aus Japan seien auf dem Weg nach China. Dies führte zu der Völkerbundresolution vom 14. Mai. Paris und London vereinbarten, Informationen über Kampfgaseinsätze zu sammeln und später zu entscheiden, ob man die Berichte dem Völkerbund zuleite ${ }^{137}$.

Im August kamen von der Jangtse-Front neue Berichte, die von 19 Verletzten durch Senfgas, dann von zwei durch Kampfgas ausgelöschten Bataillonen und einem über zwei Wochen andauernden Gaseinsatz durch Japan sprachen. Vor dem Völkerbund erklärten die Chinesen am 5. September, sie hätten japanische Dokumente erbeutet, die systematischen Giftgasgebrauch bewiesen. Frankreichs Militärattaché Rousselle, der erst im Juni nach China gekommen war und sich seit Anfang August in der französischen Konzession in Hankou aufhielt, bezweifelte die Berichte, begab sich aber mit seinen britischen und amerikanischen Kollegen sowie einem französischen und einem britischen

\footnotetext{
${ }^{136}$ Note de la sous-direction d'Asie-Océanie, 24.5.1938 (MAE Papiers 1940, CabBonnet 3); Hoppenot an Léger, Note, 12.5., Arnal an Bonnet, T 84, 13.5.1938 (MAE Chine 661); $101^{\mathfrak{e}}$ session du conseil, $8^{e}$ séance, 14.5.1938 (JO-SDN, S. 359f.); Avenol an Walters, 11.5.1938 (MAE Fonds Avenol 1); Communiqué au conseil. Projet de résolution, C 192.1938.VII, 14.5.1938; Bonnet, discours en séance publique du conseil, 14.5.1938 (MAE SDN 367). Bonnets Rede ist abgedruckt in Albert MAYBON, Le conflit sino-japonais, in: L'Asie française 361, Bd. 38 (1938), S. 175-177; Massigli, Runderlaß, 31.5., Avenol an Bonnet, 3.9.1938 (MAE Chine 661; Papiers d'agents, Avenol 34).

${ }^{137}$ Requête Gvt. Chin., C.478.M.319.1937.VII, 14.10.1937 (MAE Chine 660); Intelligence Shanghai an War Office, 18.10., Military Intelligence, Memorandum, 23.10.1937 (FO 371/20958, F 8287/9/10; SD 793.94/10917); Lacoste an Naggiar, L, 2.4., Naggiar an Bonnet, T 614, 9.5.1938 (MAE Chine 721, 661); Appel du gouvernement chinois, C.166.M.93.1938.VIl, 9.5., Léger an Corbin, T 1363, 18.5., Corbin an Bonnet, T 1257, 24.5., Léger an Naggiar, T 240-42, 26.5.1938 (MAE SDN 364).
} 
Arzt dennoch am 4. September mit dem Auto in die betroffene, 120 Kilometer südöstlich von Hankou gelegene Region ${ }^{138}$. Zwei Tage später kehrte Rousselle schwer krank in die Stadt zurück. Zwei Tage nach seiner Rückkehr starb Rousselle in Hankou im Internationalen Krankenhaus an der Ruhr ${ }^{139}$.

Oberstleutnant Rousselle, der die Stadt ohne die Berichte vom Giftgaseinsatz nicht verlassen hätte, war nicht nur ein Opfer der Ruhr, sondern auch der chinesischen Propaganda geworden. Die Attachés fanden keine Giftgasspuren. Chinas Beweise waren auffällig dünn: Das angeblich ausgelöschte Bataillon reduzierte sich auf einen Soldaten. Selbst bei ihm fanden Dr. Henry Gourmelon von der Francis Garnier und Surgeon Lieutenant Hamilton von der HMS Falcon keine Hinweise auf Gas. Beim zweiten Fall wurde aus vier $\gg v e r-$ seuchten« Militärs ein gesunder Soldat, der dritte von China genannte Sachverhalt betraf erneut den ersten Fall. Nach Rousselles fataler Reise an den Jangtse brachen die Berichte über Giftgaseinsätze ab. Die von China präsentierten japanischen Dokumente waren nichtssagend ${ }^{140}$. Sehr wahrscheinlich setzte Japan, zumindest bis zum Sommer 1940, kein Giftgas ein ${ }^{141}$.

${ }^{138}$ Lagarde an Lacoste, L 116, 12.8., Naggiar an Colin, T 47-49, 28.8., Colin an Naggiar, T 133-34, 30.8., T 151, 5.9., communication de la délégation chinoise, C.251.M.149.1938.VIII, 5.8.; C.271.M.164.1938.VII, 24.8., Massigli an Naggiar, T 450, 27.8., Naggiar an Bonnet, T 1209-10, 29.8.1938 (MAEN Pékin A 600, MAE Chine 726); Communications de la délégation chinoise, C.283.M.171.1938.VII., 5.9., C.340.M.206.1938.VII, 24.9.; Appell du gouvernement chinois, C.349.1938.VII, 29.9.1938 (MAE SDN 364, 367). Guillermaz bezeichnet seinen Kollegen als eine der stärksten Persönlichkeiten des französischen Generalstabes (Une vie pour la Chine, S. 31 ).

${ }^{139}$ Colin an Naggiar, T 156, 6.9, T 165, 7.9., T 166-67, 8.9., Naggiar an Bonnet, T 1267, T 1274, 8.9., Lacoste an Naggiar, L 521, 16.9.1938; Perretier an Knobel, L 281, 26.1.1939 (MAEN Pékin A 346, 600); Rapport du capitaine Chauveau, Hankou, 14.9., Guillermaz, 17.9.1938 (SHAT 7 N 3291).

${ }^{140}$ Colin an Naggiar, T 168-69, 9.9., Naggiar an Bonnet, T 1277, 10.9.1938 (MAEN Pékin A 600, MAE Chine 661); $103^{\mathrm{e}}$ session du conseil, $2^{\circ}$ séance, 30.9.1938 (JO-SDN, S. 869ff.); Admirality an Halifax, 12.1.; SEH, renseignement 850, 25.5.1939 (FO 371/23470, F 398/149/10; CAOM CM 92); Clark Kerr an Halifax, 24.5., War Office an Eden, 13.8.1940 (FO 371/24692, F 3638, F 3806/247/10).

${ }^{141}$ Überzeugt vom Einsatz chemischer Waffen an der chinesischen Front äußert sich lediglich ISHIDA (Der »totale Krieg«, S. 438, Fußnote 27). Der US-Vize-Militärattaché DORN glaubt, angesichts seiner Überlegenheit habe Japan den Einsatz von Gas nicht notwendig gehabt (The Sino-Japanese War, S. 234). WILSONS Berichte über japanische Einheiten zur chemischen Kriegführung und vor Hankou getötete Regimenter (When Tigers Fight, S. 125-126, S. 128) beruhen wohl allein auf den falschen Angaben der chinesischen Regienung. ELPHICK äußert, es habe Berichte über den Einsatz von Giftgas in China gegeben (Far Eastern File, S. 235). Gerhard L. WEINBERG schreibt, Japan habe Gas gegen China eingesetzt, wobei es, vor allem bis 1941 , zu mehreren tausend Toten gekommen sei. Die Frage müsse aber weiter untersucht werden (A World at Arms. A Global History of World War II, Cambridge 1994, S. 59). Peter WILLIAMS und David WALLACE behaupten, im Mai 1929 sei auf der Okuno-Insel bei Hiroshima im Tadami Army Arsenal die Produktion von Senfgas aufgenommen worden. Die Hauptfabrik und die Ausrüstung hätten aus Frankreich gestammt, ab 1933/34 seien diese Waffen getestet worden. Im Nomonhan-Konflikt 1939 gegen die Sowjets und 1940 gegen China seien biologische Waffen eingesetzt worden (Unit 731. Japan's Secret Biological Warfare in World War II, New York 1989, S. 32f.). Vom Einsatz chemischer Waffen ist in ihrem Buch nicht die Rede. Auch Gordon DANIELS schreibt nur vom Einsatz biologischer Waffen (Japan at War, in: Richard BowRING, Peter KORNICKI [Hg.], The Cambridge Encyclopedia of Japan, Cambridge u.a. 1993, S. 95-105 [S. 97]). 
Ende Mai 1938 schwoll die Pressekampagne gegen Frankreich an. Einige japanische Zeitungen schrieben, Frankreich unterstütze China umfassend: Nach Abzug der deutschen Militärmission habe Chiang Kai-shek fünf französische Offiziere engagiert, Haiphong sei wichtiger Umschlagplatz für den Waffentransit nach China, und die Bahnlinie Langson-Nanning werde gebaut, um China mit Waffen zu versorgen. Die Zeitschrift »Kaizo« schrieb, in Indochina mißhandelten Franzosen Einheimische; die Japaner in Indochina glaubten, daß ein Tag ausreiche, um Indochina zu besetzen. Andere Zeitungen forderten die Besetzung Hainans. Botschafter Sugimura beschwerte sich persönlich bei Bonnet über den Bau der Nanning-Bahn. Henry warnte, die Gefahr einer japanischen Okkupation Hainans sei noch nie so groß gewesen. Japanische Offiziere wollten mit der Kampagne die Expansion in den Süden durchsetzen. Léger fürchtete, Japan wolle sich der Zusicherung entledigen, Hainan nicht zu besetzen. Als Schritt, um eine Besetzung zu verhindern, erwog Léger, einen Teil der Insel unter französischen Schutz zu stellen. Paris wies die Vorwürfe zurück: Man halte die Transitregeln genau ein. Der Bau der Bahnlinie Langson-Nanning, die für Waffentransporte gesperrt bleibe, sei schon vor Konfliktbeginn beschlossen worden. In Chinas Dienste getreten seien nur französische Zivilpiloten, auf die Paris keinen Einfluß habe. Léger erklärte Tokio, falls Japan eine antifranzösische Haltung einnehme, könne Paris seine Transitpolitik revidieren. Henry beteuerte im Gaimusho Frankreichs Aufrichtigkeit. Nun stoppten die Attacken zunächst ${ }^{142}$.

Das plötzlich An- und Abschwellen der Kampagne deutet darauf hin, daß sie von der Regierung orchestriert wurde. Das Innenministerium in Tokio besaß nach dem "Gesetz zur Friedenserhaltung" von 1925 das Recht zur Zensur. Doch auch Japans Presse hatte ein Interesse daran, patriotisches Feuer (gegen welchen Gegner auch immer) zu schüren und martialische Berichte zu veröffentlichen, weil dies die Auflage in die Höhe trieb ${ }^{143}$.

Henry beteuerte am 9. Juni gegenüber Außenminister Ugaki, Frankreichs Politik sei nicht nur korrekt, sondern freundschaftlich, solange Japan seine Haltung nicht ändere. Ugaki erwiderte, derzeit habe Japan keine Absicht, Hainan zu besetzen. Er glaube den französischen Erklärungen. Der General schlug vor, Japaner sollten sich in Indochina umsehen, damit sie die Öffentlichkeit von Frankreichs Position überzeugen könnten. Henry protestierte: Dies gleiche einer Untersuchungskommission. Zudem müsse derjenige die Behauptungen

${ }^{142}$ Henry an Bonnet, T 247-52, 30.5., T 253, 31.5., L 76, 30.5., T 259, 1.6., Léger an Henry, T 15860, 1.6., T 161-63, 2.6.1938 (DDF IX, 478, 487, 496; MAE Japon 126, Chine 723; DDF IX, 506); Havas Tokio, un avertissement à la France, 31.5., Lacoste an Naggiar, L 374, 2.6.1938 (MAE Japon 126); Léger an Naggiar, T 247-48, 31.5., Léger an Corbin, T 1631-38, 31.5.1938 (MAE Chine 723).

${ }^{143}$ Louise Young, Japan's Wartime Empire in China, Vortrag, Münchenwiler Confer. ") The Shadows of Total War. Europe, East Asia and the United States, 1919-1939«, August 1999, S. 1-21 (S. 6f.). 
beweisen, der sie aufstelle. Bisherige Vorwürfe seien nie belegt worden. Um den Konflikt über die Nanning-Bahn zu entschärfen, regte Ugaki an, die Arbeiten bis Kriegsende zu unterbrechen. Nach dem 90-minütigen Gespräch gewann Henry den Eindruck, daß Ugaki sich um Entspannung bemühe. Doch drei Tage später flaute die Kampagne wieder auf: Nun wurde verbreitet, zwischen Frankreich und China gebe es ein Geheimabkommen zur Waffenversorgung Chinas und zur gemeinsamen Verteidigung Hainans ${ }^{144}$.

Charles-Arsène Henry glaubte, die neuen Meldungen habe China lanciert, um Paris in eine Lage zu manövrieren, in der es seine Neutralität aufgebe. Im Gaimusho erklärte der Botschafter, China wolle Tokio und Paris gegeneinander aufbringen. Wenn Frankreich trotz seiner freundschaftlichen Haltung des Transits beschuldigt werde, müsse es sich überlegen, ob es nicht besser tatsächlich Waffentransporte durch Indochina erlaube. Nach Paris meldete er, Teile der Armee und die Marine, die den Krieg nach Südchina ausdehnen wollten, nähmen die Gerüchte begierig auf. Nach Auffassung von Havas wolle Japans Militär mit den Attacken auf Frankreich den Eindruck vermitteln, daß Chinas Widerstand nur wegen der ausländischen Hilfe andauere. Da Tokio keinen Streit mit Moskau und London wolle, bleibe Paris als Zielscheibe. Tokio wolle zudem Spielraum erhalten, um vielleicht doch Hainan zu besetzen. Der Generalstab der Armee in Paris nahm an, das Ablenken von eigenen Mißerfolgen sei Hauptgrund der antifranzösischen Kampagne ${ }^{145}$. Vermutlich spielten alle Faktoren für die Angriffe eine Rolle.

Eine neue Attacke begann, obwohl Paris über die Agentur Havas Tokio Friedenssignale gesandt hatte: Havas meldete, Frankreich widersetze sich der japanischen Durchdringung Nordchinas nicht. Dies sorgte selbst bei den Briten für besorgte Nachfragen, doch die japanische Presse ließ sich nicht beruhigen: Alle Zeitungen Shanghais gaben am 16. Juni die Domei-Meldung wieder, französische Kriegsschiffe brächten Waffen nach China. Wenn Frankreich seine Unterstützung für China nicht einstelle, werde Hainan besetzt. Ugaki setzte sich nun selbst an die Spitze der Kampagne. Der Minister erklärte öffentlich, durch die Unterstützung Chinas verschlechterte Frankreich sein Verhältnis zu Japan. Er denke trotz aller französischen Dementis an das Sprichwort "Wo Rauch ist, da ist auch Feuer«. Léger beschwerte sich, daß Paris, das eine strikte Neutralität verfolge, angegriffen werde, während

\footnotetext{
${ }^{144}$ Henry an Bonnet, T 270-75, 10.6., T 279, 14.6.1938 (DDF X,1; MAE Japon 126); Naggiar (Hongkong) an Bonnet, T 29, 13.6., François-Poncet an Bonnet, T 2474, 15.6.1938 (MAE Chine 724); Thiébaut an EMA.2, L 67, 14.6., Léger an Henry, T 178-79, 14.6.1938 (SHAT 7 N 3331, DDF X, 22).

${ }^{145}$ Henry an Bonnet, T 281-83, 16.6., T 284-88, 16.6., T 289, T 290-91, 17.6.1938 (DDF X, 35; MAE Chine 724, SDN 364, Japon 127); Havas Tokio, les attaques de la presse japonaise, 16.6.1938 (MAE Japon 126); STS-bulletin, 1.6., Knobel an Bonnet, T 766, 8.6.1938 (MAE Chine 533, 723); Colonies, bulletin de renseignement, 15.5., EMA.2, rapport, 20.6.1938 (SHAT 11 H 76, 7 N 2515).
} 
Moskau und London China unterstützten und dafür von Ugaki mit Freundschaftsbeteuerungen belohnt würden. Henry solle Ugaki mit der Aufhebung des Transitverbots drohen. Bevor Henry dies tun konnte, warf Ugaki Frankreich am 18. Juni offentlich vor, es ermutige Chinas Widerstand gegen Japan. Japanische Zeitungen berichteten, Naggiar habe China Waffenlieferungen und Militärberater versprochen. Zwei Tage später forderte Ugaki, in Indochina müsse der Waffenschmuggel untersucht werden, ehe er eine Ehrenerklärung für Frankreich abgeben könne. Henry schloß nicht mehr aus, daß Japan Hainan angreife, zumal ein Sprecher des Gaimusho erklärte, über die Besetzung der Insel entscheide allein die Marine. Eine zeitweilige Okkupation verstoße nicht gegen den Vertrag von 1907. Seit dem 17. Juni häuften sich die Meldungen über den Beschuß der Inselhauptstadt Hoihao durch japanische Flugzeuge und Schiffe. Am 19. Juni versuchten 40 japanische Matrosen, unter dem Schutz von Schiffsartillerie in Schaluppen auf Hainan zu landen ${ }^{146}$.

Die Asienabteilung hielt die Besetzung der Insel für denkbar. Die Bedrohung existiere, so Hoppenot, auch wenn Japan vielleicht nur bluffe. Bonnet wollte die USA bitten, sich in Tokio für die Sicherheit Hainans einzusetzen. Auf Anraten Hoppenots, der Anfragen in Washington für nutzlos hielt, bat er aber zunächst nur die Briten um Hilfe. Am 21. Juni informierte Bonnet dann doch Bullitt über Indochinas bedrohliche Lage und regte in London an, Hainan, zumindest an zwei oder drei Punkten, wie es einschränkend einen Tag später hieß, präventiv durch französische und britische Truppen zu besetzen. Bonnet erklärte, diplomatische Demarchen reichten nicht mehr, um ein japanisches fait accompli abzuwenden. Die Situation spitzte sich zu, als Tokio am 21. Juni erklärte, Hainan gehöre zur Kampfzone. Henry nahm an, Japan werde nun früher oder später Hainan besetzen. Während der Marine-Geheimdienst am Folgetag schrieb, Japans Kräfte reichten für den Angriff auf Hainan nicht aus, meldete Henry, ein Informant habe ihm neue Gerüchte über die Besetzung Hainans zugetragen ${ }^{147}$.

Mitten in der höchsten Spannung stoppte die Pressekampagne plötzlich. Selbst als Chinas Oberster Verteidigungsrat Paris öffentlich für die tatkräftige

\footnotetext{
${ }^{146}$ Knobel an Bonnet, T 814, 17.6., T 821, 20.6., Jankélévitch an Bonnet, T, 19.6.1938 (MAE Chine 724); FNEO an EMG.2, T 6565-67, 16.6.1938 (SHM 1 BB9 39); Marine EMG.2 an Diplomatie, T 4005, 18.6.1938 (MAE Japon 127); Léger an Henry, T 182-85, 18.6., Henty an Bonnet, T 293-99, 19.6., T 302-7, 20.6.1938 (DDF X, 50, 56, 60); Brévié an Mandel, T 626, T 702, 19.6., T 710, 20.6., T 716, 22.6., T 740, 27.6.1938 (CAOM FM 678); Diplomatie an EMG.2, T 112, 18.6., T 114, 20.6., T 116, 21.6.1938 (SHM 1 BB9 39). Militärattaché Rousselle urteilte, Japan sei nicht fähig, Hainan überraschend anzugreifen (Rousselle, Note, 20.6.1938, SHAT 7 N 3290).

${ }^{147}$ Notes de la sous-direction d'Asie-Océanie [I und II], 20.6.1938 (MAE Chine 724, Japon 127); Bullitt an Hull, 21.6.1938 (SD 793.94/13280); Bonnet an Corbin, T 1904-8, 21.6., compte rendu, réunion du 22-6-1938 (DDF X, 64, 73); Léger an Henry, T 188, 22.6., Henry an Bonnet, T 308-9, 21.6., T 325-27, 22.6., STS an EMG.2, T 1478-79, 22.6.1938 (MAE Chine 724, 676; SHM 1BB9 39).
} 
Hilfe dankte, nutzte dies nur eine Zeitung zum Angriff auf Frankreich. Grund der Unterbrechung der Kampagne war der Ausbruch eines schweren Fischereistreites mit Moskau. In London war Frankreichs Initiative zur Besetzung Hainans verpufft. Staatssekretär Richard Austen Butler warnte Tokio jedoch im Unterhaus, eine japanische Besetzung Hainans werde zu Komplikationen führen. Großbritannien und Frankreich würden einander dann so unterstützen, wie es die Situation erfordere ${ }^{148}$.

Eine Woche nach der Unterbrechung lebte die Pressekampagne wieder auf. Diesmal wurde Henry signalisiert, der Bau der Bahnlinie nach Nanning bereite Japan die größten Sorgen. Viele Zeitungen in Indochina warnten vor einer japanischen Besetzung Hainans und Indochinas. Auch Konteradmiral Petit, Chef der Marine in Indochina, zeigte sich gegenüber US-Vizekonsul Palmer bedrückt über die Drohungen. Als sich die am 21. Juni von Ugaki vorgelegte Liste angeblicher Transporte durch Indochina als völlig haltlos herausstellte, konterten Léger und Bonnet: Weitere ungerechtfertigte Beschuldigungen seien mit der französischen Würde unvereinbar, telegraphierte Bonnet am 29. Juni seinem Botschafter in Tokio, der dies dem Außenminister persönlich sagen solle. Falls Tokio weiter öffentlich Mißtrauen äußere, werde die französische Regierung Konsequenzen ziehen. Was dies meinte, ließ Bonnet offen. Für einen Moment schien sich die Lage zu entspannen, als Ugaki dem britischen Botschafter versicherte, die Besetzung Hainans sei »jetzt nicht geplant $\ll$. Diese Aussage besaß nach Henrys Ansicht immerhin »einen gewissen Wert«.

Als Henry Ugaki am 3. Juli aufsuchte, zeigte sich der Außenminister aber angriffslustig wie selten. Ugaki klagte, ständig kämen neue Nachrichten über den Transit durch Indochina. Indochina solle japanische Beobachter zulassen und den Bau der Nanning-Bahn aufgeben. Auf Henrys Drohung, falls die Kampagne andauere, müsse Paris den Transit erlauben, erwiderte Ugaki, dann untersuche auch er, wie er reagiere. Henry mahnte Paris, auf keinen Fall das Transitverbot aufzuheben. Der Botschafter und der französische ArmeeGeneralstab fürchteten, ein Angriff auf Hainan werde vorbereite ${ }^{149}$.

Die deutschen Diplomaten in Tokio gewannen den Eindruck, Frankreich sei zum »Hauptfeind Nummer Eins« geworden. Der Waffentransit sei aber kein ausreichender Grund für die Angriffe. Geschäftsträger Kolb glaubte, daß die

\footnotetext{
${ }^{148}$ Henry an Bonnet, T, 22.6., T 328-31, 24.6.1938 (MAEN Londres C 486; DDF X, 87); Léger an Naggiar, T 293, 23.6., Naggiar an Bonnet, T 885-86, 30.6.1938 (MAE Japon 127); Grew an Hull, 28.6.1938 (FRUS 1938, III, S. 207); New York Times, London and Paris to Protect Hainan, Wam Tokyo to Keep Hands off Chinese Island Opposite French Indo-China, 28.6.1938.

${ }_{149}^{14}$ Henry an Bonnet, T 339-40, 28.6.1938 (MAE Japon 127); Palmer (Saigon) an Hull, 29.6.1938 (SD 793.94/13510); Bonnet an Henry, T 192-97, 29.6.1938 (DDF X, 112, MAE SDN 364); Grew an Hull, 28.6.1938 (FRUS 1938, III, S. 207); Henry an Bonnet, T 341-43, 30.6., T 347-53, 3.7.1938 (MAE SDN 366; DDF X, 139); EMA.2, 8.7.1938 (SHAT 7 N 2515).
} 
japanische Regierung mit der antifranzösischen Kampagne Frankreich die Ausdehnung seiner Einflußzone in Südchina verleiden und die Bevölkerung auf die Besetzung Hainans vorbereiten wolle. Mit den Drohungen gegen Paris wolle Tokio auch die anderen Mächte einschüchtern. Nach der Auffassung des US-Botschafters Joseph Grew bewiesen die Angriffe auf Frankreich, wie blank die Nerven in Japan lagen, weil die Kriegsanstrengungen größer wurden als gedacht. Nach Henrys Gespräch mit Ugaki ebbten die Angriffe auf Paris ab. Die Asienabteilung führt dies auf Henrys Erklärung und das gemeinsame Auftreten mit den Briten zurück, mit denen Ugaki einen modus vivendi suchte.

Entscheidend für Japans Zurückhaltung war aber wohl, daß sich ein schwerer sowjetisch-japanischer Grenzkonflikt entwickelte. Tokio wollte nicht auch noch Paris gegen sich aufbringen, wie Japans Generalkonsul in Hanoi seinem deutschen Kollegen erklärte. Am 15. Juli schrieb die Zeitung des Außenministeriums »Japan Times « in einem Leitartikel, Frankreich und Japan hätten Interesse an einer Verständigung. Als versöhnliches Zeichen suchte der Abgeordnete Shinohara, begleitet vom frankophilen Oberst Kobayashi, Henry auf, um einen zehntägigen Besuch in Frankreich zu vereinbaren ${ }^{150}$.

Mitte August forderten einzelne Zeitungen erneut die Besetzung Hainans, aber der japanische Abgeordnete Inouye Kyoshiro schrieb in Domei, in Indochina werde weniger Kriegsmaterial transportiert, als man glaube. In Shanghai erklärte ein hoher japanischer Beamter Naggiar, die Pressekampagne habe nur innenpolitische Ziele gehabt. Das Militär wisse, daß China über Hongkong, nicht über Haiphong versorgt werde. Die Franzosen seien für Japan weit ungefährlicher als die Sowjets, die Amerikaner oder die Briten. Alle Informationen in Paris deuteten darauf hin, daß Tokio so tief in den Krieg in China verwickelt war, daß es weder Hainan noch Indochina angreifen konnte. Naggiar urteilte, der Krieg werde für Japan zur Tragödie. Tokio wolle deshalb die Beziehungen zum Westen und zur Sowjetunion verbessern ${ }^{151}$.

$\mathrm{Zu}$ diesem Zeitpunkt bekriegten sich japanische und russische Truppen. Schwere Gefechte an der mandschurisch-sowjetischen Grenze, nahe der Grenze zu Korea, beschäftigten im Juli und August 1938 die Weltöffentlichkeit. Im Konflikt um den 149 Meter hohen Hügel von Changkufeng standen sich 12 japanische und 27 sowjetische Bataillone, insgesamt 40000 Mann,

\footnotetext{
${ }^{150}$ Kolb an Ribbentrop, 5.7., Grew an Hull, 11.7.1938 (AA Botsch Paris 444b 4; FRUS 1938, III, S. 218f.); Kolb an Ribbentrop, 13.7., Neumann an Ribbentrop, 15.7.1938 (AA Pol VIII 59 1); Note de la sous-direction d'Asie-Océanie, 19.7., Henry an Bonnet, T 384, T 385, 17.7.1938 (MAE Chine 747, Chine 725, Japon 127); EMG.2, bulletin de renseignement $n^{\circ} 39,10.8 .1938$ (SHM 1BB2 92).

ISI Thiébaut an EMA.2, L 94, 15.8.1938 (SHAT 7 N 3331); Domei, Hongkong, 20.8.1938 (MAE Japon 127); Naggiar an Bonnet, T 950-52, 9.7., T 1040-44, 26.7., T 1045-49, 27.7.1938 (MAE Chine 725; DDF X, 265, 277); Henry an Bonnet, T 372, 8.7.1938 (DDF X, 164); Saint-Quentin an Bonnet, T 682, 8.7.1938 (MAE Chine 725); Bullitt an Hull, 26.7.1938 (SD 740.00/430).
} 
100 Flugzeuge und 200 Panzer gegenüber ${ }^{152}$. Der Konflikt begann, als der Fernost-Kommandeur des Geheimdienstes NKWD Lyushkow zu den Japanern flüchtete. Um das Überlaufen weiterer Soldaten zu verhindern, besetzten die Sowjets vom 9. bis 13. Juli den umstrittenen Hügel. Ab 15. Juli gingen in Paris Meldungen über Zusammenstöße an der Grenze ein. Frankreichs Diplomaten in Asien und Bonnet glaubten, daß Japans Armee den Konflikt mit Moskau begrenzen wolle. Der Marine-Geheimdienst in Shanghai und der Generalstab in Paris nahmen an, Tokio wolle Moskau Widerstand testen ${ }^{153}$.

Nach den ab 1. August eingehenden Berichten von den Gefechten, die von 100 und 200 Toten sprachen, kam Charvériat zu dem Urteil, der Grenzkonflikt habe nur lokalen Charakter. Von den Konsuln in der Mandschurei, dem Militär in Tientsin sowie den Botschaften in Tokio, Shanghai und Moskau ließ sich Bonnet genau informieren, denn der Ausbruch größerer Kämpfe hätte das Gleichgewicht in Europa gestört. Als sich von beiden Seiten Divisionen auf die Front zubewegten, wurde Paris nervös: Bonnet warnte den Generalstab, die Sowjetunion müsse derzeit starke Verbände am Pazifik zurückhalten. Er bestellte Botschafter Suritz ein, um die Sowjets zur Zurückhaltung aufzufordern, und intervenierte bei Zeitungen, die Moskaus Friedfertigkeit anzweifelten. Als es am 11. August zum Waffenstillstand kam, zeigte Bonnet seine Erleichterung: Er ließ Litwinow persönlich gratulieren ${ }^{154}$.

Massigli in Paris, Botschafter Coulondre, sein Vertreter Payart und Militärattaché Oberst Palasse in Moskau sowie Fregattenkapitän Robbe, der Chef des Marine-Geheimdienstes in Shanghai, bewerteten den Ausgang als Moskauer Erfolg, denn die Sowjets behaupteten ihre Geländegewinne. Für Henry zeigte die Schlacht die Erschöpfung der japanischen Truppen. Tokio werde sich nun gegenüber Moskau zurückhalten. Coulondre schrieb später, die Schlacht habe dem Kreml demonstriert, daß er im Osten nichts zu befürchten

\footnotetext{
${ }^{152}$ Alvin D. Coox, The Anatomy of a Small War: The Soviet-Japanese Struggle for Changkufeng/Khasan 1938, Westport, London 1977, S. 14, S. 27, S. 92, S. 324, S. 370; O. Edmund CLUBB, Conflict in the Chinese Borderlands, 1917-1950, in: Raymond GARTHOFF (Hg.), Sino-Soviet Military Relations, New York, Washington, London 1966, S. 9-43 (S. 30f.).

${ }^{153}$ Leurquin an Bonnet, L 89, 1.7., Henry an Bonnet, T 356-57, 2.7., T 396, 22.7., Germain an Naggiar, L 86, 5.7.; Coulondre an Bonnet, T 349-51, 16.7., T 553, 18.7., T 567-72, 22.7., Lépissier an Bonnet, T 88, 23.7.1938 (MAE Japon 146); Henry an Bonnet, T 386-92, 20.7., Naggiar an Bonnet, T 1025-28, 21.7., Coulondre an Bonnet, T 574-76, 25.7., T 581-86, 31.7., T 592-94, 2.8.1938 (DDF $\mathrm{X}, 232,243,262,308,314$ ); Bullitt an Hull, 26.7.1938 (SD 740.00/430); Exposé du ministre au Conseil du 29 juillet 1938 (MAE Papiers 1940, cabinet Bonnet 3); EMG.2 an Diplomatie, T 4918, 23.7., STS-bulletin, 1.8.1938 (MAE Chine 725, 533).

${ }_{154}$ Coulondre an Bonnet, T 589-91, 1.8., Fain an Bonnet, T 418-19, T 416, 2.8., 3.8.; Naggiar an Bonnet, T 1095-97, 4.8., T 1123-24, 8.8., Lacoste an Bonnet, T 83, 4.8., Militärattaché London, Note, 4.8.1938 (MAE Japon 146, 147); Compte rendu, liaison hebdomadaire, 3.8., Militär Tientsin an Mandel, T 662, 3.8.1938 (SHAT 7 N 2525, 11 H 60); Diplomatie an EMG.2, T 143, 5.8., Bullitt an Hull, 5.8., Bonnet an Coulondre, T 486-87, 11.8 .1938 (SHM 1 BB9 40, SD 760f.62/544, DDF X, 358).
} 
habe. Das französische Militär in Asien schloß einhellig, im Fall eines Krieges in Europa werde Japan die Sowjetunion wahrscheinlich nicht angreifen ${ }^{155}$.

Chinas Regierung wollte den Grenzkonflikt nutzen, um mit Japan Frieden zu schließen. Wie Naggiar am 9. August erfuhr, erwog Chiang Kai-shek Englands, Amerikas, womöglich auch Frankreichs Regierung zu bitten, in Tokio zu sondieren. Naggiar hielt die Friedenschancen für gering, empfahl aber offiziöse Demarchen, da sich Chiang sonst an Moskau, Berlin oder Rom wende, Paris aber die prowestlichen Kräfte in Chinas Regierung stärken müsse.

Weil die Briten ihre Sondierungen geheim hielten, empörte sich Paris. Als Bonnet am 10. August nachfragte, bestritt der britische Geschäftsträger Sir Ronald Campbell jede Kenntnis des Vorgangs, klagte dann aber im Foreign Office, die britische Politik werde vor den Franzosen geheim gehalten, selbst wenn die Fakten am Folgetag in der "Times« stünden. London teilte Paris nun mit, Ugaki habe Craigie Ende Juni und Ende Juli angedeutet, Gespräche mit Chiang seien möglich. London müsse in Tokio aber allein sondieren, weil Japan ein gemeinsames Vorgehen des Westens als Druck ansehe ${ }^{156}$.

Massigli, Naggiar und Henry fürchteten, daß China mit der Vermittlung die Mächte in den Konflikt hineinziehen wolle. Als Washington Schlichtungsversuche ablehnte, beschränkte sich Craigie gegenüber Ugaki auf den Hinweis, daß Premierminister Chamberlain britische Vermittlung angeboten habe. $\mathrm{Zu}$ Bonnets Befriedigung stellten die Briten weitere Bemühungen ein ${ }^{157}$. Tokio führte von Juni bis Dezember 1938 mit Chinas Finanzminister H.H. Kung über Mittelsmänner und mit Wissen Chiangs erfolglose Friedensgespräche ${ }^{158}$.

${ }^{155}$ Compte rendu de la liaison hebdomadaire, 17.8., Coulondre an Bonnet, T 624-26, 13.8.1938 (DDF X, 398, 377); Payart an Bonnet, L 240, 24.8.1938 (MAE Japon 148); Palasse an EMA.2, D 493, 21.8., Henry an Bonnet, T 434-40, 15.8.1938 (DDF X, 430, 383); STS-bulletin, 1.9.1938 (MAE Chine 534); Craigie an Halifax, 15.9.1938 (DBFP, $3^{\text {rd }}$ series, VIII, 97); Robert CoULONDRE, Von Moskau nach Berlin, 1936-1939. Erinnerungen des französischen Botschafters, Bonn 1950, S. 203; STS an EMG.2, T 1516, 30.9.1938 (SHM 1 BB9 41); STS-bulletin, 1.10.1938 (MAE Chine 534).

${ }^{156}$ Naggiar an Bonnet, T 1130-37, 9.8.1938 (DDF X, 341); Naggiar an Bonnet, T 1145, 13.8., Massigli an Naggiar, T 421, 11.8., Truelle an Bonnet, T 816-17, 13.8., Corbin an Bonnet, T 1876-77, 26.7.1938 (MAE Chine 726, SDN 364); Campbell an Sargent, 11.8., Mallet an Campbell, 20.8.1938 (FO 371/21592, C 8578/13/17); Cambon an Bonnet, T 2007-10, 13.8.1938 (DDF X, 374); Campbell an Halifax, 13.8.1938 (DBFP, $3^{\text {rd }}$ series, VIII, 17); Massigli, Note, 14.8.1938 (MAE Chine 726).

${ }^{157}$ Massigli an Henry, T 265-70, 14.8., Henry an Bonnet, T 444-49, 16.8.1938 (DDF X, 381, 394); Naggiar an Bonnet, T 1160-62, T 1175-78, 16.8., 19.8., Massigli an Corbin T 2582, Saint-Quentin T, Henry T, Naggiar T, 16.8., Massigli an Naggiar, T 444, 22.8.1938 (MAE Chine 726); Campbell an Halifax, 16.8., Halifax an Campbell, 18.8.1938 (DBFP, $3^{\text {rd }}$ series, VIII, 26, 34).

${ }^{158}$ Sino-Japanese Peace Talks June-September, 1938. Extracts from the Diary of General Ugaki, translated by Commander E.H.M. Colegrave, in: G[eoffrey] F[rancis] HUDSON, Far Eastern Affairs, No. 1. St. Anthony's Papers No. II, London 1957, S. 94-103; BARNHART, Japan and the World, S. 117; SuN, China and the Origins, S. 103. 


\subsection{Keine Kraftprobe um die Paracels und die Spratlys}

Der neue Kolonialminister Georges Mandel drückte der französischen Politik in den beiden Archipelen Paracels und Spratlys schnell und energisch seinen Stempel auf. Sein wichtigster Gegenspieler wurde - die französische Marine.

In der Fortsetzung früherer Bitten bat London die Franzosen Mitte April 1938, ihre Souveränität über die Inseln effektiver auszuüben, etwa durch die Besiedlung der Inseln. Den Plan, auf den Spratlys einen Flugplatz zu errichten, verfolgte London nicht mehr, als sich die mangelnde Eignung der kleinen Sandinseln zeigte. Französische Experten hielten die Schaffung eines Flugplatzes für möglich, aber für so teuer und die Inseln für so schwer zu verteidigen, daß Brévié die Anlage ablehnte. Als London sich nicht mehr um einen Flugplatz bemühte, sank auch in Paris das Interesse an dem Projekt ${ }^{159}$.

Am 4. Mai 1938 forderte Bonnet Mandel auf, Einheimische auf den Spratlys anzusiedeln und den Bau des Flugplatzes voranzutreiben. Da die französische Regierung aus Gründen der Souveränität und des Prestiges ein britisches Engagement auf der Inselgruppe abgelehnt habe, müsse sie jetzt handeln. Mandel stellte mit Billigung des Quai d'Orsay aber das Flugplatz-Projekt ein und betrieb dafür energisch die Ansiedlung von Vietnamesen auf den Spratlys. Als die Stabschefs der Streitkräfte vor der Präsenz japanischer Siedler auf den Inseln warnten, erhöhte Mandel sein Engagement: Bereits am Folgetag wies er Brévié an, sofort einen Beamten zu den Spratlys zu schicken. Die Marine bat er, den Beamten dorthin zu bringen. Innerhalb einer Woche stellte Brévié eine Mission aus einem Beamten, einem Offizier und einigen Polizisten zusammen. Der Transport könne durch den Bojenleger Armand Rousseau erfolgen, die Präsenz eines Kriegsschiffes bei der Landung sei aber unverzichtbar ${ }^{160}$.

Gegen Mandels Auftrag protestierte der Chef der Flottille in Indochina, Konteradmiral Petit, der jedes Engagement auf den Inselgruppen ablehnte. Er schrieb, schon in den Paracels, die näher an Indochina lägen und deshalb wichtiger seien, schade die Entsendung von Kriegsschiffen, denn einer eventuellen Konfrontation mit Japan müsse die Marine ausweichen. Sie verliere dann ihr Gesicht, Frankreichs Prestige in Asien leide. Um auf den weniger wichtigen Spratlys einen Konflikt mit Japan zu vermeiden, solle man die Inseln an

\footnotetext{
159 Note de la sous-direction d'Asie-Océanie, 25.4.1938 (MAE Chine 751); Halifax an Phipps, 14.4., Phipps an Massigli, aide-mémoire, 25.4, Report, Committee of Imperial Defence, 6.7 .1938 (FO 371/22175, F 3819, 4430, 4231/956/61); Ronald, Memerandum (FO 371/22176, F 4727/4727/61); HMS Herald, Report, 18.4., Rochat, Note, 19.4., Brévié an Mandel, L 2304, 13.5.1938 (MAE Chine 750, 751). ${ }^{160}$ Bonnet an Mandel L 617, 4.5., Mandel an Bonnet, L 669, 5.5., Brévié an Mandel, L 2304, 13.5.; Compte rendu, 4.5., note de la sous-direction d'Asie-Océanie, 28.5.1938 (MAE Chine 751; DDF IX, 278, 473); Mandel an Brévié, T 350, 5.5., Brévié an Mandel, T 598, 21.5.1938 (CAOM FM 672, 678).
} 
England abtreten! Vize-Admiral Le Bigot unterstützte Petit, indem er in Paris erstmals Anweisungen für den Fall einer Konfrontation mit Japan erbat.

Der für die Besiedlung der Spratlys verantwortliche Gouverneur Cochinchinas warnte, bei einer Besetzung müsse man den japanischen Fischern Flagge, Funkgerät und Waffen abnehmen, was zu Zwischenfällen führen könne. Die kleine vietnamesische Gruppe könne zudem jederzeit Opfer eines japanischen Handstreichs werden. Deshalb solle man sich mit Japan diplomatisch einigen. Brévié antwortete, es solle nicht gegen die japanischen Siedler vorgegangen werden. Die Asienabteilung im Quai d'Orsay hielt es dagegen für sinnvoll, den Japanern die Waffen abzunehmen und die Funkstation auszuschalten, gerade um eine militärische Reaktion zu vermeiden. Was geschehen sollte, falls die Japaner zur Gewalt griffen, sagte aber auch Hoppenot nicht: In einer Aufzeichnung am 28. Mai 1938 ließ er die Frage offen. Anfang Juni ordnete Mandel an, binnen vier Wochen eine Mission auf der Armand Rousseau zu den Spratlys zu entsenden. Dafür verlangten er und Brévié erneut den Schutz durch ein Kriegsschiff. Bonnet regte am 9. Juni eine Konferenz zwischen dem Kolonial-, dem Marine- und dem Außenministerium an. Aber die Flottenführung lehnte das Treffen $\mathrm{ab}$, um nicht unter Druck zu geraten ${ }^{161}$.

Parallel zu den Planungen für eine Besiedlung der Spratlys hatte Mandel Ende Mai Brévié angewiesen, die seit Februar beabsichtigte Entsendung von Siedlern zu den Paracels anzugehen. Wie im Fall der Spratlys weigerte sich die Marine in Indochina, an der Mission teilzunehmen, solange keine Anweisung des Marineministers vorlag. Brévié plante zunächst, Personal und Fracht mit dem Marine-Hochseeschlepper Valeureux und der Zollschaluppe Capitaine Coulon zu dem Archipel zu bringen. Dann verlangte auch er die Teilnahme eines Kriegsschiffes. Als die Marineführung dies ablehnte, versuchte es Brévié mit einer Requirierung der Marne und der Valeureux, was Petit mit Unterstützung der Marineführung in Paris verhinderte. Brévié einigte sich mit Petit, die Mission mit einem Frachter zu den Paracels zu transportieren. Die Aviso Marne sollte den Frachter bis zum Ziel begleiten. Doch selbst gegen diese Beteiligung erhob Petit in letzter Minute wieder Bedenken ${ }^{162}$.

Am 10. Juni fuhren der Frachter Albert Sarraut und der Zolldampfer Capitaine Coulon in Tourane ab, um indochinesische Milizionäre in Zivil auf

\footnotetext{
${ }^{161}$ Petit an Campinchi, D, 6.5., note de la sous-direction d'Asie-Océanie, 28.5., Bonnet an Mandel, D 757, 9.6.1938 (DDF IX, 293, 473, 546); FNEO an EMG.2, T 6475-77, 23.5.1938 (SHM 1 BB9 39); Brévié an Mandel, T 586, 18.5., T 622, 30.5., T 633, 2.6., T 638, 4.6.1938 (CAOM FM 678); Mandel an Bonnet, L 818, 3.6.1938 (MAE Chine 751); Mandel an Brévié, T 420, 4.6.1938 (CAOM FM 672). ${ }_{162}$ Brévié an Mandel, T 608, 25.5.1938 (MAE Chine 746); Marine Saigon an EMG.2, T 1079, 27.5., T 869, 28.5., T 1099, 4.6.1938 (SHM 1 BB9 39); EMG.2 an FNEO, T 3219, 28.5., EMG.2 an Marine Saigon, T 3232, 5.6.1938 (SHM 1 BB9 181); Brévié an Mandel, T 7 C.C., 29.5., T 622, 30.5., T 649, 6.6.1938 (CAOM FM 678); Mandel an Brévié, T 420, 4.6.1938 (CAOM FM 672).
} 
die Inseln Boisée und Pattle zu bringen. Auf Pattle sollte der Hauptposten entstehen, die Japaner auf der Île Boisée sollten mit Fahne und Funkgerät toleriert werden. Die Marne blieb dann doch in Tourane, um nur im Notfall einzugreifen. Als die Milizionäre am 13. Juni feierlich die französische Flagge auf Pattle hissten, wurde Chinas Regierung von dem Vorgehen informiert ${ }^{163}$.

Während der Operation auf Pattle tauchten am 27. Juni zwei japanische Kriegsschiffe auf, japanische Wasserflugzeuge überflogen die Insel. Die Marine setzte die Marne zu den Paracels in Marsch - jedoch nur, weil sich die Atmosphäre auf den Paracels überraschend entspannte und die Marine an dem sich anbahnenden Erfolg teilhaben wollte. 20 japanische Offiziere, angeführt von Fregattenkapitän Naoi Tochio, der sich auf Französisch als Ritter der Ehrenlegion vorstellte, kamen auf die Insel und erklärten, sie wollten nur einen Tag bleiben. Beide Seiten bemühten sich um ein freundschaftliches Klima. Der japanische Kapitän sagte nur, er erkenne die französische Besetzung nicht an. Als am 29. Juni auf der Île Boisée 25 Milizionäre aus Indochina landeten, ankerten erneut die zwei japanischen Kriegsschiffe in der Nähe, um das Vorgehen zu beobachten. Als unbewaffnete japanische Matrosen an Land gingen, fürchtete der Chef der indochinesischen Gruppe einen Konflikt, doch Fregattenkapitän Naoi versicherte, seine Matrosen gingen nur spazieren. Am 30. Juni drohte Naoi. Der Kapitän erklärte, womöglich werde er angewiesen, die Indochinesen von der Île Boisée zu entfernen. Der französische Kommandeur erwiderte, er verlasse die Insel ohne Befehl seiner Regierung nicht. Mandel wies die Milizionäre an, $Z$ wischenfälle zu vermeiden. Im Falle einer Aufforderung, die Insel zu verlassen, sollten sie seine Befehle abwarten.

Unmittelbar nach Abschluß der Besetzung der zwei Inseln durch die Milizionäre wies Bonnet Henry an, das Gaimusho von der Inbesitznahme der Paracels durch Frankreich zu informieren. Als Rechtsnachfolger Annams habe Frankreich solide Rechte auf den Archipel. Tokio habe bislang keine Ansprüche erhoben, deshalb stelle jeder Versuch Japans, Forderungen mit Gewalt durchzusetzen, eine Verletzung französischer Souveränität dar. Henry solle erklären, seine Regierung freue sich über die höflichen Beziehungen zwischen den französischen Behörden und den japanischen Privatleuten, deren wirtschaftliche Interessen Paris achte. Frankreich werde keine Verletzung seiner Rechte hinnehmen. Die internationale Presse wurde am 3. Juli von dem Schritt informiert. Das Foreign Office erkannte die französischen Ansprüche sofort an und versprach, diese in Tokio zu unterstützen. Das japanische Außenministerium, das erst am 4. Juli Henrys Äußerung erhielt, reagierte zunächst nicht.

${ }^{163}$ EMG.3 an Saigon, T 3254, 8.6., T 3267, 14.6.1938 (SHM 1 BB9 182); Mandel an Brévié, T 424, 8.6., T 423, 10.6., T 444, 15.6.; Brévié an Mandel, T 655, 8.6., T 669, 10.6., T 670, 11.6. ., T 693, 15.6.; Knobel an Konsul Hankéou, T 309-10, 13.6.1938 (CAOM FM 672,678, MAE Chine 746). 
Chinas förmliche Erklärung, die Koo am 7. Juli bei Bonnet abgab, daß die Paracels chinesisch blieben, archivierte der Quai d'Orsay nicht einmal ${ }^{164}$.

Nach Fregattenkapitän Naois Drohung bat Brévié um die Entsendung des Kreuzers Primauguet und eines U-Bootes in den Archipel. Konteradmiral Petit reagierte unerwartet: Gegen den Willens Bréviés beorderte er die Marne nach nur drei Tagen in den Paracels "wegen des Monsuns und dringender Inspektionsarbeiten« nach Saigon zurück, darin vom Marineministerium in Paris unterstützt. Petit deutete an, daß die Präsenz eines japanischen Kreuzers und eines Torpedobootes auch ein Grund für die Abreise der Marne war. Während das Torpedoboot den abfahrenden Zolldampfer Capitaine Coulon begleitete, blieb der japanische Kreuzer vor der Île Boisée liegen. Am 1. Juli erklärte Naoi dem Chef der französischen Gruppe, Inspektor Grérersen, Japan erkenne Frankreichs Ansprüche nicht an. Auf der Île Boisée standen den 21 Japanern und 151 Kulis aus Formosa, die bereits 15 Häuser und fünf Hallen errichtet hatten, und den ab und zu auf die Insel kommenden Matrosen des japanischen Kreuzers nur eine Handvoll indochinesischer Milizionäre unter dem Kommando des agent journalier Tuttier gegenüber. Tuttier hatte nach Abfahrt der Capitaine Coulon keine Verbindung zum Hauptteil der französischen Mission, den 30 Milizionären unter dem garde principal Brutus auf der Insel Pattle ${ }^{165}$.

Am 2. Juli sagte der japanische Kommandant auf der Île Boisée der Gruppe aus Indochina, die Landung von Truppen zur Besetzung der Insel stehe unmittelbar bevor. Angesichts der Kräfteverhältnisse wiesen Brévié und Mandel die Milizionäre an, sie sollten Widerstand leisten, aber Blutvergießen vermeiden. Frankreichs Entschlossenheit, keine Verletzung seiner Rechte hinzunehmen, die Bonnet noch am 1. Juli unterstrichen hatte, war kaum mehr zu erkennen. Bonnet wies Henry an, das Gaimusho aufzufordern, friedlich auf den Spratlys vorzugehen. Auch Frankreich handle gewaltlos und lasse japanische Zivilisten gewähren. Doch Henry lehnte die Vorsprache im Gaimusho ab, weil sie Nervosität zeige. Der stattdessen ins Marineministerium entsandte Flottenattaché erhielt vom Kabinettschef des Ministers die Antwort, Japans Marine behalte sich das Recht vor, Truppen anzulanden. Attaché Rosati hielt es aber für unwahrscheinlich, daß Japan gewaltsam vorgehe.

In Paris erklärte das Marineministerium dem Quai d'Orsay, es lehne jede Entsendung von Kriegsschiffen ab und verlange eine diplomatische Lösung.

${ }^{164}$ Marine Saigon an EMG.2, T 1157, 27.6., T 1162, 29.6., T 992-93, 30.6.1938 (SHM 1 BB9 39); Brévié an Mandel, T 744, 28.6., T 754, T 756, 30.6., T 758, T 770, 1.7.1938 (CAOM FM 678); Mandel an Brévié, T 487, 1.7.1938 (CAOM FM 672); Bonnet an Henry, T 198-203, 1.7.1938; Corbin an Bonnet, T 1607-8, 2.7.1938 (DDF X, 128,133); CHINA HANDBOOK 1937-1945, S. 300.

${ }_{165}$ Brévié an Mandel, T 761, 1.7., T 777, 2.7., T 783-84, 3.7.1938 (CAOM FM 678); Mandel an Brévié, T 490, T 495, 2.7.1938 (CAOM FM 672); Marine Saigon an EMG.2, T 1169-73, 2.7.1938 (SHM 1 BB9 39); EMG.3 an Marine Saigon, T 3344, 2.7.1938 (SHM 1 BB9 182). 
Öffentlich gab Paris seinem Vorgehen einen zivilen Anstrich: Man habe nur Personal für den Bau und den Betrieb eines Leuchtturms, einer Wetter- und einer Funkstation entsandt, um die Sicherheit der Schiffahrt und den Schutz vor Taifunen zu erhöhen. Die annamitischen Gendarme auf Pattle und Boisée sollten den Schutz vor Piraten gewährleisten. Die angebliche Okkupation der Paracels, die ausländische Propaganda vermelde - deutsche und chinesische Zeitungen sahen französisch-japanische Spannungen in den Paracels aufziehen -, bestehe nur im Ausbau eines französischen Gebiets. Vertraulich wurde den französischen Botschaftern in den großen Hauptstädten mitgeteilt, Paris habe einer möglichen Besetzung des Archipels durch Japan zuvorkommen wollen. Chinas Regierung war mit der Entwicklung zufrieden ${ }^{166}$.

Das Gaimusho zeigte, daß es die Situation nicht verschärfen wollte. Horinouchi beharrte gegenüber Henry am 8 . Juli darauf, daß Japan die französische Position nicht anerkenne und sich Maßnahmen vorbehalte, signalisierte aber auch, daß keine militärische Operation auf den Paracels geplant sei. Der Posten auf der Île Boisée meldete eine plötzliche Entspannung der Haltung der Japaner, die offenbar eine neue Anweisung erhalten hätten. Bonnet wiederholte in seiner Antwort auf Horinouchi, man beschneide die Rechte der Japaner auf den Inseln nicht und wolle Zwischenfälle vermeiden. Mandel wies Brévié an, die Japaner ungestört zu lassen. Als Henry am 12. Juli mit Außenminister Ugaki über die Paracels sprach, beklagte dieser die Plötzlichkeit der französischen Besetzung und warnte vor Zwischenfällen, zeigte sich aber sehr entspannt. Der Ton blieb freundlich, eine Pressekampagne blieb aus. Massigli und die Asienabteilung nahmen deshalb an, daß Tokio die Angelegenheit diplomatisch lösen wolle. Henry urteilte, die entschlossene, aber gemäßigte Haltung der französischen Regierung habe den japanischen Behörden gezeigt, $\mathrm{da} \beta$ Paris nicht geneigt sei, Erpressungen nachzugeben ${ }^{167}$.

Die feste Haltung gegenüber Japan und die (Zwischen-)Lösung der Paracels-Frage wurden im französischen Ministerrat, im State Department und im Foreign Office mit großer Befriedigung registriert. Die »South China Morning Post« kommentierte, die französische Besetzung der Paracels zeige, daß Frankreich, wenn seine Interessen bedroht seien, schnell und furchtlos

\footnotetext{
${ }^{166}$ Brévié an Mandel, T 785, 4.7.; Mandel an Brévié, T 497, 4.7.1938 (CAOM FM 678, 672); Bonnet an Henry, T 211-12, Corbin, 4.7., Bonnet an Washington, T 271-75, Rom, Berlin, London, Tokio, Shanghai, 5.7.1938 (DDF X, 141, 147); Marine Saigon an EMG.2, T 1176-79, 4.7.; EMG.2 an Diplomatie, T 4443, 5.7.1938 (SHM 1 BB9 39, 182); Henry an Bonnet, T 359-61, 5.7., Chargé Berlin an Bonnet, L 717, 7.7., Naggiar an Bonnet, T 941-45, 8.7.1938 (MAE Chine 746); EMA.2, note, 8.7., ministre des Colonies, section de renseignements, note, 15.8.1938 (SHAT $7 \mathrm{~N} 2519,11 \mathrm{H} \mathrm{76}$ ).

${ }^{167}$ Henry an Bonnet, T 364-70, 8.7., T 377-79, 12.7.1938 (MAE Chine 746, 747); Henry an Bonnet, T 371, 8.7., L 123, 18.7.191938 (MAE Japon 127); Bonnet an Henry, T 221-24, 9.7., compte rendu de la liaison hebdomadaire, 13.7.1938 (DDF X, 173, 203); Mandel an Brévié, T 518, 10.7., note de la sous-direction d'Asie-Océanie pour le ministre, 19.7.1938 (CAOM FM 472, MAE Chine 747).
} 
handele. Großes Lob erhielt das Vorgehen auch bei deutschen Diplomaten. Der Konsul in Hanoi berichtete nach Berlin:

Die Besetzung der Paracels-Inseln ist ein geschickter Zug auf dem ostasiatischen Schachbrett gegenüber dem japanischen Gegenspieler und beweist, daß Frankreich entschlossen ist, seine fernöstlichen Interessen zu wahren. Die japanische Animosität gegen Frankreich kann nur unter diesem Gesichtspunkt verstanden werden.

Respekt vor dem französischen Vorgehen bezeugte auch die Stellungnahme des deutschen Botschafters in Tokio:

Die Augenblickswirkung des Ereignisses lag hauptsächlich in der überraschenden Erkenntnis, daß Frankreich imstande war, mitten in einem papiemen Krieg von Protesten, Demarchen und Pressehetzen zur Tat überzugehen. Japans offizielle Reaktion auf die Besetzung der Inselgruppe trug auch durchaus die Merkmale der Überraschung und nicht geringen Verlegenheit und war auf einen nachgiebigen Ton gestimmt, der von Frankreich bereitwillig erwidert wurde.

Einige Zeitungen in Japan ahnten, wer hinter dem raschen Handeln stand: Sie kritisierten das Vorgehen des »übereifrigen Kolonialministers Mandel « ${ }^{168}$.

Das öffentliche und heimliche Lob aus deutschem und japanischem Mund überdeckte den heftigen internen Streit zwischen den französischen Behörden über die Rolle der Marine bei der Besetzung der Paracels. Naggiar kritisierte, erst die Abwesenheit französischer Kriegsschiffe habe Japans Widerstand provoziert. Japanische Offiziere respektierten ausländische Kameraden, verachteten aber Zivilisten. Da Japans Marine Admiral Le Bigot achte, hätte er den Konflikt um die Inseln leicht lösen können.

Le Bigot widersprach: Die Marine müsse von Paracels und Spratlys fernhalten, wenn Paris einen Krieg vermeiden wolle. Ein Rückzug indochinesischer Milizionäre habe geringere Folgen für Frankreichs Prestige als die Vertreibung einer Infanterieabteilung oder eines kleinen Kriegsschiffs. Léger und Henry stimmten Le Bigot zu: Die Abwesenheit des Militärs habe den zivilen Charakter der Mission betont, alles andere hätte Japans Militär provozieren können. Zwei Taifune über den Paracels und eine Grippeepidemie unter den Franzosen sowie eine Beri-Beri-Epidemie auf Pattle, die unter den Japanern für hundert Kranke und zehn Tote sorgte, nahm im Juli beiden Gruppen jeden Willen zum Konflikt. Im August brach auf Boisée eine Typhusepidemie aus. Daß das Gaimusho Mitte August die Frage der Souveränität über die Inseln nur für die Zukunft offen halten wollte und daß chinesische Zeitungen unter japanischer Kontrolle schrieben, Japan habe Frankreichs

\footnotetext{
${ }^{168}$ Exposé au Conseil des ministres, 7.7.1938 (MAE RFD 27); Bullitt an Hull, 7.7.1938 (FRUS 1938, III, S. 534f.); Saint-Quentin an Bonnet, T 681, 8.7.; T 987, 12.7., Corbin an Bonnet, T 1674, 11.7.1938 (MAE SDN 366, Chine 747); SEH, renseignement 709, 20.7.1938 (CAOM CM 82); Neumann an Ribbentrop, 15.7., Ott an Ribbentrop, 29.7.1938 (AA Pol VIII 59 1).
} 
Standpunkt zu den Paracels akzeptiert, zeigte die Entspannung zwischen Paris und Tokio ${ }^{169}$.

Schon Anfang Juni 1938 hatte Mandel von Brévié die Ansiedlung von Fischern auf den Spratlys gefordert. Diese sollten von Polizisten begleitet und auf dem Bojenleger Armand Rousseau zu den Inseln gebracht werden. Der Schutz durch Kriegsschiffe sei unnötig. Um die Entwicklung auf den Paracels abzuwarten, verzögerte sich der Beginn der Mission auf Anfang Juli 1938. Petit warnte, der Auftrag sei eine folie: Das Schiff sei nicht geeignet; auch der Monsun, Taifune und die Haltung der Japaner stellten große Risiken dar ${ }^{170}$.

Ohne Beteiligung der Marine einigten sich Mandel und Bonnet am 7. Juli, die Spratly-Mission rasch durchzuführen, aber die Japaner auf der Hauptinsel Itu Aba nicht zu provozieren. Zögere man, könne man von Japan überholt werden, was die Frage der Souveränität und des Prestiges in aller Schärfe stelle, erklärte Bonnet. Falls man schnell handle, nehme man Tokio die Möglichkeit, Frankreichs Vorgehen auf den Paracels auf den Spratlys wettzumachen. Sie entschieden, alles zu vermeiden, was einen Zwischenfall auslösen könne. Nur 20 Milizionäre, verkleidet als annamitische Fischer, sollten die Insel besiedeln. Neben Baumaterialien für Häuser, Lebensmitteln und Geräten durften sie lediglich einige Waffen und ein Funkgerät mitführen. Eine Verantwortung der französischen Regierung für die Ansiedlung dürfe nicht erkennbar sein. Falls die Mission scheitere, werde Paris jede Kenntnis abstreiten. Die Annamiten sollten sich um ein gutes Verhältnis zu den Japanern bemühen. Bemerkenswerterweise war es der sonst so forsche Mandel, der ein sehr vorsichtiges Vorgehen forderte, während der sonst konfliktscheue Bonnet ein robusteres Auftreten verlangte. Der Grund für das Verhalten beider Politiker lag nahe: Die Verantwortung für ein Scheitern hätte bei Mandel gelegen.

Emeut protestierte Konteradmiral Petit. Das Vorgehen auf Itu Aba sei sun enfantillage dangereux« und schade der Entspannung auf den Paracels. Japan werde die Fischer unterwerfen. Das inoffizielle Vorgehen - das Petit vorher selbst gefordert hatte - belege die Unwirksamkeit der französischen Rechte über die Spratlys. Am 21. Juli kamen die Fischer auf dem Frachter Francis Garnier auf Itu Aba an. Die erste Besiedlung erfolgte ohne Probleme. Die Annamiten gerieten in Angst, als sie hörten, daß die Japaner bewaffnet waren.

\footnotetext{
${ }^{169}$ Naggiar an Bonnet, T 927-28, 5.7., T 935-37, 6.7., Léger an Naggiar, T 345, 7.7., Henry an Bonnet, T 373, 9.7.1938 (MAE Chine 746); FNEO an EMG.2, T 6690, 8.7., T 5-6, 9.7.; EMG.2 an FNEO, T 3372, 11.7.1938 (SHM 1 BB9 39, 182); Brévié an Mandel, T 817, 12.7., T 858, 23.7., T 863, 25.7., T 865-66, 27.7., T 920, 9.8., T 958, 26.8.1938 (CAOM FM 678); Henry an Bonnet, $T$ 442-43, 16.8., Naggiar an Bonnet, T 1193-94, 22.8.1938 (MAE Chine 747).

${ }^{170}$ Mandel an Brévié, T 424, 8.6., T 478, 28.6., T 502, 5.7.1938 (CAOM FM 672); EMG.3 an Marine Saigon, T 3267, 14.6., Marine Saigon an EMG.2, T 1169-72, 2.7.1938 (SHM 1 BB9 182, 39); Brévié an Mandel, T 692, 15.6., T 745, 28.6., T 759. 29.6., T 767, 1.7., T 787, 4.7.1938 (CAOM FM 678).
} 
Um die Moral zu heben, entsandte Mandel einen französischen Beamten, wobei auch bei ihm keine Verbindung zur Regierung erkennbar sein durfte ${ }^{171}$.

Am 8. August spitzte sich die Lage zu: Der japanische Minenleger Katsuriki legte vor Itu Aba an. Am Folgetag bestellte der Kommandeur den Leiter der Annamiten-Gruppe ein und forderte ihn auf, Frankreichs Flagge einzuziehen und die Insel zu verlassen. Japans Regierung suchte aber eine diplomatische Lösung: Am 11. August sprach Botschafter Sugimura mit Bonnet, am Tag darauf mit Massigli und fragte, ob Frankreich die Annamiten von Itu Aba abziehen könne, um Streit mit den Japanern, die bereits vorher auf der Insel gewesen seien, zu vermeiden. Japan wolle die Frage der Souveränität offen halten. Zeitgleich schufen die Japaner vor Ort Fakten: Sie stellten am 13. August japanische Grenzpfähle auf und kündigten an, mehrere hundert Arbeiter zum Phosphatabbau auf die Inseln zu schicken. Bonnet wies deshalb in Tokio erneut auf die französischen Rechte hin, fügte aber an, Paris verlange von den japanischen Bewohnern nicht einmal die Beachtung französischer Gesetze. Horinouchi antwortete in einem gemäßigten Ton, der zeigte, daß Japan seinen Anspruch nicht aufgeben, aber auch nicht mit Gewalt durchsetzen wollte ${ }^{172}$.

Am 22. August kam der Frachter Francis Garnier an, um Versorgungsgüter und den französischen Beamten Burollaud als Leiter der angeblichen Fischer anzulanden. Ein japanischer Offizier forderte die Gruppe auf, die Arbeit einzustellen, und drohte mit Konsequenzen. Die Franzosen entluden unbeirrt weiter. Die Japaner, die die 300 Matrosen des Minenlegers hätten einsetzen können, blieben passiv. Erneut hatten sich die Franzosen in schwieriger Lage behauptet. Die Proteste in Paris von Botschaftsrat Miyasaki Katsutaro bei Hoppenot und Botschafter Sugimura bei Massigli blieben folgenlos. Am 27. August hatte sich die Lage auf Itu Aba so weit entspannt, daß der französische Anführer den Chef der japanischen Siedler und den Kommandeur des Minenlegers empfing und das japanische Kriegsschiff die Inselgruppe verlie $\beta^{173}$.

${ }^{171}$ Notes de la sous-direction d'Asie-Océanie, 5.7., 19.7.1938 (MAE Chine 751, 747); Bonnet an Mandel, D 896, 7.7.1938 (DDF X, 162); Mandel an Brévié, T 510, 8.7., T 564, 1.8.1938 (CAOM FM 672); Wilson an Hull, 20.8.1938 (SD 851.014/90); Marine Saigon an EMG.2, T 1189, 12.7., T 1193, 16.7., T 129, 17.7., T 1160, 25.7.; EMG.2 an FNEO, T 3380, 13.7.1938 (SHM 1 BB9 39, 182); Brévié an Mandel, T 832, 16.7., T 849, 20.7., T 882, 31.7., T 902, 2.8.1938 (CAOM FM 678).

${ }^{172}$ Saigon an EMG.2, T 1216-17, 9.8., T 1218-19, 10.8.1938 (SHM1 BB9 40); Diplomatie an Colonies, L, 12.8.; Brévié an Mandel, T 923, 10.8., T 933, 12.8., T 938, 15.8.1938 (CAOM FM 677, 678); Massigli, note, visite de l'ambassadeur du Japon, 12.8., Henry an Bonnet, T 452, 19.8.; Bonnet an Henry, T 274-78, 17.8., Gaimusho an Henry, L 55, 22.8.1938 (MAE Chine 751; DDF X, 397, 433).

${ }_{173}$ Brévié an Mandel, T 947, 19.8., T 958, 26.8., T 963, 30.8.1938 (CAOM FM 678); Brévié an Mandel, L 3863, 16.9., STS-bulletin, 1.9.1938 (MAE Chine 751, 534); Saigon an EMG.2, T 1230-31, 24.8., T 1233, 25.8., T 1237, 27.8., T 1243, 31.8.1938 (SHM 1 BB9 40); Note de la sous-direction d'Asie-Océanie, 26.8.1938 (MAE Japon 127); Mandel an Brévié, T 610, 27.8.1938 (CAOM FM 672). 
Petit wollte jeden Konflikt ausschließen. Am 12. August schlug er eine Übereinkunft zwischen Tokio und Paris vor: Kriegsschiffe beider Nationen sollten die Archipele nicht mehr aufsuchen, auf gar keinen Fall gleichzeitig. Als durch die Abfahrt des japanischen Minenlegers die letzte Spannung auf den Spratlys gewichen war, erlaubte die Marineführung am 1. September 1938 wieder Fahrten zu den Paracels. Als kein Konflikt mehr drohte, strebte die Marine offensichtlich danach, einen Teil des Ruhms abzubekommen ${ }^{174}$.

Naggiar verlangte die Präsenz der Marine in den Archipelen. Zurückhaltung werde als Schwäche interpretiert. Es sei ein Wunder, daß Petits Weigerung, sich an der Besetzung der Paracels und der Spratlys zu beteiligen, nicht zum Scheitern geführt habe. Guillaume Georges-Picot, Frankreichs Vertreter in Chungking, warf der Marine Defätismus vor. Sie verweigere sich, obwohl der Ministerrat die Besetzung der Inselgruppen beschlossen habe. Brévié sah den Kern des Übels in der engen Freundschaft der Admiräle Petit, Le Bigot und Darlan. Der Generalgouverneur klagte:

Il est assez ennuyeux de remarquer que la Marine préconise en Extrême-Orient une politique défaitiste de liquidation des intérêts français qui nous coûtera l'Indochine, au moment où M. Campinchi, ministre de la Marine, critique les accords de Munich et reproche au gouvernement français de n'avoir pas voulu risquer un conflit dans une affaire où des intérêts français étaient beaucoup moins directement en cause que dans les affaires d'Extrême-Orient.

Als Bonnet Marineminister Campinchi bat, dafür zu sorgen, daß die französische Marine auf beiden Inselgruppen durch eine höhere Präsenz mit Japan gleichziehe, wies Campinchi die Forces navales d'Extrême-Orient entsprechend an. Doch schon die Anwesenheit von 15 Japanern auf den Spratlys ließ Darlan am 22. Dezember 1938 die Erlaubnis für Fahrten von Kriegsschiffen zu der Inselgruppe zurücknehmen ${ }^{175}$.

Trotz oder wegen des nach Mandels Amtsantritt mutigeren Auftretens der französischen Repräsentanten in beiden Archipelen vermied Tokio eine Konfrontation. Japan bemühte sich in dieser Phase generell, die Europäer nicht unnötig zu provozieren. Zudem waren die Machtverhältnisse im Südchinesischen Meer so eindeutig, daß Japan auf den Inselgruppen jederzeit klare Verhältnisse schaffen konnte, wenn es wollte.

\footnotetext{
${ }^{174}$ Saigon an EMG.2, T 1220-24, 12.8.; EMG.2 an Marine Saigon, T 3513, 1.9.1938 (SHM 1 BB9 40, 182); Mandel an Brévié, T 633, 6.9.1938 (CAOM FM 672).

${ }^{175}$ Naggiar an Bonnet, L 1262, 5.9., bordereau d'envoi, $\mathrm{n}^{\circ}$ 616/S, 6.9.1938, extrait résumé d'une lettre privée du 20.8 reçue par M. Naggiar; Georges-Picot an Bonnet, L, 25.10.1938 (MAE Chine 751, 676); Bonnet an Mandel und Campinchi, D 1450, D 1531, 28.11., note de la sous-direction d'Asie-Océanie, 22.11.1938 (DDF XII, 426, 359); EMG.2 an Colonies, L 8243, 1.12.1938 (CAOM FM 677); Darlan an Bonnet, L 1735, 22.12.1938, Diplomatie an Marine, L 8, 6.1.1939 (MAE Chine 751, 752).
} 


\subsection{Französische Behörden zwischen Trotz und Kollaboration}

Mit Beginn der Kämpfe im Sommer 1937 hatte Japans Regierung versichert, sie taste die ausländischen Rechte in China nicht an. Für Japans Kontrolle über die eroberten Gebiete wurden die Konzessionen jedoch zum Hindernis. In den Enklaven fanden chinesische Guerillas, Zeitungen und Banken Zuflucht. Dies untergrub die japanische Herrschaft über ganze Regionen. Japans Druck auf die Konzessionen wuchs mit Chinas Widerstand. Solange der japanische Vormarsch anhielt, blieben die Reibereien zwischen den Mächten und Japan begrenzt. Französische Diplomaten und Offiziere verteidigten Frankreichs Position in China, indem sie an den Prinzipien unbeugsam, oft starrköpfig, festhielten, sich aber in praktischen Fragen nachgiebig zeigten.

Dies zeigte sich auch im Post- und Fernmeldewesen. Generalkonsul Lépissier und sein britischer Kollege verwehrten im Sommer 1937 den japanischen Behörden in Tientsin die Kontrolle über das chinesische Telegraphenamt in der französischen Konzession und über das Postamt in der britischen Konzession. Die chinesische Post verlegte Mitte August 1937 ihren Sitz in japanisch besetztes Gebiet und unterwarf sich japanischer Zensur. Im Telegraphenamt wollten weder Lépissier noch Chinas Regierung eine japanische Kontrolle dulden. Als Japan im Dezember 1937 heftiger drängte, schloß das Büro zum Jahresende 1937. Eine mandschurische Gesellschaft übernahm dessen Funktion. Das städtische Telefonnetz wollten die Generalkonsuln nicht an Japan übergeben. Als Kompromiß wurden zwei Netze aufgebaut, eines für die europäischen Konzessionen, eines für das chinesische Stadtgebiet. Damit konnten die Japaner den Nachrichtenaustausch der Chinesen kontrollieren, die Mächte hatten aber einen Eingriff in ihre Konzessionen abgewehrt ${ }^{176}$.

Wichtigster Streitpunkt Ende 1937 und in der ersten Hälfte des Jahres 1938 war die Kontrolle der Schulen. Im Herbst 1937 hatte Japan alle chinesischen Universitäten und höheren Schulen geschlossen. Die Japaner versuchten, auch die École municipale française in der Konzession und die École des hautes études des jésuites im chinesischen Teil Tientsins zu inspizieren; die französischen Schulen wurden zudem aufgefordert, an projapanischen Feiern teilzunehmen. Nach diplomatischen Protesten in Tientsin und Peking duldete Japan die Unabhängigkeit der französischen Anstalten. Im Gegenzug entfernten die französischen Schulen die Bücher, die Japan für subversiv halten könnte. Die Beziehungen gestalteten sich so konfliktfrei, daß die Franzosen im Mai 1938 die Freilassung des mit einer Französin verheirateten Professors Chen Mien

${ }^{176}$ Naggiar an Delbos, T 820, 7.12., Lépissier an Delbos, L 51, 9.12.; T 21, 29.12., Lacoste an Delbos, T 344, 17.12.1937; Lépissier an Naggiar, L 11, 1.2.1938 (MAE Chine 714, 715, 716, 767). 
erreichten, der wegen der Behandlung unliebsamer Themen an der chinesischen Université franco-chinoise in Peking festgenommen worden war ${ }^{177}$.

Im Juni 1938 erhöhten die chinesischen Marionettenbehörden den Druck auf die Französisch-Chinesische Universität. Sie lösten Klassen auf, entließen mißliebige Lehrer und bemühten sich (vergeblich) um die Kontrolle der Bibliothek. Auch die Deutsch-Chinesische und die Amerikanisch-Chinesische Universität setzten sie unter Druck. Als Charles Lépissier fürchtete, die jesuitische École des hautes études in Tientsin, die einzige Schule dieses Typs in Nordchina, könne erpreßt werden, schickte er die Schüler am 14. Juni für drei Monate in die Ferien. Darufhin drang die chinesische Polizei in die Schule ein. Lépissier handelte. Er erschien mit Oberst Jacomy und einer Kompanie französischer Soldaten in der Schule. Die Polizisten flüchteten. Japans Militär ärgerte der französische Triumph, vor allem der Bericht der Zeitung »Excelsior «, die schrieb, das französische Militär habe japanische Soldaten aus der Schule verjagt. Letztlich setzten sich die Besatzer doch durch: Die Französisch-Chinesische Universität, die Japan nicht ihre Loyalität versprechen wollte, verließ im August 1938 die Stadt. Im September empfahl Lacoste den französischen Schulen, Lehrern und Schülern außerhalb der Schulzeit die Teilnahme an einer Demonstration gegen Chiang Kai-shek zu erlauben. Die französischen Einrichtungen wahrten so ihr Gesicht ${ }^{178}$.

Konflikten gingen auch die französischen Firmen aus dem Weg. Das Grand Hôtel de Pékin, aus Hoppenots Sicht das einzige geglückte französische Wirtschaftsunternehmen in Nordchina, wurde von seinen Eigentümern, der Banque franco-chinoise, im Februar 1938 für eine Million Yen an japanische Unternehmer verkauft. Léger versuchte vergeblich, den Handel zu vereiteln, da das Einziehen der Flagge über dem berühmten Hotel Frankreichs Position schwäche. Im zweiten großen französischen Unternehmen Pekings, der zu 50 Prozent französischen Compagnie des tramways, suchte der Hauptaktionär, die Banque franco-chinoise, die Verständigung mit den Japanem und tolerierte, daß diese die chinesischen Mitglieder des Aufsichtsrates bestimmten ${ }^{179}$.

Lépissier klagte Anfang Januar 1938 über Japans zunehmenden Druck auf die französische und die britische Konzession. Die Japaner unternähmen alles, um deren Existenz zu erschweren. Die von Japan installierte Marionettenregie-

\footnotetext{
${ }^{177}$ Lépissier an Delbos, L 44, 13.11.1937 (MAE Chine 767); Lacoste an Delbos, T 328, 10.12., T 341, 16.12.1937 (MAE Chine 714, 715); Lacoste an Naggiar, L 312, 10.5.1938 (MAE Chine 769).

${ }^{178}$ Lacoste an Naggiar, T 52-55, 12.6., T 56-57, 13.6., T 59, 14.6., Lépissier an Bonnet, L 38, 15.6.; Massigli an Naggiar, T 412-13, 8.8., Lacoste, Note, 19.9.1938 (MAE Chine 769, 770); Lépissier an Naggiar, L 70, 15.6., L 71, 19.6.; Jacomy an Mandel, T 140, 16.6.1938 (SHAT 11 H 61, 57).

179 Lockhart an Hull, 27.11.1937 (SD 793.94/11829); Note de la sous-direction d'Asie-Océanie, 9.2.1938 (MAE Chine 767); Banque franco-chinoise an Hoppenot, L, 23.2., Lacoste an Naggiar, L 179, 11.3.; Naggiar an Bonnet, T 628-29, 11.5.1938 (MAE Chine 768, 769).
} 
rung in Peking kündigte an, sie wolle die Extraterritorialität abschaffen, eine Zentralbank einrichten und alle Behörden sowie die Wirtschaft kontrollieren. Bis in den Herbst 1938 blieb das Verhältnis der französischen Vertreter zu den neuen Herren in China aber meist komplikationsfrei. Für wie ungefährdet Frankreichs Diplomaten die französischen Privilegien im Frühjahr 1938 hielten, zeigte sich daran, daß sie es sich erlaubten, über zwei nebensächlichen Fragen einen Prinzipienstreit mit Japan vom Zaun zu brechen, nämlich über die Verdunkelung des Botschaftsviertels in Peking, wobei Japan einlenkte, und über die Parade einer chinesischen paramilitärischen Jugendorganisation in Peking, die Naggiar schließlich akzeptierte ${ }^{180}$.

In einer anderen Frage war französische Hartnäckigkeit berechtigt. Das Foreign Office überlegte zur Jahreswende 1937/38, ob es nach der Anerkennung einer chinesischen Regierung in Peking durch Japan nicht das diplomatische und militärische Personal aus der Hauptstadt abziehen solle, um eine implizite Anerkennung des Marionettenregimes zu vermeiden. Léger warnte davor, übereilt jahrzehntealte Rechte aufzugeben. Nach französischem und amerikanischem Widerspruch rückte London von der Idee ab. Lediglich privat empfingen der britische und der französische Konsul den MarionettenBürgermeister von Tientsin. Die offiziösen Kontakte zu dem Regime liefen über die japanische Botschaft und General Terauchis Stab, der im Januar 1938 nach Peking verlegt wurde, um die dortige Regierung zu unterstützen ${ }^{181}$.

Die Autorität der französischen Konzession in Tientsin blieb unbestritten: Die Japaner betraten erst nach Erlaubnis französisches Gebiet, und nach dem Abzug eines US-Regimentes Anfang März 1938 lehnten die Franzosen die Bitte der US-Marines, die verbliebenen 250 Soldaten in Frankreichs Konzession unterzubringen, ab, weil dies die französische Hoheit untergrabe. Auf die Ansprüche der projapanischen chinesischen Eisenbahnverwaltung auf Räume in den Bahnhöfen von Tientsin und Tongkou reagierte Lépissier selbstbewußt: Er entsandte kleine Militärkontingente zu den Bahnstationen ${ }^{182}$.

$\mathrm{Daß}$ die japanisch-französischen Beziehungen in China gediehen und trotz der Verschlechterung im Herbst 1938 bis zum März 1945 nie in eine offene Konfrontation abglitten, lag auch an den intensiven persönlichen Kontakten,

\footnotetext{
${ }^{180}$ Lépissier an Delbos, L 1, 5.1; Lacoste an Delbos, T 9-10, 11.1.1938 (CAOM NF, FM 106; MAE Chine 717); Lacoste an Lockhart, 4.2.1938 (SD 793.94/12854); Naggiar an Delbos, T 216-20, 13.2., Corbin an Delbos, T 348, 16.2.1938 (MAE Chine 767, 768).

${ }^{181}$ Phipps, Note, 17.12., Corbin an Delbos, T 3036, 22.12.; Léger an Corbin, L 2913, 20.12.; Foreign Office an Cambon, 29.12.1937 (MAE Chine 715, 562, 767); Naggiar an Delbos, T 66, 11.1., Lacoste an Delbos, T 16-17, 21.1.1938 (MAE Chine 717, SDN 363).

${ }_{182}$ Lépissier an Delbos, L 10, 28.2.; Lépissier an Delbos, L 13, 8.3., Naggiar an Paul-Boncour, L 206, 24.3., Lacoste an Naggiar, T 185, 28.3.1938 (MAE Chine 828, 720); Lépissier an Jacomy, L, 31.5.1938 (SHAT 11 H 63).
} 
die japanische und französische Offiziere pflegten. Hatten viele französische Diplomaten bereits Abneigungen gegen China und Sympathien für Japan, so war diese Haltung bei den Offizieren, die ja die Konzessionen gegen China verteidigen sollten, noch ausgeprägter. Oberst Henri Casseville, der von 1928 bis 1933 in China Militärattaché war und im November 1938 das Kommando über das französische Heer in China übernahm, schrieb 1934 in einem Buch, China sei ein chaotisches Land, dessen Führer intrigant und eitel, anarchisch und streitsüchtig seien. Japan hingegen sei eine energische, fleißige und disziplinierte Nation, deren Expansion moralisch gerechtfertigt sei. Camille Sabattier, früherer Oberkommandierender in China und bis 1938 Militärattaché, schrieb, die Umstände hätten Japan zur Expansion gezwungen. China stellt er nicht so negativ wie Casseville, aber als fremdenfeindlich dar. Auch Vize-Admiral Jean Decoux, der im Sommer 1939 das Kommando der Fernostflottille übernahm, äußert sich in seinen 1949 veröffentlichen Memoiren deutlich: Im Gegensatz zu Frankreichs früherem Verbündeten Japan hätten Amerikaner und Briten in der Zwischenkriegszeit versucht, Frankreichs Heeres- und Marinepotential zu schwächen. Man dürfe Japan ebensowenig als imperialistisch bezeichnen wie China als demokratisch. Decoux' Vorgänger VizeAdmiral Le Bigot schrieb im Sommer 1939, Chinas Sympathie für den Westen sei durch seine Fremdenfeindlichkeit und seine geheime Hoffnung gebremst, eines Tages die Konzessionen übernehmen zu können ${ }^{183}$.

Zufällig, aber symbolträchtig hatte sich der Kommandeur der Fernostflottille bei Beginn des Konfliktes ausgerechnet in Japan aufgehalten. Als am 7. Juli 1937 die Schüsse an der Marco-Polo-Brücke fielen, befand sich das Flaggschiff der Flottille, die Lamotte Picquet, begleitet von der Aviso Dumont d'Urville, bei einem offiziellen Besuch in Yokohama, wo sie am 29. Juni aus Kobe kommend eingetroffen war. Am 1. Juli wurde Vize-Admiral Le Bigot, drei Offizieren sowie Botschafter Henry die Ehre zuteil, vom Kaiser empfangen zu werden, der den vier Offizieren Orden verlieh. Die Lamotte Picquet fuhr am 9. Juli nach Shanghai, die Dumont d'Urville besuchte bis zum 19. Juli Nagasaki. Le Bigot freute sich über sehr positive Presseberichte in Japan ${ }^{184}$.

In diesem Klima gegenseitigen Respekts war es selbstverständlich, daß bei Ausbruch der Kampfhandlungen um Peking Ende Juli 1937 die 30 Japaner, die sich noch in Zentral- und Südchina aufgehalten hatten, mit Hilfe der französischen Behörden und der Yunnanbahn über Yunnanfu aus China evakuiert

${ }^{183}$ CASSEVILle, Nankin contre Tokyo; SABATTIER, Le destin, S. 363f.; DeCouX, À la barre de l'Indochine, S. 60f.; FNEO, compte rendu, 5.7.1939 (SHM 1 BB4 74). General NOLDE hingegen drückte im Buch »La Chine de Chiang Kai Shek« ebenso Bewunderung für Japan wie Achtung vor China aus.

${ }^{184}$ Marine, situation mensuelle au 5.6. et au 3.7.1937 (SHM 1BB2 134); Police, bulletin mensuel, juin 1937 (MAEN Shanghai *324); Extrait du rapport, mission du Lamotte-Picquet et du Dumont d'Urville [Juli 1937] (MAE Ac 78); FNEO an EMG.3, T 1049, T 1052, 13.7.1937 (SHM 1 BB9 127). 
wurden. Der Beginn der Kämpfe verschlechterte zunächst das Klima: Den Franzosen wurde angedeutet, durch die Nähe zu Japans Feinden Sowjetunion und Großbritannien seien sie den Japanern suspekt geworden. Vom Mißtrauen japanischer Offiziere gegen Frankreich wegen dessen Nähe zu Rußland und England hörte auch der stellvertretende Militärattaché in Tokio, der japanisch sprechende Hauptmann Aiby, der mit Zustimmung des Quai d'Orsay im März 1938 nach Peking gefahren war, um die Atmosphäre zu verbessern. Aiby riet, persönlichen Kontakt zu japanischen Offizieren aufzunehmen. Oberst Jacomy, Chef der Garnison in Tientsin, erwiderte, die Beziehungen zum japanischen Militär seien bereits sehr freundschaftlich ${ }^{185}$.

Botschafter Henry nahm Aibys Bericht zum Anlaß, neue Anweisungen an das französische Militär in China zu verlangen. Der bisherige Rat an die Offiziere, Distanz zu halten, müsse, so Henry, »humanisiert« werden, denn die fehlenden menschlichen Beziehungen zwischen den französischen und japanischen Stäben in Nordchina könnten zu gefährlichen Zwischenfällen führen. Henry bot an, seinen Militärattaché Thiébaut nach Peking zu entsenden, um den Kontakt herzustellen, was Naggiar als Einmischung in seine Kompetenzen zurückwies. In einer ersten Stellungnahme erwiderte Naggiar, er habe dem Militär stets Höflichkeit auf der Ebene militärischer Kameradschaft empfohlen. Aibys Bericht sei nicht fundiert. Vier Tage später bezog Naggiar ausführlich Stellung: Seine Rechtfertigung vom 1. April 1938 über acht Seiten war eines der längsten Telegramme, das der Botschafter je aus China absetzte. Naggiar schrieb, es gebe regelmäßige, direkte und höfliche Beziehungen zwischen dem japanischen und dem französischen Militär, Aibys Vorwürfe seien ungerechtfertigt. Naggiar wies dennoch das Militär in Peking und Tientsin an, persönliche Kontakte zu den japanischen Offizieren aufzunehmen. Den Offizieren empfahl er, größte Höflichkeit gegenüber dem japanischen Militär an den Tag zu legen, dabei aber strikt französische Würde und Rechte zu behaupten. Um das Aufnehmen guter Beziehungen zu erleichtern, erhielt Hauptmann Noirjean, Chef der Botschaftswache, 200 Dollar ${ }^{186}$.

Schon vor Aibys Besuch hatte sich Naggiar um ein gutes Verhältnis zu den japanischen Truppen bemüht. Auf seine Bitte hatten im November 1937 Admiral Le Bigot und Oberst Jacomy in Shanghai Höflichkeitsbesuche bei

\footnotetext{
${ }^{185}$ Naggiar an Delbos, T 261, 2.8., Lockhart an Hull, 3.8.1937 (MAE SDN 355, SD 793.94/9144); Botschafter Hidaka (Nanking) an Naggiar, 14.8., Naggiar an Delbos, L 364, 15.9.1937 (MAE Japon 126); Note d'Astier de Villatte, 30.7., Baeyens an EMG.2, L 2668, 12.10.1937 (SHAT 11 H 61, MAE Chine 709); Aiby, compte rendu, [17.4.], Jacomy an Naggiar, L 312, 22.6.1938 (SHAT 11 H 63).

${ }^{186}$ Henry an Paul-Boncour, T 156-60, 26.3., Naggiar an Paul-Boncour, T 420-23, 27.3., Naggiar an Bonnet, L 440, 3.7., Lacoste an Jacomy, L 7/P, 5.4., Diplomatie an Colonies, L 484, 5.4.1938 (MAE Chine 563); Naggiar an Paul-Boncour, T 451-59, 1.4.1938 (MAE Japon 126); Lacoste an Jacomy, L 7/P, 5.4., Jacomy an Lacoste, L 182-C/1, 8.4.1938 (SHAT 11 H 63).
} 
General Matsui, dem Oberkommandierenden der japanischen Südfront, und Militärattaché General Harada unternommen. Naggiar empfahl der französischen Konzession in Shanghai, Japan großzügige Durchfahrtsgenehmigungen zu gewähren, und bemühte sich im März 1938 auffällig um die Freundschaft der Japaner: Der Chef der französischen Garnison in Shanghai, Oberstleutnant Perretier, erhielt 500 Dollar. Die Summe sei zu nutzen »für den Erhalt bester persönlicher und kameradschaftlicher Beziehungen zwischen französischen und japanischen Truppen«. Nun, nach dem Aiby-Bericht, setzte sich Naggiar, obwohl Paris Aibys Bericht nicht bewertet hatte, für noch engere Beziehungen zwischen japanischen und französischen Offizieren $\operatorname{ein}^{187}$.

In Tientsin warfen sich Oberst Jacomy und Stabschef Oberstleutnant Astier de Villatte dem japanischen Militär geradezu an den Hals. Zehn Tage nach Naggiars Bitte suchte Astier de Villatte den japanischen Stabschef General Okabe auf; vier Tage später, am 15. April 1938, besuchte Jacomy Oberbefehlshaber General Terauchi in Peking. Die beiden französischen Offiziere berichteten von sehr herzlichen Gesprächen und einem familiären Ton. Ihre Gegenüber hätten versprochen, sich um die Vermeidung von Zwischenfällen zu bemühen. Jacomy stellte gegenüber den französischen Diplomaten heraus, er sei der einzige ausländische Kommandeur, der persönliche Beziehungen zu Terauchi pflege. Die Zuneigung schien gegenseitig: Terauchi sagte Jacomy, sein Vater, der Marschall, habe seine militärische Ausbildung den Franzosen zu verdanken. In der Tat genoß Frankreichs Armee bis in die dreißiger Jahre einen guten Ruf in japanischen Militärkreisen. Gegenüber der Journalistin Viollis äußerten sich japanische Stabsoffiziere 1932 enthusiastisch über das französische Militär. Marschälle wie Napoleon, Joffre oder Pétain seien ihre Vorbilder, Franzosen und Japaner seien kriegerische Völker, die zusammen die Welt erobern könnten. Die Offiziere lobten die hohe Qualität der Flugzeuge, U-Boote und der Artillerie Frankreichs. Sicher hatte der Ruf der französischen Waffen unter der diplomatischen Defensive in Europa gelitten, aber französisches Militär genoß in Japan weiterhin großen Respekt ${ }^{188}$.

Die Inbrunst, mit dem Jacomy die Beziehungen zu seinen »japanischen Kameraden« pflegte, nahm noch zu: Am 25. April 1938 empfing er General Ida, der Japans Truppen in Tientsin kommandierte, mit militärischen Ehren. Auch Ida dachte gern zurück: Er habe 1929 die internationale Parade bei Marschall Fochs Begräbnis kommandiert und habe beste Erinnerungen an Frankreich.

\footnotetext{
187 Jacomy an Moutet, L, 1.12.1937, Moutet an Jacomy, L 56, 13.1.1938 (MAE Chine 1062, SHAT 11 H 63); Naggiar an Paul-Boncour, T 451-59, 1.4., Naggiar an Delbos, T 211-12, 11.2.; Léger an Henry, T 129-30, 4.4., Naggiar an Perretier, 17.3.1938 (MAE Japon 126, Chine 775, 563).

${ }^{188}$ Astier de Villatte, Note $\mathrm{n}^{\circ} \mathrm{D}-31$, très secret, 11.4.1938 (SHAT 11 H 61); Jacomy an Lacoste, T, 15.4., Lacoste an Naggiar, T 222, 15.4.; Knobel an Bonnet, T 51 1-12, 16.4., Jacomy an Naggiar, L 209, 16.4.1938 (MAEN Pékin A 345, MAE Chine 563); Vıollis, Le Japon et son empire, S. $100 \mathrm{f}$.
} 
Anfang Mai erwiderten Jacomy und Astier de Villatte den Besuch im japanischen Militärclub in Tientsin. Als Astier de Villatte seinen »Kameraden« mit dem selten benutzten Vornamen anschrieb und die beiden Obersten ihre japanischen Gegenüber zum Essen in ihre Familien einluden, wurde es den Japanern zuviel: Sie lehnten die Einladung höflich ab, weil sie viel zu tun hätten. Astier de Villatte erwiderte die Absage am 11. Mai 1938 mit einem Brief, der es verdient, vollständig zitiert zu werden:

Mon colonel, je vous suis infiniment reconnaissant de votre lettre de ce jour et $\mathrm{j}$ 'ai parfaitement compris les arguments que vous m'avez exposés. Les sentiments du devoir dans l'Armée japonaise sont comme dans l'Armée française placés au-dessus de toute autre considération. Aussi je ne peux que souhaiter pour vous-même, pour votre famille et pour moi-même qu'une situation plus normale vous permette de disposer de loisirs plus importants. Néanmoins la porte de ma maison vous sera toujours ouverte et je serai grandement honoré si un jour vous vouliez bien vous y rendre. Peut-être pourrez vous voir toutefois donner dès maintenant aux Officiers de votre État-Major la permission de venir chez moi dîner en toute simplicité le soir. Même si vos Officiers ne connaissent pas nos coutumes cela ne peut être pour eux une raison de ne pas venir: entre Officiers animés du même idéal pour leur pays il ne peut y avoir aucune gêne mais une franche camaraderie à exposer ses idées. Tels sont, mon colonel, les sentiments que je tenais à vous exprimer et que de vive voix je n'aurai peut-être pas pu vous exposer avec autant de netteté. Veuillez agréer l'expression de mes vifs sentiments de camaraderie ${ }^{189}$.

Als der Oberst schrieb, daß Kameradschaft, gleiche Ideale und Pflichtgefühl die japanische und die französische Armee vereinten, hatte er wohl vergessen, daß sich Japans Armee nicht zu Manövern in China aufhielt. Nur zehn Tage zuvor hatte die französische Tageszeitung "La Vie« Japans grausame Kriegführung verurteilt und geschrieben, es sei unmöglich, Augen und Herz vor den Schrecken des großen Leichenfeldes voller Greuel zu verschließen.

Naggiar war zufrieden über die persönlichen Kontakte, für die Japaner stets empfänglich seien. Die Anbiederung blieb nicht auf Nordchina beschränkt: In Shanghai lud Oberstleutnant Perretier Anfang Mai Oberstleutnant Kikuchi zum Essen nach Hause ein, und er nahm Ende Mai - wie die amerikanischen, britischen und italienischen Kollegen - an japanischen Feiern zum Jahrestag der Schlacht von Tsushima teil. Weil sich die Kontakte so gut entwickelten, sandte Naggiar Anfang Juni noch einmal Schecks über 200 Dollar an das Militär in Nordchina, 400 Dollar an die Truppe in Shanghai sowie Anfang Juli 300 Dollar an das Heer in Nordchina, damit diese die Kameradschaft weiter pflegen konnten. Er verzichtete aber wohl darauf, einen eigenen Fonds dafür einzurichten, wie es Jacomy und Lépissier gefordert hatten. Immerhin hatte Naggiar aber so viel Würde, daß er es ablehnte, Japan besonders zu danken,

${ }^{189}$ FTFC, EM.2, note no 62, 22.4., Jacomy an Naggiar, L 68.226-C/2, 25.4.1938 (SHAT 11H 61, 63); Ida an Jacomy, L, 10.5., Oberstleutnant Tsujimura an Astier de Villatte, L, 11.5., Astier de Villatte an Keukichi Tsujimura, L D 83, 10.5., D-87, 11.5.1938 (SHAT 11 H 61). 
als das Kriegsministerium in Tokio für den von Japanern im Juli 1937 in Tientsin versehrten Unteroffizier Chrétien ein Schmerzensgeld zahlte ${ }^{190}$.

Die besondere Sorge um die Beziehungen zum japanischen Militär hatte der Quai d'Orsay nicht angeordnet, aber er war darüber informiert und billigte die Pflege. Als der japanische Generalstab im Mai 1938 um einen Platz an der französischen Kriegsakademie bat und seinerseits Hauptmann Aiby den Eintritt zur Kriegsakademie in Tokio ab November 1938 gewährte, räumte der französische Generalstab Anfang Juni mit Zustimmung des Quai d'Orsay diesen Platz ein. Mitte Juni gab Japan die Zulassung zurück.

Der Sommer 1938 brachte die japanisch-französischen Militärbeziehungen zum Blühen: Die Franzosen bereiteten den Besuch von General Iseki, Generalinspekteur der japanischen Artillerie und Absolvent der französischen Kriegsakademie, in Tientsin und Shanghai vor. Admiral Le Bigot, höchstrangiger französischer Offizier in China, sollte Anfang Juli General Terauchi in Peking besuchen. In letzter Minute sagte Terauchi aus Zeitmangel ab. Dafür wurden Militärattaché Thiébaut und zwei Leutnants der französischen Truppen zur Besichtigung der Front eingeladen. Hauptmann Aiby durfte zehn Wochen bei einem japanischen Infanterieregiment hospitieren ${ }^{191}$.

Die Beziehungen zwischen französischen und japanischen Offizieren blieben eng: Als Astier de Villatte am 15. Juli von Shanghai nach Tientsin reisen wollte, ließ er sich mit Zustimmung Naggiars von einem japanischen Flugzeug und begleitet von einem japanischen General nach Nordchina bringen. Drei Tage später besuchte der neue Kommandeur der japanischen Truppen in Shanghai, General Kuno, offiziell Oberstleutnant Perretier, aber nicht die Briten. Kuno war von 1917 bis 1921 in Frankreich eingesetzt gewesen und äußerte sich nun sehr herzlich gegenüber den Franzosen. Er sorgte dafür, daß japanische Militärfahrzeuge in Shanghai mit Nummernschildern fuhren, auf die die französischen Behörden zuvor lange vergeblich gedrängt hatten. Die vielen militärischen Mittag- und Abendessen sowie französisch-japanischen Cocktails in Shanghai hatten offenbar Erfolg: Der japanische Leutnant Aso, Adjutant von Admiral Sisido, nannte bei einem Besuch am 20. Juli 1938 die Beziehungen zwischen beiden Truppen "noch nie so gut wie heute « und gab darin wohl auch das Urteil seines Chefs wieder. Ganz selbstverständlich lud

\footnotetext{
${ }^{190}$ La Vie, 1.5., Naggiar an Lacoste, L 448, 5.5., Détachement Français de Changhai, Aide Mémoire, 17.5., Naggiar an Lacoste, L, 1.6., Naggiar an Perretier, L, 1.6., Henry an Bonnet, T 301, 19.6., Naggiar an Bonnet, T 829, 25.6; Naggiar an Bonnet, L 370, 30.5 .1938 (MAE Chine 563, 577); Lacoste an Naggiar, L, 17.6., Naggiar an Lépissier, L 39, 1.7.1938 (MAEN Pékin A 345).

${ }^{191}$ Dentz an Diplomatie, L 2744, 11.5.1938 (MAE Japon 126); Thiébaut an EMA.2, L 39, 16.6., compte rendu $\mathrm{n}^{\circ}$ 79, 10.7., L 64, 15.11.1938 (SHAT $7 \mathrm{~N}$ 3331); Henry an Naggiar, $\mathrm{T}$ 110, 25.5., Naggiar, Note, 2.6.1938 (MAE Chine 563); Knobel an Lacoste, T 272, 16.6., Lacoste an Naggiar, L 425, 10.7.1938 (MAEN Pékin A 345); Militär Tientsin an Guerre, T 687, 31.8.1938 (SHAT 11 H 61).
} 
General Kuwaki, der neue Oberkommandierende in Nordchina, Oberst Jacomy und Astier de Villatte am 15. August in seine Residenz ein. Der französische Luftwaffenattaché Commandant de La Ferté Sénectère urteilte, die persönlichen Beziehungen der japanischen Offiziere $z u$ den Franzosen seien weit besser als die zu den anderen ausländischen Offizieren ${ }^{192}$.

Die beteiligten französischen Offiziere und Diplomaten sahen ihr Verhalten als klugen Weg, um französische Interessen in China zu bewahren. Mit der von Naggiar oft beschworenen Würde hatte die distanzlose Anbiederung an die Okkupanten aber nichts zu tun. Die Briten verhielten sich kaum würdiger. Das britische Militär in Shanghai erhielt im November 1937, so die Information des US-Generalkonsuls, »orders from London«, ihre japanischen Kollegen zu besänftigen. Bei einem Essen erschien den US-Vertretern das Bemühen des kommandierenden britischen Generals, freundlich zu den Japanern zu sein, »allzu offensichtlich«.

Mitte Dezember mußte Außenminister Eden der Öffentlichkeit Fotos erklären, die japanische und britische Soldaten bei Feiern zeigte. Im Mai 1938 kam der britische Militärattaché in Tokio, Generalmajor Piggott, für eine Woche nach Shanghai, um bei höchsten Stellen mit Einladungen zum Essen »die englisch-japanische Herzlichkeit wiederzubeleben«. Dies gelang ihm so gut, daß im Unterhaus die Fraternisierung kritisiert wurde. Die Idee, die persönlichen Beziehungen zwischen britischen und japanischen Offiziellen zu verbessern, um die Respektierung britischer Rechte in China zu erreichen, stammte von Naggiars Kollegen Sir Archibald Clark Kerr. Nach seiner Rückkehr aus Shanghai sprach Piggott eine Stunde mit Außenminister Ugaki. Zum Gegenbesuch luden die Japaner Sir Percy Noble, den Kommandeur der Fernostflotte, nach Japan ein ${ }^{193}$.

Kontakte, die nicht im Blickfeld der Öffentlichkeit standen, waren noch enger. Bis zum Herbst 1938 dienten sieben britische Offiziere in japanische Einheiten, um Japanisch zu lernen. Im Juni 1939 waren es noch vier Offiziere.

${ }^{192}$ Naggiar an Bonnet, L 513, 29.7.1938 (MAE Chine 563); Aide-mémoire, 20.7.[1938] (MAEN Pékin A 345); Major Eda, Tientsin, an Villatte, 14.8.1938 (SHAT 11 H 61); La Ferté Sénectère, rapport, 4.8.1938 (MAE Chine 565). Transporte französischer Offiziere durch die japanische Luftwaffe waren offenbar üblich. Im Dezember 1939 erhielt Militärattaché Yvon anstandslos einen Platz im Flugzeug von Shanghai nach Hankou, und selbst im Juni 1940 bat das französische Heer die Japaner mit großer Selbstverständlichkeit um einen Transport innerhalb Chinas (Georges-Picot an Cosme, T 709, 8.12.1939, MAEN Pékin A 346; TRNQuiER, Le temps perdu, S. 92f.).

${ }_{193}$ Gauss an Hull, 17.11.1937 (SD 793.94/11166); FO Minute, 16.12.1937 (FO 371/21018, F 11223/6799/10); Clark Kerr an Halifax, 1.6., 5.6., Parliamentary Question, 16.6., Craigie an Halifax, 18.6., 30.6.1938 (FO 371/22152-53, F 6012, 6606, 7419, F 8037/1155/10); Naggiar an Bonnet, T 704, 27.5.1938 (MAE Chine 577). 
London und Tokio tauschten von 1936 bis 1938 zudem Geheimdienstinformationen über die Sowjetunion aus ${ }^{194}$.

Dank der guten Beziehungen zwischen japanischen und französischen Offizieren wurden im Sommer 1938 in Tientsin alle Zwischenfälle beigelegt. Die Vorfälle häuften sich: Im Mai verübten Provokateure in japanischem Auftrag in Frankreichs Konzession einen Bombenanschlag auf einen chinesischen Zeitungsverlag. Ein japantreuer chinesischer Bankier sollte dort entführt werden. Japanische Truppen drohten sofort mit Einmarsch in die Konzession. Japans Polizei versuchte mehrfach, in der Konzession Untersuchungen durchzufuihren, was französische Beamte unterbanden. Den Hauptgrund für die Aggressionen sah Lépissier in dem neuen japanischen Personal, das der gemäßigten Politik des bisherigen Generalkonsuls Horiuchis nicht folge. Lépissier räumte ein, daß Chiang Kai-shek die Konzession als Zentrum des Widerstands mißbrauche. Jüngste Ereignisse, schrieb der französische Konsul am 7. Juni, einen Tag, nachdem zwei Zeitbomben gegen japanische Einrichtungen in der Konzession explodiert waren, zeigten, daß Japans Beschwerden oft berechtigt seien. Teils durch heftige Proteste, teils durch freundschaftliches Einwirken auf Japans Kommandeure erreichte er, daß diese Anfang Juli den Durchgang japanischer Soldaten durch die Konzession unterbanden ${ }^{195}$.

Mitte Juli 1938 verschlechterte sich in Tientsin das Klima zwischen dem japanischen Militär und den Konzessionen Frankreichs und Großbritanniens. Lacoste führte das auf die Agitation japanischer Extremisten und die antifranzösische Propaganda von Domei zurück. Lépissier klagte, daß China die Konzessionen für antijapanische Aktivitäten nutze: Im April sei ein Guerillaführer in die französische Konzession geflüchtet, am 20. Juli habe die britische Polizei in ihrer Konzession einen Kommandoposten der Guerilla mit Funk, Waffen und Blankopässen entdeckt. Angesichts von 250000 Partisanen in Nordchina, so japanische Schätzungen, die 150000 japanische Soldaten banden, konnte Japan die Konzessionen als Ruhezone seiner Feinde kaum dulden. Lépissiers Polizei fand Ende Juli Waffen und Munition, die den Japanern gestohlen worden waren. Wenig später drangen japanische Polizisten in Zivil in die Konzession ein, weil eine chinesische Druckerei Geldscheine für Chiang Kai-shek herstellte. Die Japaner verlangten die Auslieferung der beteiligten 22

\footnotetext{
${ }^{194}$ Craigie an Halifax, T 28, 25.1.1938 (FO 371/22177, F 2301/11/23); Craigie, Report, 1.1.1940 (FO 371/24743, F 2417/2417/23); ELPHICK, Far Eastern File, S. 234f. Ob US-Militärs sich anbiederten, ist unklar. Bei Militärattaché Stilwell, der Japan nicht mochte, scheint dies ausgeschlossen, doch ordneten die USA im Herbst 1938 neun Sprachoffiziere in japanische Einheiten ab (TUCHMAN, Sand gegen den Wind, S. 173, S. 200; Thiébaut an EMA.2, L 136, 24.11.1938; SHAT 7 N 3331).

${ }^{195}$ Jacomy an Mandel, T 140, 16.6., Jacomy an General Ida, L 851, 29.6.1938 (SHAT 11 H 57, 61); Naggiar an Bonnet, T 756-57, 6.6., L 483, 18.7.1938 (MAE Chine 723, 829); Lépissier an Bonnet, L 37, 7.6., L 41, 5.7., Lacoste an Horiuchi, 2.7.1938 (MAE Chine 828, 725, 829).
} 
Arbeiter, was Lépissier aber verweigerte. Die Briten in Shanghai lieferten chinesische Verdächtige üblicherweise an die Japaner aus ${ }^{196}$.

Am 1. September 1938 vertraute der deutsche Generalkonsul Stoller seinem französischen Kollegen aus Solidarität unter Europäern an, Japans Armee habe am Vorabend ihren Bürgern befohlen, binnen zehn Tagen die britische und die französische Konzession zu verlassen. Erste Umzüge hatten begonnen. Japans Armee ließ einen Fesselballon mit einem Beobachter über der französischen Konzession aufsteigen, 22 Flugzeuge überflogen die Konzessionen. Direkt vor britischem und französischem Gebiet errichteten die Japaner Bunker mit Geschützen und Maschinengewehren, um beide Konzessionen zur Zusammenarbeit bei der Bekämpfung antijapanischer Kräfte zu zwingen ${ }^{197}$. In Shanghai erklärte Naggiar dem japanischen Gesandten Tani, Vorwürfe an Briten und Franzosen, sie gingen nicht gegen Chiang Kai-sheks Männer vor, seien ungerechtfertigt. Naggiar bat Henry um sofortige Intervention im Gaimusho. Er solle klarstellen, daß ein bewaffnetes Vorgehen der japanischen Armee auf Frankreichs bewaffneten Widerstand stoßen werde.

Weil die Japaner ihren Auszug nicht begründeten, konnten die Franzosen über die Ursache nur spekulieren: Oberstleutnant Astier de Villatte glaubte an wirtschaftliche Repressalien; der Marine-Geheimdienst vermutete erst, es gehe Japans Armee um die Auslieferung der Gelddrucker, dann, Grundstückspekulationen hätten die Armee motiviert. Die Asienabteilung im Quai d'Orsay nahm an, Japan wolle den Einsatz japanischer Polizisten und eine Durchmarscherlaubnis für seine Truppen in den Konzessionen durchsetzen; womöglich wollten die Kommandeure die Konzessionen erobern. Der Stab der US-Armee und Naggiar hielten es für wahrscheinlich, daß weitere Schritte gegen die Konzession folgen würden. Aktueller Anlaß der Evakuierung, erklärten Japaner einem französischen Hauptmann in Tongkou, war ein Guerillaüberfall am 25. August, bei dem die Japaner zehn Partisanen festnahmen. Alle zehn seien in der britischen Konzession gegen Cholera geimpft worden, ihr MG stamme aus der britischen Konzession, und die meisten Guerillas wohnten auch dort. Wie weit die beiden Konzessionen Japan aber bereits entgegengekommen waren, beschrieb der deutsche Generalkonsul:

\footnotetext{
${ }^{196}$ Lacoste an Naggiar, L 425, 10.7., Lacoste an Bonnet, T 86, 18.8.; STS-bulletin, 1.8.1938 (MAE Chine 770, 533); Lépissier an Naggiar, L 85, 21.7., Lépissier an Bonnet, L 50, 2.8.1938 (MAE Chine 829); Lépissier an Naggiar, L 89, 30.7., Lépissier an Jacomy, L 53, 30.7.1938 (SHAT 11 H 63).

${ }^{197}$ Naggiar an Bonnet, T 1224-28, 1.9., Naggiar an Lépissier, T 1229-31, 1.9.; Naggiar an Henry, T 1228-31, 1.9., Lépissier an Bonnet, L 59, 5.9.; L 67, 6.10.1938 (MAE Chine 770, 829, 728); EMG.2, bulletin de renseignement, 16.11.1938 (SHM 1BB2 92); Materials for the private report to the report by Minister Ugaki, East Asia Bureau, 21.9.1938 (TWCT, II, S. 3584f., Exhibit No. 269).
} 
Sie erlauben den Durchzug bewaffneter japanischer Truppen gegen eine rein formelle vorherige Anmeldung, während Truppen ohne Waffen frei passieren können. Sie unterdrücken chinesisch-nationalistische, antijapanische Propaganda im Interesse der Neutralität und der Aufrechterhaltung der Ordnung [...]. Sie durchsuchen alle mit Dampfern ankommenden Chinesen sowie regelmäßig täglich die chinesischen Hotels nach Agitatoren, Waffen und Munition; sie überwachen Theater und Kinos und haben die in der ersten Zeit des Konflikts hervorgeschossene chinesische nationalistische >Moskitopresse` (die großen Blätter waren bekanntlich verschwunden) unterdrückt. Sie führen ferner, wenn ihnen von den Japanem konkrete Verdachtsfälle mitgeteilt werden, Haussuchungen bei chinesischen Bewohnern aus. Aber diese \Mit<-Arbeit genügt den Japanern, wie auch mein japanischer Kollege ausdrücklich versicherte, durchaus nicht ${ }^{198}$.

Die Franzosen wußten um ihre Machtlosigkeit. So rasch wie die Bedrohung gekommen war, verging sie wieder: Der japanische Vize-Konsul Shima sagte am 3. September in Tientsin, die Evakuierung werde abgebrochen. Informationen aus Tokio, Peking und Tientsin zufolge hatten Extremisten im Generalstab Terauchis die Aktion ohne Wissen der Diplomaten angeordnet. Der japanische Generalkonsul Tashiro war nach Tokio geflogen, um den Abbruch der Maßnahme zu erreichen. Als auch japanische Geschäftsleute protestierten, beendete die Armee die Evakuierung, forderte aber die Übergabe der in den Konzessionen deponierten Silberreserven der Chinesischen Nationalbank. Gegenüber den französischen Truppen behielt das japanische Militär seinen freundlichen Ton bei. Es bat Oberstleutnant Astier de Villatte, bei den zivilen Behörden zu erreichen, daß »antijapanische Kräfte« keinen Schutz erhielten. Bei einem Treffen japanischer und französischer Militärs zwei Tage später blieb der Ton herzlich. Lépissier griff zu einem bewährten Mittel, um die Spannungen weiter abzubauen: Er schlug Briten, Italienern und Japanern ein wöchentliches Abendessen der vier Polizeichefs vor. Die Japaner stimmten unregelmäßigen Treffen zwischen französischen und japanischen Offizieren zu. Um nach der gescheiterten Evakuierung ihr Gesicht zu wahren, plante Japans Armee, einen Sperr-Ring um die Konzessionen zu legen, wie Lépissier vom italienischen Konsul Steffineli erfuhr. Nach Informationen Steffinelis und Stollers ziele die Blockade auf Shanghai, das besetzt werden solle. Der Versuch werde aber in Tientsin unternommen, weil er dort leichter realisierbar sei. Lépissier und die Asienabteilung in Paris beruhigten, daß die Konzessionen in Shanghai seit November 1937 in ihrer bedrängten Lage gut hätten leben können ${ }^{199}$.

\footnotetext{
${ }^{198}$ De Villatte an Jacomy, T 688, 1.9.1938 (SHAT 11 H 60); STS-bulletin, 1.9., 1.10.1938 (MAE Chine 534); Note de la sous-direction d'Asie-Océanie, 2.9.1938 (MAE Chine 829); Memorandum for the Chief of Staff, 2.9.1938 (SD 793.94/13833); Capitaine Batz, commandant de la gamison de Tongkou, an Jacomy, L 36, 8.9.1938 (SHAT 11 H 63); Stoller an Ribbentrop, 2.9.1938 (AA PoI VIII 58 B 1).

${ }_{199}$ Note sur l'entretien officiel, Astier de Villatte, 3.9.1938 (SHAT 11 H 61); Naggiar an Lépissier, T 1282-84, 10.9., Naggiar an Bonnet, T 1244-48, T 1250, 3.9.; Henry an Bonnet, T 485-88, 3.9.; Lépissier an Bonnet, L 62, 19.9.; Lacoste an Bonnet, L 575, 5.9.; Naggiar an Bonnet, $T$ 1253-58, 4.9., Lépissier an Bonnet, L 59, 5.9., note de la sous-direction d'Asie-Océanie, 5.9.1938 (MAE Chine 770, 830, 829).
} 
In Shanghai blieben die Spannungen zwischen Franzosen und Japanern gering, obwohl China die französische Konzession für seinen Kampf nutzte: Geheime Einrichtungen der chinesischen Regierung, vom Büro der Central News Agency über eine Propagandaabteilung der Kuomintang, politische Theatergruppen und eine Geheimuniversität bis hin zu Spionage-, Mord- und Terrororganisationen, die Chiang Kai-sheks Militärgeheimdienst unterstanden, hatten ihren Sitz in der französischen Konzession oder nutzten sie als Basis. Dies war zeitgenössisch aber wohl weder den Japanern, noch den Franzosen bekannt. Renommiert war jedoch die Härte, mit der Frankreichs Polizei in der Konzession für Ordnung sorgte. Insbesondere vor Jahrestagen nahmen französische Ordnungskräfte hunderte von Chinesen fest. Darunter befand sich am 7. Juli 1938 Chiang Hai-sheng, der mit Bombenanschlägen in der Internationalen Konzession in Verbindung stand. Die Franzosen übergaben ihn dem Internationalen Stadtrat, der ihn den japanischen Behörden auslieferte. Bis Mitte August lieferte das Settlement 35 »verdächtige « Chinesen aus, von denen die Japaner 20 exekutierten. Naggiar hielt die Auslieferungen für ein Zeichen der Schwäche: Die Japaner seien sich ihrer Überlegenheit über die Weißen nicht sicher. Zeige man Angst, stelle Japan weitere Forderungen; demonstriere man Entschlossenheit, halte es inne. Die Führung der französischen Konzession sprach zwar Durchsuchungen mit den Japanern ab, hielt aber auch am Prinzip ihrer Autorität fest, als sie drei japanische Polizisten, die im August 1938 in ihre Konzession vordrangen, festnahm. Mit der französischen Mischung aus Entgegenkommen und Festigkeit erklärte sich Naggiar, daß die japanische Propaganda sich vor allem gegen die Internationale Konzession richtete ${ }^{200}$.

Hauptgründe für die japanische Verschonung der französischen Konzession dürften aber gewesen sein, daß das Settlement Hauptziel des chinesischen Terrorismus war, da in der französischen Konzession nur wenige Japaner wohnten oder Geschäfte unterhielten ${ }^{201}$ und weil es für die Japaner im Settlement, an dem sie förmlich mitbeteiligt waren, leichter war, die Ordnung von innen her zu untergraben.

Das Vorzeigen der Folterinstrumente durch Japans Armee in Tientsin hatte Folgen: Lépissier versicherte Anfang September seinem japanischen Kollegen, die Konzession dulde keine Unruhe. Alle aus japanischer Sicht subversiven Bewegungen würden unterdrückt. Lépissier ging bei Zusagen offenbar soweit, daß Naggiar ihm die förmliche Zusammenarbeit mit den Japanern untersagte.

${ }^{200}$ PoSHEK, Passivity, S. 35f., S. 78f.; WAKEMAN, The Shanghai Badlands, S. 18f.; Naggiar an Bonnet, T 950-52, 9.7.; Consulat général, note, 8.8., Naggiar an Bonnet, T 1153, 15.8., L, 18.8., L 19.8., Naggiar an Tani, L, 18.8., service de police, note, 25.8.1938 (MAE Chine 725, 1063).

${ }^{201}$ Christian HENRoT, ,Little Japan in Shanghai: an Insulated Comunity, 1875-1945, in: Robert BiCKERS, Christian HeNRIOT (Hg.), New Frontiers. Imperialism's New Communities in East Asia, 1842-1953, Manchester, New York 2000, S. 146-169 (S. 151f.). 
Stoller skizzierte die Haltung des britischen und des französischen Generalkonsuls so:

Sie würden vernünftigen japanischen Vorschlägen, wie man noch mehr Sicherheit produzieren könne, entgegenkommen. Aber sie könnten ihre Konzessionen nicht mehr oder weniger den Japanern aushändigen, indem sie offiziellen japanischen Agenten, Polizei und Gendarmerie eine Mitwirkung bei Polizeimaßnahmen einräumten.

Über den Umfang der Kooperation konnte sich Japan nicht beschweren: Am 18. September nahm die französische Polizei zwei 20-jährige Chinesen fest, die eine geheime Bombenproduktion in der englischen Konzession betrieben hatten. Lépissier lieferte mit Naggiars Zustimmung die Männer an die chinesische Polizei in japanischen Diensten aus. Später zeigte sich, daß japanische Stellen hinter den beiden Chinesen standen. Offenbar wollte Japan den Willen der beiden Konzessionen zur Zusammenarbeit auf die Probe stellen ${ }^{202}$.

\subsection{Die Sudetenkrise und ihre Folgen im Fernen Osten}

Die Logik der französischen Politiker und Militärs, Frankreichs Position im Fernen Osten beruhe auf der Sicherheit am Rhein, schlug im September 1938 um: Weil in Europa der Ausbruch eines Krieges drohte, geriet auch die französische Position in Asien ins Rutschen. Im gesamten Verlauf der Dritten Republik war bei den Franzosen die Furcht vor einem japanischen Angriff auf die Konzessionen nie größer als in den letzten Septembertagen 1938.

Schon Anfang September glaubte Naggiar, die Lage in Europa habe Japans Evakuierungsversuch in Tientsin ausgelöst. Die chinesische projapanische Presse schrieb, daß Japan - wie 1914 das deutsche Pachtgebiet in Tsingtao die westlichen Konzessionen besetzen und britische und französische Bürger internieren werde. Dies befürchteten die Europäer in Shanghai bereits. Den Widerstand der Franzosen in Tientsin testete Japans Militär am 10. September, als zwei japanische Infanterieabteilungen einen Teil der Konzession besetzten. Nach Erscheinen des französischen Generalkonsuls Lépissier und des Oberkommandierenden Jacomy zogen die Japaner wieder $\mathrm{ab}^{203}$.

\footnotetext{
${ }^{202}$ Naggiar an Lépissier, T 1256-58, 4.9., T 1282-84, 10.9.1938 (MAE Chine 770); Stoller an Ribbentrop, 14.9.1938 (AA Pol II Po 3 England Bez GB-Japan 3); Naggiar an Lépissier, T 166, 19.9., Lépissier an Naggiar, T, 20.9., L, 4.10.; Lépissier an Bonnet, L 67, 6.10.1938 (MAE Chine 830, 728). ${ }^{203}$ Naggiar an Bonnet, T 1244-48, 3.9.1938 (MAE Chine 770); Memorandum, 2.9.1938 (SD 793.94/13833); Astier de Vilatte, L 127/Cab, note du chef d'état-major, 11.9.1938 (SHAT 11 H 61); Naggiar an Bonnet, T 1501-3, 11.9., L 63, 21.9.1938 (MAE Chine 830).
} 
Auch das Klima zwischen den westlichen und den japanischen Diplomaten in Peking kühlte deutlich ab. Die Japaner erklärten Lacoste und seinem britischen Kollegen Young, die Zeiten, in denen man die Rechte der Mächte respektiert habe, seien vorbei. Lacoste und Young gewannen den Eindruck, daß die Vertreter des Gaimusho in Peking, die früher auf das Militär mäßigend eingewirkt hätten, ihrer Armee nur noch in Ausnahmefällen Widerstand leisteten, wie bei der vom Heer befohlenen Evakuierung Tientsins. In allen anderen Fragen, wie beim Verbot des »Journal de Pékin« und der »Peking and Tientsin Times« oder der vorübergehenden Festnahme zweier französischer Soldaten, denen erklärt wurde, außer Dienst genössen sie keine Extraterritorialität, beugten sich die Diplomaten der Willkür des Militärs. Den besonders schweren Stand der Franzosen erklärte Lacoste damit, daß die Mitglieder der japanischen Botschaft meist in den USA ausgebildet worden seien und deshalb Spanier und verwandte Völker verachteten. Jedoch wurden Bitten der Amerikaner, der Briten und der Deutschen in Peking mit dem gleichen Hochmut verworfen wie die der Franzosen und der Italiener. Die drei westlichen Demokratien gingen deshalb dazu über, Proteste über die Mißachtung ihrer Rechte in Nordchina in Tokio vorzubringen. Als Gründe für das gewandelte Klima vermutete Lacoste stärkere Aktivitäten der Guerillas, das Scheitern der japanischen wirtschaftlichen Pläne für Nordchina sowie die Möglichkeit eines Krieges in Europa, der die Mächte in Asien schwächen werde ${ }^{204}$.

In Paris fürchtete der Generalstab der Armee, daß Japans Armee bei einem Konflikt in Europa gegen Südchina oder die Sowjetunion vorgehe. Daß seit langem am 9. September wieder ein japanisches Flugzeug Hainan überflog, schien auf japanische Pläne für die Insel hinzudeuten. Nur Henry urteilte, Japans Armee sei zu erschöpft für größere Angriffe. »[U]ne initiative folle des militaires déchaînés « gegen die Konzessionen hielt Henry aber für denkbar. Am 10. September bat Naggiar Bonnet erstmals um Instruktionen für den Fall eines japanischen Angriffs auf die Konzessionen, den die Lage in Europa möglich gemacht habe. Bis dahin war ein solcher Angriff in den Plänen nicht vorgesehen, sondern nur Attacken durch Chinesen, die die Mächte gemeinsam abwehren wollten (»Plan $\mathrm{Z} \ll$ ). Allein in Tientsin hatten Briten und Franzosen im Herbst 1937 einen Plan für die Verteidigung gegen japanische Verbände (»Plan 50«) erstellt. In Shanghai sahen die 1931 und 1934 erarbeiteten Pläne bis 1939 vor, gemeinsam mit Japan die Konzessionen gegen China zu verteidigen. Naggiars Lage wurde dadurch erschwert, daß der Oberkommandierende der französischen Streitkräfte in China, Admiral Le Bigot, gerade Bali besuchte. Dem Oberkommandierenden der französischen Heeresverbände, Oberst Ja-

${ }^{204}$ Lacoste an Naggiar, L 529, 17.9., Naggiar an Henry, T 1322, 18.9.1938 (MAE Chine 770); Young an Clark Kerr, 21.9., 19.10.1938 (FO 371/22164, F 12289/12289/10; FO 371/22052, F 13206/12/10). 
comy, wollte Naggiar die Führung der Truppen in Shanghai nicht anvertrauen, weil er große Zweifel an dessen Eignung hatte ${ }^{205}$.

Mit der wachsenden Kriegsgefahr in Europa stellte sich allen Soldaten und Diplomaten in China und den in Paris für die Fernostpolitik Verantwortlichen die Frage, ob sie die für Frankreichs Position in China so wichtigen Konzessionen im Ernstfall verteidigen wollten. Bislang hatten die Franzosen, verglichen mit den anderen Mächten, ihrer militärischen Präsenz eine herausragende Position eingeräumt. Die Franzosen unterhielten im Spätsommer 19381900 Soldaten in Nordchina, die auf das Ost-Arsenal bei Tientsin (1200 Mann), die Konzession in Tientsin und die Botschaft in Peking (je 250 Mann), sowie die drei Posten Tongkou, Shanhaikouan und Chingwangtao an der Bahnstrecke von Tientsin zum Meer verteilt waren. Damit unterhielten die Franzosen im Norden so viele Truppen wie Briten (900 Mann), Amerikaner (600 Mann) und Italiener (400 Mann) zusammen. In Shanghai hielten sich, nachdem Amerikaner und Briten im ruhigen Sommer 1938 ihre Verbände um 60 Prozent reduziert hatten, 2000 französische, 1000 amerikanische, 900 britische und 700 italienische Soldaten auf. Frankreichs Truppen wurden ergänzt durch 50 Soldaten in Kanton und 200 Mann in Hankou. Rechnet man die 200 Soldaten in Kwangchowan hinzu, unterhielt Frankreich in China das beachtliche Kontingent von knapp 4400 Mann, von denen etwa 2300 aus Indochina kamen ${ }^{206}$.

Offizieller Grund ihrer Präsenz in China war, die Sicherheit französischer Händler und Missionare zu garantieren. In den Jahren 1938 bis 1939 lebten ohne Soldaten und Diplomaten - rund 2600 Franzosen in China ${ }^{207}$. Damit wurde jeder französische Bürger in China von zwei Soldaten geschützt. Schon dieses Verhältnis zeigt, daß die französischen Truppen in China nur noch französische Rechtsansprüche, also ihre eigene Anwesenheit, verteidigten.

Moutet hatte unter Hinweis auf die in China anfallenden Kosten von 70 Millionen Francs pro Jahr - ein Zehntel der Militärausgaben des Kolonialministe-

${ }^{205}$ EMA.2, note, 5.9., Diplomatie an Marine, T 172, 13.9 .1938 (SHAT 7 N 3133, SHM 1 BB9 40); Henry an Bonnet, T 493-99, 11.9.1938 (DDF XI, 85); Craigie an Halifax, 15.9.1938 (FO 371/22185, F 9887/152/23); Hentschel an Lépissier, L 310, 30.9., Lépissier an Hentschel, L 101, 14.10., Lépissier an Delbos, L 34, 15.10.1937; Cosme an Daladier, T 1036-37, 22.9.1939 (MAE Chine 785, 1064); FNEO, Plan de défense de la concession française de Shanghai, rédaction octobre 1936; Naggiar an Bonnet, T 1279-80, 10.9., T 1292-93, 11.9.1938 (SHM 1 BB4 74, MAE Chine 575).

${ }^{206}$ Die Franzosen änderten die Stärke ihrer Kontingente bis zum Herbst 1939 in Kanton und Hankou nicht, reduzierten aber die Zahl der Soldaten in Nordchina auf 1250 sowie in Shanghai auf 1350 (über die militärische Stärke informieren Aufstellungen aus SHAT $11 \mathrm{H} \mathrm{60,61,63,79).}$

${ }^{207}$ Die Fernostflottille kam im Febnuar 1939 bei ihrer Statistik auf 2248 in China lebende Franzosen. Dieser Zahl sind 360 französische Missionare hinzufügen. Offenbar verließen von 1936 bis 1939 fast 1000 Franzosen, 900 aus Shanghai und 70 aus Tientsin, China. Das Außenministerium ging 1943 von 2560 in China lebenden Franzosen aus (FNEO, note 12, tableau des nationaux français en Chine en dehors des missions, 11.2.1939, SHM 1 BB4 74; Revue générale des avoirs français en Chine, Vichy, 3.3.1943, MAE bureau d'études Jean Chauvel 135). 
riums - im Februar 1937 eine Reduzierung der Truppen in den Konzessionen verlangt, die man billiger durch Flugzeuge verteidigen könne. General Gamelin erwiderte, nur Heeresverbände könnten Ordnung schaffen. Aber die Diskussion blieb theoretisch. Naggiar und Léger waren sich im November 1937 einig, daß sich die Frage, wie man auf einen Angriff auf die Konzessionen reagiere, angesichts der französisch-japanischen Beziehungen nicht stelle ${ }^{208}$.

Der im August 1937 ernannte Kommandeur der französischen Heerestruppen in China, Oberst Henri Jacomy, sah die Lage allein aus militärtaktischer Perspektive: Er plante, in Nordchina Krieg zu führen, und verlangte die Aufgabe strategisch wertloser Standorte und den Bau neuer Bunker. In Pekings Diplomatenviertel wollte er Mauern durchbrechen und Bürgersteige verbarrikadieren. In seinem Kriegsszenario kam Jacomy zu dem Schluß, daß er in Nordchina, wo eine Konzession und ein Botschaftsviertel zu verteidigen waren, nicht beweglich sei. Vize-Admiral Le Bigot spottete, der Oberst träume davon, eine zweite Boxer-Expedition zu kommandieren. Jacomy selbst wollte von Tientsin nach Shanghai versetzt werden. Im Dezember 1937 wurde klar, daß Jacomy Angst um seine persönliche Sicherheit hatte ${ }^{209}$. Der Oberst hatte den Sinn der französischen militärischen Präsenz nicht verstanden: Von den Truppen hatte Ruhe und Entschlossenheit auszugehen. Vermochten sie einen Gegner nicht abzuschrecken, hatten sie bereits versagt. Gegen die um Zehnerpotenzen stärkere japanische Armee war ein Kampf aussichtslos. Jacomys Kriegsplan hielt Sabattier für Unsinn. Naggiar versuchte deshalb alles, um Jacomy im entfernten Tientsin zu halten ${ }^{210}$. Schon bei dessen Ankunft in China hatte Naggiar Jacomys fehlende China-Erfahrung bemängelt. Nun überging der Botschafter den Kommandeur systematisch. Später urteilte Naggiar, der Oberst habe die wesentlichen Gegebenheiten in China nicht verstanden ${ }^{211}$.

\footnotetext{
${ }^{208}$ Comité permanent de la défense nationale, procès-verbal de la séance du 15.2., Lépissier an Hentschel, L 77, 30.8.; Naggiar an Delbos, T 705-6, 15.11., Léger an Naggiar, T 312, 16.11.1937 (SHAT 2 N 22, 11 H 60; MAE Chine 1062); Robert FRANKENSTEIN, Le prix du réarmement français (1935-1939), Paris 1982, S. 303.

209 Jacomy an Colonies, L, [August 1937]; Jacomy an Offiziere, Instruction, 27.11.1937 (SHAT $11 \mathrm{H}$ 57); Jacomy an Moutet, T, 30.11 .1937 (SHM I BB9 131); Jacomy an Moutet, T 440-43, 15.12., T 447-50, 20.12.1937 (SHAT 11 H 60); Jacomy an Lacoste, L 539, 17.12.1938; Jacomy an Moutet, L 542, 17.12., Jacomy an Naggiar, L 459, 25.12., L, 31.12.1937 (SHAT 11 H 57); Le Bigot an Naggiar, L, 18.11.1938 (MAE Chine 564); Lacoste an Naggiar, L 777, 20.12.1937 (MAEN Pékin A 100).

${ }_{210}$ Sabattier, notes, 22.12., 13.12.1937 (MAEN Pékin A 100, 345). Jacomy an Audeguis, L 586, 31.12.1937, Jacomy an Guerre, $T$ 464, 5.1., Jacomy an Moutet, $T$ 478, 15.1., Jacomy an Naggiar, $L$ 41, 15.1. T 506, 29.1., T 505, 31.1.1938 (SHAT 11 H 57, 60); Naggiar an Jacomy, L 2, 8.1., L 5, 17.1., T 8, 28.1., T 10, 1.2.; Jacomy an Naggiar, T, 8.1.1938 (SHAT 11 H 64, 57); Naggiar an Delbos, T 26-29, 6.1., T 102-5, 17.1., Léger an Naggiar, T 21-22, 18.1.1938 (MAE Chine 562).

${ }^{211}$ Jacomy an Steeg, T 584, 19.4., Jacomy an Mandel, L, 25.4.1938 (SHAT $11 \mathrm{H} \mathrm{60,77);} \mathrm{Naggiar} \mathrm{an}$ Paul-Boncour, T 392-94, 24.3., Naggiar an Bonnet, L 766, 14.11.1938 (MAE Chine 575, 564); Naggiar an Delbos, L 70, 14.1.1938, T 358, 25.8.1937 (MAEN Pékin A 345bis, MAE Chine 704).
} 
Jacomy kam auch nicht mit der Überordnung des Botschafters zurecht. Dieser war Oberbefehlshaber der Truppen in China. Nach einer Anweisung, auf die sich Marine, Armee und Diplomatie nach sieben Jahren Diskussion 1935 geeinigt hatten, war der Botschafter verantwortlich für den Schutz der Franzosen in China. Das Oberkommando hatte seinen Anweisungen zu folgen, falls der Botschafter nicht sogar selbst die Truppen führte, wie es Naggiar bevorzugte. Oberkommandeur aller Truppen in China war der Chef der Fernostflottille, sein Stellvertreter der kommandierende Oberst der Heeresverbände in China. Die Frage, ob französische Truppen die Konzessionen gegen einen Angriff Japans verteidigen sollten, war im Frühjahr und Sommer 1938 in Paris ergebnislos diskutiert worden. Die Überlegungen wurden dringlicher, als die USA ihr Militär in China reduzierten. Am 14. Februar 1938 gab Washington den Abzug von zwei Bataillonen aus Nordchina bekannt ${ }^{212}$.

General Billotte, Präsident des Comité consultatif de défense des colonies, hatte im Januar 1938 erstmals dargelegt, daß die Konzessionen einem Angriff durch reguläre Truppen nicht standhalten könnten. Deshalb solle man die Verbände aus China abziehen und die Anstrengungen auf Indochina konzentrieren. Le Bigot, der noch mit China als potentiellem Angreifer rechnete, stimmte Billottes Schlußfolgerungen zu. Die Marineführung in Paris jedoch hielt die Diskussion eines Abzugs für verfrüht.

Der Generalstab der Armee und der Kolonialminister drängten im März und April 1938 weiter auf den Abzug der Truppen. Es sei nicht zu rechtfertigen, teure Truppen, die in Indochina gebraucht würden, in China zu halten, wo sie sich im Fall eines Angriffs nicht einmal verteidigen könnten. Breche ein Weltkrieg aus, an dem Japan auf Seiten der Gegner Frankreichs teilnehme, könnten die Truppen nicht mehr nach Indochina abziehen. Um die Folgen des Abzuges abzumildern, solle dieser sofort beginnen, aber nur langsam fortschreiten. General Louis-Antoine Colson, der Generalstabschef der Armee, regte an, die Artillerie, die am wenigsten in China gebraucht werde, sofort nach Indochina zu verlegen.

Léger wies die Vorschläge des Militärs kategorisch zurück: Frankreich dürfe nicht den geringsten Zweifel aufkommen lassen, daß es seine Rechte verteidige. Gemessen an den gewaltigen Aufgaben in China sei die Stärke des Militärs angemessen. Nur die Artillerie, die in China nicht gebraucht werde, könne abziehen. Der Marine-Geheimdienst unterstützte Léger: Ein Abzug aus China

\footnotetext{
${ }^{212}$ Instruction interministerielle, 6.4.1935 (SHM 1BB2 113); Naggiar an Delbos, T 904-7, 20.12., Naggiar an Delbos, T 915, 23.12.1937 (MAE Chine 715, SDN 359); Jacomy an EMG.2, T 457-58, 24.12.1937 (SHAT 7 N 3319, 11 H 60); Henry an Welles, 8.2., Welles an Henry, 14.2.1938 (FRUS 1938, III, S. 77f., S. 86f.); US-Army an Jacomy, 14.2.; Naggiar an Delbos, T 225-29, 14.2.; EMG.2, bulletin, 17.3.1938 (SHAT 11 H 57, MAE SDN 363, SHM 1BB2 92).
} 
sehe nach präventiver Kapitulation aus, der Erpressungen in Europa folgen würden ${ }^{213}$. Nach weiterem Druck aus dem Kolonialministerium stimmten der Quai d'Orsay und Naggiar Mitte August 1938 zu, ab 1. Oktober die Artillerie aus Tientsin nach Indochina abzuziehen ${ }^{214}$.

Wegen der Spannungen in Europa war Mitte September 1938 an Abzug nicht zu denken. Stattdessen stellte sich noch drängender die Frage, ob sich französische Truppen einem Angriff auf die Konzessionen widersetzen sollten. Am 14. September, zwei Tage, nachdem Hitler auf dem Nürnberger Parteitag mit einem Angriff auf die Tschechoslowakei gedroht hatte, verlangte Naggiar von Bonnet dringend Anweisungen für den Fall eines Angriffs auf die Konzessionen. Oberst Jacomy befahl am 14. September seinen Männern, im Kriegsfall die Konzessionen zu verteidigen. Weil »das Schlimmste zu befürchten« sei, ließ er den Funkcode ändern und das Verbrennen der Geheimdokumente vorbereiten.

Am gleichen Tag sprach Jacomy mit den Briten darüber, ob man die 1700 britischen und französischen Frauen und Kinder in US-Kasernen bringen könne. Léger rief für den 20. September eine Konferenz der Ministerien für Koloniales, Heer, Marine und Äußeres ein. Als aus dem Kolonialministerium die Generäle Bührer und Noiret sowie der Leiter der Politischen Abteilung Gaston Joseph und die Vize-Chefs der Generalstäbe von Marine und Heer, Konteradmiral Bourragué und General Dentz, mit Léger und Hoppenot zusammentrafen, hatte sich die Lage weiter verdüstert. Domei meldete, die Franzosen in Shanghai bereiteten die Evakuierung der Konzession vor. Nachrichten aus Indochina ließen einen Angriff Japans auf die Kolonie möglich erscheinen: Am 13. September hatte Paris erfahren, daß die japanische Marine die Insel Waichow im Golf von Tongking, 25 Meilen südlich von Pakhoi, besetzt hatte und dort vermutlich einen Flugplatz errichtete. Von dort aus hätte Japan Hainan, Südchina und den Schiffsverkehr nach Indochina angreifen können. Am 19. September wurden vor Hainan starke Luft- und Marineaktivitäten der Japaner unter Einsatz eines Flugzeugträgers gemeldet. Mandel sagte, die Sudentenkrise habe die Besetzung Waichows ausgelöst. Am

${ }^{213}$ General Billotte, plan d'ensemble de défense des colonies [Januar 1938]; Steeg an Delbos, L 433, 9.3., Bührer an Gamelin, L 57, 28.3., Colson an Bonnet, L 1585, 11.4., Léger an EMA, L 1255, 30.4.1938 (SHAT 2 N 246, 11 H 64); Bourragué an Billotte, L 19, 4.2., Billotte an Steeg, L 30, 17.2.; Le Bigot an Naggiar, L 18, 15.2., STS-bulletin, 1.7.1938 (SHM 1 BB2 182, MAE Chine 563, 533).

${ }^{214}$ EMA, note, [mai 1938]; Bührer an Gamelin, L, 11.5., Mandel an Bonnet, T 1030, 8.6., Léger an Naggiar, T, 15.6., Jacomy an Naggiar, T 625, 18.6., Lacoste an Naggiar, T 348, T 350-51, 6.7., Naggiar an Bonnet, T 1022-24, 21.7., Naggiar an Lépissier, T 21, 22.7., Naggiar an Jacomy, T, 18.8.1938 (SHAT 11 H 64); Jacomy an Mandel, T 637-40, 8.7.1938 (SHAT 11 H 60). 
20. September erstellte Militärattaché Thiébaut in Tokio eine Studie über die Landungsboote und -schiffe der japanischen Marine ${ }^{215}$.

Die Konferenz beschloß, den Oberbefehl trotz dessen Abwesenheit bei Le Bigot zu lassen und ihn nicht Jacomy zu übertragen. Diese Festlegung wurde Naggiar sofort mitgeteilt, die Entscheidung über das Verhalten im Falle eines Angriffs dagegen erst zwei Tage später. Léger, Hoppenot und die Generäle einigten sich, bewaffneten Widerstand nicht einmal zu erwägen. Dort, wo ein Rückzug möglich sei, wie in Shanghai, solle dieser nach Indochina oder in das Settlement von Shanghai erfolgen. Das Kontingent in Hankou solle nach Kanton oder Chungking abziehen. Wo eine Evakuierung unmöglich sei, wie in Peking und Tientsin, solle sich die Truppe auf ihre Internierung, am besten bei Amerikanern, notfalls bei Japanem, einstellen. In jedem Fall solle die Zahl der Soldaten sofort deutlich reduziert werden. Davon sollten auch die Briten überzeugt werden, telegraphierte Léger an Naggiar. Die USA wolle man erst im letzten Moment ansprechen - wohl, um in Washington den Eindruck französischer Schwäche zu vermeiden. Diese Anweisung vom 22. September war in der Sudetenkrise die letzte, mit der der Quai d'Orsay auf die Lage im Fernen Osten Einfluß nahm, obwohl die Asienabteilung warnte, daß ein japanischer Angriff auf französische und britische Interessen in China bei einem Krieg in Europa wahrscheinlich sei. Zur Besänftigung Japans gab der Quai d'Orsay in einer Handelsfrage nach: Paris erlaubte am 20. September den Import japanischer Porzellanwaren und Fischkonserven, der im Juli untersagt worden war, um Tokio zur Begleichung von Zahlungsrückständen zu bewegen ${ }^{216}$.

Üblicherweise führte der Quai d'Orsay seine Botschafter an der kurzen Leine. Doch die Folgen der Sudetenkrise in China - wie schon die Bedrohung Shanghais im August 1937 - hatte Naggiar allein zu meistern. In Paris kamen die Konzentration auf die Krise in Europa und die Einsicht, in Asien ohnehin nur abwarten zu können, zusammen. Am 22. September schien die Konfrontation zwischen Japan und Frankreich in Tientsin zu beginnen: 25 japanische

\footnotetext{
${ }^{215}$ Naggiar an Bonnet, T 1305-7, 14.9.; Jacomy an die Kommandeure in Nordchina, T 696, Kopie an Naggiar, Mandel, 14.9.1938 (DDF XI, 135; SHAT 11 H 60); TRINQUIER, Le temps perdu, S. 59; Jamieson an Halifax, 14.9., Halifax an Lindsay, 20.9.1938 (DBFP, $3^{\text {rd }}$ series, VIII, 93, 104); Naggiar an Bonnet, T 1316-17, 15.9.1938 (MAE Chine 830); Léger an Défense nationale, T 2928, 17.9., Thiébaut an EMA.2, L 56, 20.9.1938 (SHAT 11 H 64, $7 \mathrm{~N}$ 3334); Lacoste an Naggiar, T 454, 20.9.1938 (MAEN Pékin A493); Brévié an Mandel, T 1024, 13.9., T 1052, 18.9., T 1054, T 1059, 19.9., T 1063, T 1066, 21.9.1938 (CAOM FM 678); Linnell an Hull, 21.9.; Bullitt an Hull, 15.9.; Diplomatie an EMG.2, T 192, 21.9.1938 (SD 793.94/13930, FRUS 1938, III, S. 290, SHM 1 BB9 41). ${ }^{216}$ Notes de la sous-direction d'Asie-Océanie, 20.9., 23.9.1938 (MAE Japon 127, DDF XI, 319); Léger an Naggiar, T 474, 20.9.1938 (MAE Chine 575, SHAT 11 H 64); Jacomy an Naggiar, T 705, 21.9.; Léger an Naggiar, T, 22.9.1938 (SHAT 11 H 60, 7 N 3249); Amaury VERRON, La révolte des Boxers et le Corps français d'occupation de Chine, 1901-1945, in: WEBER (Hg.), La France en Chine, S. 145-161 (S. 156); Quiring an Ribbentrop, 27.9., Kühn an Ribbentrop, 4.11.1938, Ott an Ribbentrop, 9.3.1939 (AA Botsch Paris 863 a2).
} 
Soldaten drangen in das Büro der französischen Polizei ein, weil ein französischer Polizist einen betrunkenen japanischen Fahrer angehalten hatte. Doch auf Anweisung des Generalstabs in Tokio zogen die Japaner wieder ab. Lépissier plante die Evakuierung von 400 französischen und 700 britischen Frauen und Kinder, wohl auch, weil die japanische Presse drohte, die Konzession "von der Landkarte zu radieren«. Oberst Sugeyasu suchte Oberstleutnant Astier de Villatte am 23. September auf, um sich über den Schutz »antijapanischer Kräfte« durch die französische und britische Konzession zu beschweren. Der Sprecher des Außenministeriums in Tokio beschwichtigte aber, Japan achte die Rechte der Ausländer in China und in den Konzessionen ${ }^{217}$.

In Indochina hatte das Heer am 3. September die ersten zwei Stufen der Mobilisierung ausgelöst, die Marine bereitete die Alarmierung vor. Die Bewegungen der italienischen Kriegsschiffe Montecucoli und Colleoni, die in Ostasien kreuzten, wurden ab dem 13. September nach Paris gemeldet ${ }^{218}$. Am 21. September beschlagnahmte Brévié elf Dewoitine-Flugzeuge, deren Lieferung an China er seit Ende Juli auf Mandels Bitte verzögert hatte. Die Maschinen waren jedoch kaum bewaffinet. Langstreckenflugzeuge der Air France wollte Brévié als Bomber einsetzen. Am 24. September, als in Bad Godesberg das Treffen von Hitler und Chamberlain scheiterte, begann die Fernostflottille mit Kriegsvorbereitungen: Die U-Boote entfernten die Nationalitätsmerkmale. Am 26. September wurden die Kriegsschiffe angewiesen, sichere Häfen anzulaufen und Standortmeldungen zu verschlüsseln. Die Entwaffnung der Kanonenboote auf dem Jangtse wurde geplant. Brévié fragte Mandel nach den Linien eines Kriegsplans gegen Japan und Siam, der aber gar nicht existierte ${ }^{219}$.

$\mathrm{Zu}$ diesem Zeitpunkt hatte Japans Luftwaffe bereits massiv den Luftraum Indochinas verletzt. Am 22. September überflogen 20 japanische Flugzeuge verschiedene Städte. Über Hanoi wurden drei Maschinen gesichtet. Auch die Marineaktivitäten in Südchina verstärkten sich. Am 26. September zeigten sich acht japanische Flugzeuge über der 20 Kilometer von der chinesischen Grenze entfernte Stadt Caobang. Der Marine-Geheimdienst nahm an, die

217 Jacomy an Brunet, T 706, 21.9., Jacomy an Lacoste, T 708, 22.9.1938 (SHAT 11 H 60); Naggiar an Bonnet, T 1349-53, 22.9., Naggiar an Henry, T 1373, 23.9., Naggiar an Bonnet, T 1378-79, 23.9., Lépissier an Bonnet, L 65, 25.9.1938 (MAE Chine 830); FTFC EM.2, compte rendu, 23.9.1938 (SHAT 11 H 61); Havas, le Japon et les intérêts étrangers en Chine, 23.9.1938 (MAE Chine 1063).

${ }^{218}$ FNEO an EMG.2, T 6827-28, 4.9., T 6842, 9.9., Marine Saigon an EMG.2, T 1251, 5.9., T 1261, 7.9., T 1254, 9.9.1938 (SHM 1 BB9 40); Crosby an Halifax, 5.9.1938 (FO 371/21590, C 9208/8/17); EMG.3 an Saigon, T 3558, 6.9., T 3563, 6.9., T 3572, 7.9., T 3648, 13.9.1938 (SHM 1 BB9 182).

219 Note de la sous-direction d'Asie-Océanie, 21.9.1938 (MAE Chine 560); Johnson an Hull, 4.11.1938 (FRUS 1938, III, S. 363f.); FNEO an EMG.2, T 6879-80, 24.9.1938 (SHM 1 BB9 41); EMG.3 an FNEO, T 3789, 24.9., T 3781, 26.9.1938 (SHM 1 BB9 182); Brévié an Mandel, T 893, 1.8., T 1072, 22.9., T 1089-90, 26.9., T 1103-4, T 1108, 29.9., T1153, 12.10.1938 (CAOM FM 678); Mandel an Brévié, T 556, 29.7., T 584, 9.8., T 702, 29.9., T 751, 15.10.1938 (CAOM FM 672). 
Überflüge sollten Paris einschüchtern. Doch sie konnten auch helfen, Informationen für einen späteren Angriff zu beschaffen. In Indochina begannen, wie der deutsche Konsul schrieb, »Nervosität und [eine] Kriegsspsychose« um sich zu greifen. Am 30. September fand die erste Luftschutzübung statt, alle Reservisten waren mobilisiert. Die Kolonialverwaltung hielt einen Angriff Japans auf Indochina oder Kwangchowan, das ebenfalls überflogen wurde, für möglich. Henry meldete, Tokio habe über eine Ausweitung der Operationen in den Süden wohl noch nicht entschieden ${ }^{220}$. Er vermutete, Japan werde einen Krieg in Europa zu einem Schlag gegen China nutzen, gegenüber den westlichen Mächten und ihren Konzessionen aber neutral bleiben. Der Service de transit beruhigte wiederholt, es gebe weder in Shanghai noch in Tientsin konkrete Hinweise auf einen bevorstehenden Angriff der Japaner ${ }^{221}$.

Naggiar bewahrte völlige Ruhe: Die Anweisung aus Paris, bei einem Angriff auf die Konzessionen auf bewaffneten Widerstand zu verzichten, hielt er geheim. Von einem Truppenrückzug wollte er zunächst nichts wissen. Dabei hielt er einen japanischen Übergriff auf die Konzessionen für gut möglich, zumal er annahm, daß Japan bei einem Krieg in Europa einen Frieden mit China anstreben werde, um freie Hand gegen Moskau und den Westen zu haben ${ }^{222}$.

Paul-Émile Naggiar war entschlossen, Drohungen resolut zu widerstehen. Wie ernst es dem Botschafter war, zeigte er in Shanghai: An den Grenzen der Konzession ließ er die Sandsackposten durch Zementblockhäuser ersetzen und die Verteidigungsstellungen ausbauen. Einem deutschen Kollegen versicherte ein französischer Diplomat, $\gg d a ß$ man die Konzession nicht kampflos aufgeben werde, da sich dies mit dem französischen Ehrbegriff nicht vereinbaren lasse«. Die Briten hingegen zogen eines ihrer zwei Bataillone aus Shanghai nach Hongkong ab, ohne Paris zu konsultieren. Der Abzug schwächte die britische Position, während die Proteste der Shanghaier Marionettenbehörden gegen den Ausbau der französischen Stellungen zeigten, daß sie die französische Entschlossenheit registriert hatten. Naggiars Mut und sein Ungehorsam

${ }^{220}$ Brévié an Mandel, T 1070, 22.9, T 1084, 24.9., T 1093, 26.9., T 1097, 28.9., T 1115, 1.10.1938 (CAOM FM 678); Naggiar an Bonnet, T 1366-69, 23.9., STS-bulletin, 1.10.1938 (MAE Chine 727, 534); Léger an Henry, T 321-22, 26.9., Henry an Bonnet, T 526, 29.9., 26.9.1938 (MAE Japon 127, 123); Saigon an EMG.2, T 1065, 3.10 .1938 (SHM I BB9 41); Palmer an Hull, 3.10 .1938 (SD 851G.20/11); Neumann an Ribbentrop, 30.9., 5.10.1938 (AA PoI VIII 60 2). Die französischen Dokumente erwähnen nur die Überflüge vom 22. September, die beiden ausländischen Konsuln berichten nur von dem Überflug Caobangs am 26. September. Möglicherweise fand nur die Luftraumverletzung vom 22. September statt, über die Neumann und Palmer aber falsch informiert wurden.

${ }^{221}$ Henry an Bonnet, T 493-99, 11.9., T 503, 15.9.1938 (DDF XI, 85, 153); Henry an Bonnet, T 512, 22.9., T 518-21, 26.9.1938 (MAE Japon 123); Henry an Bonnet, T 529, 29.9.1938 (MAE Chine 727); Henry an Bonnet, T 276-77, 30.9.1938 (DDF XI, 483); STS-bulletin, 1.10.1938 (MAE Chine 534).

${ }^{222}$ Naggiar an Bonnet, T 1394-95, 26.9., Georges-Picot an Bonnet, L 214, 15.9., Naggiar an Henry, T 1396, 26.9., Naggiar an Bonnet, T 1400, 26.9.1938 (MAE Chine 575, 727, Japon 123, DDF XI, 361). 
gegenüber Légers Anweisung, sich im Zweifel nachgiebig zu zeigen und Einheiten abzuziehen, hatten Erfolg: Während der Sudetenkrise verhielten sich japanische Zivilisten und Militärs zu den Franzosen in Shanghai nach Naggiars Urteil äußerst korrekt, bisweilen sogar herzlich und verständnisvoll. Erneut hatte sich aber gezeigt, wie André Nolde betont, daß die feste Haltung der Franzosen in den Konzessionen viel mehr das Ergebnis lokaler Überlegungen und der Handlungen Naggiars war als das der Anweisungen aus Paris ${ }^{223}$.

In Tientsin hingegen wäre die Lage beinahe entgleist, als Oberst Jacomy ohne Rücksprache mit Naggiar am 28. September überstürzt die Evakuierung der Konzession anordnete. Am 27. September, nachdem ein hoher japanischer Offizier Jacomy angekündigt hatte, im Kriegsfall wolle man Frankreich zwei Wochen Zeit geben, um die Konzession zu verlassen, bereitete Jacomy - noch mit Naggiars Billigung - die Evakuierung der Familien vor. Bei den Briten, die am 22. September angewiesen wurden, Pekings Evakuierung einzuleiten, griff Panik um sich: Die Bewohner der britischen Konzession in Tientsin verlangten am 27. September von ihrem Konsul, mit Japan zu verhandeln, um einen Handstreich zu verhindern. Zeitgleich befahl der Oberkommandeur in Hongkong den britischen Truppen in Nordchina, ihren Abzug vorzubereiten. Jacomy, der zwei Wochen zuvor seinen Offizieren noch jeden Gedanken an Rückzug verboten hatte, erfuhr von dieser Anweisung und bat am 28. September Kolonialminister Mandel um die Erlaubnis, Nordchina evakuieren zu dürfen. Mandel stimmte zu, falls die Briten wirklich abzögen ${ }^{224}$.

In der Hektik des sauve qui peut blieb kein Platz für grundsätzliche Überlegungen, aber zwischen einem britischen und einem französischen Truppenabzug gab es einen bedeutenden Unterschied: Ein Rückzug unter Druck wäre für beide Staaten erniedrigend gewesen, aber für das Foreign Office war seit einigen Jahren klar, daß die Konzessionen keine Zukunft hatten und daß deren Preisgabe »als Teil der Lösung bei Kriegsende«, wie es in einem Papier der Asienabteilung im Herbst 1938 hieß, naheliegend war ${ }^{225}$. Die Franzosen waren davon weit entfernt. Ein Rückzug in der Krise war für die Briten nur eine graduelle, für die Franzosen aber eine prinzipielle Frage.

${ }^{223}$ Bracklo an Ribbentrop, 4.10.1938 (AA Pol VIII 58 A2); Fourth Marines, Shanghai, R-2 Report, 29.9.1938 (SD 793.94/14316); Henry an Bonnet, T 535-38, 5.10.; Naggiar an Bonnet, L, 15.10.1938 (MAE Chine 728, 805); STS-bulletin, 1.11.1938 (MAE Chine 534); André NolDE, Une mission militaire française auprès de Tchang Kai-Chek en 1939. Un épisode peu connu de l'histoire diplomatique de l'immédiate avant-guerre, in: Revue de défense nationale 27 (1971), S. 976-985 (S. 980).

${ }^{224}$ Lacoste an Naggiar, T 459, 22.9., T 462-63, 27.9., Naggiar an Lacoste, T 376, 28.9., Lépissier an Naggiar, T 197-98, 27.9.1938 (MAEN Pékin A 493); Naggiar an Bonnet, T 1415-16, 29.9., Lacoste an Naggiar, T 464-66, 28.9.1938 (MAE Chine 830, 564); Jacomy an Naggiar, T 720-21, 28.9., Jacomy an Naggiar, T 723-25 und Chef d'EM des Colonies, T 726-28, 28.9.1938 (SHAT 11 H 60); Mandel an Bréviè, T 692, Mandel an Jacomy, T 693, 28.9.1938 (CAOM FM 672).

${ }^{225}$ Memoranda, 16.11.1938 (FO 371/22176, F 12923/4727/61). 
Naggiar bat Bonnet, sich in London für den Verbleib der britischen Truppen einzusetzen, und erlaubte Jacomy, die Artillerie aus Tientsin abzuziehen. Bei Bonnet regte er am 28. September an, bei einer Verschärfung der Lage die Hälfte der Truppen aus Nordchina und eines von drei Bataillonen aus Shanghai abzuziehen. Als der Botschafter aber erfuhr, daß die Briten ihren Abzug nur erwogen, forderte er Jacomy und Brévié auf, den Rückzug und die Evakuierung zu stoppen; den Außenminister bat er, im Kolonialministerium die sofortige Ablösung des Kommandeurs durchzusetzen. Jacomy hatte seine Lage noch erschwert, weil er auch seine eigene Versetzung nach Indochina betrieben hatte, was nicht für seine Tapferkeit sprach. Mandel löste Jacomy noch am 30. September als Commandant supérieur $\mathrm{ab}^{226}$.

Jacomy hatte am 28. September versagt, aber auch Le Bigot hatte gewankt. Am 27. September hatte er ohne Naggiars Wissen den Abzug aller Schiffe aus China verlangt, am 30. September forderte er, zwei Bataillone aus Shanghai und die Kanonenboote vom Jangtse abzuziehen ${ }^{227}$. Mit der Ablösung Jacomys wollten Naggiar und der Quai d'Orsay auch ein länger schwelendes Problem lösen. Am 1. Oktober schrieb Bonnet an Mandel, man zweifle seit einem Jahr, ob Jacomy die notwendige Besonnenheit besitze. Charles Lépissier bezichtigte Jacomy mehrfach des Größen- und Verfolgungswahns und des Realitätsverlustes. Von Mitte Juli bis Anfang September gestattete es sich der Oberst zudem, an der Küste zu bleiben, während die Konzession in Tientsin in Gefahr war. Bührer wirft Jacomy noch in seinen Memoiren Größenwahn vor ${ }^{228}$.

Nach dem Abschluß des Münchener Abkommens am 30. September entspannte sich die Lage in Tientsin schlagartig. Stabile Verhältnisse zogen auch in Shanghai ein, obwohl dort am 30. September der chinesische Politiker Tang Shaoyi, der Regierungschef der Marionettenregierung in Nanking werden sollte, ermordet worden war. Japans Propaganda forderte die Abschaffung der Konzessionen, aber bei dem verbalen Säbelrasseln blieb es. Sogar die guten Beziehungen zwischen französischen und japanischen Militärs lebten wieder auf: Am 11. Oktober besuchte überraschend General Sakurei, der die Brigade in Shanghai befehligte und der von 1923 bis 1935 Vize-Militärattaché in Paris

\footnotetext{
${ }^{226}$ Naggiar an Bonnet, T 1405-8, 28.9., Naggiar an Lépissier, T 184, 28.9., Naggiar an Jacomy, T 38, 30.9., Jacomy an Mandel, T 729, 29.9., Jacomy an Guerre, T 730-33, 30.9., T 748-49, 4.10., Jacomy an Brévié, T 747, 3.10.1938 (SHAT 11 H 64, 60); Lacoste an Naggiar, T 467, 28.9.1938 (MAEN Pékin A 345); Naggiar an Jacomy, T 1413, 28.9., Naggiar an Bonnet, T 1414, 29.9., Naggiar an Brévié, T 1422, 29.9., Naggiar an Bonnet, T 1423-25, 30.9., Mandel an Jacomy, T, 30.9.1938 (MAE Chine 564, CAOM FM 672); TRINQUIER, Temps perdu, S. 60; BÜHRER, Aux heures tragiques, S. 81. ${ }^{227}$ Naggiar an Bonnet, T 1403-4, 28.9., Hoppenot an Naggiar, T 494, 29.9., Naggiar an Le Bigot, T 1419, 30.9.1938 (MAE Chine 575); Le Bigot an Naggiar, T 6912-14, 30.9.1938 (SHM 1 BB9 41).

${ }^{228}$ Bonnet an Mandel, L 1207, 1.10.1938 (MAE Chine 563); Lépissier an Naggiar, L, 17.1., 31.7.1938 (MAE Chine 562, 563); Lépissier an Jacomy, L, 25.7.1938 (MAEN Pékin A 345); Naggiar an Bonnet, T 1423-25, 30.9., L 766, 14.11.1938 (MAE Chine 564); BÜHRER, Aux heures tragiques, S. 81.
} 
gewesen war, mit vier Offizieren Oberstleutnant Perretier. Dabei herrschte, wie auch bei Perretiers Gegenbesuch am Folgetag, eine herzliche Atmosphäre ${ }^{229}$.

Und doch änderte der 30. September die Lage in Asien deutlich: Frankreich hatte mit dem Münchener Abkommen nach dem Urteil von Klaus Hildebrand mit erschütternder Eindeutigkeit vor aller Welt als Großmacht abgedankt und war, so Hans F. Bellstedt, nun nur noch eine einsame Macht zweiten Ranges. Zwar wurde den Franzosen in Asien der Spiegel der in Europa erlittenen Demütigung nicht so sehr vorgehalten wie den Briten. Aber Chinas Regierung meinte die Regierungen in London und Paris, als sie das Münchener Abkommen ein Zeichen der Abdankung der Mächte nannte ${ }^{230}$.

Im Schatten der Sudentenkrise standen die Beratungen des Völkerbundes. Vor dem Treffen Ende September sondierten Chinas Botschafter, welche Resonanz Sanktionsforderungen gegen Japan hätten. Paris und London rieten zu größter Zurückhaltung. Auf Moskaus Hilfe hoffend entschied Chinas Regierung dennoch, wie sie erklärte, den Völkerbund »einer letzten Prüfung zu unterziehen«. Am 11. September 1938 beantragte die chinesische Delegation in Genf trotz Interventionen Pierre Arnals, Joseph Paul-Boncours und des britischen Staatssekretärs Butler die Verhängung von Sanktionen. Der von PaulBoncour eingeschaltete sowjetische Außenminister Litwinow lehnte es ab, die Chinesen zu mäßigen. Nach Einschätzung des US-Generalkonsuls Bucknell wollte China aber nicht den Völkerbund in die Enge treiben, sondern sich von London und Paris die Sanktionsforderung gegen konkrete Hilfe abhandeln lassen. Dieses Geschäft deutete Wellington Koo an, als er Arnal sagte, ehe er den Rat mit seiner Forderung konfrontiere, wolle er mit Bonnet sprechen ${ }^{231}$.

Bonnet ließ die chinesische Gesprächsbitte mehrere Tage unbeantwortet. Koo wollte sich nun nicht länger hinhalten lassen und beantragte im Rat Sanktionen. Der Rat eröffnete am 19. September das Verfahren und lud Japans Regierung ein, ihre Position in Genf zu erläutern. Die Mächte waren sich einig, nach der erwarteten japanischen Ablehnung - anders als in der Charta vorgesehen - keine weitere Untersuchung durchzuführen, da die Fakten bekannt seien. Am 22. September lehnte Außenminister Ugaki die Einladung aus

\footnotetext{
${ }^{229}$ Naggiar an Lépissier, T 212, 7.10.1938 (MAEN Tokyo B 78); WAKEMAN, The Shanghai Badlands, S. 48; Domei, 11.10., Perretier, aide-mémoires, 28.10., 13.10., 14.10.1938 (MAE Chine 1063, 563).

${ }^{230}$ Klaus HILDEBRAND, Das vergangene Reich. Deutsche Außenpolitik von Bismarck bis Hitler, Stuttgart ${ }^{2}$ 1996, S. 663; BELLSTEDT, »Apaisement«, S. 122; Georges-Picot an Naggiar, T 1102-9, 7.11.1938 (MAE Chine 658).

${ }^{231}$ Massigli, Note, 9.9., Naggiar an Bonnet, T 1296-99, 11.9.1938 (MAE SDN 367); Communication de la délégation chinoise, 11.9.1938 (C.300.M.176.1938.VII); Arnal, Note, 12.9., Amal an Bonnet, T 115, 13.9., T 137, 16.9.1938 (MAE SDN 367); Note sur l'appel de la Chine, Genf, 14.9.1938 (MAE Chine 661); Bucknell an Hull, 13.9.1938 (FRUS 1938, III, S. 508); Amal an Bonnet, T 124, 14.9.1938 (MAE Chine 661); SDN-JO, supplément spécial $n^{\circ} 183$, actes de la $19^{e}$ session ordinaire de l'assemblée, séances plénières, compte rendu des débats, Genf $1938,5^{\mathrm{e}}$ séance, 16.9.1938, S. $51 \mathrm{f}$.
} 
Genf ab. In Shanghai spottete der französische Marine-Geheimdienst, man dürfe sich über den höflichen Ton der japanischen Absage freuen, obwohl das Prestige des Völkerbundes schon so tief gesunken sei ${ }^{232}$.

Allen Beteiligten war klar, daß angesichts der Kriegsgefahr in Europa eine Diskussion über Sanktionen in Asien sinnlos war. Im kleinen Kreis empfahl Avenol am 24. September, der Rat solle Japans Äußerung zur Kenntnis nehmen, auf den Bericht des Konsultativausschusses von 1937 verweisen und es jedem Staat überlassen, ob er Sanktionen anwende. Beim nächsten informellen Treffen am 27. September in Avenols Büro beugte sich Koo dem Druck der Ereignisse. Er bat, der Rat solle feststellen, nun seien die Mitglieder berechtigt, Sanktionen gegen Japan zu verhängen. Briten, Franzosen und Sowjets stimmten zu. Eine offiziöse Note der japanischen Regierung, wonach sie im Fall der Anwendung von Sanktionen erwäge, die Interessen und die Konzessionen der Mächte in China nicht weiter zu respektieren, zeigte dem Westen, wie gering sein Spielraum war. Wegen der Lage in Europa wurde die für den 30. September angesetzte Sitzung der Vollversammlung abgesagt. China nahm am 29. September, als in München Chamberlain, Daladier, Hitler und Mussolini zusammentrafen, die Forderung nach kollektiven Sanktionen zurück. Am nächsten Tag ermächtigte der Rat die Mitgliedsstaaten, individuell Sanktionen nach Artikel 16 der Charta zu verhängen - ein Beschluß eher juristischen als praktischen Charakters, wie Arnal erläuterte. Der Rat betonte, daß Sanktionen "Elemente der Zusammenarbeit verlangen, die noch nicht alle gesichert sind «, was auf die Haltung der USA verwies, bekräftigte frühere Resolutionen, die die Mitglieder aufforderten, China individuell zu helfen, und versicherte, China habe Anspruch auf die Sympathie und die Hilfe der Mitglieder des Völkerbundes. Nach der Abstimmung erklärte Paul-Boncour öffentlich, er habe sich eine festere Resolution gewünscht, doch leider seien die derzeitigen Möglichkeiten begrenzt ${ }^{233}$.

Die Tagung während der Sudetenkrise brachte China nichts und untergrub die Autorität des Völkerbundes weiter, denn bis dahin galten beschlossene Sanktionen als verbindlich. Für Arnal, Paul-Boncour, Naggiar, Henry und Knobel war es undenkbar, verpflichtenden Sanktionen zuzustimmen. Naggiar

\footnotetext{
${ }^{232}$ Procès-verbal de la $102^{\mathrm{e}}$ session du conseil, $3^{\mathrm{e}}$ séance, 17.9.1938 (JO-SDN, S. 843ff.); Amal an Bonnet, T 147, 19.9.1938 (MAE Chine 661); $102^{*}$ session du conseil, procès-verbal, $4^{e}$ séance publique, 19.9.1938 (MAE SDN 367); SDN-JO, supplément spécial ${ }^{\circ} 183,7^{\mathrm{e}}$ séance, 21.9.1938, $\mathrm{S}$. 70f.; Henry an Bonnet, T 514, 22.9.; STS-bulletin 1.10., 1938 (MAE Chine 661, 534); Communication du gouvernememt japonais, C.326.M.193.1938.VII, 22.9.1938 (MAE SDN 367).

${ }_{233}$ Arnal an Bonnet, T 184, 24.9., T 199, 27.9., T 216, 30.9.; Havas, le Japon devant la menace de sanctions, 28.9., Amal an Bonnet, T 215, 29.9.1938 (MAE Chine 661, 727; SDN 367); Bucknell an Hull, 27.9., Sous-direction de la SDN, lettre circulaire, 18.10.1938 (SD 793.94/13964, MAEN Londres C 479); $103^{\mathrm{e}}$ session du conseil, $2^{\mathrm{e}}$ séance, 30.9.1938 (JO-SDN, S. 869ff.); SDN-JO, supplément spécial $\mathrm{n}^{\mathrm{o}} 183$, actes de la $19^{\mathrm{e}}$ session de l'assernblée, compte rendu des débats, Genf 1938, S. $96 \mathrm{f}$.
} 
schrieb, falls Frankreich an Sanktionen teilnehme, solle es die Konzessionen räumen, um die unehrenhafte Übergabe nach einem Ultimatum zu vermeiden. Mit dem Eintreten für fakultative Sanktionen hatte Paris ein weiteres Element der kollektiven Sicherheit aufgegeben. Die Völkerbundabteilung im Quai d'Orsay beschönigte, das Prinzip kollektiver Sanktionen werde unter günstigeren Umständen wieder aufleben. Bonnet und Léger hielten die Verteidigung des Prinzips aber wegen der Lage in Europa für völlig aussichtslos ${ }^{234}$.

Auf die Sanktionsdebatte reagierte Japan. Es drohte am 4. Oktober den Rückzug aus den technischen Organisationen des Völkerbundes an, dem Internationalen Büro für Arbeit, den Ausschüssen für Gesundheit, Mandate, Soziales, Opium, Steuern, Verkehr und Wirtschaft, dem Institut für Intellektuelle Zusammenarbeit, dem Internationalen Gerichtshof sowie einem Expertenkomitee zur Hilfe für bedürftige Ausländer. Noch am 26. September hatte Amau mit dem Rat einen Richter des Internationalen Gerichtshofs gewählt. Der Rat hatte am 30. September Kusama als Mitglied des Ständigen Opium-Zentralkomitees bestätigt. Für die Mitgliedschaften zahlte Japan bis 1938 - anders als China - ordentliche Beiträge. Am 3. November vollzog Tokio den Austritt. Tokio sicherte der Mandatsabteilung offiziös zu, es werde weiter pro forma jährliche Berichte über seine Mandate Mariannen, Karolinen und MarschallInseln vorlegen. Dafür, daß Tokio dem Völkerbund die Möglichkeit gab, sein Gesicht zu wahren, revanchierte sich Genf. China hatte im Juni 1938 eine Untersuchung des Vorwurfs verlangt, Japan mobilisiere die Pazifikinseln unter Mandat militärisch. Im Mandatsausschuß bemühten sich am 3. und 4. November außer dem spanischen und dem britischen Vertreter alle Mitglieder, in den Worten des Vorsitzenden Orts, »die [durch Japans Rückzug] aufgetretene Änderung der Situation nicht zu übertreiben«. Frankreichs Delegierter Giraud sorgte mit dafür, daß Chinas Vorwurf gar nicht erst untersucht wurde ${ }^{235}$.

Die Kriegsgefahr in Europa war mit dem Münchener Abkommen gerade gewichen, als Indochina extrem bedroht schien. Am 1. Oktober fürchteten die Behörden in Indochina eine japanische Landung bei Pakhoi; acht oder neun japanische Kriegsschiffe seien dort aufgefahren, japanische Zivilisten hätten die Stadt verlassen. In Hongkong, Kwangchowan und Hanoi herrschte Panik,

\footnotetext{
${ }^{234}$ Naggiar an Bonnet, T 1355-57, T 1427-32, 30.9.1938 (MAE Chine 662; DDF XI, 486); Knobel an Henry, L, 1.10.; Henry an Bonnet, T 543, 10.10.1938 (MAEN Pékin A 312, MAE Japon 127); Sousdirection de la SDN an Bonnet, 12.10., Bonnet an die Botschaften, L, 23.10.1938 (MAE Chine 663).

${ }^{235}$ Déclaration, bureau du Japon pour les conférences internationales, 4.10 .1938 (VB R 3611); $103^{\mathrm{e}}$ session, ${ }^{\text {re }}$ séance, 26.9., $2^{\mathrm{e}}$ séance, 30.9.1938 (JO-SDN, S. 868 ff); Note Avenol, 2.11.1938 (VB R 3631); Bureau du Japon an Avenol, 2.11., Haller, section des mandats, an Avenol, 22.10.1938 (VB R 4128); Lettre du gouvernement japonais, 3.11.1938, C.415.M.260.1938; Communication de la délégation chinoise, 13.6.1938, C.207.M.113.1938.VII; Procès-verbal de la $102^{\mathrm{e}}$ session du conseil, $3^{\mathrm{e}}$ séance, 17.9., $103^{\mathrm{c}}$ session, $1^{\mathrm{re}}$ séance, 26.9.1938 (JO-SDN, S. 843, S. 868); Commission des mandats, procès-verbal de la $35^{\mathrm{e}}$ session, du 24.10. au 8.11.1938, 8.11.1938; C.418.M.262.1938.VI.
} 
ein Abzug der französischen Truppen in Kwangchowan wurde erwogen. Am 9. Oktober berichtete Naggiar, Japan habe drei Divisionen auf Taiwan konzentriert, ein Angriff auf Südchina stehe bevor. Am 12. Oktober landeten 30000 japanische Soldaten nicht bei Pakhoi, sondern in der Biasbay bei Kanton ${ }^{236}$.

Das Gaimusho versicherte Henry, Japans Militär werde in Südchina die Interessen dritter Mächte respektieren. Paris nahm an, daß Tokio vor allem Chiang Kai-sheks Regime von dem wichtigen Versorgungsweg über Kanton und Hongkong abschneiden wolle ${ }^{237}$. In der Einschätzung der Ursachen der Landung waren sich Naggiar, Georges-Picot, Luftwaffenattaché de La Ferté Sénectère, Alexander Cadogan, der Generalstab in Paris und die Asienabteilung im Quai d'Orsay einig: Die in München gezeigte Konfliktscheu habe Tokio zum Angriff ermutigt. Am 15. Oktober meldete Domei, Japan sei nach der Münchener Konferenz zu dem Schluß gekommen, daß auf internationaler Ebene keine Gefahren drohten. Die französischen Experten waren sich sicher, $\mathrm{da} ß$ sich Chinas Versorgung verschlechtern werde. Sonst unterschieden sich ihre Analysen: La Ferté Senectère vermutete, Japan werde den Westen in China ausschalten. Das Deuxième Bureau des Kolonialministeriums schrieb, Japan verfolge jetzt eine Politik des "Asien den Asiaten«, konkretisierte die Folgen für Frankreich aber nicht. Der Marine-Geheimdienst in Shanghai urteilte, ein Angriff Japans auf Hainan sei nun denkbar geworden. Die Nordgrenze Tonkins sei jetzt die vierte bedrohte Grenze Frankreichs ${ }^{238}$.

Der Generalstab in Paris schrieb, ein Ziel der Landung könne Hainan sein. Noch gebe es aber keine Hinweise auf eine feindselige Haltung Japans gegen Frankreich, selbst bei einem deutsch-französischen Krieg bleibe Tokio wohl neutral. Auch Henry beruhigte: Ministerpräsident Fürst Konoe, der nach Ugakis Rücktritt das Außenamt übernommen hatte, wolle nicht mit dem Westen brechen. Hoppenot notierte, französische Interessen seien nicht unmittelbar bedroht, aber die Besetzung Hainans sei möglich.

Erstmals seit der Brüsseler Konferenz versuchte der Quai d'Orsay, Washington wieder ins Spiel zu bringen. Hoppenot äußerte am 13. Oktober, die Lage im Fernen Osten könne nur stabilisiert werden, wenn die USA Japan

\footnotetext{
${ }^{236}$ U.S. Intelligence Report, 4.10.; Simon an Bonnet, T 18-20, 3.10., Naggiar an Bonnet, T 1447, 9.10.; Brévié an Mandel, T 1145, 10.10.1938 (SD 793.94/14349, MAE Chine 728, CAOM FM 678).

${ }^{237}$ Henry an Bonnet, T 549, 12.10., T 557-58, 14.10.; T 546-48, 12.10., Léger an Henry, T 451, 22.11.1938 (DDF XII, 83, 116, MAE SDN 365, Japon 128); Tani Masayuki an Naggiar, L 9, 17.10.; Léger an Corbin, T 3288, 15.10., Corbin an Bonnet, T 2754-56, 24.10., Naggiar an Bonnet, T 1461, 12.10. 1938 (MAE Chine 663, 728); Brévié an Mandel, T 1157, 13.10.1938 (CAOM FM 678).

${ }^{238}$ Naggiar an Bonnet, T 1467-72 S, 14.10., Georges-Picot an Naggiar, D 275, 28.11., Corbin an Bonnet, T 2692-95, 14.10.1938 (DDF XII, 115, 431, 121); La Ferté Sénectère à la Chambre, L, 30.10.1938 (MAE Chine 729); Colonies, EMG.2, Bulletins de renseignement, 15.10., 16.11.1938 (SHAT 11 H 76, SHM 1BB2 92); Note de la sous-direction d'Asie-Océanie, 21.11.; Naggiar an Bonnet, T 1483-85, 15.10., STS-bulletin, 1.11.1938 (MAE Chine 713, 534); SHAI, Origins of the War, S. 153.
} 
deutlich $\mathrm{zu}$ »vernünftigem Verhalten« aufforderten. Acht Tage später sagte Bonnet Wilson, ohne die aktive Mitwirkung der USA könne in Ostasien nichts erreicht werden. Hoppenot erklärte Wilson, Japan nehme nur dann Rücksicht auf die Interessen der westlichen Mächte, wenn diese in Tokio geschlossen aufträten. Offensichtlich war die Münchener Konferenz Anlaß für die neuen Versuche, Washington in Asien zu einer engeren Kooperation bewegen. Das State Department reagierte jedoch nicht. Die Tatsache, daß vor Indochina keine japanischen Schiffe erschienen, beruhigte Paris etwas ${ }^{239}$.

Am 13. Oktober 1938, als Hoppenot ein stärkeres Engagement der USA wünschte, versicherte Léger Japan Frankreichs Freundschaft. Er wies Henry an, im japanischen Außenministerium zu erklären, daß es aufgrund der Völkerbundbeschlüsse keine Sanktionen geben werde, von Frankreich schon gar nicht, das stets ein Gleichgewicht angestrebt habe. Der Leiter der EuropaAbteilung im Außenministerium Inoue zeigte sich zufrieden. Ohnehin gab sein Ministerium den Briten die Hauptschuld für die Genfer Beschlüsse. Sechs Tage später, am 19. Oktober, wies Léger Henry an, er solle Tokio versichern, Paris werde keine Sanktionen anwenden. An diesem 19. Oktober berichtete Naggiar von dem außerordentlich schwachen Widerstand Chinas vor Kanton und Hankou und wiederholte seine gängige Empfehlung für Notzeiten: Wie schon im Dezember 1937 und im Februar 1938 riet er zur Auffrischung (»rajeunissement«) des französisch-japanischen Vertrages von 1907 und dazu, sich in China auf die Verteidigung französischer Rechte zu konzentrieren. Am 21. Oktober fiel Kanton, am 25. Oktober besetzte Japan Hankou. Weitere Offensiven begann Japan bis 1944 in Nord- und Zentralchina nicht ${ }^{240}$.

Léger plädierte auch für neuerliche Flottenbesuche. Am 18. Oktober regte er im Marineministerium an, wieder französische Kriegsschiffe in japanische Häfen zu entsenden. Dabei solle man nur auf die üblichen, besonders kompromittierend erscheinenden Ordensverleihungen verzichten. Der Generalstab der Marine begrüßte die Flottenbesuche. Naggiar stimmte sofort zu, zumal sich Japans Truppen bei der Besetzung Kantons und Hankous keiner Exzesse hingegeben hätten, wie man sie nach dem Beispiel Nankings habe befürchten müssen. Henry lehnte Besuche ab, da sich die Lage nicht grundlegend geändert habe. Vize-Admiral Le Bigot zögerte: Der Besuch sei voreilig. Es dürfe nicht der Eindruck entstehen, daß er nach Japan reise, um dem Sieger zu

${ }^{239}$ EMG.2, note de renseignement, 13.10.1938 (MAE Chine 728); Henry an Bonnet, T 559-60, 15.10.1938 (DDF XII, 130); Wilson an Hull, 13.10., 29.10., 21.10.1938 (FRUS 1938, III, S. 318f., S. 351f., SD 751.62/490); STS-bulletin, 1.11.1938 (MAE Chine 534).

${ }^{240}$ Grew an Hull, 7.10.1938 (SD 793.94/14131); Léger an Henry, T 349-51, 13.10., Henry an Bonnet, L 196, 17.10., Léger an Bonnet, T 361, 19.10.1938 (MAE Japon 127); Naggiar an Bonnet, T 1500-5, T 1513-14, 19.10.1938 (DDF XII, 167, 169); Naggiar an Bonnet, T 1515, 19.10.1938 (MAE SDN 365); Compte rendu de la liaison hebdomadaire aux Affaires étrangères, 19.10.1938 (DDF XII, 173). 
gratulieren. Falls Orden verteilt werden könnten und der Besuch nicht mehr als Zeichen der Schwäche erscheine, sei er einverstanden. Bis Le Bigots Stellungnahme aber im Quai d'Orsay ankam, war es Anfang Dezember 1938, und Léger hielt einen Besuch mittlerweile für inopportun ${ }^{241}$.

Ohne daß es einer Anweisung aus Paris bedurft hätte, verstärkten in China französische Militärs und Diplomaten ihre Bemühungen um gute Kontakte zu den Japanern. Militärattaché Thiébaut kam Ende Oktober erneut aus Tokio nach Peking und Tientsin. Der japanischsprechende Hauptmann Fleurant wurde nach Tientsin versetzt. Naggiar lud seinen Kollegen Tani in Shanghai zum Essen ein. In Tientsin waren die Beziehungen zwischen französischem und japanischem Heer so gut, daß Oberst Delsuc bat, seinem Verbindungsoffizier einen Dauerausweis für japanische Militärgebäude auszustellen. Mitte November lobten Botschaftsrat Knobel und das japanische Generalkonsulat in Shanghai die guten Beziehungen zwischen ihren Behörden in Kanton und Hankou. Der Marine-Geheimdienst in Shanghai berichtete, Franzosen würden, anders als die Briten, von japanischen Behörden sehr freundlich behandelt. Als PaulÉmile Naggiar am 11. November 1938 China verließ und nach Moskau wechselte, bilanzierte er, in den Konzessionen herrsche ein gutes französisch-japanisches Klima, ohne daß die Franzosen auf Rechte verzichtet hätten ${ }^{242}$.

Einen anderen Streit räumte die französische Regierung aus. Als Teil der Kriegsvorbereitungen während der Sudentenkrise hatte Mandel die Kolonien am 24. September angewiesen, Eisenerzexporte zu unterbinden. Der Generalgouverneur durfte Ausnahmen zulassen. Am 4. Oktober verlangte Japans Generalkonsul in Hanoi eine Erklärung für das Exportverbot, das auch schon von Japans Presse attackiert wurde. Mit Hinweis auf Anträge der örtlichen Handelskammern bat Brévié Paris um die Aufhebung. Abteilungsleiter Inoue warnte Baron Fain im Gaimusho, das Verbot bringe die Meinung in Japan gegen Frankreich auf. Bis April 1940 hätten japanische Firmen den Import von mindestens 260000 Tonnen Eisenerz aus Indochina geplant. Gleichzeitig dechiffrierten französische Behörden ein Telegramm des japanischen Konsuls in Hanoi, der wirtschaftliche und militärische Vergeltungsmaßnahmen gegen Indochina bis zur Besetzung Hainans vorschlug. Brévié und Mandel forderten

${ }^{241}$ EMG.2 an FNEO, T 4002, 18.10., T 4116, 19.11.; Rosati an EMG.2, T 15, 27.10., FNEO an EMG, T 6977, 29.10.1938 (SHM 1 BB9 182, 41); Le Bigot an EMG.2, L 130, 14.11., Marine an Diplomatie, L, 5.11, 7.12.1938 (MAE Chine 575-576); FNEO an EMG.2, T 7000, 8.11. T 7001, 7003, 9.11., T 7029, 21.11., T 7031, 23.11.; Chauvel an EM.2, L 1594, 16.12.1938 (SHM 1 BB9 42; BB3 20).

${ }^{242}$ Thiebaut an Casseville, 25.10.1938 (SHAT 11 H 79); Thiébaut an EMA.2, L 66, 20.11.1938 (SHAT $7 \mathrm{~N}$ 3331); Naggiar an Bonnet, T 1614-16, 30.10., T 1731, 15.11.1938 (MAE Chine 765, Chine 563); Delsuc an General Kuwaki, Oberkommandeur Tientsin, L 1325, 29.10.1938 (SHAT $11 \mathrm{H}$ 61); Hidaka an Knobel, 19.11.1938 (MAE Japon 128); STS-bulletin, $\mathrm{n}^{\circ} 191,1.11 ., \mathrm{n}^{\circ} 211,1.12 .1938$ (MAE Chine 534); Naggiar an Bonnet, T 1700-2, 11.11 .1938 (MAE Japon 127). 
eine härtere Haltung gegenüber Japan. Aber der Quai d'Orsay blieb auf der nachgiebigen Linie: Hoppenot versicherte am 13. Oktober der japanischen Botschaft, Japan erhalte weiter Erze. Mandel wies Brévié am 19. Oktober an, Japan wie zuvor mit Eisen- und Manganerzen zu versorgen ${ }^{243}$.

Georges Mandels Forderung nach einer festeren Politik gegenüber Japan beantwortete der Quai d'Orsay mit einer acht Seiten langen Darlegung. Mit der Ausdehnung des Krieges nach Südchina sei zwischen Japan und den Mächten die Gefahr der Spannungen stark gestiegen. Konflikte könne man nur vermeiden, wenn man der bisherigen Politik treu bleibe: Frankreich verteidige seine Interessen und sein Prestige in China, indem es keiner Einschüchterung nachgebe und die Konzessionen behaupte sowie Maßnahmen ergreife, damit Indochina nicht zum Zentrum des chinesischen Militärnachschubs werde, was die Kolonie direkt oder indirekt japanischen Repressionen aussetzen würde.

Drei Tage später malte die Asienabteilung die Perspektive einer japanischen Kontrolle über Südchina weiter aus. Für Indochinas Sicherheit sowie Frankreichs Interessen in Asien könne dies enorme Folgen haben, warnte Hoppenot. Außer der üblichen Forderung, Frankreich müsse seine ideelle Position und Interessen in China entschlossen verteidigen, und der Warnung, man dürfe das Waffentransitverbot durch Indochina nicht aufheben, hatte er aber keinen Vorschlag, wie Paris auf Japans Machtgewinn reagieren solle. Georges-Picot forderte eine Politik der Stärke, sah aber grundsätzlich keine Alternative zur bisherigen Politik: Einzige konkrete Abweichung davon war seine Anregung, für die Erlaubnis des Eisenexports eine Gegenleistung zu verlangen ${ }^{244}$. Aber Georges-Picot kannte ja Japans Druck in dieser Frage nicht. Die herrschende Politik des apaisement in Asien schien ohne Gegenmodell zu bleiben.

Die in der Sudetenkrise sichtbar gewordene Schwäche ließ die französische Regierung eine Kampagne entfesseln, wie mächtig Frankreich durch seine Kolonien sei. Seit dem 19. Jahrhundert hatte die Koloniallobby argumentiert, durch die Kolonien bleibe Frankreich Großmacht. Der Chef des Parti colonial in der Abgeordnetenkammer Léon Archimbaud betonte in den zwanziger Jahren, sla France sera une grande puissance colonisatrice ou elle cessera d'être la France«. Albert Sarraut warb 1922 für die Idee »d'une entité nouvelle où la Patrie continentale et les Frances d'outre-mer [...] composeraient la force réelle d'une Plus Grande France, appuyant sa sécurité, non plus sur 40 millions

${ }^{243}$ Brévié an Mandel, $\mathrm{T} 1121,4.10$., T 27.GT, 5.10., T 1165-71, 14.10., T 1175-76, 15.10 .1938 (CAOM FM 678); Léger an Henry, T 176-78, 8.4.1939 (DDF XV, 305); Henry an Bonnet, T 546-48, T 550-53, 12.10., T 567-71, 21.10.1938 (MAE SDN 365, Japon 127, Chine 728); Mandel an Bonnet, L 1539, 15.10., Mandel an Brévié, T 755, 19.10.1938 (CAOM NF 106, FM 672); Wilson an Hull, 13.10.1938 (FRUS 1938, III, S. 318f.).

${ }^{244}$ Bonnet an Mandel, L 1282, 22.10.1938 (MAE Japon 127); Note de la sous-direction d'AsieOcéanie, 25.10.1938 (MAE SDN 365); Georges-Picot an Bonnet, L, 25.10.1938 (MAE Chine 676). 
mais sur 100 millions d'être humains«. Octave Homberg spitzte es auf die Formel zu: „C'est grâce à ses colonies que la France [...] est encore une nation mondiale, et non pas une petite nation européenne«. 1931 propagierte Tardieu die aus dem Jahr 1917 stammende Formel »De l'empire nous viendrait le salut en cas de menace«. Ab 1935 betonte die Kolonialpropaganda, daß man gegenüber der deutschen Gefahr auf das Empire bauen müsse ${ }^{245}$. Das Echo in der Bevölkerung blieb begrenzt.

Diese Argumente nahm Frankreichs Regierung in einer neuen Kampagne auf, und zwar bereits vor der Münchener Konferenz: Am 20. September wies Bildungsminister Jean Zay die Grundschulen an, im Geographieunterricht verstärkt die französischen Kolonien zu behandeln. Die Schulen wurden beauftragt, eine journée scolaire de la France d'outre-mer zu organisieren, Bücher und Stipendien sollten koloniale Ideen verbreiten. Am 21. September regte Georges Mandel die Schaffung von Lehrstühlen für Kolonialgeschichte und Kolonialgeographie an. Im Kolonialministerium wurde eine Informationsabteilung geschaffen, in der die junge Angestellte Marguerite Donnadieu (die spätere Marguerite Duras) das Werk "L'Empire français» verfaßte. Der Abgeordnete Jean de Baumont erklärte in "L'Illustration«, in einem Krieg könne Frankreich drei Millionen Soldaten aus den Kolonien erwarten. In der Kriegsgefahr war in der Metropole, gestützt auf die Erfahrung des Ersten Weltkriegs, die Hinwendung zu den Kolonien instinktiv, wie Paul-Marie de la Gorce schreibt ${ }^{246}$. Angeregt von der Regierung, begann zu Beginn 1939 die Produktion von vier Spielfilmen mit kolonialen Sujets, der Dokumentarfilm »La France est un empire« wurde vom Staat finanziert. Die Wochenschauen betonten die Stärke der Kolonialtruppen. Durch die Kolonien sei Frankreich in Sicherheit, war die Botschaft der Filme. Bei den Feiern zum Jahrestag des Waffenstillstandes am 11. November 1938 wurde der Beitrag der Kolonien und bei der Truppenparade am 14. Juli 1939 die Anwesenheit des Kaisers von Annams und des Prinzen von Kambodscha gefeiert ${ }^{247}$.

Im Dezember 1938, im Januar und im Februar 1939 bekannte sich die Abgeordnetenkammer einstimmig zum Wert des Empire. Vor allem Daladier bediente sich kolonialer Rhetorik. "Grace à son empire, la France est la seconde

${ }^{245}$ AgERON, Les colonies, S. 45; Albert SARRAUT, La mise en valeur des colonies françaises, Paris 1922, S. 17; Octave HOMBERG, La France des cinq parties du monde, Paris 1927, zit. nach GiRARDET, L'Idée coloniale, S. 311; AGERON, France coloniale, S. $259 f$.

${ }^{246}$ YounG, France and the Origins, S. 123; GIRARDET, L'Idée coloniale, S. 122; Mandel an Brévié, T 672, 21.9.1938 (CAOM FM 672); AGERON, France coloniale, S. 261; DERS., Les colonies, S. 62f.; DeRS., Empires, in: AZÉMA, BÉdARIDA (Hg.), 1938-1948, S. 309-320 (S. 316); Wilson an Hull, 2.9.1938 (SD 851.01/45); DE LA GORCE, L’Empire écartelé, S. 13.

${ }^{247}$ Marianne BENTELI, Daniel JAY, Jean-Pierre JEANCOLAS, Le cinéma français: thèmes et public, in: RÉmond, Bourdin (Hg.), La France et les Français, S. 27-41; BūHrer, Aux heures tragiques, S. 103. 
grande nation du monde [...]. En lui réside pour une large part l'avénir de la France. Nous le considérons comme intangible«, erklärte der Regierungschef Ende Oktober 1938 beim Parteikongreß der Radikalsozialisten in Marseille.

Die Absichten, die Mandel mit der Kampagne verfolgte, sind offensichtlich: Sie diente seinem persönlichen Renommee. Zudem entzog er, indem er das Bild eines starken Frankreich zeichnete, dem apaisement die Basis, wie der Abgeordnete Montigny im Dezember 1938 bei Botschafter Phipps klagte: "The campaign was, Montigny is certain, launched by Mandel for the express purpose of wrecking the policy of appeasement followed by Daladier and Bonnet after Munich «. Einige Maßnahmen im November 1938, wie Mandels Anweisung, in Indochina mehr Baumwolle, Rizinus und Soja anzubauen, erhöhten tatsächlich das Potential der Kolonien, die Metropole zu unterstützen.

Welche Ziele Daladier und Bonnet mit der Kolonialpropaganda verfolgten, ist umstritten. Jean Bouvier argumentiert, das Herausstellen der wachsenden französischen Stärke durch die Kolonien habe eine Politik des apaisement gegenüber Deutschland ermöglichen sollen. Bonnet habe darauf verweisen können, daß man die Entwicklung der Kolonien abwarten müsse. Auch Hans F. Bellstedt schreibt, die Regierung habe mit der Hinwendung nach Übersee die Abkehr von Europa verdecken wollen. Schon zeitgenössisch warfen zwei antimunichois, die Journalisten Henri de Kérillis und Pertinax, Daladier und Bonnet vor, diese strebten einen repli impérial, einen Rückzug in das Kolonialreich an, um die Aufgabe Osteuropas zu erleichtern. Charles-Robert Ageron hält dem entgegen, daß kein Mitglied der Regierung den Rückzug in das Kolonialreich propagiert habe. Daladier habe die »imperiale Mythologie« genutzt, um Frankreich zu ermutigen und in Europa zu stärken ${ }^{248}$.

Tatsächlich war die Betonung des Empire ein wichtiger Teil des discours munichois: Schon im Sommer 1938 sagte der apaisement-Politiker Flandin, Frankreichs Zukunft liege in seinem Kolonialreich - nicht in der Verteidigung des Status quo in Europa. Bis weit ins Jahr 1939 argumentierte er, Frankreichs Preisgabe Osteuropas und die Stärkung der Kolonien bildeten eine Einheit. Auch der Bericht, den Senator Aimé Berthod in Bonnets Namen dem Parteikongreß der Radikalsozialisten im November 1938 vorlegte, folgte Flandins Gedanken: Berthod empfahl eine Besinnung auf Frankreichs vitale Interessen, eine Politik des apaisement und »la mise en valeur des liens avec l'empire colonial pour conserver à la France un rôle international et éviter un repli

\footnotetext{
${ }^{248}$ Phipps an Halifax, 16.11., 5.12.1938, 4.2.1939 (FO 371/21600-601, 22909, C 14025, 15350/55/17, 1547/25/17); Mandel an Brévié, T 847, 16.11., T 896, 27.11.1938 (CAOM FM 672); PERTINAX, Les fossoyeurs, Bd. 1, S. 117; BovVIER, GIRAULT, THOBIE, L'impérialisme, S. 251; BELLSTEDT, "Apaisement«, S. 132f.; Charles-Robert AGERON, À propos d'une prétendue politique de »repli impérial« dans la France des années 1938-1939, in: Revue d'histoire maghrébine 12 (1978), S. 225-237.
} 
excessif«. Daladier äußerte sich vor dem Kongreß in Marseille ähnlich: Frankreich müsse sich auch mit Hilfe der Kolonien wirtschaftlich und politisch stärken. Bis dies soweit sei, müsse es friedliche Außenbeziehungen pflegen. Mit neuer Macht könne Paris offensiver auftreten ${ }^{249}$. Während des Parteitags gehörten für Daladier apaisement in Europa und Stärkung der Kolonien zusammen. Ohnehin hatte sich Daladier, wie René Girault und Elisabeth du Réau zeigen, nach München Bonnets Linie angeschlossen und in Marseille eine vermittelnde Position eingenommen, auch, weil er die Anhänger des apaisement innenpolitisch brauchte. Kurzfristig sah er keine Alternative zur außenpolitischen Nachgiebigkeit, mittelfristig sollte Aufrüstung neue Spielräume schaffen. Erst nach Italiens neuen Forderungen Ende November verband der Regierungschef die koloniale Propaganda mit Härte in Europa. Am 7. Februar 1939 drückte sich Daladier dann eindeutig aus:

La politique impériale serait une politique de repli de la France? Je dis, moi, que c'est une politique d'affirmation française [...] C'est par la formation d'un bloc de 80 millions d'hommes que se trouvent pour la France les moyens les plus sûrs de faire entendre sa voix dans l'Europe et dans le monde ${ }^{250}$.

Max Tacel nimmt an, daß die Kolonien tatsächlich ein Pfeiler der französischen Macht waren, Jean-Louis Miège und Robert Aldrich schränken ein, die meisten Franzosen hätten an die Stärke des Empire als Beweis des französischen Weltmachtstatus geglaubt. Doch Frankreichs Regierungen hatten dem salut par l'empire längst die Basis entzogen: Der Anteil der Militärausgaben für die Kolonien war seit 1932 um vier Fünftel geschrumpft ${ }^{251}$. Die Kolonien wurden nicht in die Lage versetzt, die Metropole massiv zu unterstützen, weil dies zunächst Investitionen erfordert hätte. Die führenden Politiker sahen in den Kolonien eher eine Last als das Heil. Ageron und Andrew/Kanya-Forstner urteilen deshalb, das Kolonialreich sei für die Franzosen vor allem ein Mythos zur Kompensation gewesen. So wie nach 1870/71 sei der Mythos eines mächtigen Empire benutzt worden, um eine defätistische Öffentlichkeit aufzurichten und die Ohnmacht Frankreichs zu verdecken ${ }^{252}$. Ageron spitzt weiter zu, die Regierung habe die koloniale Untätigkeit mit imperialem Geschwätz

\footnotetext{
${ }^{249}$ MAYAFFRE, Exalter l'empire pour déserter l'Europe, S. 273f.; BERSTEIN, Le parti radical-socialiste, S. 277f.; DU RÉAU, Daladier, S. 303f.

${ }^{250}$ GiRAulT, Décideurs, S. 39; Elisabeth DU RÉAU, Gouvermement et haut commandement français devant la perspective de la guerre (sep. 1938-sep. 1939), in: Guerres mondiales et conflits contemporains 166 (1992), S. 149-165 (S. 155f.); AGERON, À propos d'une prétendue politique, S. 237.

${ }^{251}$ TACEL, La France et le monde, S. 131; Jean-Louis MIÈGE, Expansion europénne et décolonisation de 1870 à nos jours, Paris 1973, S. 309; ALDRICH, France and the South Pacific, S. XVIII; FRANKENSTEIN, Le prix, S. 303.

${ }^{252}$ MICHEL, La puissance par l'empire, S. 44; Charles-Robert AGERON, La perception de la puissance française en 1938-39. Le mythe impérial, in: Revue française d'histoire d'outre-mer 254 (1982), S. 7-22 (S. 20); ANDREW, KANYA-FORSTNER, France Overseas, S. 251.
} 
(»verbiage«) verbunden und habe nicht einmal selbst an ihre Propaganda von dem unerschöpflichen Reservoir an Menschen und Rohstoffen geglaubt ${ }^{253}$.

Tatsächliches Gewicht besaßen die Kolonien allein als Wirtschaftsfaktor. Während der Weltwirtschaftskrise hatte ihre Bedeutung als Absatzmarkt zugenommen. Der Anteil der französischen Exporte, die im Empire verkauft wurden, stieg von 1928 bis 1936 von 17,3 auf 33,3 Prozent und sank bis 1938 wieder auf 27,2 Prozent ${ }^{254}$. Indochina war nach Algerien größter Abnehmer französischer Waren. Durch die gewaltigen Exporte an Reis, Kautschuk, Zinn, Kohle und Eisenerz innerhalb Asiens war Indochina neben dem Maghreb die einzige Besitzung, die ständig Handelsüberschüsse erwirtschaftete, allein von 1928 bis 1938 3,8 Milliarden Francs ${ }^{255}$. Frankreichs Macht vergrößerten die Kolonien damit nur indirekt. Le salut par l'empire war lediglich ein Mythos.

Frankreich und die französisch-japanischen Beziehungen hatten die ersten 15 Monate des Fernostkonflikts unbeschadet überstanden. Paris und Tokio bemühten sich, die Interessen der anderen Macht zu respektieren. Die im Münchener Abkommen demonstrierte Schwäche des Westens steigerte jedoch die Aggressivität der Extremisten in Japan und führte zur Verlagerung der Kampfhandlungen nach Südchina, was die potentielle Bedrohung für Indochina erhöhte. Für den Quai d'Orsay war dies ein zusätzlicher Grund, an seinem Axiom festzuhalten, Japan keinesfalls zu provozieren.

${ }^{253}$ AGERON, Empires, S. 316; DERS., De l'Empire à la dislocation de l'Union française (1939-1956), in: Thobie, Meynier, COQUery-Vidrovitch, AGeron (Hg.), Histoire de la France coloniale, S. 309-408 (S. 312).

${ }_{254}$ BersteIN, MilZA, Histoire de la France, Bd. 2, S. 262f.; BouChe, Histoire de la colonisation française, Bd. 2, S. 307f.; SAUVY, Histoire économique, Bd. 2, S. 164; MiĖGE, Expansion, S. 290.

${ }^{255}$ Daniel HÉMERY, Capitalism colonial et développement, in: BROCHEUX, HÉMERY (Hg.), Indochine: la colonisation amibigue, S. 112-174 (S. 168f.); HAAS, Französisch-Indochina, S. 23. 